QA: QA

ANL-EBS-MD-000004 REV 02

September 2004

\title{
General Corrosion and Localized Corrosion of the Drip Shield
}

Prepared for:

U.S. Department of Energy

Office of Civilian Radioactive Waste Management

Office of Repository Development

1551 Hillshire Drive

Las Vegas, Nevada 89134-6321

Prepared by:

Bechtel SAIC Company, LLC

1180 Town Center Drive

Las Vegas, Nevada 89144

Under Contract Number

DE-AC28-01RW12101 


\section{DISCLAIMER}

This report was prepared as an account of work sponsored by an agency of the United States Government. Neither the United States Government nor any agency thereof, nor any of their employees, nor any of their contractors, subcontractors or their employees, makes any warranty, express or implied, or assumes any legal liability or responsibility for the accuracy, completeness, or any third party's use or the results of such use of any information, apparatus, product, or process disclosed, or represents that its use would not infringe privately owned rights. Reference herein to any specific commercial product, process, or service by trade name, trademark, manufacturer, or otherwise, does not necessarily constitute or imply its endorsement, recommendation, or favoring by the United States Government or any agency thereof or its contractors or subcontractors. The views and opinions of authors expressed herein do not necessarily state or reflect those of the United States Government or any agency thereof. 
QA: QA

General Corrosion and Localized Corrosion of the Drip Shield ANL-EBS-MD-000004 REV 02

September 2004 


\begin{tabular}{|l|l|l|}
\hline \multirow{2}{*}{ OCRWM } & Model Signature Page/Change History & Page iii \\
\cline { 3 - 3 } & & 1. Total Pages: 150 \\
\hline
\end{tabular}

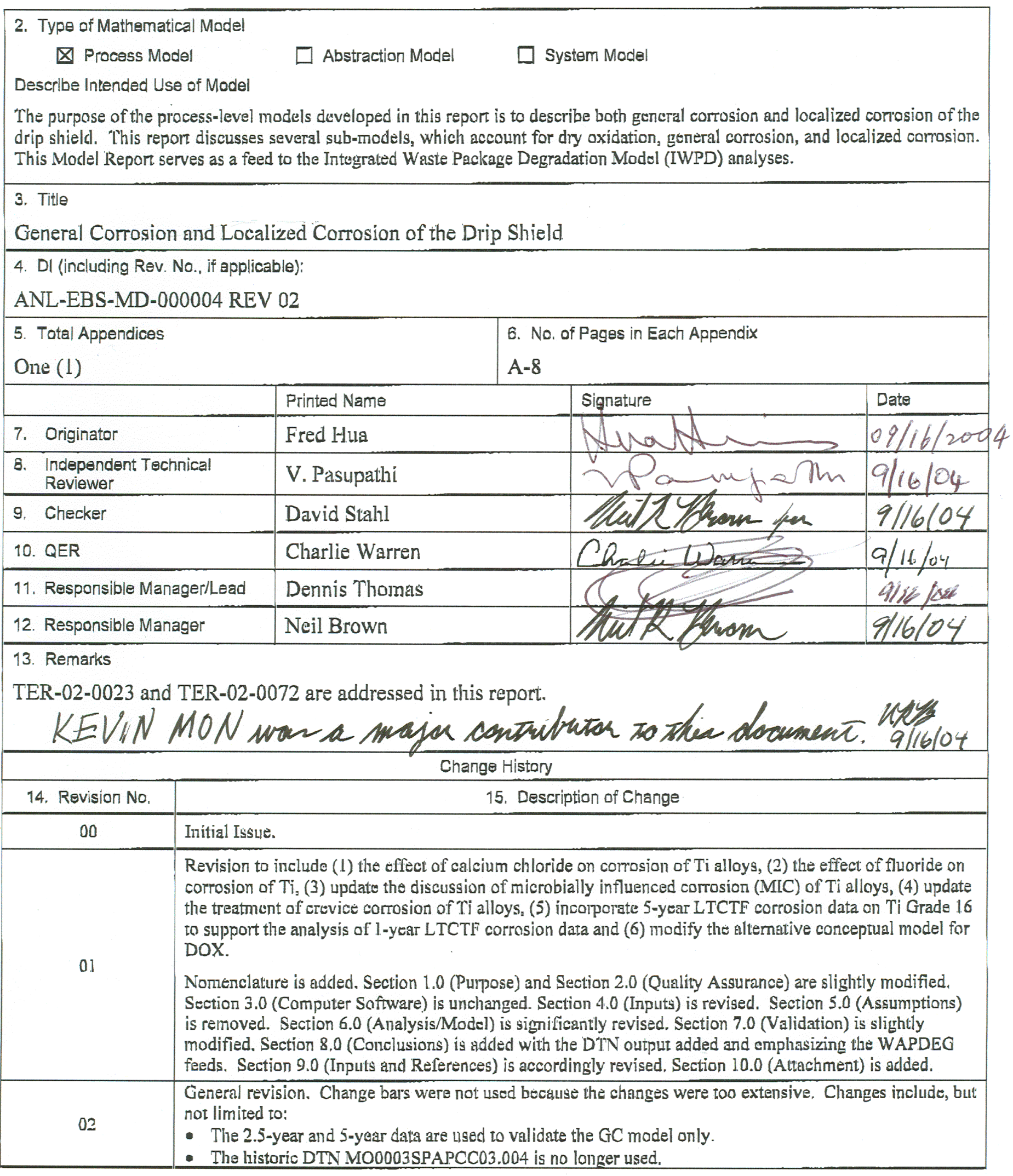




\begin{tabular}{|l|l|l|}
\hline \multirow{2}{*}{ OCRWM } & Model Change History (ContinUed) & Page iv \\
\cline { 3 - 3 } & 1. Total Pages: 150 \\
\hline
\end{tabular}

3. Title

General Corrosion and Localized Corrosion of the Drip Shield

4. DI (including Rev. No., if applicable):

ANL-EBS-MD-000004 REV 02

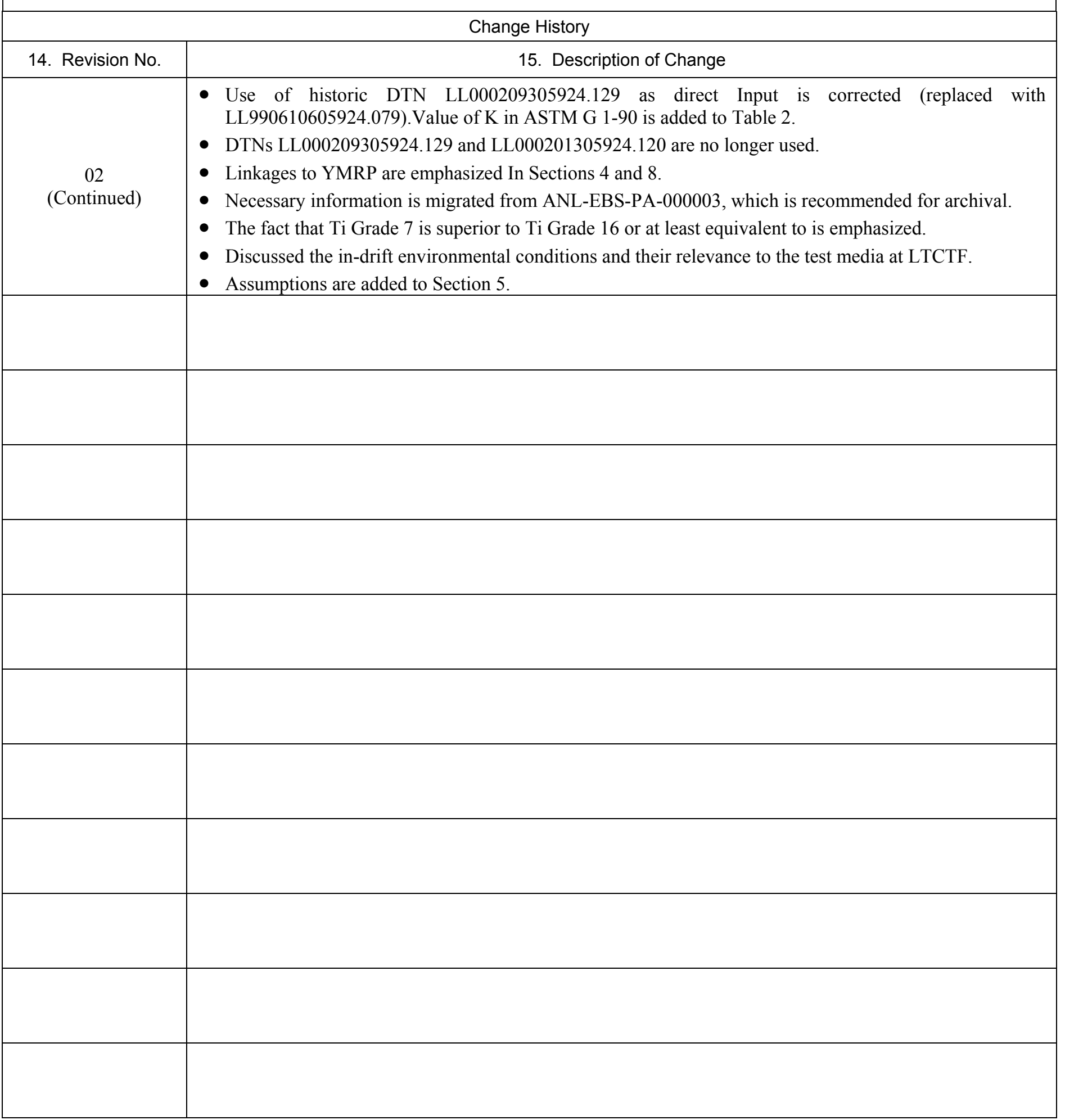




\section{CONTENTS}

Page

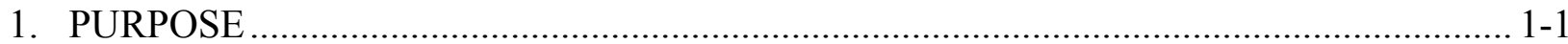

1.1 BACKGROUND ON TITANIUM GRADE 7 ..................................................... 1-1

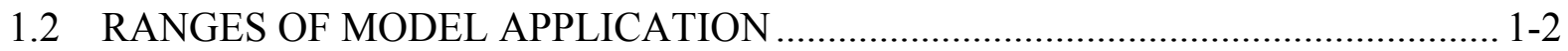

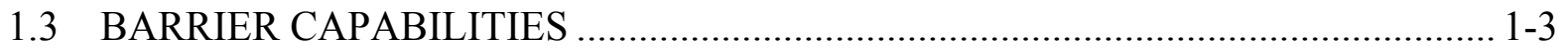

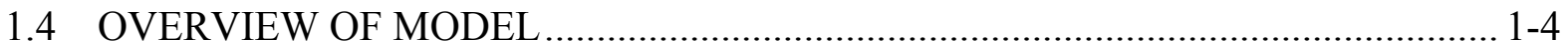

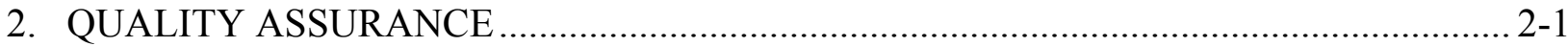

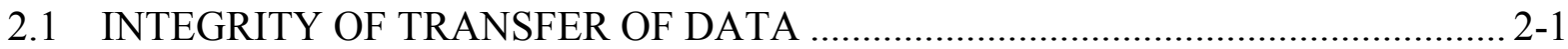

3. COMPUTER SOFTWARE AND MODEL USAGE ………............................................ 3-1

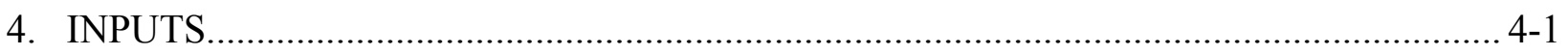

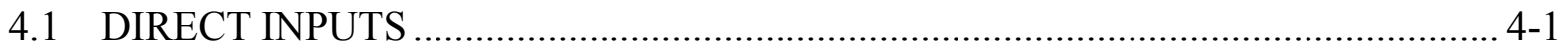

4.1.1 Definition of Parameters ....................................................................... 4-1

4.1.2 Identification of Input Data......................................................................... 4-1

4.1.3 Description of Direct Input Parameters .................................................... 4-2

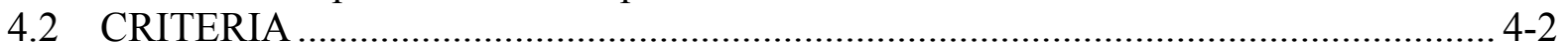

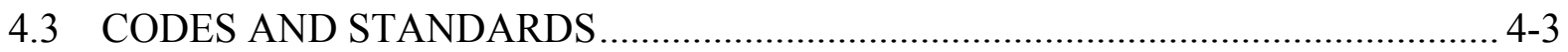

4.3.1 Standards for Test Media .................................................................. 4-3

4.3.2 Cyclic Polarization Measurements ............................................................... 4-4

4.3.3 General Corrosion Measurements................................................................. 4-4

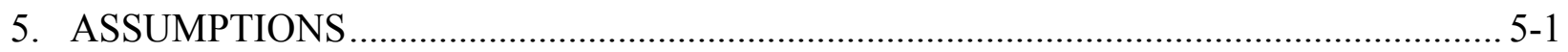

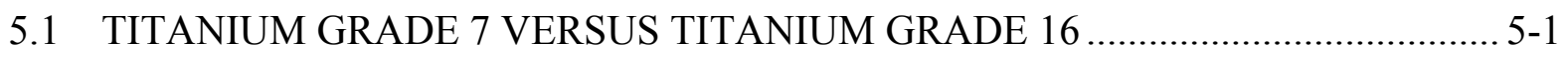

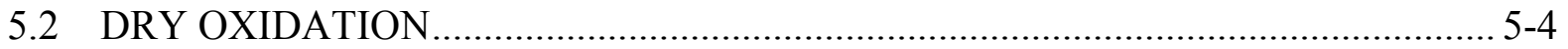

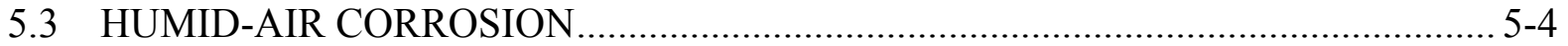

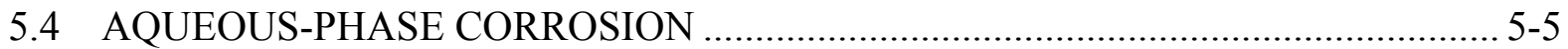

5.5 DRIPPING CONDENSATE FROM INNER SURFACE OF THE DRIP SHIELD.... 5-5

5.6 THRESHOLD FOR LOCALIZED CORROSION ……………............................. 5-5

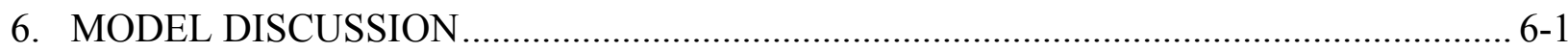

6.1 EXPECTED IN-DRIFT TEMPERATURE AND HUMIDITY …………………..... 6-2

6.2 RELATION OF IN-DRIFT CHEMICAL MODEL RESULTS TO CORROSION

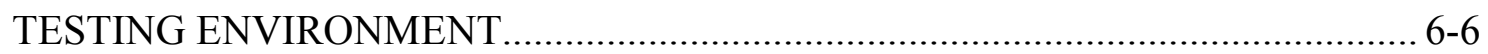

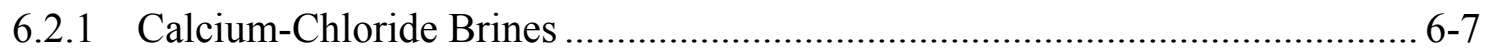

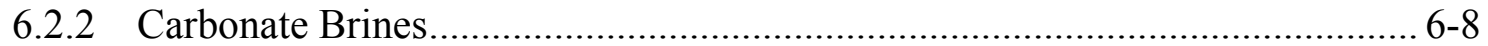

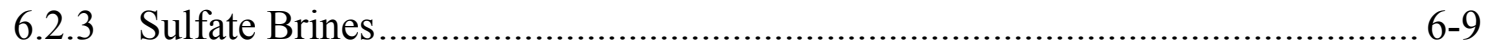

6.3 CORROSION MODES AND CORROSION OF THE DRIP SHIELD

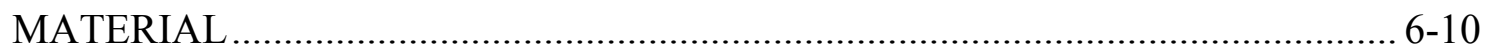

6.3.1 Dry Oxidation ..........................................................................................

6.3.2 Humid-Air Corrosion......................................................................... 6-12

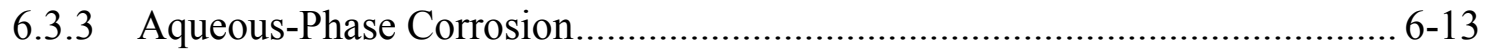

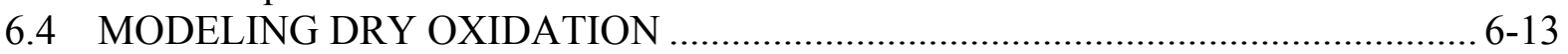




\section{CONTENTS (Continued)}

6.4.1 Primary Model for Dry Oxidation 6-14

6.4.2 Alternative Conceptual Model for Dry Oxidation......................................... 6-17

6.4.3 Dry Oxidation Model Uncertainty ............................................................. 6-22

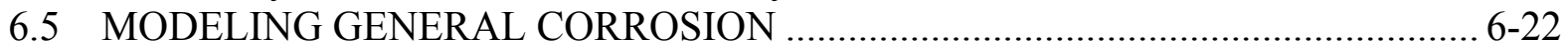

6.5.1 Long-Term Corrosion Test Facility Tests.................................................. 6-22

6.5.2 Modeling Corrosion of Inner and Outer Surfaces of the Drip Shield............. 6-23

6.5.3 Calculation of Corrosion Rate Based Upon Weight-Loss Measurement ....... 6-24

6.5.4 Model Uncertainty ................................................................................. 6-29

6.5.5 Composite Model for the General Corrosion Rates for Drip Shield .............. 6-36

6.5.6 Alternative Conceptual Models for the Representation of Drip Shield General Corrosion Rates............................................................................. 6-39

6.5.7 Influence of Fluoride on the Corrosion of Titanium....................................... 6-41

6.5.8 Influence of Calcium Chloride on General Corrosion of Ti Grade 7 ............. 6-46

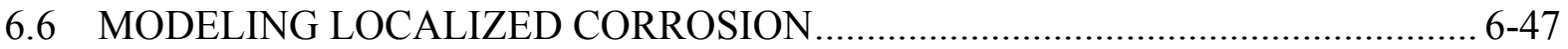

6.6.1 Threshold Potential for Ti Grade 7 ............................................................ 6-47

6.6.2 Cyclic Polarization in Synthetic Concentrated J-13 Well Waters .................. 6-48

6.6.3 Correlation of Potential Versus Temperature and Composition for Various Test Media ............................................................................................ 6-54

6.6.4 Crevice Corrosion .................................................................................... 6-56

6.6.5 Influence of Calcium Chloride on Localized Corrosion of Ti Grade 7 .......... 6-57

6.7 OTHER FACTORS CONSIDERED IN MODELING DRIP SHIELD

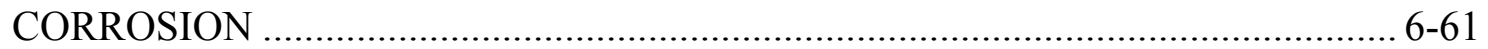

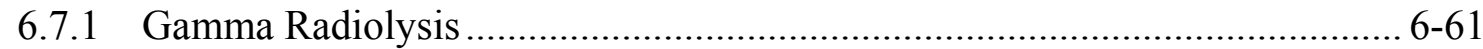

6.7.2 Microbially Influenced Corrosion.............................................................. 6-62

6.7.3 Aging and Phase Stability ...................................................................... 6-63

6.7.4 Effects of Irregular Environmental Conditions............................................. 6-63

6.8 SUMMARY ASSESSMENT OF ALTERNATIVE CONCEPTUAL MODELS...... 6-64

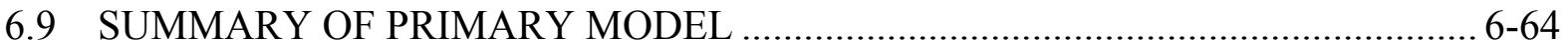

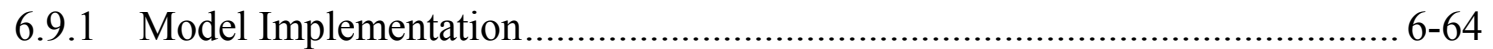

6.9.2 Summary of Primary Model Uncertainties .................................................. 6-65

6.10 DESCRIPTION OF BARRIER CAPABILITY ……............................................ 6-66

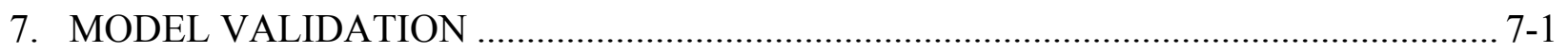

7.1 CONFIDENCE BUILDING DURING MODEL DEVELOPMENT TO ESTABLISH SCIENTIFIC BASIS AND ACCURACY FOR INTENDED USE....... 7-1

7.2 CONFIDENCE BUILDING AFTER MODEL DEVELOPMENT TO SUPPORT THE SCIENTIFIC BASIS OF THE MODEL .................................................... 7-2

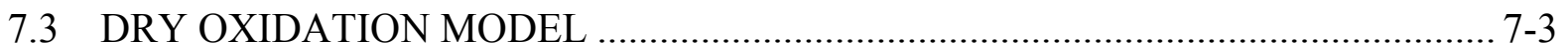

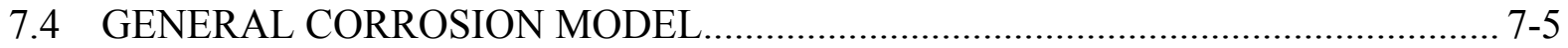

7.4.1 Corrosion Rates Based Upon 5-Year Weight-Loss Measurements ................... 7-6

7.4.2 Comparison of 1-, 2.5-, and 5-Year General Corrosion Rates.......................... 7-9

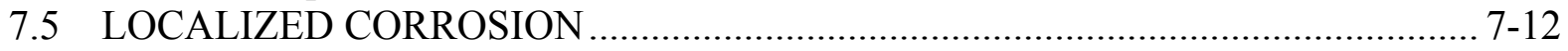

7.6 MODEL VALIDATION SUMMARY ……………………………………….... 7-13 
CONTENTS (Continued)

Page

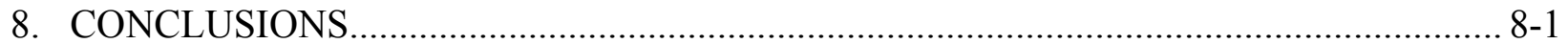

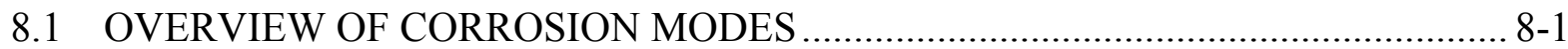

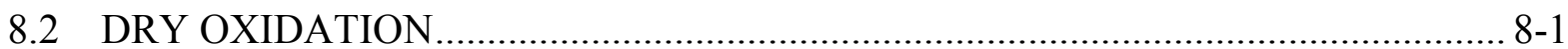

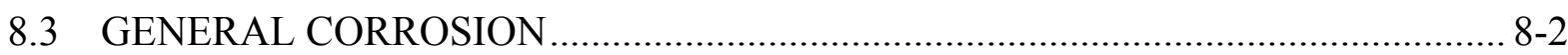

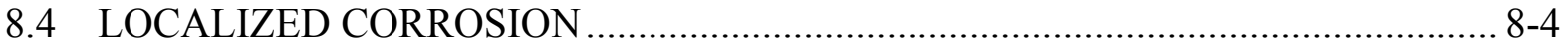

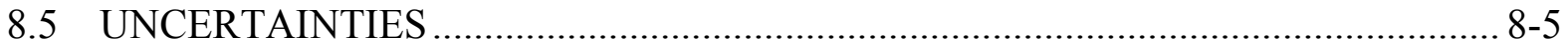

8.6 YUCCA MOUNTAIN REVIEW PLAN ACCEPTANCE CRITERIA ........................ 8-5

8.6.1 System Description and Demonstration of Multiple Barriers............................. 8-6

8.6.2 Degradation of Engineered Barriers ………………………….................... 8-7

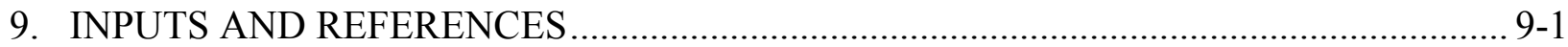

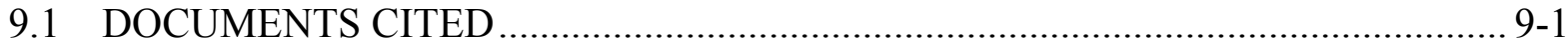

9.2 CODES, STANDARDS, REGULATIONS, AND PROCEDURES ........................... 9-8

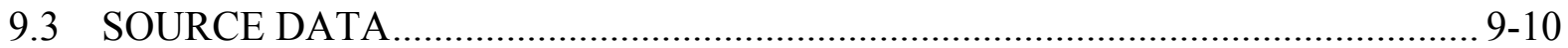

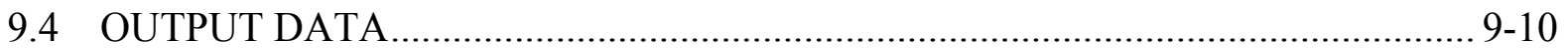

APPENDIX A DETAILED CALCULATION OF EQUATIONS (38) AND (39) AND FIGURE 19 AND FIGURE 20 (TI GRADE $7 \Delta$ E ANALYSIS) .................. A-1 
INTENTIONALLY LEFT BLANK 


\section{FIGURES}

Page

1. Schematic Representation of Corrosion Model for Ti Grade 7 Drip Shield ......................... 1-4

2. Schematic of the Relationship Between the Relevant Titanium Alloys ............................. 5-3

3. Schematic Illustration of Corrosion Modes and Modeling Approaches in Section 6 .......... 6-2

4. Waste Package Temperature and Relative Humidity Ranges .............................................. 6-4

5. Thermohydrologic Variables for the "Hottest" Waste Package in the Low-Probability Seismic Collapsed Drift Scenario...................................................................................... 6-5

6. Schematic Illustrations of Logarithmic, Parabolic, and Linear Growth of Oxides ............. 6-12

7. Logarithmic Regression of Dry Oxidation Rate Data for Titanium at $400^{\circ} \mathrm{C}, 500^{\circ} \mathrm{C}$,

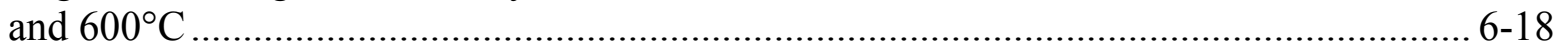

8. Determination of Apparent Activation Energy of Dry Oxidation in Logarithmic Growth Model .................................................................................................... 6-20

9. Predicted Logarithmic Oxide Growth on Titanium at $100^{\circ} \mathrm{C}, 200^{\circ} \mathrm{C}$, and $300^{\circ} \mathrm{C}$............ 6-21

10. Distribution of General Corrosion Rates of Ti Grade 16: LTCTF 1-Year Weight-Loss Samples

11. Distribution of General Corrosion Rates of Ti Grade 16: LTCTF 1-Year Crevice Sample

12. Distribution of General Corrosion Rates of Ti Grade 16: LTCTF 1-Year Weight-Loss Samples (Negative Rates Removed)

13. Distribution of General Corrosion Rates of Ti Grade 16: LTCTF 1-Year Weight-Loss and Crevice Samples (Negative Rates Removed) ....................................................... 6-37

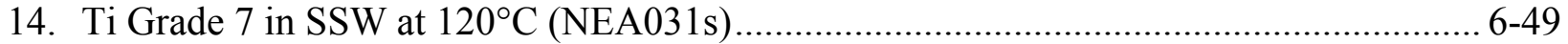

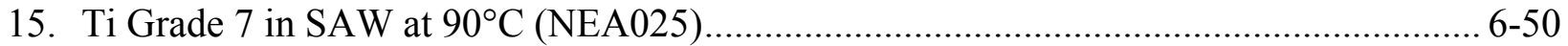

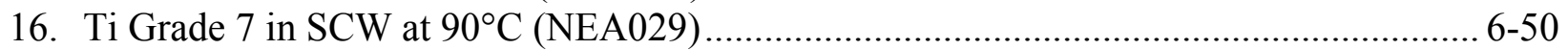

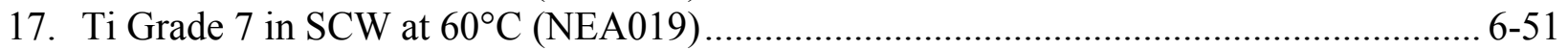

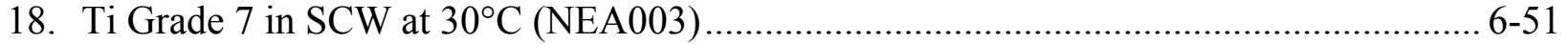

19. The Median $\Delta E$ and $-4 \sigma$ Confidence Interval Surface Versus $p H$ and Absolute Temperature for Ti Grade 7 Using a Chloride Ion Concentration of 3 mol/L ................. 6-55

20. The Median $\Delta E$ and $-4 \sigma$ Confidence Interval Surface versus $p H$ and base 10 Logarithm of Chloride Ion Concentration for Ti Grade 7 Using an Absolute Temperature of 400 $\mathrm{K}$

21. An Example Cyclic Polarization Curve of Ti Grade 7 in $8 \mathrm{M} \mathrm{CaCl}_{2}$ Water at $100^{\circ} \mathrm{C}$, Showing Very Large $\Delta E\left(E_{20}-E_{c o r r}\right)$ and a Perfect Passive Region Below About 1.5 $\mathrm{V}_{(\mathrm{SSC})}$.

22. Distribution of General Corrosion Rates of Ti Grade 16: LTCTF 5-Year Weight-Loss Specimens.

23. Distribution of General Corrosion Rates of Ti Grade 16: LTCTF 5-Year Crevice Specimens....

24. Comparison of 1-Year and 5-Year Corrosion Rates Obtained from Weight-Loss Specimens. 


\section{FIGURES (Continued)}

Page

25. Comparison of 1-Year and 5-Year Corrosion Rates Obtained from Crevice Specimens .... 7-9

26. Ti Grade 7 2.5-Year a) Weight-Loss and b) Crevice Specimen Corrosion Rates.............. 7-10

27. Comparison of 1-Year (Ti Grade 16), 2.5-Year (Ti Grade 7), and 5-Year (Ti Grade 16) Corrosion Rates Obtained from Weight-Loss Specimens and Crevice Specimens, Showing the Decreasing Trend in Corrosion Rate. 


\section{TABLES}

Page

1. Chemical Composition (wt \%) of Ti Grade 7 (UNS R52400) and Ti Grade 16 (UNS R52402)

2. Input Data

3. ASTM B 265-02 Specifications for Chemical Composition Requirements (wt \%) of Relevant Titanium Alloys in this Report

4. ASTM B 265-02 Specifications for Mechanical Properties of Relevant Titanium Alloys

5. Features, Events, and Processes Included (Screened In) in This Model Report $6-2$

6. Features, Events, and Processes Excluded (Screened Out) in This Model Report

7. Composition of Standard Test Media Based on J-13 Well Water $6-7$

8. Titanium Dry Oxidation Thickness 6-15

9. Titanium Dry Oxidation Thickness: Measured versus Calculated Using Equation 9....... 6-16

10. Parameters in Dry Oxidation Rate Logarithmic Model Determined by Regression Analysis $6-18$

11. Summary of Error Analysis for Corrosion Rates Based Upon Weight-Loss Measurements. 6-30

12. Error Analysis for LTCTF Corrosion Rates-Definitions. 6-31

13. Error Analysis for LTCTF Corrosion Rates-Chosen Weight Loss of 0.0001 Grams 6-32

14. Error Analysis for LTCTF Corrosion Rates-Chosen Weight Loss of 0.001 Grams 6-33

15. Error Analysis for LTCTF Corrosion Rates- Chosen Weight Loss of 0.01 Grams 6-34

16. Cumulative Distribution Function for General Corrosion Rates of Titanium Grade 16: LTCTF 1-year Weight-Loss Samples (No Negative Rates) 6-38

17. Cumulative Distribution Function for General Corrosion Rates of Ti Grade 16: LTCTF 1-Year Weight-Loss and Crevice Samples (No Negative Rates)

18. General Corrosion Rates of Ti Grade 7 in Selected Test Media Containing High Concentrations of Chlorides of $\mathrm{Ca}^{2+}, \mathrm{Mg}^{2+}$ and $\mathrm{Fe}^{3+}$ Ions at Elevated Temperature 6-47

19. Summary of Cyclic Polarization Data for Ti Grade 7 in Repository-Relevant Conditions (SDW and SCW) $6-52$

20. Summary of Cyclic Polarization Data for Ti Grade 7 in Repository-Relevant Conditions (SAW and SSW).

21. Electrochemical Tests of Ti Grade 7 in Environments Containing $\mathrm{Ca}$ and $\mathrm{Mg}$.

22. Alternative Conceptual Models Considered.

23. Summary of 1-, 2.5, and 5-Year Corrosion Data Comparison......................................... 7-11

24. Output of Primary Model for Dry Oxidation of Titanium ............................................... 8-2

25. Output of Model for General Corrosion of Ti Grade 16 (Ti Grade 7) ................................ 8-4

26. Output of Model for Localized Corrosion of Ti Grade 7 .................................................... 8-5 
INTENTIONALLY LEFT BLANK 


\section{ABBREVIATIONS AND ACRONYMS}

ASM

ASTM

BSW

CSNF

DHLW

DTN

FEP

GC

HLW

LA

LC

LLNL

LTCTF

Q

QA

$\mathrm{RH}$

SAW

SCE

SCW

SDW

SNF

SSW

TER

TSPA

UNS

UZ

WAPDEG

WL
American Society of Metals

American Society for Testing and Materials

basic saturated water

commercial spent nuclear fuel

DOE-owned high-level radioactive waste

data tracking number

feature, event, or process

general corrosion

high-level waste

License Application

localized corrosion

Lawrence Livermore National Laboratory

Long Term Corrosion Test Facility

quality data or data qualified for use

quality assurance

relative humidity

simulated acidic concentrated water

saturated calomel electrode

simulated concentrated water

simulated dilute water

spent nuclear fuel

simulated saturated water

technical error report

total system performance assessment

unified numbering system

unsaturated zone

waste package degradation code

weight loss

Yucca Mountain Project 


\section{NOMENCLATURE}

$a$

$a_{l}$

$\Delta a$

A

$b$

$\Delta b$

$b_{0}$

$b_{1}$

$b_{2}$

$c$

$\Delta c$

C

$\Delta C$

$d_{0}$

$d_{1}$

$d_{2}$

$d_{3}$

$D_{\text {oxide }}$

D

$E_{a}$

$E_{\text {corr }}$

$E_{\text {critical }}$

$E_{p}$

$E_{\text {crevice }}$

$E_{b}$

$E_{200}$

$E_{20}$

$E_{10}$

$E_{\text {repass }}$

$E_{\text {prot }}$

$E_{r p}$

$E_{\text {rcrev }}$

$E_{R 20}$

$E_{R 10}$

$E_{R 1}$

$f(y)$

F dimension of weight-loss sample

constant in integrated form of logarithmic law for dry oxidation model

change in $a$

area of specimen

dimension of weight-loss sample

change in $b$

coefficient in regression equation

coefficient in regression equation

coefficient in regression equation

dimension of weight-loss sample

change in $c$

molar concentration

the change in molar concentration

constant determined from fitting Equation 38

constant determined from fitting Equation 38

constant determined from fitting Equation 38

constant determined from fitting Equation 38

diffusivity of reacting species through protective oxide

density

Arrhenius activation energy

corrosion potential

critical potential - threshold for localized attack

pitting potential

crevice corrosion potential

passive film breakdown potential

the potential in the forward scan of a cyclic polarization curve where the current density first reaches $200 \mu \mathrm{A} / \mathrm{cm}^{2}$

potential at which the forward scan current density reaches $20 \mu \mathrm{A} / \mathrm{cm}^{2}$

potential at which the forward scan current density reaches $10 \mu \mathrm{A} / \mathrm{cm}^{2}$

repassivation potential

protection potential

repassivation potential for pitting

repassivation potential for crevice corrosion

potential at which the reverse scan current density reaches $20 \mu \mathrm{A} / \mathrm{cm}^{2}$

potential at which the reverse scan current density reaches $10 \mu \mathrm{A} / \mathrm{cm}^{2}$

potential at which the reverse scan current density reaches $10 \mu \mathrm{A} / \mathrm{cm}^{2}$

probability density function

Faraday's constant 


\begin{tabular}{|c|c|}
\hline $\begin{array}{l}i_{\text {corr }} \\
i_{\text {pass }}\end{array}$ & $\begin{array}{l}\text { corrosion current density } \\
\text { passive current density }\end{array}$ \\
\hline$J_{\text {oxide }}$ & flux of reacting species through protective oxide \\
\hline$k_{p}$ & rate constant in parabolic dry oxidation model \\
\hline$k_{p 0}$ & rate constant pre-exponent in parabolic dry oxidation model \\
\hline$k_{l}$ & rate constant in logarithmic dry oxidation model \\
\hline$k_{l 0}$ & constant in Arrhenius equation for logarithmic model for dry oxidation \\
\hline$k_{l(100)}$ & rate constant in logarithmic dry oxidation model at $100^{\circ} \mathrm{C}$ \\
\hline$k_{l(200)}$ & rate constant in logarithmic dry oxidation model at $200^{\circ} \mathrm{C}$ \\
\hline$k_{l(300)}$ & rate constant in logarithmic dry oxidation model at $300^{\circ} \mathrm{C}$ \\
\hline$k_{l(400)}$ & rate constant in logarithmic dry oxidation model at $400^{\circ} \mathrm{C}$ \\
\hline$k_{l(500)}$ & rate constant in logarithmic dry oxidation model at $500^{\circ} \mathrm{C}$ \\
\hline$k_{l(600)}$ & rate constant in logarithmic dry oxidation model at $600^{\circ} \mathrm{C}$ \\
\hline$K$ & constant in calculation of corrosion rate from weight loss \\
\hline$K$ & temperature in Kelvin \\
\hline$p$ & wall penetration due to corrosive attack \\
\hline$R$ & universal gas constant \\
\hline$R^{2}$ & coefficient of determination \\
\hline RH & relative humidity \\
\hline$R H_{\text {critical }}$ & threshold $R H$ for humid-air corrosion and aqueous-phase corrosion \\
\hline$t$ & exposure time during weight-loss measurement \\
\hline$t$ & exposure time in dry oxidation model \\
\hline$T$ & temperature (degrees Celsius or Kelvin) \\
\hline$T_{\text {clad }}^{\max }$ & maximum cladding temperature \\
\hline$T_{D W}^{\max }$ postclosure & maximum drift wall temperature after closure \\
\hline$w($ or $W)$ & measured weight loss \\
\hline$\Delta w$ & change in $w$ \\
\hline$w_{\text {oxide }}$ & formula weight of oxide formed during dry oxidation \\
\hline$x$ & independent variable in regression equation \\
\hline$x$ & oxide film thickness in parabolic dry oxidation model \\
\hline$x_{0}$ & initial oxide thickness in parabolic dry oxidation model \\
\hline$x_{i}$ & measured parameter in sensitivity (error) analysis \\
\hline$X$ & oxide thickness in logarithmic dry oxidation model \\
\hline$X_{400^{\circ}} \mathrm{C}$ & oxide thickness at $400^{\circ} \mathrm{C}$ \\
\hline$X_{500^{\circ}} \mathrm{C}^{2}$ & oxide thickness at $500^{\circ} \mathrm{C}$ \\
\hline$X_{600}{ }^{\circ} \mathrm{C}$ & oxide thickness at $600^{\circ} \mathrm{C}$ \\
\hline$y$ & dependent variable in regression equation \\
\hline$y$ & computed value in sensitivity (error) analysis \\
\hline
\end{tabular}


$z_{i}$

$\sigma$

$\mu$

$\rho$

$\Delta \rho$

$\varepsilon$ valence (charge) of the $i^{\text {th }}$ ion

standard deviation

mean

density of Ti Grade 7

change in $\rho$

the error term in localized corrosion model 


\section{PURPOSE}

The repository design includes a drip shield (BSC 2004 [DIRS 168489]) that provides protection for the waste package both as a barrier to seepage water contact and a physical barrier to potential rockfall.

The purpose of the process-level models developed in this report is to model dry oxidation, general corrosion, and localized corrosion of the drip shield plate material, which is made of Ti Grade 7. This document is prepared according to Technical Work Plan For: Regulatory Integration Modeling and Analysis of the Waste Form and Waste Package (BSC 2004 [DIRS 171583]).

The models developed in this report are used by the waste package degradation analyses for TSPA-LA and serve as a basis to determine the performance of the drip shield. The drip shield may suffer from other forms of failure such as the hydrogen induced cracking (HIC) or stress corrosion cracking (SCC), or both. Stress corrosion cracking of the drip shield material is discussed in Stress Corrosion Cracking of the Drip Shield, the Waste Package Outer Barrier, and the Stainless Steel Structural Material (BSC 2004 [DIRS 169985]). Hydrogen induced cracking of the drip shield material is discussed in Hydrogen Induced Cracking of Drip Shield (BSC 2004 [DIRS 169847]).

\subsection{BACKGROUND ON TITANIUM GRADE 7}

Alloy 22 is used as the corrosion-resistant waste package outer barrier. Stainless Steel Type 316 is used for construction of the structural support underneath the waste package outer barrier. The Stainless Steel Type 316 inner cylinder increases the overall strength of the waste package. Drip shields will be installed over the waste packages prior to repository closure. The drip shields divert any moisture that seeps from the drift walls around the waste packages to the drift floor. The drip shields also reduce any damage to waste packages in the event of rockfalls as emplacement drifts degrade over time. The drip shields will be made of titanium to provides corrosion resistance and structural strength. Titanium alloys are considered for construction of the drip shield because of their excellent corrosion resistance under nuclear waste repository environment conditions. The drip shield design uses Ti Grade 7 (UNS R52400) for the drip shield plates. The chemical compositions of Ti Grades 7 and 16 (UNS R52402) are shown in Table 1. The materials for the repository drip shield design were selected after the testing program for the Long-Term Corrosion Test Facilities (LTCTF) was initiated.

When the LTCTF became operational in 1996, Ti Grade 16 was a potential candidate material for the corrosion-resistant barrier. In 1998-99, the Project progressed to the license application (LA) design, in which the titanium drip shield is considered an engineered barrier. The drip shield has water diversion plates made from Ti Grade 7, a very corrosion-resistant alloy because of its high palladium (Pd) content (Schutz 2003 [DIRS 168772]; Hua et al. 2004 [DIRS 167022]). Ti Grade 7 was added to the testing program and specimens were added to the LTCTF in 2000. Their exposure anniversaries, therefore, differ from Ti Grade 16. These two materials have almost identical chemical compositions, except that Ti Grade 7 contains 0.12 to $0.25 \mathrm{wt} \%$ Pd while Ti Grade 16 contains 0.04 to $0.08 \mathrm{wt} \%$ palladium (Table 1) and a slightly lower carbon content. Ti Grade 16 was used as an analog of Ti Grade 7 at the LTCTF for the 
1-year and 5-year weight-loss tests due to its compositional similarity to Ti Grade 7 . In this report, the Ti Grade 16 1-year corrosion rate data are used for model development, while the Ti Grade 16 5-year data are used for model validation. The LTCTF has also obtained two and half-year corrosion rate data for Ti Grade 7 under the same test conditions. The 2.5-year Ti Grade 7 corrosion rate data are also used for model validation. The corrosion performance of Ti Grade 7, because of its higher palladium content, is superior to that of Ti Grade 16. This is further discussed in Section 5.1 and validated in Section 7.4.

Table 1. Chemical Composition (wt \%) of Ti Grade 7 (UNS R52400) and Ti Grade 16 (UNS R52402)

\begin{tabular}{|c|c|c|c|c|c|c|c|c|c|}
\hline & $\mathbf{N}$ & C & $\mathbf{H}$ & 0 & $\mathrm{Fe}$ & $P d$ & $\begin{array}{c}\text { Residual } \\
\text { (each) }\end{array}$ & $\begin{array}{c}\text { Residual } \\
\text { (total) }\end{array}$ & Titanium \\
\hline Ti Grade 7 & $\begin{array}{c}0.03 \\
(\max )\end{array}$ & $\begin{array}{c}0.10 \\
(\max )\end{array}$ & $\begin{array}{l}0.015 \\
(\max )\end{array}$ & $\begin{array}{c}0.25 \\
(\max )\end{array}$ & $\begin{array}{c}0.30 \\
(\max )\end{array}$ & $\begin{array}{c}0.12 \text {-to } \\
0.25\end{array}$ & 0.1 (max) & $0.4(\max )$ & Remainder \\
\hline Ti Grade 16 & $\begin{array}{c}0.03 \\
(\max )\end{array}$ & $\begin{array}{c}0.08 \\
(\max )\end{array}$ & $\begin{array}{l}0.015 \\
(\max )\end{array}$ & $\begin{array}{c}0.25 \\
(\max )\end{array}$ & $\begin{array}{c}0.30 \\
(\max )\end{array}$ & $\begin{array}{c}0.04-\text { to } \\
0.08\end{array}$ & 0.1 (max) & $0.4(\max )$ & Remainder \\
\hline
\end{tabular}

Source: DTN: MO0003RIB00073.000 [DIRS 152926].

The properties and performance of titanium and its alloys are reviewed in detail elsewhere (CRWMS M\&O 1999 [DIRS 102933]; CRWMS M\&O 2000 [DIRS 154666]). The excellent corrosion resistance of titanium alloys results from the formation of a stable continuous, highly adherent, and protective oxide passive film (primarily $\mathrm{TiO}_{2}$ ) on the metal surface. The passive films on titanium and its alloys are stable over a wide range of potentials and $\mathrm{pH}$ values (Pourbaix 1974 [DIRS 100817], pp. 213 to 222). Also, due to its extremely high affinity for oxygen, a damaged oxide can generally reheal itself instantaneously, even when just traces of oxygen (e.g., at the order of ppm) or water (moisture) are present (Schutz and Thomas 1987 [DIRS 112147]). Oxygen or water vapor, or both, will be present in the repository environment.

\subsection{RANGES OF MODEL APPLICATION}

Although the corrosion models in this report were developed using information from a wide range of titanium alloys, the models are primarily intended to apply to the corrosion of titaniumpalladium alloys, in particular, the Ti Grade 7 used for the drip shield.

Due to the limited availability of long-term low-temperature oxidation data, the dry oxidation of titanium alloys is modeled based on scientifically well-established rate laws and limited shortterm high temperature laboratory data. The diffusion coefficient for oxygen in $\alpha$ titanium is very low (Section 6.4). In addition, significant oxidation of titanium alloys will not occur below about $300^{\circ} \mathrm{C}$ (Schutz and Thomas 1987 [DIRS 112147]). The oxidation of titanium and its alloys obeys a parabolic law at temperatures below about $600^{\circ} \mathrm{C}$ and a logarithmic law at temperatures below about $200^{\circ} \mathrm{C}$ (Schutz and Thomas 1987 [DIRS 112147]). Therefore, the dry oxidation model, although derived using short-term $(\sim 2 \mathrm{hr})$ oxidation data taken at temperatures up to $700^{\circ} \mathrm{C}$, can be regarded as applicable to the exposure times $(\sim 10,000$ years $)$ and temperatures (below $300^{\circ} \mathrm{C}$, see Section 6.1) relevant to the drip shield service exposure conditions.

The drip shield will be exposed to a wide range of configurations and environmental conditions during its service life. Initially, the underlying waste packages will be relatively hot due to the 
heat generated from radioactive decay. As a result, the drip shield surface will remain dry initially, and under these conditions dry oxidation would be the primary corrosion scenario. The temperature will eventually drop to levels where both humid-air corrosion (Section 6.3.2) and aqueous-phase corrosion (Section 6.3.3) are possible. Crevices will form between the drip shield and its invert support structure. Crevices may also form between the drip shield and mineral precipitates, corrosion products, dust, rocks, and biofilms on the outer surfaces. The relevance of the corrosion testing conditions to the in-drift environments is discussed in Section 6.2. A complete discussion of the repository environmental conditions can be found in Engineered Barrier System: Physical and Chemical Environment Model (BSC 2004 [DIRS 169860]).

The crevice environment is more severe than the near-field environment. The hydrolysis of dissolved metal leads to the accumulation of $\mathrm{H}^{+}$ions and a corresponding decrease in $\mathrm{pH}$. Fielddriven electromigration of various anions into the crevice will occur to balance cationic charge associated with $\mathrm{H}^{+}$ions (Gartland 1997 [DIRS 105020]; Walton et al. 1996 [DIRS 105114]; Shoesmith et al. 1995 [DIRS 117892]; BSC 2004 [DIRS 169847]). These severe conditions set the stage for subsequent attack of this corrosion-resistant material by general corrosion, localized corrosion (including crevice corrosion and pitting), hydrogen-induced cracking, stress corrosion cracking, or other modes of degradation. This report investigates the potential for dry oxidation, general corrosion, and localized corrosion of the drip shield barrier. Stress corrosion cracking of the drip shield material is discussed in Stress Corrosion Cracking of the Drip Shield, the Waste Package Outer Barrier, and the Stainless Steel Structural Material (BSC 2004 [DIRS 169985]). Hydrogen induced cracking of the drip shield material is discussed in Hydrogen Induced Cracking of Drip Shield (BSC 2004 [DIRS 169847]).

\subsection{BARRIER CAPABILITIES}

10 CFR 63 [DIRS 156605] defines a barrier as "any material, structure, or feature that, for a period to be determined by NRC, prevents or substantially reduces the rate of movement of water or radionuclides from the Yucca Mountain repository to the accessible environment, or prevents the release or substantially reduces the release rate of radionuclides from the waste." 10 CFR 63.102 (h) and 10 CFR 63.113 (a) [DIRS 156605] requires the repository system to include multiple natural and engineered barriers.

The capability of a barrier is defined by its ability to achieve one or more of the functions described above (i.e., the extent to which it can prevent or delay the movement of water or radionuclides, or prevent or reduce the release rate from the waste). In this report, the drip shield is considered as the barrier to prevent or reduce water flow that could contact the waste package, and in the event of a waste package breach prevents or reduces water flow from contacting the waste form. The drip shields divert any moisture that might seep from the drift walls, including condensed water vapor, around the waste packages to the drift floor for thousands of years. Because of the low corrosion rates of titanium (Section 6.5.4.2), the initial breaches of the drip shields due to corrosion degradation processes will not occur until approximately 35,000 years (obtained by dividing the $15 \mathrm{~mm}$ drip shield thickness by the sum of the maximum values in Table 16 and Table 17). Therefore, even in the event of a breach of a waste package before its corresponding drip shield, advective transport of radionuclides cannot occur until after approximately 35,000 years. The ability of the drip shield to prevent or reduce water flow is the property that makes the drip shield a part of the engineered barrier system. 


\subsection{OVERVIEW OF MODEL}

The conceptual model for degradation of the Ti Grade 7 drip shield includes several degradation modes (e.g., dry oxidation, general corrosion, and localized corrosion) and is illustrated in Figure 1. A threshold $\mathrm{RH}, R H_{\text {critical }}$, is first used to determine whether or not dry oxidation will occur. If dry oxidation is determined to occur $\left(R H<R H_{\text {critical }}\right)$, a parabolic growth law is used to calculate the corrosion rate as a function of temperature. This model is discussed in greater detail in Sections 6.3.1 and Section 6.4. If the exposure $R H$ is greater than or equal to the $R H_{\text {critical }}$, humid-air corrosion will occur in the absence of dripping water (Section 6.3.2), and aqueous-phase corrosion will occur in the presence of dripping water (Section 6.3.3). Humid-air corrosion and aqueous-phase corrosion are treated as general corrosion only if $E_{\text {corr }}<E_{\text {critical }}$ (Section 6.5) or general corrosion and localized corrosion if $E_{\text {corr }} \geq E_{\text {critical }}$ (Section 6.6).

The corrosion of the inner surface of the drip shield is more likely to be dry oxidation and humid-air corrosion, while the outer surface of the drip shield is more likely to undergo dry oxidation, humid-air corrosion, and aqueous-phase corrosion. Therefore, from the point of view of modeling drip shield corrosion, it is reasonable to model the corrosion of the inner and outer surfaces of the drip shield separately (Section 6.3). The model developed in this report does not a priori exclude the possibility of localized corrosion under the "no-drip" condition, as localized corrosion can occur in the presence or absence of dripping water. Localized corrosion can occur if the right "dust deliquescence" chemistry is reached at $R H$ values equal to or greater than the $R H_{\text {critical }}$. The localized corrosion model does not require differentiation between the "drip" and "no-drip" situations because in either case the same criterion for localized corrosion initiation will be used to predict whether or not localized corrosion will initiate (Section 6.6).

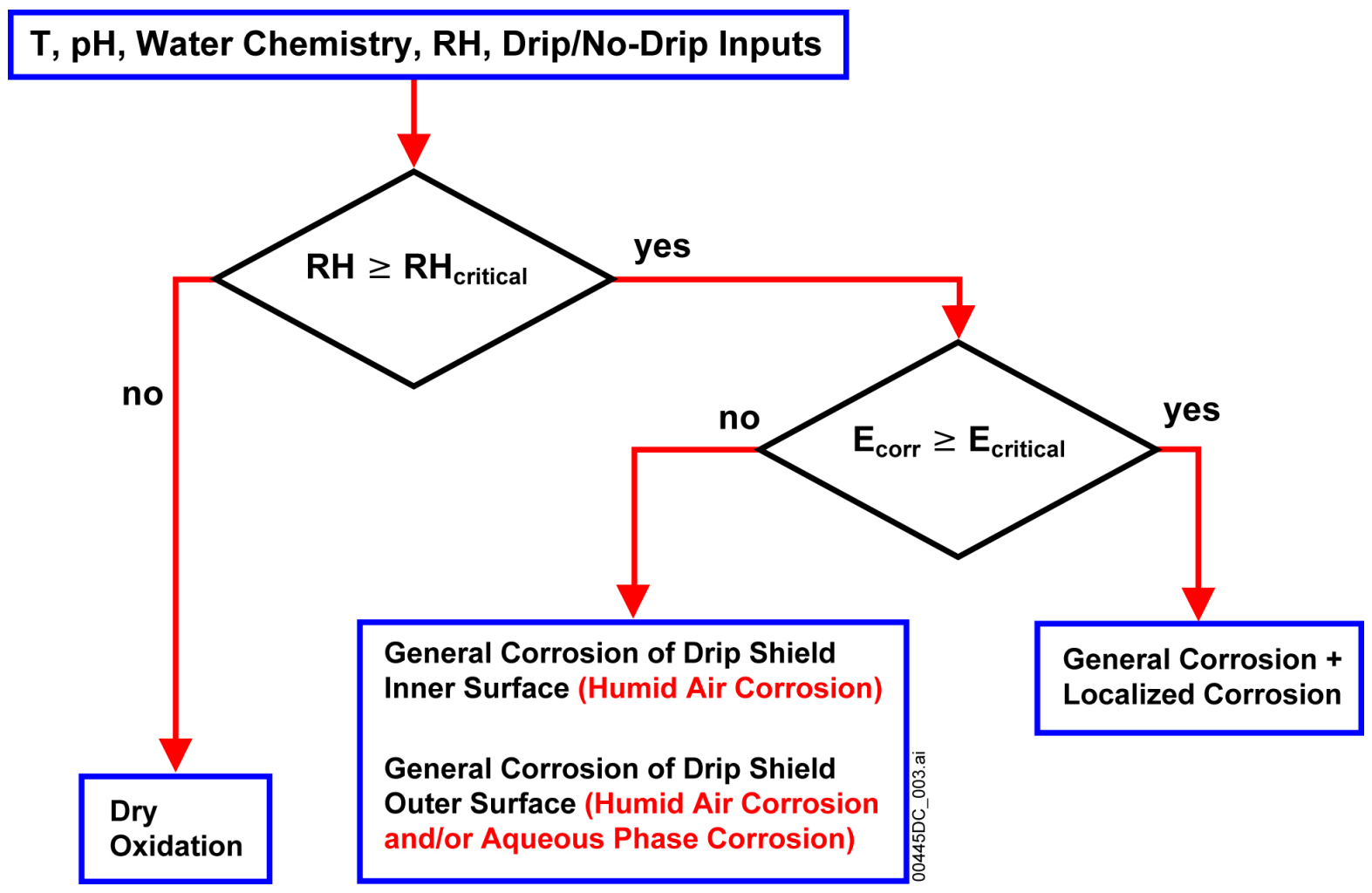

Figure 1. Schematic Representation of Corrosion Model for Ti Grade 7 Drip Shield 
The corrosion of the inner surface of the drip shield is modeled based on a cumulative distribution function developed from the measured weight loss of specimens with the "weightloss" geometry (i.e., without a creviced area) exposed for one year in the LTCTF and validated by using the LTCTF 2.5- and 5-year exposure test data and literature information. The corrosion of the outer surface of the drip shield is modeled based on a cumulative distribution function developed from the measured weight loss of specimens with both the "weight-loss" and "crevice" geometry exposed for one year in the LTCTF and validated by using the LTCTF 2.5and 5-year exposure test data and literature information. General corrosion is discussed further in Section 6.5.

The corrosion potential $\left(E_{\text {corr }}\right)$ and critical potential $\left(E_{\text {critical }}\right)$ are used to determine whether the mode of attack is general corrosion only or both general and localized corrosion. If $E_{\text {corr }} \geq$ $E_{\text {critical }}$, both general corrosion and localized corrosion occur. The localized corrosion initiation model developed in this report predicts whether localized corrosion will initiate. This is discussed in more detail in Section 6.6. As will be seen in Section 6.6, localized corrosion is not likely to occur under exposure conditions expected in the repository.

Other factors that may influence the corrosion of the drip shield material in repository environments are also considered. The effects of calcium chloride on localized corrosion and general corrosion of titanium alloys are discussed in Sections 6.6.5 and 6.5.8, respectively. The effects of fluoride on corrosion of Ti Grade 7 are discussed in Section 6.5.7. The effects of radiolysis (Section 6.7.1), microbially influenced corrosion (Section 6.7.2) and aging and phase instability (Section 6.7.3) are also addressed in this report. Section 6.9 contains a discussion of model implementation. 
INTENTIONALLY LEFT BLANK 


\section{QUALITY ASSURANCE}

The Quality Assurance (QA) program applies to the development of this technical product. The technical work plan associated with this activity (BSC 2004 [DIRS 171583]), was prepared per AP-2.27Q, Planning for Science Activities. The drip shields have been determined to be important to waste isolation in accordance with AP-2.22Q and, therefore, are classified as Safety Category (SC) on Q-List (BSC 2004 [DIRS 168361]) and by Safety Classification of SSCs and Barriers (BSC 2004 [DIRS 170992]). The methods used to control the electronic management of data as required by AP-SV.1Q, Control of the Electronic Management of Information, were accomplished in accordance with the technical work plan.

This document is prepared in accordance with AP-SIII.10Q, Models, and reviewed in accordance with AP-2.14Q, Document Review.

\subsection{INTEGRITY OF TRANSFER OF DATA}

The methods used to control the electronic management of data as required by AP-SV.1Q, Control of the Electronic Management of Information, were accomplished in accordance with Technical Work Plan For: Regulatory Integration Modeling and Analysis of the Waste Form and Waste Package (BSC 2004 [DIRS 171583]). The inputs to this report are documented according to the AP-3.15Q, Managing Technical Product Inputs procedure. The methods used to control the electronic management of data as required by AP-SV.1Q, Control of the Electronic Management of Information, were accomplished in accordance with the technical work plan. The process for control of the electronic management of information on evaluation of work activities/processes/process functions, outlined in Section 5.0 of AP-SV.1Q, is followed to ensure accuracy, completeness, and security of information and data used in preparation of this report. Examples of process controls mentioned in AP-SV.1Q are (a) access to the information contained on personal computer is password protected; (b) secured backup copies are appropriately labeled and stored before changes are made and kept until the changes are confirmed and correct; (c) physical electronic media (tape, diskette, CD-ROM, etc.) are appropriately labeled; and (d) for nonphysical electronic media, transport mechanisms can be e-mail, TCP/IP, Netbios, etc. and methods of receipt verification may include visual inspection, transmission verification settings, check sums, application information integrity check, etc. 
INTENTIONALLY LEFT BLANK 


\section{COMPUTER SOFTWARE AND MODEL USAGE}

Excel 97 SR-2 is a commercial off-the-shelf software program used in this report. The computations performed in this report using Excel use only standard functions and are documented in sufficient detail to allow an independent technical reviewer to reproduce or verify the results by visual inspection or hand calculation without recourse to the originator. Therefore, this software is exempt from LP-SI.11Q-BSC, Software Management. Excel 97 SR-2 is appropriate for its intended use because it offers the mathematical and graphical functionality necessary to perform and document the numerical manipulations used in this analysis. Excel 97 SR-2 was executed on an Optiplex GX260 Workstation (CRWMS M\&O tag 501481, located in the Summerlin Offices, Las Vegas, Nevada) with the Windows 2000 operating system.

Mathcad 2001i is a commercial off-the-shelf software program used in this report. The computations performed in this report using Mathcad 2001i use only standard functions and are documented in sufficient detail to allow an independent technical reviewer to reproduce or verify the results by visual inspection or hand calculation without recourse to the originator. Therefore this software is exempt from LP-SI.11Q-BSC, Software Management. Mathcad 2001i is appropriate for its intended use because it offers the mathematical and graphical functionality necessary to perform and document the numerical manipulations used in this analysis Mathcad 2001i was executed on an Optiplex GX260 Workstation (CRWMS M\&O tag 152849, located in the Summerlin Offices, Las Vegas, Nevada) with the Windows 2000 operating system. 
INTENTIONALLY LEFT BLANK 


\section{INPUTS}

\subsection{DIRECT INPUTS}

\subsubsection{Definition of Parameters}

The parameters used in this report are defined in the nomenclature section of this document.

Table 2. Input Data

\begin{tabular}{|c|c|c|c|}
\hline Data Description & Data Origin & DTN & $\begin{array}{c}\text { Data Use in this Model } \\
\text { Report }\end{array}$ \\
\hline $\begin{array}{l}\text { Universal gas } \\
\text { constant }\end{array}$ & Lide 1991 [DIRS 131202] & $\mathrm{N} / \mathrm{A}$ & Sections 6.4 .1 and 6.4 .2 \\
\hline $\begin{array}{l}\text { Titanium alloy dry } \\
\text { oxidation oxide layer } \\
\text { thickness }\end{array}$ & $\begin{array}{l}\text { Schutz and Thomas } 1987 \\
\text { [DIRS 112147] }\end{array}$ & $\mathrm{N} / \mathrm{A}$ & $\begin{array}{l}\text { Development of dry oxidation } \\
\text { model in Section } 6.4 \text {, Figure } 7, \\
\text { Figure } 8 \text {, Figure 9, Table } 8, \\
\text { Table } 9 \text {, and Table } 10\end{array}$ \\
\hline $\begin{array}{l}\text { Cyclic polarization } \\
\text { curves for Ti Grade } 7\end{array}$ & LLNL & $\begin{array}{l}\text { LL010105512251.011 } \\
\text { [DIRS 155623] }\end{array}$ & $\begin{array}{l}\text { Analysis of localized corrosion } \\
\text { of the drip shield in Section } \\
6.6 \text {, Figure } 14 \text { through } \\
\text { Figure 18, Table } 19 \text {, and } \\
\text { Table 20, Appendix A }\end{array}$ \\
\hline $\begin{array}{l}\text { Electrochemical test } \\
\text { results of titanium } \\
\text { alloy (Grade } 7 \text { ) } \\
\text { exposed to high } \\
\text { chloride and high } \\
\text { temperature } \\
\text { conditions. }\end{array}$ & LLNL & $\begin{array}{l}\text { LL030409412251.050 } \\
\text { [DIRS 163647] }\end{array}$ & $\begin{array}{l}\text { Analysis of effects of calcium } \\
\text { chloride on drip shield } \\
\text { corrosion in Section } 6.5 .8 \text { and } \\
\text { Section 6.6.5 }\end{array}$ \\
\hline $\begin{array}{l}\text { Target compositions } \\
\text { of aqueous solutions } \\
\text { used for corrosion } \\
\text { testing }\end{array}$ & LLNL & $\begin{array}{l}\text { LL040803112251.117 } \\
\text { [DIRS 171362] }\end{array}$ & $\begin{array}{l}\text { Analysis of localized corrosion } \\
\text { of the drip shield in Section } \\
6.6 \text {, Figure } 19 \text { and Figure 20, } \\
\text { Appendix A. }\end{array}$ \\
\hline $\begin{array}{l}1 \text {-year general } \\
\text { corrosion rates for } \\
\text { Ti Grade } 16\end{array}$ & $\begin{array}{l}\text { Estill } 1998 \text { [DIRS 117697], } \\
\text { Section } 2.2\end{array}$ & $\begin{array}{l}\text { LL990610605924.079 } \\
\text { [DIRS 104994] }\end{array}$ & $\begin{array}{l}\text { General corrosion rate test } \\
\text { data for developing the } \\
\text { aqueous-phase corrosion } \\
\text { model analysis of Section } 6.5\end{array}$ \\
\hline Value of $\mathrm{K}$ & $\begin{array}{l}\text { ASTM G 1-90 } \\
\text { [DIRS 103515] }\end{array}$ & N/A & Equation 22 \\
\hline $\begin{array}{l}\text { Atomic weight of } \\
\text { chlorine }\end{array}$ & $\begin{array}{l}\text { Sargent-Welch Scientific } \\
\text { Company 1979 } \\
\text { [DIRS 110056] }\end{array}$ & $\mathrm{N} / \mathrm{A}$ & Appendix A \\
\hline
\end{tabular}

\subsubsection{Identification of Input Data}

The data used for dry oxidation modeling were obtained from ASM Metals Handbook (Schutz and Thomas 1987 [DIRS 112147], Figure 25) and accepted as established fact per AP-SIII.2Q, Qualification of Unqualified Data.

The data available for aqueous general corrosion modeling were obtained by the YMP program at the Long Term Corrosion Test Facility (LTCTF) for Ti Grade 16 (the 1-year data). These data consist of long-term corrosion weight change measurements per ASTM G 1-90 ([DIRS 103515]) 
of samples of Ti Grade 16 (as a surrogate for Ti Grade 7 with lower palladium content) in humid or aqueous environments at $60^{\circ} \mathrm{C}$ and $90^{\circ} \mathrm{C}$ for one year. The 1-year data are used for model development (Section 6.5). The experimental data supporting the localized corrosion model consisted of cyclic polarization, corrosion potential versus temperature, and electrochemical measurements on Ti Grade 7 conducted at the LLNL per ASTM G 5-94 ([DIRS 117479]) methodology.

Input source data directly used in developing the titanium alloy oxidation and corrosion models of this report were obtained from the sources shown in Table 2.

The treatment of uncertainties in input data and parameters is discussed in Section 6.

\subsubsection{Description of Direct Input Parameters}

Titanium alloy aqueous corrosion rate information and data from the scientific and technical literature, the project-sponsored LTCTF weight-loss experiments, and cyclic polarization measurements were used as a basis for this process-level model. The literature data used in the development of the dry oxidation model is accepted as established fact (Schutz and Thomas 1987 [DIRS 112147]). The Project's experimental data used in the development of the general corrosion and localized corrosion models are compliant with the requirements from Quality Assurance Requirements and Description (DOE 2004 [DIRS 171539]) and are, therefore, qualified (Estill 1998 [DIRS 117697]; DTN: LL990610605924.079 [DIRS 104994]). The test media in the LTCTF are discussed in Section 6.2, along with the relevance of in-drift chemical model results to the corrosion testing media. Determination of the listed parameters is discussed in more detail in Section 6.

\subsection{CRITERIA}

The drip shield is designed to protect the waste package, thereby, prolonging waste package life. Therefore, the drip shield must help meet criteria specific to the waste package. Table 3-1 of Technical Work Plan For: Regulatory Integration Modeling and Analysis of the Waste Form and Waste Package (BSC 2004 [DIRS 171583]) identifies the following Acceptance Criteria based on the requirements mentioned in Project Requirements Document (Canori and Leitner 2003 [DIRS 166275]) and Yucca Mountain Review Plan, Final Report (NRC 2003 [DIRS 163274]):

(1) System Description and Demonstration of Multiple Barriers (NRC 2003 [DIRS 163274], Section 2.2.1.1.3; Canori and Leitner 2003 [DIRS 166275], PRD-002/T-014, PRD-002/T-016)

Specific requirements involve identifying multiple barriers (natural and engineered), describing the capabilities of these barriers to isolate waste, and providing technical bases for capabilities descriptions consistent with the postclosure performance objectives. To comply with these requirements, the following acceptance criteria are identified in Table 3-1 of Technical Work Plan For: Regulatory Integration Modeling and Analysis of the Waste Form and Waste Package (BSC 2004 [DIRS 171583]):

AC1: Identification of Barriers is Adequate 
AC2: Description of the Capability of Identified Barriers is Acceptable

AC3: Technical Basis for Barrier Capability is Adequately Presented

(2) Degradation of Engineered Barriers (NRC 2003 [DIRS 163274], Section 2.2.1.3.1.3; Canori and Leitner 2003 [DIRS 166275], PRD-002/T-015).

Specific requirements include describing deterioration or degradation of engineered barriers and modeling degradation processes using data for performance assessment, including total system performance assessment (TSPA). Consideration of uncertainties and variabilities in model parameters and alternative conceptual models are also required. To fulfill these requirements, the following acceptance criteria are identified in Table 3-1 of Technical Work Plan For: Regulatory Integration Modeling and Analysis of the Waste Form and Waste Package (BSC 2004 [DIRS 171583]):

AC1: System Description and Model Integration are Adequate

AC2: Data are Sufficient for Model Justification

AC3: Data Uncertainty is Characterized and Propagated Through the Model Abstraction

AC4: Model Uncertainty is Characterized and Propagated Through the Model Abstraction

AC5: Model Abstraction Output is Supported by Objective Comparisons

Acceptance Criteria from Yucca Mountain Review Plan, Final Report (NRC 2003 [DIRS 163274]) are discussed further in Section 8.6.

\subsection{CODES AND STANDARDS}

One general standard used in this document is ASTM C 1174-97 [DIRS 105725], Standard Practice for Prediction of the Long-Term Behavior of Materials, Including Waste Forms, Used in Engineered Barrier Systems (EBS) for Geological Disposal of High-Level Radioactive Waste.

\subsubsection{Standards for Test Media}

The following test media standards are used in this report:

- UCRL-ID-132285 [DIRS 110868], Formulation and Make-Up of Simulated Dilute Water, Low Ionic Content Aqueous Solution.

- UCRL-ID-132286 [DIRS 110890], Formulation and Make-Up of Simulated Concentrated Water (SCW), High Ionic Content Aqueous Solution.

- UCRL-ID-132287 [DIRS 110867], Formulation and Make-Up of Simulated Acidic Concentrated Water (SAW), High Ionic Content Aqueous Solution. 


\subsubsection{Cyclic Polarization Measurements}

The following cyclic polarization standards are used in this report:

- ASTM G 3-89 [DIRS 138911], Standard Practice for Conventions Applicable to Electrochemical Measurements in Corrosion Testing (Section 3, Vol. 3.02, pp. 36 to 44)

- ASTM G 5-94 [DIRS 117479], Standard Reference Test Method for Making Potentiostatic and Potentiodynamic Anodic Polarization Measurements (Section 3, Vol. 3.02, pp. 54 to 57)

- ASTM G 48-99a [DIRS 138917], Standard Test Methods for Pitting and Crevice Corrosion Resistance of Stainless Steels and Related Alloys by Use of Ferric Chloride Solution (Section 3, Vol. 3.02, pp. 181 to 186)

- ASTM G 61-86 [DIRS 127897], Standard Test Method for Conducting Cyclic Potentiodynamic Polarization Measurements for Localized Corrosion Susceptibility of Iron-, Nickel-, or Cobalt-Based Alloys (Section 3, Vol. 3.02, pp. 231 to 235).

\subsubsection{General Corrosion Measurements}

The following general corrosion standards are used in this report:

- ASTM G 1-90 [DIRS 103515], Standard Practice for Preparing, Cleaning, and Evaluating Corrosion Test Specimens (Section 3, Vol. 3.02, pp. 15 to 21)

- ASTM G 48-99a [DIRS 138917], Standard Test Methods for Pitting and Crevice Corrosion Resistance of Stainless Steels and Related Alloys by Use of Ferric Chloride Solution (Section 3, Vol. 3.02, pp. 181 to 186). 


\section{ASSUMPTIONS}

\subsection{TITANIUM GRADE 7 VERSUS TITANIUM GRADE 16}

It is assumed that, due to the higher palladium (Pd) content, the resistance of Ti Grade 7 to general and localized corrosion is superior or at least equivalent to that of Ti Grade 16.

The mechanical properties and corrosion resistance of materials largely rely on their microstructure and chemical composition. The chemical compositions and mechanical properties, per ASTM B 265-02 (2002 [DIRS 162726]), of the relevant titanium alloys, are shown in Table 3 and Table 4. In Table 3 and Table 4, Ti Grades 2, 12, 16, and 7 are $\alpha$-alloys while Ti Grades 5 and 24 are $\alpha-\beta$ alloys. Ti Grade 7 contains slightly higher wt $\%$ of palladium ( 0.12 to $0.25 \mathrm{wt} \%)$ as compared to Ti Grade $16(0.04$ to $0.08 \mathrm{wt} \%)$ and slightly more carbon. The mechanical properties specified by ASTM B 265-02 [DIRS 162726] are identical for Ti Grades 2, 16, and 7. They are also identical for Ti Grades 5 and 24 and for Ti Grades 9 and 18 (Table 4) (ASTM B 265-02 [DIRS 162726]). 
Table 3. ASTM B 265-02 Specifications for Chemical Composition Requirements (wt \%) of Relevant Titanium Alloys in This Report

\begin{tabular}{|c|c|c|c|c|c|c|c|c|c|c|c|c|}
\hline Material & $\begin{array}{c}\text { UNS } \\
\text { Designation }\end{array}$ & $\mathbf{N}$ & C & $\mathbf{H}$ & 0 & $\mathrm{Fe}$ & $\mathrm{Al}$ & V & Pd & $\begin{array}{c}\text { Residual } \\
\text { (each) }\end{array}$ & $\begin{array}{c}\text { Residual } \\
\text { (total) }\end{array}$ & Titanium \\
\hline Ti Grade 12 & R53400 & 0.03 & 0.08 & 0.015 & 0.25 & 0.30 & - & - & - & $\begin{array}{c}0.2 \text { to } 0.4 \\
\text { Mo }\end{array}$ & $\begin{array}{c}0.6 \text { to } 0.9 \\
\mathrm{Ni}\end{array}$ & balance \\
\hline Ti Grade 2 & R50400 & 0.03 & 0.08 & 0.015 & 0.25 & 0.30 & - & - & - & 0.1 & 0.4 & balance \\
\hline Ti Grade 16 & R52402 & 0.03 & 0.08 & 0.015 & 0.25 & 0.30 & - & - & $\begin{array}{c}0.04 \text { to } \\
0.08\end{array}$ & 0.1 & 0.4 & balance \\
\hline Ti Grade 17 & R52252 & 0.03 & 0.08 & 0.015 & 0.18 & 0.320 & - & - & $\begin{array}{c}0.04 \text { to } \\
0.08\end{array}$ & 0.1 & 0.4 & balance \\
\hline Ti Grade 7 & R52400 & 0.03 & 0.10 & 0.015 & 0.25 & 0.30 & - & - & $\begin{array}{c}0.12 \text { to } \\
0.25\end{array}$ & 0.1 & 0.4 & balance \\
\hline Ti Grade 11 & R52250 & 0.03 & 0.10 & 0.015 & 0.18 & 0.20 & - & - & $\begin{array}{c}0.12 \text { to } \\
0.25\end{array}$ & 0.1 & 0.4 & balance \\
\hline Ti Grade 5 & R56406 & 0.05 & 0.08 & 0.015 & 0.20 & 0.40 & $\begin{array}{c}5.5 \text { to } \\
6.75\end{array}$ & $\begin{array}{c}3.5 \text { to } \\
4.5\end{array}$ & - & 0.1 & 0.4 & balance \\
\hline Ti Grade 24 & R56405 & 0.05 & 0.08 & 0.015 & 0.20 & 0.40 & $\begin{array}{c}5.5 \text { to } \\
6.75\end{array}$ & $\begin{array}{c}3.5 \text { to } \\
4.5 \\
\end{array}$ & $\begin{array}{c}0.04 \text { to } \\
0.08\end{array}$ & 0.1 & 0.4 & balance \\
\hline Ti Grade 9 & R56320* & 0.03 & 0.08 & 0.015 & 0.12 & 0.25 & $\begin{array}{c}2.5 \text { to } \\
3.5\end{array}$ & $\begin{array}{c}2.0 \text { to } \\
3.0\end{array}$ & - & 0.1 & 0.4 & balance \\
\hline Ti Grade 18 & R56322 & 0.03 & 0.08 & 0.015 & 0.15 & 0.25 & $\begin{array}{c}2.5 \text { to } \\
3.5\end{array}$ & $\begin{array}{c}2.0 \text { to } \\
3.0\end{array}$ & $\begin{array}{c}0.04 \text { to } \\
0.08\end{array}$ & 0.1 & 0.4 & balance \\
\hline
\end{tabular}

Source: ASTM B 265-02 [DIRS 162726], Table 2.

NOTE: * UNS R56320 requires lower $\mathrm{N}, \mathrm{C}, \mathrm{O}$, and $\mathrm{H}$. 
Table 4. ASTM B 265-02 Specifications for Mechanical Properties of Relevant Titanium Alloys

\begin{tabular}{|c|c|c|c|c|c|c|c|c|}
\hline \multirow[b]{3}{*}{ Material } & \multirow{3}{*}{$\begin{array}{c}\text { UNS } \\
\text { Designation }\end{array}$} & \multirow{2}{*}{\multicolumn{2}{|c|}{$\begin{array}{c}\text { Minimum } \\
\text { Tensile } \\
\text { Strength, ksi }\end{array}$}} & \multicolumn{4}{|c|}{ Yield Strength, $0.2 \%$ Offset } & \multirow{3}{*}{$\begin{array}{l}\text { Minimum } \\
\text { Elongation } \\
\text { in } 2 \text { in., \% }\end{array}$} \\
\hline & & & & \multicolumn{2}{|c|}{ Mi } & \multicolumn{2}{|c|}{ Max } & \\
\hline & & ksi & $\mathrm{MPa}$ & ksi & $\mathrm{MPa}$ & ksi & $\mathrm{MPa}$ & \\
\hline Ti Grade 12 & R53400 & 70 & 483 & 50 & 345 & - & - & 18 \\
\hline Ti Grade 2 & R50400 & 50 & 345 & 40 & 275 & 65 & 450 & 20 \\
\hline Ti Grade 16 & R52402 & 50 & 345 & 40 & 275 & 65 & 450 & 20 \\
\hline Ti Grade 17 & R52252 & 35 & 240 & 25 & 170 & 45 & 310 & 24 \\
\hline Ti Grade 7 & R52400 & 50 & 345 & 40 & 275 & 65 & 450 & 20 \\
\hline Ti Grade 11 & R52250 & 35 & 240 & 25 & 170 & 45 & 310 & 24 \\
\hline Ti Grade 5 & $\mathrm{R} 56406$ & 130 & 895 & 120 & 828 & - & - & 10 \\
\hline Ti Grade 24 & R56405 & 130 & 895 & 120 & 828 & - & - & 10 \\
\hline Ti Grade 9 & R56320* & 90 & 620 & 70 & 483 & - & - & 15 \\
\hline Ti Grade 18 & R56322 & 90 & 620 & 70 & 483 & - & - & 15 \\
\hline
\end{tabular}

Source: ASTM B 265-02 [DIRS 162726], Table 1.

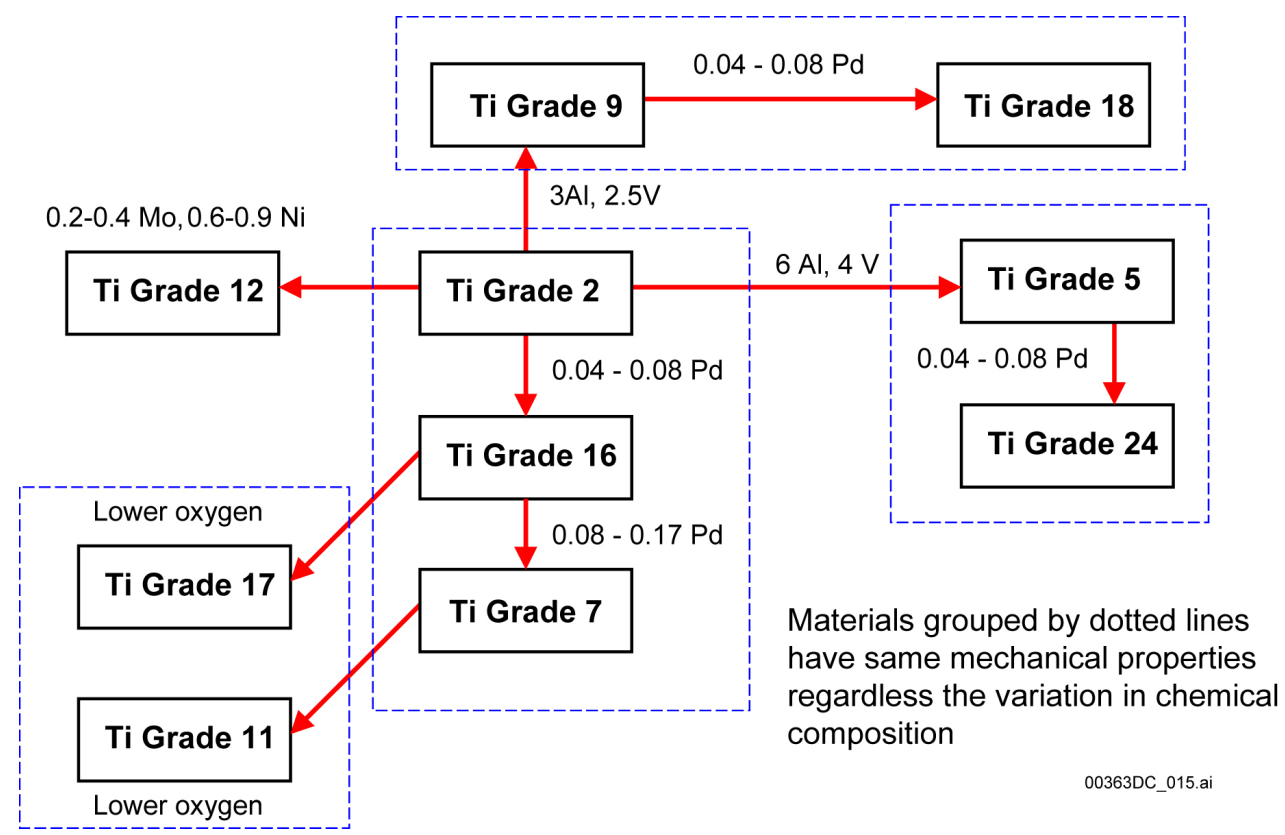

NOTE: Alloys grouped by dotted lines have the same mechanical properties, regardless of the chemical compositions (amount of Pd).

Figure 2. Schematic of the Relationship Between the Relevant Titanium Alloys

As shown schematically in Figure 2, based on the data in Table 3 and Table 4 the addition of a small amount of palladium to Ti Grade 2 to form Ti Grades 16 and 7 does not alter the mechanical properties of the alloy. While further addition of palladium (and a negligible amount of carbon) to Ti Grade 16 to yield Ti Grade 7 does not affect the mechanical properties of the alloy, the resistance to general and localized corrosion is improved (Schutz 2003 [DIRS 168772]). Ti Grade 16 was used as an analog of Ti Grade 7 at the LTCTF for the 1-year 
and 5-year weight-loss tests due to its compositional similarity to Ti Grade 7. The corrosion performance of $\mathrm{Ti}$ Grade 7, because of its higher palladium content, is superior or at least equivalent to that of Ti Grade 16 (Schutz 2003 [DIRS 168772]).

Therefore, the assumption that the resistance to general and localized corrosion of Ti Grade 7 is superior or at least equivalent to those of $\mathrm{Ti}$ Grade 16 is valid. This assumption is used throughout this report.

\subsection{DRY OXIDATION}

It is assumed that dry oxidation of the drip shield occurs at any $\mathrm{RH}$ below the threshold $\mathrm{RH}$ $\left(R H_{\text {critical }}\right)$ for humid-air corrosion.

Although no values for the threshold $\mathrm{RH}$ are presented in this report, the existence of a threshold $\mathrm{RH}$ is mentioned throughout this document. The critical relative humidity is the relative humidity below which water will not form on a clean metal surface and electrochemical processes will not occur (ASM International 1987 [DIRS 133378], p. 82). For clean metal surfaces, the relative humidity must exceed about $60 \%$ before a thin film of moisture will form on the metal surface, providing an electrolyte for ionic current transfer (ASM International 1987 [DIRS 133378], p. 82). Cleanliness, corrosion product build-up, and hygroscopic salts or contaminants can cause water absorption at lower relative humidities (ASM International 1987 [DIRS 133378], p. 80). On this basis, the existence of a threshold RH for initiation of corrosion processes is a reasonable assumption and consistent with data presented in corrosion handbooks.

Dry oxidation forms an adherent, protective oxide film of uniform thickness. This observation is supported by experience with titanium that shows that in general, the rate of dry oxidation is limited by mass transport through the growing metal oxide film, and the oxide thickness obeys a parabolic (Welsch et al. 1996 [DIRS 114895]) or logarithmic (Shoesmith et al. 1995 [DIRS 117892]) growth law. Reasonable values of the rate constant have been derived, as discussed in Section 6.4. This is a reasonably bounding assumption supported by the extensive literature concerning the adherent and protective nature of the oxide layer formed on titanium and titanium alloys under dry air conditions and, thus, does not require further validation (Section 7.3). This assumption is used in the analysis presented in Section 6.3.

\subsection{HUMID-AIR CORROSION}

It is assumed that humid-air corrosion occurs at any $\mathrm{RH}$ above the threshold $\mathrm{RH}$ (Assumption 5.2), provided there is no dripping. It is further assumed that the rates of humid-air corrosion can be obtained from corrosion data from the LTCTF and that the general corrosion rate over the full regulatory period can be bounded by a constant rate value (selected from a cumulative distribution function, Section 6.5) that does not decrease with time. Less conservative corrosion models (such as the parabolic and logarithmic forms assumed for the dry oxidation analysis) assume that the rate decreases with time. However, the assumptions used here are reasonable bounding assumptions supported by both the initial LTCTF data (e.g., by comparing the 1-year, 2.5-year and 5-year corrosion rates obtained at LTCTF) and the available literature concerning the aqueous corrosion of titanium and titanium alloys (Section 7.4). Therefore, these assumptions are conservative and do not require further validation. These 
assumptions are used in the analysis of general corrosion and localized corrosion presented in Sections 6.3, 6.5, and 6.6.

\subsection{AQUEOUS-PHASE CORROSION}

It is assumed that at a given surface temperature, liquid-phase water can form on the drip shield in the presence of salts or mineral deposits, or both. In the presence of such deposits, a liquidphase can be established at a higher temperature than otherwise possible. Two conditions must be met for aqueous-phase corrosion to occur: (1) the presence of dripping water and (2) relative humidity above the deliquescence point of the deposit at the temperature of the drip shield surface (i.e., $R H \geq R H_{\text {critical }}$ ).

A discussion on the threshold relative humidity $\left(R H_{\text {critical }}\right)$ for humid-air corrosion can be found in Assumption 5.2. It is also assumed that the general corrosion rate may be bounded by a constant-rate value that does not decrease with time. Less conservative corrosion models assume that the rate decreases with time. General corrosion occurs uniformly over the drip shield surface. These are reasonable bounding assumptions supported by both the initial LTCTF data and the available literature concerning the aqueous corrosion of titanium and titanium alloys (Section 7.4) and require no further confirmation. This assumption is used in the analysis of general corrosion and localized corrosion presented in Sections 6.3, 6.5, and 6.6.

\subsection{DRIPPING CONDENSATE FROM INNER SURFACE OF THE DRIP SHIELD}

It is assumed that once the temperature of the drip shield drops below the dew point, condensation can occur on the inner surface of the drip shield. While clinging to the underside of the drip shield, this condensate is dilute water. This is a reasonable bounding assumption supported by both the initial LTCTF data and the available literature concerning the aqueous corrosion of titanium and titanium alloys (Section 7.4). This assumption is used in the analysis of general corrosion and localized corrosion presented in Sections 6.3, 6.5, and 6.6.

\subsection{THRESHOLD FOR LOCALIZED CORROSION}

It is assumed that no localized corrosion occurs if the open circuit corrosion potential $\left(E_{c o r r}\right)$ is less than the threshold potential for localized corrosion $\left(E_{\text {critical }}\right)$. This assumption is based on the criterion commonly used in the corrosion literature (Gruss 1998 [DIRS 100893]; Kehler et al. 2001 [DIRS 162231]; Scully et al. 1999 [DIRS 110246]) and is also used in General Corrosion and Localized Corrosion of Waste Package Outer Barrier (BSC 2004 [DIRS 169984]). Therefore, this assumption does not require further validation.

Various approaches have been used for choosing these threshold potentials and understanding the relationships between the threshold potentials and localized initiation (Gruss 1998 [DIRS 100893]; Kehler et al. 2001 [DIRS 162231]; Scully et al. 1999 [DIRS 110246]). In this report (Section 6.6), the threshold potential is defined as the potential where the current density in a cyclic polarization forward scan significantly increases (the passive film breakdown

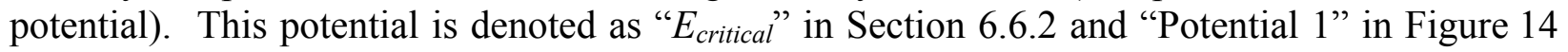
through Figure 18, respectively. 
INTENTIONALLY LEFT BLANK 


\section{MODEL DISCUSSION}

The relative importance of the model is high. The analyses performed and models developed in this report are based on both qualified experimental corrosion rate data from tests (particularly at the LTCTF) and handbook data for the oxidation and corrosion of titanium alloys.

The purpose of the oxidation/corrosion model is to account for corrosion of the drip shield material (Ti Grade 7) in environments relevant to the repository. The details on the repository environmental conditions are discussed in Engineered Barrier System: Physical and Chemical Environment Model (BSC 2004 [DIRS 169860], Section 6). The relevance of the test media at LTCTF to the repository environments is discussed in Section 2.2 of Engineering Materials Characterization Report (Estill 1998 [DIRS 117697]). The test media used for this model development are plausible environments, given the ionic species present in J-13 well water and the possible interaction of water with the near-field environment over extended periods. The possible corrosion modes that the drip shield may experience include dry oxidation, general corrosion, or localized corrosion.

This section briefly introduces the expected in-drift temperature and humidity histories (Section 6.1) and the relevance of the LTCTF test media to the in-drift chemical environments (Section 6.2). The conceptual models of dry oxidation (Section 6.3.1), humid-air corrosion (Section 6.3.2), and aqueous-phase corrosion (Section 6.3.3) are discussed followed by the detailed modeling of dry oxidation (Section 6.4), general corrosion (Section 6.5), and localized corrosion (Section 6.6). In the repository, the exposure environments for inner and outer surfaces of the drip shield are different. The major difference between the inner and the outer surfaces of the drip shield is that the outer surface will be exposed to a more complicated chemistry and geometry because of dust or mineral films (from evaporation of dripping water that could form crevices. In contrast, the inner surfaces of the drip shield will not be exposed to dripping water or significant film formation. Therefore, the general corrosion of the inner surface and the outer surface of the drip shield is modeled using different sets of corrosion data in this report (Section 6.5). This approach is schematically illustrated in Figure 3. Also, as indicated in Section 1.4, the model developed in this report does not exclude the potential for localized corrosion under the "no-drip" condition. Localized corrosion could occur if the right dust deliquescence chemistry is reached at $R H$ values equal to or greater than the $R H_{\text {critical }}$. In either the drip or no-drip case, the criterion for localized corrosion initiation will be used to predict whether localized corrosion will occur (Section 6.6).

The scope of this report also includes identification and disposition of the primary FEPs affecting postclosure drip shield degradation. The development of a comprehensive list of features, events, and processes (FEPs) potentially relevant to postclosure performance of the Yucca Mountain repository is an ongoing, iterative process based on site-specific information, design, and regulations. To support TSPA-LA, the FEP list was reevaluated in accordance with the Enhanced FEP Plan (BSC 2002 [DIRS 158966], Section 3.2). Table 5 provides a list of FEPs that are included in this report and provides specific references to sections within this report where the FEPs are discussed. Table 6 provides a list of FEPs that are excluded in this report and provides specific references to sections within this report where the FEPs are discussed. See also DTN: MO0407SEPFEPLA.000 [DIRS 170760] for a description of these FEPs and FEPS Screening of Processes and Issues in Drip Shield and Waste Package Degradation (BSC 2004 
[DIRS 169997]) for a complete list of all FEPs related to waste package and drip shield degradation.

Table 5. Features, Events, and Processes Included (Screened In) in This Model Report

\begin{tabular}{|c|c|c|}
\hline FEP No. & FEP Name & Disposition Described In \\
\hline $2.1 .03 .01 .0 \mathrm{~B}$ & General corrosion of drip shields & Sections 6.4 and 6.5. \\
\hline
\end{tabular}

Table 6. Features, Events, and Processes Excluded (Screened Out) in This Model Report

\begin{tabular}{|c|l|l|}
\hline FEP No. & \multicolumn{1}{|c|}{ FEP Name } & \multicolumn{1}{c|}{ Disposition Described In } \\
\hline 2.1.03.03.0B & Localized corrosion of drip shields & Section 6.6 \\
\hline $2.1 .03 .05 .0 \mathrm{~B}$ & Microbially influenced corrosion (MIC) of drip shields & Section 6.7.2 \\
\hline $2.1 .11 .06 .0 \mathrm{~B}$ & Thermal sensitization of drip shields & Section 6.7.3 \\
\hline $2.1 .13 .01 .0 \mathrm{~A}$ & Radiolysis & Section 6.7.1 \\
\hline
\end{tabular}

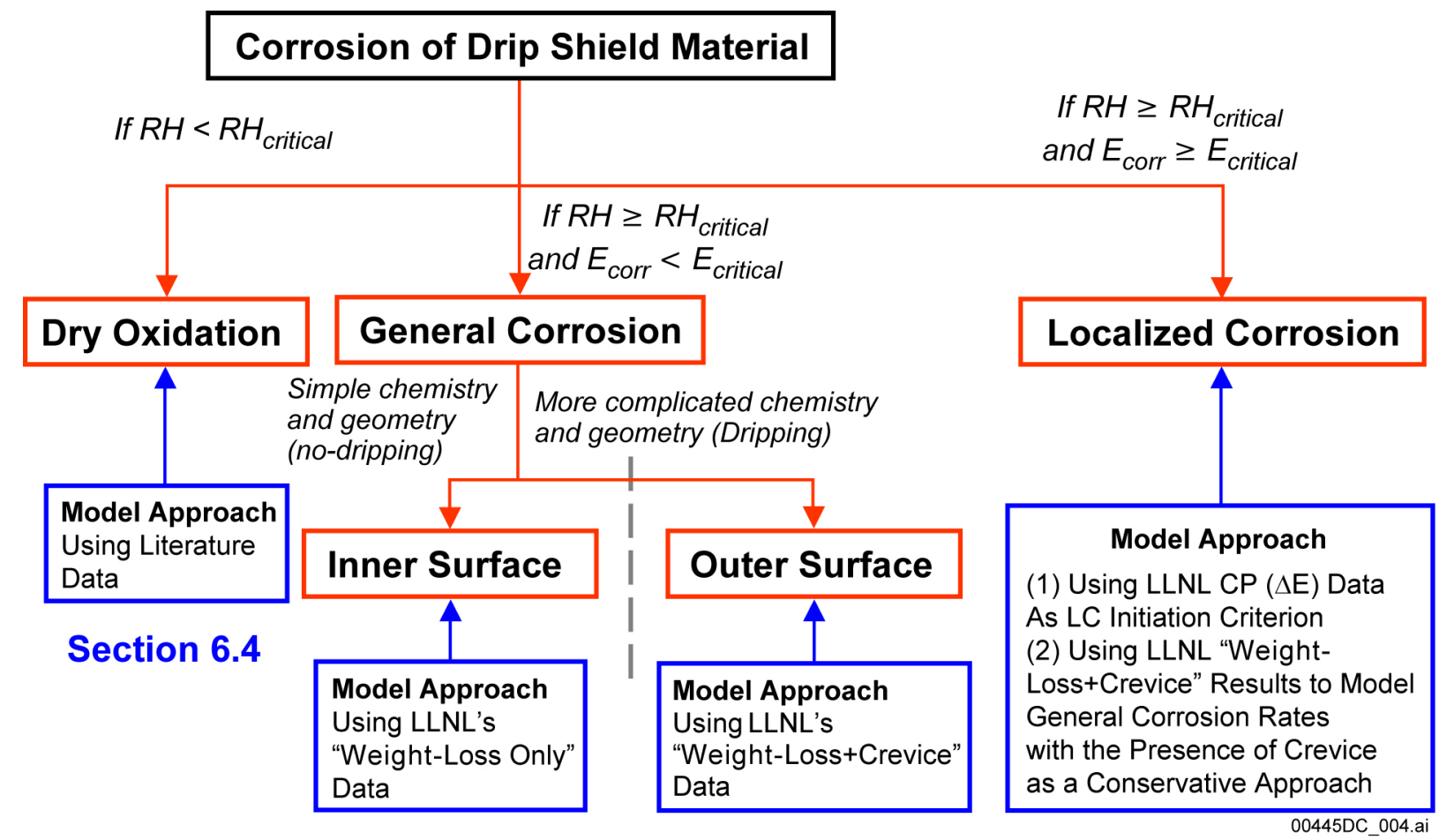

\section{Section 6.5}

\section{Section 6.6}

Note: Section 6.3 discusses conceptual models of dry oxidation and general corrosion.

Figure 3. Schematic Illustration of Corrosion Modes and Modeling Approaches in Section 6

\subsection{EXPECTED IN-DRIFT TEMPERATURE AND HUMIDITY}

Figure 4 shows a summary of the range of waste package temperature and humidity histories for all waste packages (a and b), all CSNF waste packages ( $c$ and d), and all DHLW waste packages (e and f) (BSC 2004 [DIRS 169565], Figure 6.3-53) for the TSPA base case. The ranges include the lower-bound, mean, and upper-bound infiltration flux cases and use of the mean thermal- 
conductivity values for all unsaturated zone layer units, including the host-rock units. The influence of the low-probability-seismic collapsed-drift scenario on in-drift thermohydrologic conditions is shown in Figure 5 (BSC 2004 [DIRS 169565], Figure 6.3-57). The curves for waste package temperature are bounding representations for the drip shield because the waste package (and the waste it contains) is the heat source in the repository environment. The repository design enables operation in three temperature regimes: dryout, transition, and low-temperature. The relevant attributes of each regime are summarized below (BSC 2004 [DIRS 169565]):

Dryout-Drift walls will first be dried by ventilation air during the preclosure period. During postclosure, heat generated by radioactive decay increases the waste package, drip shield, and drift wall temperatures to above the boiling point of water. Because no significant seepage is expected when drift wall temperatures are above the boiling point of water, no aqueous-phase corrosion due to seepage is expected. However, depending on the surface temperature and relative humidity conditions, the existence of liquid-phase water on the waste package or drip shield is possible due to the presence of a dust or salt deposit. In the presence of such a deposit, a thin-film liquid phase can be established at a higher temperature and lower relative humidity than otherwise possible. Thus, formation of deliquescent brines in the absence of seepage may occur, and corrosion of the waste package and drip shield is considered in the context of these solutions. Calcium chloride-type brines are possible and predicted to occur in this regime, but they occur in the host rock when temperatures are above boiling and seepage into the drift is prevented by the vaporization barrier effect.

Transition-Seepage into the drifts is possible as the waste package cools, as the temperature of the drift wall drops below the boiling point of water, and while the waste package surface temperature is at or above the boiling point of the water. Seepage waters will undergo evaporative concentration on the drip shield surface or the waste package surface at the time when the drip shield seepage diversion function is lost, thereby evolving into either carbonate- or sulfate-type brines. The drip shield will mitigate seepage effects on the waste package. However, as in the dryout regime, formation of deliquescent brines could occur in this regime.

Low Temperature-As the waste package cools to a temperature below the boiling point of water, the in-drift relative humidity will increase, so evaporated solutions cannot be as concentrated. With further cooling, the temperature will drop to below the threshold for localized corrosion for the repository-relevant environments. This threshold temperature is a function of the presence of beneficial ions, such as nitrates and sulfates. 
(a) All waste packages

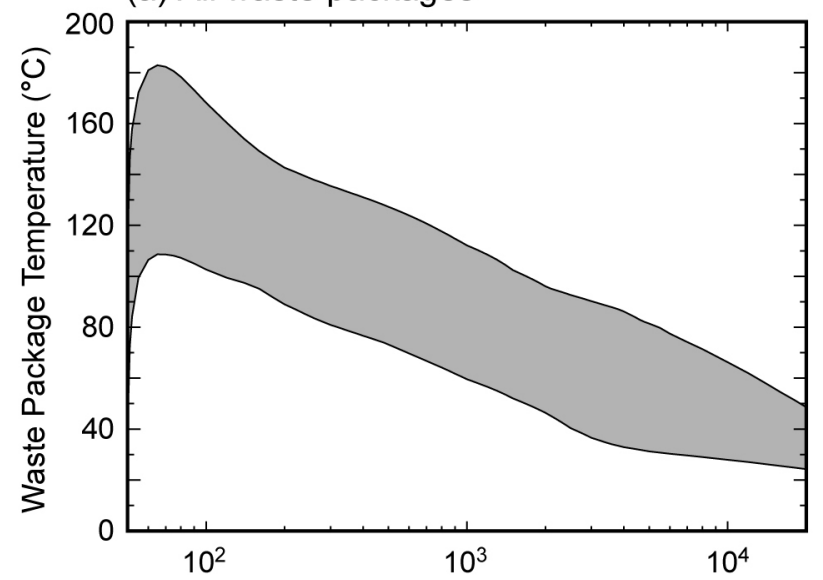

(c) All CSNF waste packages

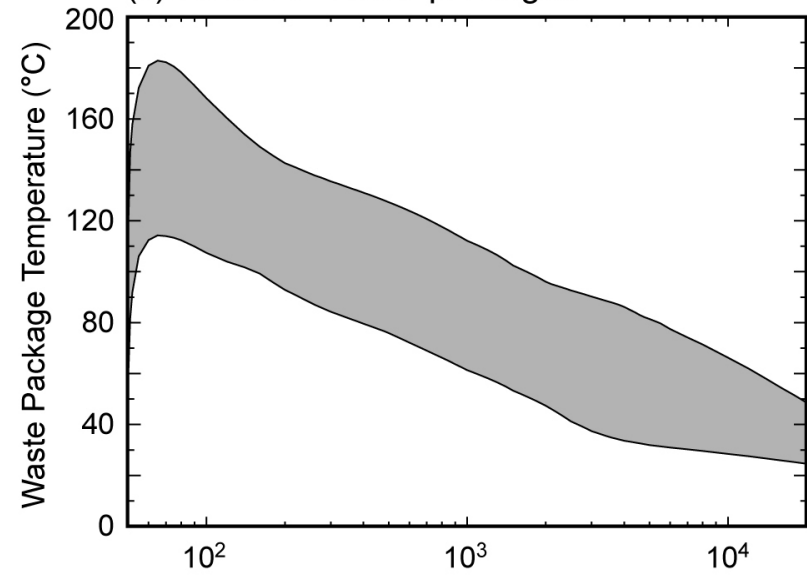

(e) All DHLW waste packages

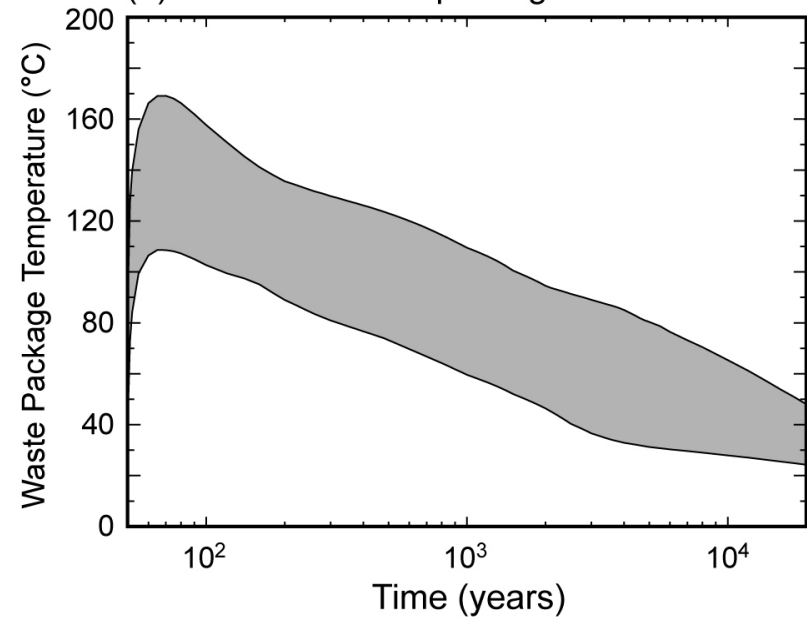

(b) All waste packages

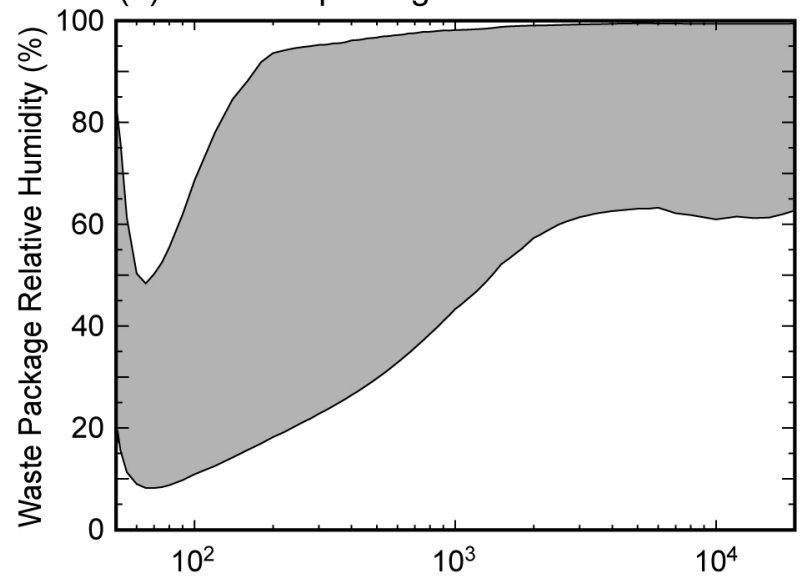

(d) All CSNF waste packages

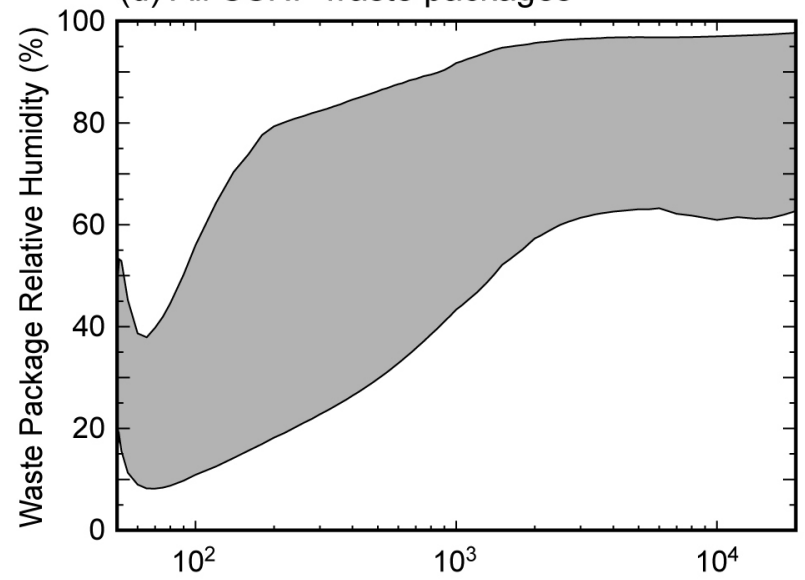

(f) All DHLW waste packages

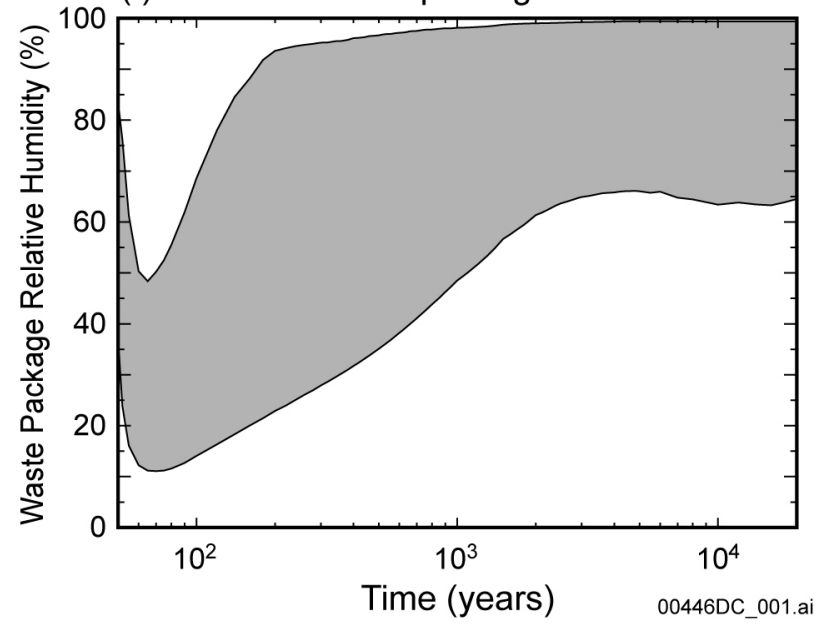

Source: BSC 2004 [DIRS 169565], Figure 6.3-53.

NOTE: The ranges include the lower-bound, mean, and upper-bound infiltration flux cases and use of the mean thermal-conductivity values for all unsaturated zone layer units, including the host-rock units.

Figure 4. Waste Package Temperature and Relative Humidity Ranges 

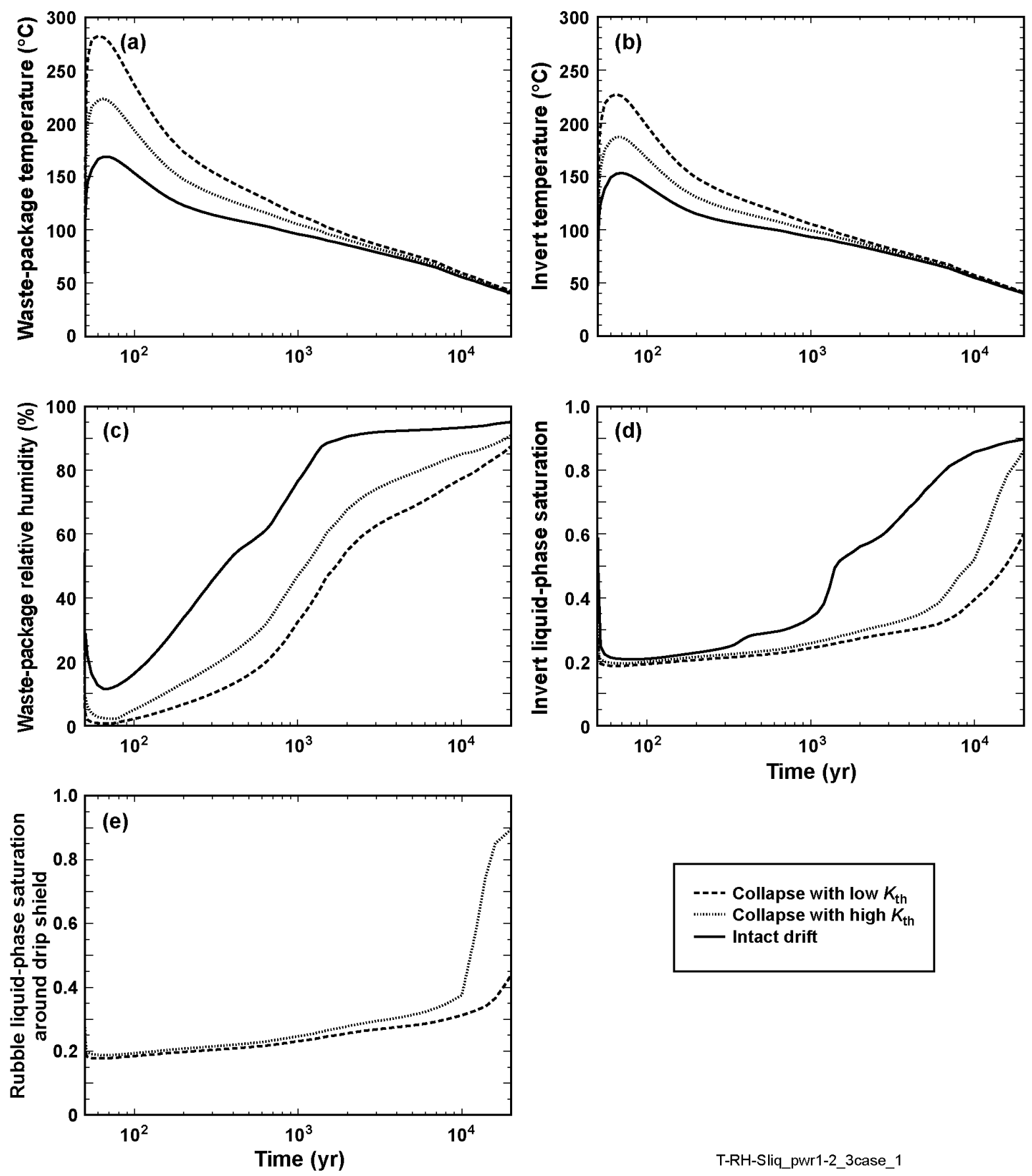

T-RH-Sliq_pwr1-2_3case_1

Source: BSC 2004 [DIRS 169565], Figure 6.3-57.

Figure 5. Thermohydrologic Variables for the "Hottest" Waste Package in the Low-Probability Seismic Collapsed Drift Scenario 


\subsection{RELATION OF IN-DRIFT CHEMICAL MODEL RESULTS TO CORROSION TESTING ENVIRONMENT}

The project has developed an understanding of the in-drift chemical environment for the three temperature regimes described in Section 6.1. The understanding is based on geochemical models and supporting data and analysis appropriate for the repository conditions. A detailed description of the evolution of the chemical environment is provided in Engineered Barrier System: Physical and Chemical Environment Model (BSC 2004 [DIRS 169860], Section 6), which includes detailed discussions of the relationship between the geochemical process model results, the range of expected in drift environments, and the chemical environments used in corrosion related testing. The model output is in the form of lookup tables, listing ion concentrations and $\mathrm{pH}$ as a function of relative humidity, temperature, and carbon-dioxide partial pressure. A brief summary of the chemical environment applicable to corrosion related testing extracted from the technical basis document on in-drift chemical environment follows.

Brines that develop on the waste packages and drip shields are the result of either evaporative concentration of seepage water or deliquescence of deposited salts. Deposited salts are due to entrained matter in the ventilation air, dust and debris deposited within the drifts, or seepage waters that have evaporated to dryness. Seepage waters do not enter the drifts until host rock temperatures fall below $100^{\circ} \mathrm{C}$. Dust salts deliquesce water from the atmosphere to form thin films on waste packages and drip shields above the normal boiling point of water (up to about $\left.140^{\circ} \mathrm{C}\right)(\mathrm{BSC} 2004$ [DIRS 169860], Section 6).

Corrosion testing to determine the response of waste package, drip shield, and other in-drift materials is carried out in environmental conditions consistent with those predicted by in-drift chemical modeling. Corrosion testing environments were chosen based on the three types of natural brines: (1) calcium chloride, (2) carbonate, and (3) sulfate. Initial studies focused on the carbonate-type brine, based on reasoning that carbonate-type waters typified by J-13 well water from the saturated zone near Yucca Mountain, are the expected types at the repository (Harrar et al. 1990 [DIRS 100814]).

The brine name reflects the chemical characteristic that distinguishes it from the other brines. Characterization of earth surface brines has, in part, guided the expected range of brine water chemistry in the repository. Some differences exist between brines formed at the earth's surface and brines formed in the repository. These differences are mainly due to the chemistry of seepage waters and surface waters giving rise to brines, and differences between the salt chemistry of dust and the dissolved salt content of such surface waters. Two important general factors specific to the repository brines are the presence of nitrate and more effective mechanisms for the removal of magnesium. Nitrate will be present in the deliquescent brines owing to multiple potential sources (BSC 2004 [DIRS 161237], Section 6.7.2.8) and the generally high solubility of nitrate minerals (BSC 2004 [DIRS 161237], Section 4.1.1.7). Magnesium will not be significant owing to a combination of low source (for the dust, as well as for at least some groundwaters) and multiple removal mechanisms (e.g., manganese sequestration in secondary silicates), most of which are enhanced by elevated temperature (BSC 2004 [DIRS 161237], Sections 6.7.2.10 and 6.7.2.11). 
Aqueous corrosion test solutions include several multi-ionic solutions based on a carbonate-base J-13 well water and test solutions containing the major species expected to affect corrosion such as nitrate ions. The standardized solutions developed as relevant test environments are presented in Table 7. These solutions include SDW, SCW, and SAW (used for testing at $30^{\circ} \mathrm{C}, 60^{\circ} \mathrm{C}$, and $90^{\circ} \mathrm{C}$ ), as well as SSW (used for testing at $100^{\circ} \mathrm{C}$ and $120^{\circ} \mathrm{C}$ ). The SSW formulation is based upon the possibility that evaporation of J-13 well water will lead to a sodium-potassium-chloride-nitrate solution. The following discussion on the relevance of the test media to the in-drift chemical environment is a summary of Engineered Barrier System: Physical and Chemical Environment Model (BSC 2004 [DIRS 169860], Section 6) and is used in this report as background information only.

Table 7. Composition of Standard Test Media Based on J-13 Well Water

\begin{tabular}{|c|c|c|c|c|c|}
\hline Ion & $\begin{array}{c}\text { SDW } \\
\left(\mathrm{mg} / \mathrm{L}^{-1}\right)\end{array}$ & $\begin{array}{c}\mathrm{SCW} \\
\left(\mathrm{mg} / \mathrm{L}^{-1}\right)\end{array}$ & $\begin{array}{c}\text { SAW } \\
\left(\mathrm{mg} / \mathrm{L}^{-1}\right)\end{array}$ & $\begin{array}{c}\text { SSW } \\
\left(\mathrm{mg} / \mathrm{L}^{-1}\right)\end{array}$ & $\begin{array}{l}\text { BSW-12 } \\
\left(\mathrm{mg} / \mathrm{L}^{-1}\right)\end{array}$ \\
\hline $\mathrm{K}^{+1}$ & $3.400 E+01$ & $3.400 \mathrm{E}+03$ & $3.400 \mathrm{E}+03$ & $1.420 E+05$ & $6.71015 E+04$ \\
\hline $\mathrm{Na}^{+1}$ & $4.090 \mathrm{E}+02$ & $4.090 \mathrm{E}+4$ & $3.769 E+04$ & $4.870 \mathrm{E}+04$ & $1.056860 \mathrm{E}+05$ \\
\hline $\mathrm{Mg}^{+2}$ & $1.000 \mathrm{E}+00$ & $<1.000 \mathrm{E}+00$ & $1.000 \mathrm{E}+03$ & $0.000 \mathrm{E}+00$ & $0.000 \mathrm{E}+00$ \\
\hline $\mathrm{Ca}^{+2}$ & 5.000E-01 & $<1.000 E+00$ & $1.000 \mathrm{E}+03$ & $0.000 \mathrm{E}+00$ & $0.000 \mathrm{E}+00$ \\
\hline $\mathrm{F}^{-1}$ & $1.400 \mathrm{E}+01$ & $1.400 \mathrm{E}+03$ & $0.000 \mathrm{E}+00$ & $0.000 \mathrm{E}+00$ & $1.3308 \mathrm{E}+03$ \\
\hline $\mathrm{Cl}^{-1}$ & $6.700 \mathrm{E}+01$ & $6.700 \mathrm{E}+03$ & $2.425 \mathrm{E}+04$ & $1.280 \mathrm{E}+05$ & $1.313155 \mathrm{E}+05$ \\
\hline $\mathrm{NO}_{3}{ }^{-1}$ & $6.400 \mathrm{E}+01$ & $6.400 \mathrm{E}+03$ & $2.30 \mathrm{E}+04$ & $1.313 \mathrm{E}+06$ & $1.394661 \mathrm{E}+06$ \\
\hline $\mathrm{SO}_{4}^{-2}$ & $1.670 \mathrm{E}+02$ & $1.670 \mathrm{E}+04$ & $3.86 \mathrm{E}+04$ & $0.000 \mathrm{E}+00$ & $1.39237 \mathrm{E}+04$ \\
\hline $\mathrm{HCO}_{3}^{-1}$ & $9.470 \mathrm{E}+02$ & $7.000 \mathrm{E}+04$ & $0.000 \mathrm{E}+00$ & $0.000 E+00$ & $0.000 \mathrm{E}+00$ \\
\hline $\mathrm{Si}$ & $27\left(60^{\circ} \mathrm{C}\right), 49\left(90^{\circ} \mathrm{C}\right)$ & $27\left(60^{\circ} \mathrm{C}\right), 49\left(90^{\circ} \mathrm{C}\right)$ & $27\left(60^{\circ} \mathrm{C}\right), 49\left(90^{\circ} \mathrm{C}\right)$ & $0.000 \mathrm{E}+00$ & $0.000 \mathrm{E}+00$ \\
\hline $\mathrm{pH}$ & 9.8 to 10.2 & 9.8 to 10.2 & 2.7 & $5.5-7$ & 12 \\
\hline
\end{tabular}

Source: DTN: LL040803112251.117 [DIRS 171362].

NOTE: $\mathrm{pH}$ measured for actual solutions at room temperature.

\subsubsection{Calcium-Chloride Brines}

The calcium-chloride brines have near neutral $\mathrm{pH}$ and no significant bicarbonate or carbonate, fluoride, or sulfate content. These brines also contain other cations such as sodium, potassium, and magnesium and other anions such as nitrate. The endpoint of the evaporative concentration of this type of brine contains $\mathrm{Ca}-\mathrm{Cl} / \mathrm{NO}_{3}$ or a mixture of $\mathrm{Ca} / \mathrm{Mg}-\mathrm{Cl} / \mathrm{NO}_{3}$. The quantity of magnesium and calcium is limited due to the precipitation of calcium carbonates, sulfates, and magnesium silicates. This is consistent with information on saline lakes where sodium is the dominant cation with the percentage of calcium varying from insignificant to about $40 \%$ (Drever 1997 [DIRS 147480]). Nitrate will be present, and endpoint brine of this type is dominated by calcium chloride and calcium nitrate. Formation of calcium chloride brines is also limited in the repository. Brine generated by dust deliquescence is likely be a potassium nitratesodium chloride brine with only a small probability of calcium due to the compositional nature of the dust leachate. Relative humidity dependence of the calcium-chloride brine composition is as follows. At low relative humidity, the aqueous solutions are dominated by calcium cations (very low sodium and potassium) and chloride and nitrate anions, because both calcium nitrate and calcium chloride are very soluble. At higher relative humidity, chloride and nitrate salts of 
sodium and potassium become soluble and dominate the aqueous solution compositions. This occurs at or above the deliquescence relative humidity for salts composed of these ions.

Corrosion test solutions corresponding to the calcium chloride brine include calcium chloride, calcium chloride plus calcium nitrate, the SSW, and sodium chloride aqueous solutions. The SSW and sodium chloride test solutions simulate the moderate relative humidity scenario where calcium is a minor component in the aqueous solution.

\subsubsection{Carbonate Brines}

The carbonate brines are alkaline and do not contain significant calcium or magnesium content. In the early stages of the evaporative concentration, calcium precipitates predominately as carbonate mineral (calcite or aragonite) under equilibrium conditions. Magnesium precipitates as a minor component in the calcium carbonate species and as magnesium silicate. Potassium may be significant in some of these brines. Nitrate is expected to be an important component, and a brine of this type may evolve through a high extent of evaporation into one in which nitrate is actually the dominant anion. The carbonate brine is likely to be represented as alkali metal (sodium or potassium) carbonate brine.

Relative humidity dependence of carbonate brine composition is as follows:

- At low relative humidity, the aqueous solutions are dominated by nitrate and chloride anions with nitrate ions dominating at the lowest relative humidity.

- At moderate relative humidity (greater than $70 \%$ relative humidity), chloride ions dominate the solution composition. The nitrate-chloride solutions will have slightly elevated $\mathrm{pH}$ due to residual carbonate in solution.

- Significant amounts of carbonate and sulfate ion are not expected until the relative humidity is greater than $85 \%$.

Corrosion test solutions corresponding to the carbonate type of brine include the SDW, SCW, BSW, and under certain circumstances, SSW and SAW aqueous test solutions (Table 7). The BSW test solution is a highly concentrated alkaline solution under repository conditions where temperatures measure its boiling point of nominally $112^{\circ} \mathrm{C}$ to $113^{\circ} \mathrm{C}$ or where the relative humidity is nominally $70 \%$ to $75 \%$. The SCW test solution is a moderately concentrated alkaline solution and solutions in this concentration range form at relative humidity in the range of $90 \%$ to $95 \%$. The SDW test solution is a dilute alkaline solution and solutions in this concentration range form at high relative humidity (greater than 99\%). These may have characteristics of solutions at the drift wall, that is, typical of in-drift seepage waters.

Under conditions of extreme evaporative concentration (i.e., low relative humidity) this type of brine containing high nitrate and chloride content would evolve into a nitrate-chloride brine with low carbonate content. The SSW test solution has characteristics of this type of brine. Likewise, the SAW test solution has characteristics of low carbonate brine and of solutions in equilibrium with relative humidity of nominally $90 \%$. The calcium and magnesium addition to this test 
solution makes it more able to sustain lower $\mathrm{pHs}$ due to the hydrolysis properties of these cations.

\subsubsection{Sulfate Brines}

The sulfate brines have near-neutral $\mathrm{pH}$ and no significant bicarbonate/carbonate and calcium content. Calcium precipitates as carbonates and possibly as sulfates. In addition, they typically have only a small amount of magnesium, though some surface brines have been observed to have high magnesium (Drever 1997 [DIRS 147480], Table 15-1, p. 333, brines 1-3). The dominant cation is typically sodium. In the repository brines, potassium is comparable to sodium, and magnesium is insignificant. A brine of this type may also evolve through a high extent of evaporation into one in which nitrate is the dominant anion.

Relative humidity dependence of the sulfate brine composition is as follows:

- At low relative humidity, the aqueous solutions are dominated by nitrate and chloride anions with nitrate ions dominating at the lowest relative humidity.

- At moderate relative humidity (greater than $70 \%$ relative humidity), chloride ions dominate the solution composition. However, unlike the carbonate brines, these brines have near neutral to slightly acidic $\mathrm{pH}$ because of the lack of a carbonate component.

- Significant amounts of carbonate and sulfate ion do not exist until the relative humidity is greater than $85 \%$ because of the increase in solubility of sulfate minerals (sodium and potassium sulfates). Magnesium sulfate is present in insignificant quantities in these brines.

The corrosion test solutions corresponding to the sulfate type of brine include the SAW and SSW. This type of brine has near neutral to slightly acidic $\mathrm{pH}$ and, as noted, magnesium is not present in seepage waters to any significant extent. The SAW test solution has characteristics of solutions in equilibrium with nominally $90 \%$ relative humidity. The SSW has characteristics of water that have undergone evaporative concentration to the extent that sulfate precipitates out of solution (this is for the magnesium-free situation).

Two important general factors specific to the repository brines are the presence of nitrate and more effective mechanisms for the removal of magnesium. Nitrate will be present in the deliquescent brines because of multiple potential sources (BSC 2004 [DIRS 161237], Section 6.7.2.8) and the generally high solubility of nitrate minerals (BSC 2004 [DIRS 161237], Section 4.1.1.7).

Magnesium ions will not be significant because of a combination of low concentration (for the dust, as well as for at least some groundwaters) and multiple removal mechanisms (e.g., manganese sequestration in secondary silicates), most of which are enhanced by elevated temperature (BSC 2004 [DIRS 161237], Sections 6.7.2.10 and 6.7.2.11).

Carbonate helps buffer $\mathrm{pH}$ in any occluded geometry such as a crevice, and sulfate acts as a corrosion inhibitor. The compositions of these environments, as well as the solution known as BSW, are given in Table 7. Small amounts of carbonate form in the SSW, SAW, and BSW 
solutions by interaction with gas phase carbon dioxide. The amount of carbonate formed was not determined experimentally because the small amounts will not affect the corrosion processes significantly.

BSW has a $\mathrm{pH}$ between 11 and 13 and a boiling point near $110^{\circ} \mathrm{C}(\mathrm{BSW}-12$ with a $\mathrm{pH}$ of 12 shown in Table 7). This test medium was established based on results from a distillation experiment. The total concentration of dissolved salts in the starting liquid was more concentrated than that in the standard SCW solution. After evaporation of approximately $90 \%$ of the water from the starting solution, the residual solution reaches a maximum chloride concentration and has a boiling point of approximately $110^{\circ} \mathrm{C}$, with a $\mathrm{pH}$ of about 11 . The synthetic BSW solution composition can be slightly modified (mainly by adding sodium hydroxide) to cover a range of $\mathrm{pH}$ values, yielding BSW-13, BSW-12, and BSW-11.

Deliquescence of dust deposited on the waste packages and drip shield is another means by which brines can form on these engineered barrier system components. In the absence of salts, condensed water can be present on smooth surfaces only if the relative humidity is $100 \%$. At lower relative humidity, most of the water evaporates, with residual water existing on the surface as a very thin adsorbate layer. Dissolved salts lower the relative humidity at which such dryout occurs due to deliquescence. Salt minerals in a dry system lower the relative humidity required for an aqueous solution to form. When the dissolved salt composition of a solution is known, the relative humidity at which dryout occurs at a given temperature can be determined. Conversely, the relative humidity for a given salt or set of salt minerals at which deliquescence occurs at a specified temperature can also be found.

In all cases, the nitrate component, the most soluble species, dominates the solution composition at the deliquescent relative humidity or eutectic point of a mineral assemblage at elevated temperatures. At higher relative humidity, chloride minerals are soluble and could become a dominant ion. It is not until the relative humidity is much higher that the sulfate and carbonate compositions become appreciable. In essence, solutions are chloride and nitrate rich at low to moderate (less than 70\%) relative humidity and, at higher relative humidity, sulfate and carbonate could be appreciable. This is discussed in more detail in Environment on the Surfaces of the Drip Shield and Waste Package Outer Barrier (BSC 2004 [DIRS 161237]).

\subsection{CORROSION MODES AND CORROSION OF THE DRIP SHIELD MATERIAL}

\subsubsection{Dry Oxidation}

The dry oxidation form of general corrosion is the direct oxidation of the titanium surface by oxygen or dry air. Dry oxidation occurs at any relative humidity $(R H)$ below the threshold value for humid-air corrosion or aqueous-phase corrosion, or both. In other words, dry oxidation occurs when the condition is met (Assumption 5.2):

$$
R H<R H_{\text {critical }}
$$


The process of dry oxidation results in the formation of an adherent, protective oxide film of uniform thickness (primarily composed of $\mathrm{TiO}_{2}$ ). The oxidation reaction is given as (Welsch et al. 1996 [DIRS 114895]):

$$
\mathrm{Ti}+\mathrm{O}_{2} \rightarrow \mathrm{TiO}_{2}
$$

Three kinetic laws (parabolic, linear and logarithmic) describe the oxidation rates for many common metals and alloys (Jones 1996 [DIRS 105076], Section 12.3). Parabolic growth behavior is often observed at high temperature where the oxide layer is compact and perfectly adherent, and migration of ions through the oxide layer is rate controlling. Often at lower temperature and for relatively thin oxide layers, oxidation is inversely proportional to time (i.e., the oxide growth abides by the logarithmic law). The mechanism of logarithmic oxide growth involves electric fields across the film when the conductivity of the oxide is low. The logarithmic growth behavior may become the parabolic growth behavior when the oxides become thicker. For instance, it has been observed that for nickel at relatively low temperature, the logarithmic growth is obeyed at $200^{\circ} \mathrm{C}$ while the parabolic behavior is obeyed at $340^{\circ} \mathrm{C}$ (Jones 1996 [DIRS 105076], p. 428). For oxidation of titanium and its alloys, a logarithmic dependence with time is typical below approximately $200^{\circ} \mathrm{C}$, but both logarithmic and parabolic behaviors have been reported between $200^{\circ} \mathrm{C}$ and $700^{\circ} \mathrm{C}$ (Schutz and Thomas 1987 [DIRS 112147]). The linear growth behavior is observed when a reaction at a phase boundary controls the growth. This normally happens at higher temperatures than those in the repository environment (e.g., greater than $700^{\circ} \mathrm{C}$ for unalloyed titanium) (Schutz and Thomas 1987 [DIRS 112147]) indicating that the linear growth law is not relevant to repository exposure conditions. The formation of pores and cracks in the oxide film is associated with a further transition from parabolic to linear film growth kinetics, wherein oxygen molecules penetrate along these faults and maintain linear growth by direct access to the metal alloy surface.

The fracturing and spalling of oxides would only be expected when linear growth kinetics are established, although it is possible that a series of layers could grow by a sequence of parabolic growth or film fracture events at the high temperature end of the parabolic growth range. Neither of these scenarios is expected under repository conditions because the maximum waste package and drip shield temperatures, below $300^{\circ} \mathrm{C}$ (BSC 2004 [DIRS 169565], Figure 6.3-57), are in the temperature range where logarithmic (or, at worst, parabolic) growth conditions apply. 


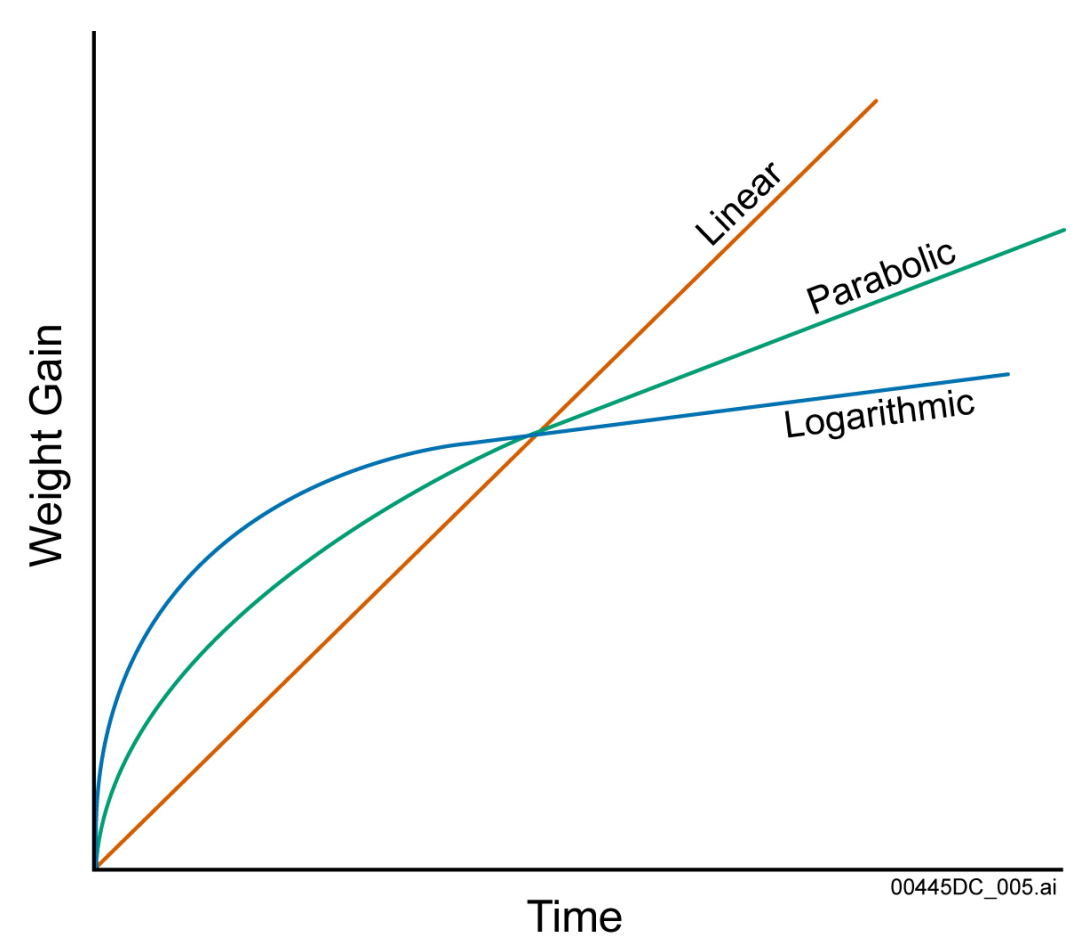

Source: Jones 1996 [DIRS 105076], Section 12.3, p. 419.

Figure 6. Schematic Illustrations of Logarithmic, Parabolic, and Linear Growth of Oxides

The relationship between the parabolic, logarithmic, and linear oxide growth behavior is schematically compared in Figure 6. Figure 6 shows that under similar conditions beyond the point of normalization, the linear growth gives the highest oxide growth rate and the logarithmic growth, the lowest; although for a very short period, the logarithmic law may yield a slightly higher corrosion rate than the parabolic law. The parabolic relation is chosen as the primary dry oxidation model in this report. As shown in Figure 6, this choice also provides a conservative approach (relative to the logarithmic growth law) for long-term modeling.

\subsubsection{Humid-Air Corrosion}

Humid-air corrosion is a type of general corrosion. Two conditions are assumed to be required (Assumption 5.3) for humid-air corrosion to occur: there must be no dripping water contact, and the exposure $R H$ must be equal to or above a threshold $R H$ value, $R H_{\text {critical }}$ :

$$
R H \geq R H_{\text {critical }}
$$

For surfaces covered with dust or salt films, or both, the $R H_{\text {critical }}$ can be taken to be the deliquescence point of the surface film. Below the $R H_{\text {critical }}$, it is not possible to form a water film thick enough to support electrochemical corrosion processes.

The general corrosion of the inner surface of the drip shield is more likely to be humid-air corrosion because there is no dripping water contact. The general corrosion of the inner surface of the drip shield is modeled based on the LTCTF data obtained from the specimens with the "weight-loss" geometry only. A cumulative distribution function has been developed from the measured weight loss of specimens with the "weight-loss" geometry (i.e., without a creviced 
area) exposed for one year in the LTCTF and validated by the LTCTF 2.5- and 5-year exposure test data. The LTCTF corrosion tests used Ti Grade 16, which is an excellent analog of Ti Grade 7 with lower palladium content (Table 1). The weight-loss specimens were exposed to both vapor and liquid phase environments. There was no significant difference between rates from the two types of exposure conditions. Therefore, data from specimens exposed to both vapor and aqueous environments were combined into a single distribution and used as the basis for estimating general corrosion rates of the inner surfaces of the drip shield, as well as the corresponding variability and uncertainty. The corrosion rate is constant and does not decrease with time, providing a conservative approach. The test details of the LTCTF tests are discussed in Section 6.5.1. The distributions and uncertainties of the drip shield inner surface general corrosion rates are discussed in Sections 6.5.3 and 6.5.4.

\subsubsection{Aqueous-Phase Corrosion}

Evaporation of dripping water can result in the formation of salt deposits on the drip shield surface. In the presence of such a deposit, a liquid-phase can potentially be established at a higher temperature than on a pristine metal surface. In the model discussed herein, two conditions must be met for aqueous-phase corrosion to occur: dripping water must be present (Assumption 5.4), and $R H$ must be greater than or equal to the $R H_{\text {critical }}$ :

$$
R H \geq R H_{\text {critical }}
$$

Due to the presence of dripping water, the environments in which aqueous-phase corrosion occurs are more complicated than that which induces humid-air corrosion. Therefore, humid-air corrosion and aqueous-phase corrosion can result in general corrosion only if $E_{\text {corr }}<E_{\text {critical }}$ or general corrosion and localized corrosion if $E_{c o r r} \geq E_{\text {critical }}$ (Assumption 5.6).

For the outer surface of the drip shield, dry oxidation, humid-air corrosion, and aqueous-phase corrosion are all possible. The general corrosion of the outer surface of the drip shield is, therefore, modeled based on the cumulative distribution function for the dripping case. The cumulative distribution function is developed by using the combination of the 1-year weight-loss specimen test data and the 1-year crevice specimen test data and validated by using the combination of the 5-year weight-loss specimen test data and the 5-year crevice specimen test data. The LTCTF 2.5-year data are used for corroborative model validation. The crevice specimen data are included in the outer surface general corrosion penetration rate distribution not only to account for crevice-like geometry that could form under mineral deposits, but also to account for the presence of dripping water that supplies a continuous source of ions to maintain crevice chemistry. The distributions and uncertainties of the drip shield outer surface general corrosion rates are discussed in Sections 6.5.3 and 6.5.4.

\subsection{MODELING DRY OXIDATION}

The engineered analogue of the titanium drip shield has been discussed in Natural Analogues Synthesis Report (BSC 2004 [DIRS 169218], Sections 6 and 7). Titanium metal does not occur in nature. Titanium is present as a major constituent in a number of refractory accessory minerals commonly found as a minor phase in igneous rocks and in heavy mineral concentrates in sediments. These minerals include sphene (titanite) $\left(\mathrm{CaTiSiO}_{4}(\mathrm{O}, \mathrm{OH}, \mathrm{F})\right)$, rutile $\left(\mathrm{TiO}_{2}\right)$, 
ulvöspinel $\left(\mathrm{Fe}_{2} \mathrm{TiO}_{4}\right)$, and ilmentite $\left(\mathrm{FeTiO}_{3}\right)$. At the Cigar Lake uranium deposit in Saskatchewan, Canada, rutile is present within uranium ore and has persisted unchanged for over a billion years in reducing groundwaters, under hydrothermal conditions, and in a radiation field. While rutile and other titanium-bearing minerals are oxides, not metals, their general resistance to alteration reflects the stable nature of titanium-bearing materials (BSC 2004 [DIRS 169218]). For engineered titanium and its alloys, the nature, composition, and thickness of the protective surface oxides that form on titanium alloys depend on environmental conditions. The titanium oxides include $\mathrm{TiO}_{2}, \mathrm{Ti}_{2} \mathrm{O}_{3}$, and $\mathrm{TiO}$. The naturally formed titanium oxide films are typically less than $10 \mathrm{~nm}$ thick, but are highly chemically resistant and can damaged by very few substances, including hot and concentrated $\mathrm{HCl}, \mathrm{H}_{2} \mathrm{SO}_{4}, \mathrm{NaOH}$, and $\mathrm{HF}$ (Schutz and Thomas 1987 [DIRS 112147]).

Due to the excellent oxidation resistance of titanium and its alloys, long-term low-temperature (e.g., $100^{\circ} \mathrm{C}$ to $200^{\circ} \mathrm{C}$ ) laboratory oxidation provides no meaningful data. In this report, the parabolic relationship, supported by laboratory oxidation data at higher temperatures for short periods, is chosen as the primary model of dry oxidation. The logarithmic relationship, also observed to apply at low temperatures (Section 6.3.1), is chosen as an alternative conceptual model. As indicated in Section 6.3.1 and shown in Figure 6, modeling dry oxidation by the parabolic relation provides a conservative approach for an oxidation system (such as the drip shield), in which oxides grow in logarithmic relation. For a prolonged time, as long as 10,000 years, the parabolic and logarithmic growth will lead to very slow increases in oxide thickness (Figure 6). Logarithmic growth essentially reaches a maximum oxide thickness (leveling out).

\subsubsection{Primary Model for Dry Oxidation}

The rate of dry oxidation will be limited by mass transport through this growing metal oxide film. According to Fick's first law (Jones 1996 [DIRS 105076], Section 12.3.1), for a linear concentration gradient across the oxide film of thickness $x$, the flux can be expressed as:

$$
J_{\text {oxide }}=-D_{\text {oxide }} \frac{\partial C}{\partial x} \approx-D_{\text {oxde }} \frac{\Delta C}{x}
$$

where $J_{\text {oxide }}$ is the molar flux of the reacting species in the oxide, $D_{\text {oxide }}$ is the diffusivity of the reacting species in the oxide, $C$ is the molar concentration, $x$ is the and $\Delta C$ is the corresponding differential molar concentration.

One can describe the oxide growth with a parabolic rate law as (Welsch et al. 1996 [DIRS 114895]):

$$
\frac{d x}{d t}=\frac{k_{p x}}{x}
$$

where $x$ is the oxide thickness, $k_{p x}$ is the thickness-based parabolic rate constant, and $t$ is the time. Integration of Equation 6 leads to: 


$$
x=\sqrt{x_{0}^{2}+k_{p x} \times t}
$$

where $x_{o}$ is the initial oxide thickness; $x$ is the oxide thickness at time, $t$; and $k_{p x}$ is a temperaturedependent parabolic rate constant. Dry oxidation of metal is a thermally activated process. Therefore, the rate constant, $k_{p}$ obeys the Arrhenius equation:

$$
k_{p}=k_{p_{0}} e^{-E_{a} / R T}
$$

where $k_{p 0}$ is a constant, $E_{a}$ is the activation energy, $R$ is the universal gas constant $(8.314 \mathrm{~J} / \mathrm{mol} \mathrm{K}$ ) (Lide 1991 [DIRS 131202], inside rear cover). These parabolic oxidation kinetics could be applied to the growth of thermal oxide films on unalloyed titanium in air at $400^{\circ} \mathrm{C}$ to $600^{\circ} \mathrm{C}$ as reported by Schutz and Thomas (1987 [DIRS 112147], p. 685, Figure 25). The data as read from the original figure are given in Table 8.

Table 8. Titanium Dry Oxidation Thickness

\begin{tabular}{|c|c|c|c|}
\hline $\begin{array}{c}\text { Time } \\
\text { (min) }\end{array}$ & $\begin{array}{c}\mathbf{4 0 0}^{\circ} \mathbf{C} \\
\text { Oxide }(\mathbf{n m})\end{array}$ & $\begin{array}{c}\mathbf{5 0 0}^{\circ} \mathbf{C} \\
\text { Oxide }(\mathbf{n m})\end{array}$ & $\begin{array}{c}\mathbf{6 0 0}^{\circ} \mathbf{C} \\
\text { Oxide (nm) }\end{array}$ \\
\hline 0 & 0.0 & 0.0 & 0.0 \\
\hline 10 & 4.4 & 17.8 & 31.1 \\
\hline 30 & 8.9 & 23.3 & 53.3 \\
\hline 60 & 11.1 & 27.8 & 83.3 \\
\hline 120 & 11.1 & 31.1 & 96.7 \\
\hline
\end{tabular}

Source: Schutz and Thomas (1987 [DIRS 112147], p. 685, Figure 25).

Significant oxidation of titanium and titanium alloys over short times occurs only above $300^{\circ} \mathrm{C}$. In the as-fabricated condition prior to extended environmental exposure, the initial oxide layer thickness $\left(x_{\mathrm{o}}\right)$ formed under normal atmospheric conditions (temperature below $150^{\circ} \mathrm{C}$ ) on all titanium alloys is very small (on the order of a few nanometers) (Schutz and Thomas 1987 [DIRS 112147], page 685 and Figure 25) and, therefore, can be ignored for the purposes of this model. The data given in Table 8 are handbook data for the oxide layer formed on unalloyed titanium in air at exposure temperature from $400^{\circ} \mathrm{C}$ to $600^{\circ} \mathrm{C}$, but cover only brief exposure times (120 minutes) (Schutz and Thomas 1987 [DIRS 112147]). These data were extracted from an experimental study that indicated the corrosion layer growth rate was parabolic with time at temperatures below $600^{\circ} \mathrm{C}$, and became linear with time at temperatures over $700^{\circ} \mathrm{C}$ (Schutz and Thomas 1987 [DIRS 112147]). The oxide layer becomes nonprotective in air at even higher temperatures. Additionally, Moroishi and Shida (1980 [DIRS 151146]) reported that the oxidation rate of commercially pure titanium in air saturated with steam at $0.1 \mathrm{MPa}$ for 24 up to 101 days at temperatures between $400^{\circ} \mathrm{C}$ and $550^{\circ} \mathrm{C}$ varied from $2.6 \mathrm{~mm} / \mathrm{yr}(\sim 5 \mathrm{~nm} / \mathrm{min})$ to $45 \mathrm{~mm} / \mathrm{yr}(\sim 86 \mathrm{~nm} / \mathrm{min})$. Linear corrosion kinetics were only observed above $550^{\circ} \mathrm{C}$. These values are higher than those in Table 8 , but are appropriate for unalloyed titanium in a hightemperature fully saturated steam environment. In contrast, the early in drift environment in which the dry oxidation model will be used is expected to be much drier (CRWMS M\&O 2000 [DIRS 154666], Section 3.1 and Appendix C). 
The testing that resulted in the data in Table 8 was performed over a short time (120 min) and at higher temperatures $\left(400^{\circ} \mathrm{C}\right.$ to $\left.600^{\circ} \mathrm{C}\right)$ compared to the service period and temperature of the drip shield. The higher temperatures used in the tests, however, qualify them as accelerated tests for the oxide layer growth per the methodology given in ASTM C 1174-97 ([DIRS 105725], Section 14). When the oxide layer is grown under such accelerating factors as temperature and anodic polarization, it tends to be amorphous and has more structural defects, whereas oxide layers grown more slowly and naturally (more typical of repository exposure) tend to be more crystalline and defect free. An amorphous or defected oxide layer would be expected to be inherently less protective than a crystalline one. Thus, any model derived using accelerated exposure conditions would have an inherent, but not precisely quantifiable, conservatism.

Taking $x_{o}$ to be zero (no oxide thickness at time zero) and fitting Equations 7 and 8 to the thickness and temperature data in Table 8 at 120 minutes yields the following expression for the oxide thickness, $x$ :

$$
x=11,340 \mathrm{e}^{-6,313 / \mathrm{T}} \mathrm{t}^{1 / 2}
$$

where $\mathrm{T}$ is the temperature in Kelvin and $\mathrm{t}$ is the time in minutes.

Table 9. Titanium Dry Oxidation Thickness: Measured versus Calculated Using Equation 9

\begin{tabular}{|c|c|c|c|c|c|c|c|c|}
\hline \multirow[b]{3}{*}{ Time } & \multicolumn{8}{|c|}{ Titanium Dry Oxidation Oxide Thickness (nm) } \\
\hline & \multirow{2}{*}{$\begin{array}{c}100^{\circ} \mathrm{C} \\
(373 \mathrm{~K}) \\
\text { Calculated }\end{array}$} & \multirow{2}{*}{$\begin{array}{c}200^{\circ} \mathrm{C} \\
(473 \mathrm{~K}) \\
\text { Calculated }\end{array}$} & \multicolumn{2}{|c|}{$400^{\circ} \mathrm{C}(673 \mathrm{~K})$} & \multicolumn{2}{|c|}{$500^{\circ} \mathrm{C}(773 \mathrm{~K})$} & \multicolumn{2}{|c|}{$600^{\circ} \mathrm{C}(873 \mathrm{~K})$} \\
\hline & & & Measured & Calculated & Measured & Calculated & Measured & Calculated \\
\hline 10 (min) & 0.0 & 0.1 & 4.4 & 3.0 & 17.8 & 10.2 & 31.1 & 26.0 \\
\hline $30(\mathrm{~min})$ & 0.0 & 0.1 & 8.9 & 5.2 & 23.3 & 17.7 & 53.3 & 45.0 \\
\hline 60 (min) & 0.0 & 0.1 & 11.1 & 7.4 & 27.8 & 25.0 & 83.3 & 63.6 \\
\hline 120 (min) & 0.0 & 0.2 & 11.1 & 10.5 & 31.1 & 35.3 & 96.7 & 90.0 \\
\hline $1(\mathrm{yr})$ & 0.4 & 13.2 & - & 695.1 & - & $2,338.1$ & - & $5,956.6$ \\
\hline $100(y r)$ & 3.7 & 132.0 & - & $6,951.3$ & - & $23,381.0$ & - & $59,565.6$ \\
\hline $1,000(y r)$ & 11.7 & 417.3 & - & $21,981.9$ & - & $73,937.3$ & - & $188,363.1$ \\
\hline $10,000(y r)$ & 36.9 & $1,319.6$ & - & $69,512.9$ & - & $23,3810.3$ & - & $595,656.4$ \\
\hline
\end{tabular}

NOTE: Measured oxide thickness values from source data: Schutz and Thomas (1987 [DIRS 112147], p. 685, Figure 25) Calculated data output DTN: MO0408MWDGLCDS.002.

Table 9 provides a comparison of the oxide thickness values from Table 8 (experimental) with values calculated using Equation 9. It is readily seen that at the temperatures relevant to the repository (BSC 2004 [DIRS 169565], Figures 6.3-53 and 6.3-57), even over long periods the model predicts negligible oxide layer growth at repository relevant temperatures (i.e., on the order of micrometers at $200^{\circ} \mathrm{C}$ ).

The application of Equation 9 to the drip shield dry oxidation involves the extrapolation of data taken over a 120 minutes to time scales five orders of magnitude longer. It also involves extrapolating the temperatures used in the testing $\left(400^{\circ} \mathrm{C}\right.$ to $\left.600^{\circ} \mathrm{C}\right)$ down to about $100^{\circ} \mathrm{C}$. To do this, these higher temperatures used in the testing must qualify as a valid accelerating factor for the oxidation per ASTM C 1174-97 ([DIRS 105725]); that is, the higher temperatures should accelerate the buildup of the oxide layer without substantially altering the mechanism of 
oxidation or the structure of the oxide layer as demonstrated by Schutz and Thomas (1987 [DIRS 112147]) for the oxide layer thickness (Fukuzuka et al. 1980 [DIRS 160395]). Extended exposure of titanium and titanium alloys to ambient atmospheric conditions (Covington and Schutz 1981 [DIRS 151102]) to a moist clay atmosphere at up to $90^{\circ} \mathrm{C}$, and to a moist air corrosion furnace at up to $150^{\circ} \mathrm{C}$, have resulted in no visible corrosion other than the thin protective oxide layer (CRWMS M\&O 2000 [DIRS 154666], Section 3.1). This is consistent with the observation that no significant corrosion degradation occurred in titanium alloys below $300^{\circ} \mathrm{C}$ (Schutz and Thomas 1987 [DIRS 112147]). These observations are consistent with the conclusion that the oxidation layers grown for short times at temperatures between $400^{\circ} \mathrm{C}$ and $600^{\circ} \mathrm{C}$ are not significantly different in nature from oxide layers grown for longer times at lower temperatures.

\subsubsection{Alternative Conceptual Model for Dry Oxidation}

The oxidation kinetics of metals depends on gas composition, temperature and exposure time. For most metals at low temperatures, the oxidation rate is inversely proportional to time (Jones 1996 [DIRS 105076]):

$$
\frac{d X}{d t} \propto \frac{k_{l}}{t}
$$

where $X$ is the oxide thickness, $k_{l}$ is the rate constant, and $t$ is time. The logarithmic law of oxide growth can be written as (Jones 1996 [DIRS 105076]):

$$
X=k_{l} \ln \left(a_{l} \cdot t+1\right)
$$

where $X$ is the oxide thickness in nanometers, $t$ is time in minutes and $k_{l}$ is the rate constant with the units of nanometers. $a_{l}$ is also a constant with the unit of inverse time $\left(\mathrm{min}^{-1}\right)$.

For titanium and its alloys, below approximately $200^{\circ} \mathrm{C}$, the logarithmic dependence with time is typical, although both the parabolic and logarithmic laws have been reported (Schutz and Thomas 1987 [DIRS 112147]). Oxide thickening on Ti Grade 7 in groundwater-saturated bentonite at $95^{\circ} \mathrm{C}$ has been suggested to follow a logarithmic growth law (Shoesmith et al. 1995 [DIRS 117892]).

By using the experimentally obtained data in Table 8, the dry oxidation rate can be regressed to the logarithmic relation (Equation 11 ) at $400^{\circ} \mathrm{C}, 500^{\circ} \mathrm{C}$, and $600^{\circ} \mathrm{C}$ as shown in Figure 7. The rate constants, $k_{l}$ and constant, $a_{l}$, obtained for $400^{\circ} \mathrm{C}, 500^{\circ} \mathrm{C}$, and $600^{\circ} \mathrm{C}$ are listed in Table 10 . The logarithmic treatment of the dry oxidation rates results in the following three equations for $400^{\circ} \mathrm{C}, 500^{\circ} \mathrm{C}$, and $600^{\circ} \mathrm{C}$, respectively:

$$
\begin{aligned}
& X_{400^{\circ} \mathrm{C}}=2.929 \ln (0.505 \cdot t+1) \\
& X_{500^{\circ} \mathrm{C}}=5.521 \ln (2.376 \cdot t+1)
\end{aligned}
$$




$$
X_{600^{\circ} \mathrm{C}}=33.85 \ln (0.148 \cdot t+1)
$$

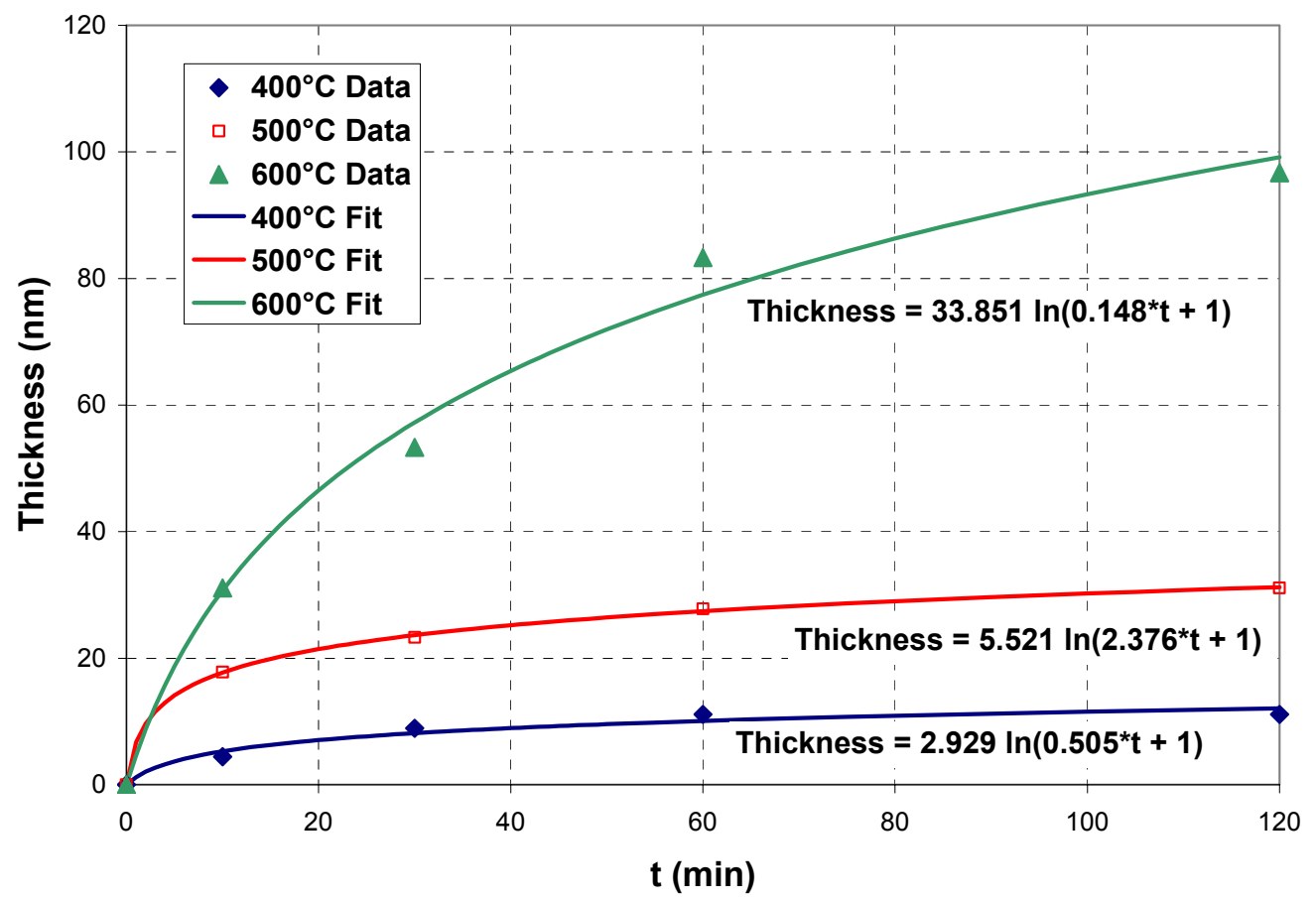

Source: Schutz and Thomas 1987 [DIRS 112147].

Output DTN: MO0408MWDGLCDS.002.

Figure 7. Logarithmic Regression of Dry Oxidation Rate Data for Titanium at $400^{\circ} \mathrm{C}, 500^{\circ} \mathrm{C}$, and $600^{\circ} \mathrm{C}$

Table 10. Parameters in Dry Oxidation Rate Logarithmic Model Determined by Regression Analysis

\begin{tabular}{|c|c|c|c|c|}
\hline $\mathbf{T}\left({ }^{\circ} \mathbf{C}\right)$ & $\mathbf{k}_{\mathbf{l}}, \mathbf{n m}$ & $\mathbf{a}_{\mathbf{l}}, \mathbf{~ m i n}^{-1}$ & $\begin{array}{c}\mathbf{X} \text { after 1,000 year, } \\
\mathbf{n m}\end{array}$ & $\begin{array}{c}\mathbf{X} \text { after 10,000 year, } \\
\mathbf{n m}\end{array}$ \\
\hline 100 & $5.4 \times 10^{-4}$ & $0.505^{*}$ & 0.01 & 0.01 \\
\hline 200 & 0.028 & $0.505^{*}$ & 0.56 & 0.63 \\
\hline 300 & 0.38 & $0.505^{*}$ & 7.45 & 8.34 \\
\hline 400 & 2.929 & 0.505 & 56.81 & 63.56 \\
\hline 500 & 5.521 & 2.376 & 115.64 & 128.35 \\
\hline 600 & 33.85 & 0.148 & 614.92 & 692.87 \\
\hline
\end{tabular}

Source: Schutz and Thomas 1987 [DIRS 112147].

Output DTN: MO0408MWDGLCDS.002.

NOTE: al value at $400^{\circ} \mathrm{C}$ used. 
Dry oxidation of metal is a thermally activated process. The rate constant, $k_{l}$, obeys the Arrhenius equation:

$$
k_{l}=k_{l 0} e^{-E_{a} / R T}
$$

where $k_{l 0}$ is a constant, $E_{a}$ is the activation energy, $R$ is the universal gas constant $(8.314 \mathrm{~J} / \mathrm{mol} \mathrm{K})$ (Lide 1991 [DIRS 131202], inside rear cover), and $T$ is the absolute temperature. The activation energy can be determined by comparing values of $k_{l}$ at two temperatures, as shown in Equations 16 and 17:

$$
\frac{k_{1}}{k_{2}}=\frac{e^{-E_{a} / R T_{1}}}{e^{-E_{a} / R T_{2}}}
$$

or

$$
\ln \left(\frac{k_{1}}{k_{2}}\right)=-\frac{E_{a}}{R}\left(\frac{1}{T_{1}}-\frac{1}{T_{2}}\right)
$$

Substituting experimentally obtained $k_{l}$ values from Table 10 for $400^{\circ} \mathrm{C}$ and $500^{\circ} \mathrm{C}$ yields:

$$
\ln \left(\frac{2.929}{5.521}\right)=-\frac{E_{a}}{R}\left(\frac{1}{773 K}-\frac{1}{673 K}\right)
$$

The activation energy is then calculated to be:

$$
E_{a}=8.314 \mathrm{~J} \mathrm{~mol}^{-1} K^{-1} \frac{\ln \left(\frac{2.929}{5.521}\right)}{\left(\frac{1}{773 K}-\frac{1}{673 K}\right)} \sim 27,000 \mathrm{~J} \mathrm{~mol}^{-1}
$$

However, using the parameters in Table 10 for $500^{\circ} \mathrm{C}$ and $600^{\circ} \mathrm{C}$ results in a different value for the activation energy:

$$
E_{a}=8.314 \mathrm{~J} \mathrm{~mol}^{-1} K^{-1} \frac{\ln \left(\frac{5.521}{33.85}\right)}{\left(\frac{1}{873 K}-\frac{1}{773 K}\right)} \sim 101,000 \mathrm{~J} \mathrm{~mol}^{-1}
$$

If $E_{a}$, is taken as constant over the temperature range of $400^{\circ} \mathrm{C}$ to $600^{\circ} \mathrm{C}$, the $k_{l}$ values in Table 10 can be regressed to an Arrhenius relationship (Equation 15) as shown in Figure 8. The rate constant as a function of temperature can, therefore, be expressed as: 


$$
\ln \left(k_{l}\right)=-7003.6 \frac{1}{T}+11.263
$$

The apparent activation energy obtained is $\sim 58.22 \mathrm{~kJ} / \mathrm{mol}$.

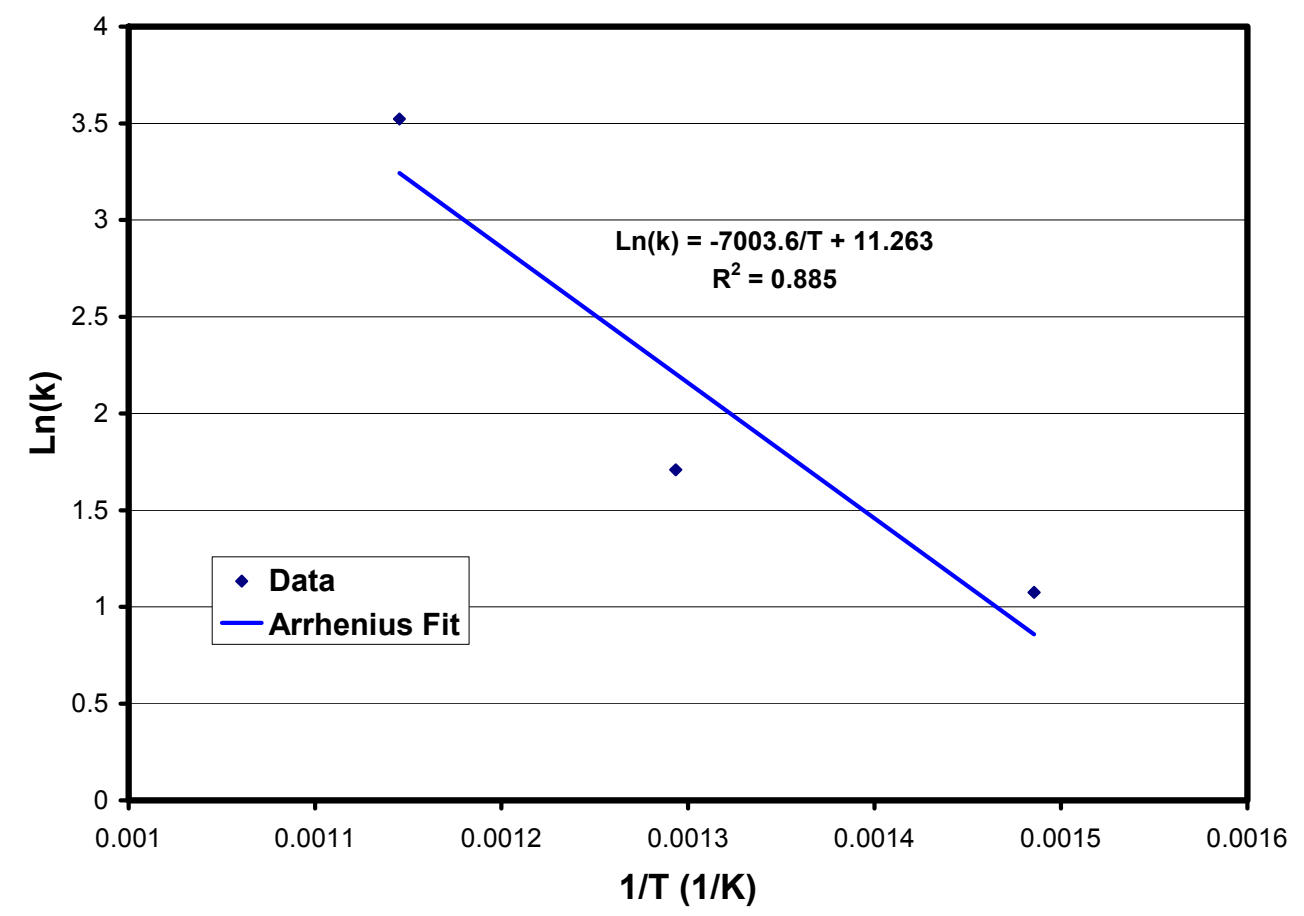

Source: Schutz and Thomas 1987 [DIRS 112147].

Output DTN: MO0408MWDGLCDS.002.

Figure 8. Determination of Apparent Activation Energy of Dry Oxidation in Logarithmic Growth Model

The rate constant, $k_{l}$, at lower temperatures (e.g., $100^{\circ} \mathrm{C}$ and $200^{\circ} \mathrm{C}$ ) can be calculated according to Equation 21. The calculated values of $k_{l(100),} k_{l(200)}$ and $k_{l(300)}$ are also listed in Table 10.

The value of $a_{l}$ might have a significant influence on the oxide film thickness, $X$, at relatively short exposure time (e.g., 60 minutes). At prolonged exposure time (e.g., 1,000 years), however, the influence of $a_{l}$ on $X$ is negligible. Therefore, the modeling decision that the value of $a_{l(400)}$ in Table 10 applies to lower temperatures does not cause significant errors in long-term prediction of oxide thickness at low temperatures. By using the $k_{l}$ values in Table 10 calculated for $100^{\circ} \mathrm{C}$, $200^{\circ} \mathrm{C}$, and $300^{\circ} \mathrm{C}$ and using an $a_{l}$ value of $0.505 \mathrm{~min}^{-1}$ for $100^{\circ} \mathrm{C}, 200^{\circ} \mathrm{C}$, and $300^{\circ} \mathrm{C}$, Figure 9 shows the oxide thickness as a function of exposure time at $100^{\circ} \mathrm{C}, 200^{\circ} \mathrm{C}$, and $300^{\circ} \mathrm{C}$ for the first 120 minutes. The oxide thickness at $100^{\circ} \mathrm{C}, 200^{\circ} \mathrm{C}$, and $300^{\circ} \mathrm{C}$, based on the logarithmic growth law, can be calculated for the prolonged exposure time. Table 10 shows that, after 10,000 years, the oxide thickness at $100^{\circ} \mathrm{C}, 200^{\circ} \mathrm{C}$, and $300^{\circ} \mathrm{C}$ will be $0.01,0.63$, and $8.34 \mathrm{~nm}$, respectively.

Figure 9 shows that the dry oxidation model based on the logarithmic growth law yields much smaller oxide thicknesses than those predicted by the parabolic growth law in Section 6.4.1. A 
comparison between Table 9 (parabolic growth law) and Table 10 (logarithmic growth law) confirms that the dry oxidation model based on the parabolic growth law is a sufficiently conservative approach.

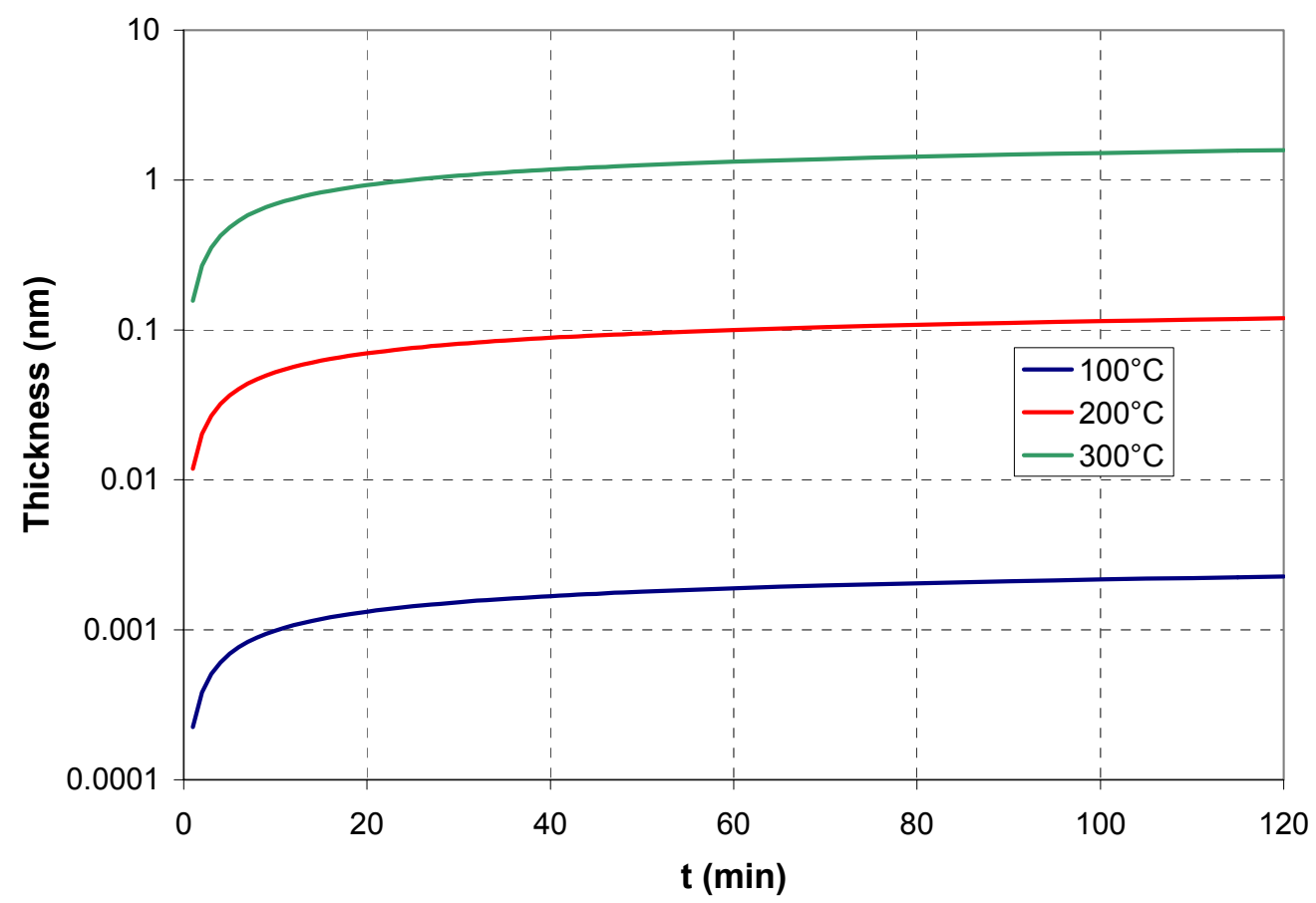

Source: Schutz and Thomas 1987 [DIRS 112147].

Output DTN: MO0408MWDGLCDS.002.

Figure 9. Predicted Logarithmic Oxide Growth on Titanium at $100^{\circ} \mathrm{C}, 200^{\circ} \mathrm{C}$, and $300^{\circ} \mathrm{C}$

Logarithmic growth provides an alternate model for the dry oxidation of titanium. The alternative model presented here is a simple approximate extrapolation of the published high temperature data (at $400^{\circ} \mathrm{C}, 500^{\circ} \mathrm{C}$, and $600^{\circ} \mathrm{C}$ ) to lower temperatures $\left(100^{\circ} \mathrm{C}, 200^{\circ} \mathrm{C}\right.$, and $300^{\circ} \mathrm{C}$ ). The data for $X$ in Table 8 were taken at $400^{\circ} \mathrm{C}$ to $600^{\circ} \mathrm{C}$. This range is very high compared with the expected drip shield maximum temperature (below 300 ${ }^{\circ} \mathrm{C}$ ) (BSC 2004 [DIRS 169565], Figure 6.3-57) and, therefore, qualifies the test as an accelerated test factor per ASTM C 1174-97 (1998 [DIRS 105725]) requirements. At $100^{\circ} \mathrm{C}$ the maximum oxide thickness predicted is virtually nil. By comparison, the primary model (Table 9) predicts oxide layer thicknesses of $3.7 \mathrm{~nm}$ after 100 years, $11.7 \mathrm{~nm}$ after 1,000 years, and $36.9 \mathrm{~nm}$ after 10,000 years of exposure at $100^{\circ} \mathrm{C}$, while the alternative conceptual model predicts an oxide layer thickness of virtually nil at $100^{\circ} \mathrm{C}$ after $100,1,000$, or 10,000 years of repository life. The naturally grown oxide layers at low temperatures over short times are generally on the order of $10 \mathrm{~nm}$ (Schutz and Thomas 1987 [DIRS 112147]). Both models' predictions lead to the conclusion that the dry oxidation of titanium and its alloys under repository conditions can be excluded from further modeling in TSPA. 


\subsubsection{Dry Oxidation Model Uncertainty}

Uncertainties in the dry oxidation model are associated with conceptual model uncertainty, parameter uncertainty, and uncertainty from mathematical simplification. Conceptual model uncertainty arises from the recommended use of a parabolic rather than a logarithmic model. The parabolic model was chosen partly because it is more conservative than the logarithmic model. The logarithmic model essentially predicts an oxide thickness of no more than $10 \mathrm{~nm}$ for the duration of the repository period at $300^{\circ} \mathrm{C}$ (Table 10), whereas the parabolic model predicts an oxide thickness of about $36.9 \mathrm{~nm}$ for 10,000 years at $100^{\circ} \mathrm{C}$ (Table 9). This generally illustrates the conceptual model uncertainty.

Parameter uncertainty arises from the fact that the oxide layer thickness is determined experimentally by comparing before-and-after specimen weights that are very close to each other. It is based on such experimental measurements that the oxide thickness values given in Table 9 and Table 10 were derived by regression analysis (Equation 9 for the parabolic law and Equations 12 through 15 for the logarithmic law). The uncertainties also exist when extrapolating the high temperature data to lower temperatures without considering the possible changes in the oxidation mechanism. However, while the parabolic law provides a conservative approach and the logarithmic law may provide a liberal approach, both models predict the dry oxidation rates of Ti Grade 7 to be far less than the roughly $1,500 \mathrm{~nm} / \mathrm{yr}$ that is required to corrode through the $15-\mathrm{mm}$-thick drip shield in 10,000 years. Therefore, the dry oxidation of Ti Grade 7 under the repository conditions can be excluded from further modeling in TSPA.

\subsection{MODELING GENERAL CORROSION}

\subsubsection{Long-Term Corrosion Test Facility Tests}

The LTCTF appears to be the most complete source of corrosion data (Estill 1998 [DIRS 117697], Section 2.2.6) for relevant titanium alloys (Ti Grade 16 with lower palladium content than Ti Grade 7) in environments relevant to the repository. This facility is equipped with an array of nearly cubic fiberglass tanks. Each tank has a total volume of $\sim 2,000$ liters and is filled with $\sim 1,000$ liters of aqueous test solution. The solution is controlled at either $60^{\circ} \mathrm{C}$ or $90^{\circ} \mathrm{C}$, covered with a blanket of air flowing at approximately $150 \mathrm{~cm}^{3} \mathrm{~min}^{-1}$, and agitated. Aerated test conditions are appropriate because in-drift gas flux and composition in the repository will not be strongly affected by interactions with in-drift and near-drift materials (CRWMS M\&O 2000 [DIRS 153246], Section 3.3.4).

In this report, all general corrosion rates, except the dry oxidation rates, are calculated by using weight-loss data obtained at the LTCTF (Estill 1998 [DIRS 117697]). The long-term corrosion tests performed at the LTCTF employed two types of specimen geometry (i.e., weight-loss specimens and crevice specimens). Both types of specimens were exposed to repository relevant environments for one, two and half, and five years, respectively. Correspondingly, there are two types of data treatments in this section. Treatment using the corrosion rate data from weight-loss specimens only is referred to as "weight-loss only" treatment. Treatment using a combination of the corrosion rate data from both weight-loss specimens and crevice specimens is referred to as "weight-loss plus crevice" treatment. Four generic types of samples (U-bends, crevices, weightloss samples, and galvanic couples) are mounted on insulating racks and placed in the tanks. 
Approximately half of the samples are submersed, and half are in the saturated vapor above the aqueous phase. A limited number of the samples are at the water line. Condensed water is present on specimens located in the saturated vapor.

The materials for the repository drip shield design were selected after the testing program for the LTCTF was initiated. Therefore, an alloy similar to Ti Grade 7 but with lower palladium content, Ti Grade 16, was initially incorporated into the LTCTF testing program. Therefore, the 1-year and 5-year corrosion rate data were obtained on Ti Grade 16, while the 2.5-year corrosion rate data were obtained on Ti Grade 7.

The weight-loss testing includes a wide range of plausible generic test media, including SDW, SCW, and SAW as shown in Table 7 (Estill 1998 [DIRS 117697], Section 2.2.6). The compositions of these test media are listed in DTN LL040803112251.117 [DIRS 171362]. The relevance of these test media to the repository environments is discussed in Section 6.2. The SDW, SCW and SAW solutions were prepared according to the technical implementation plans (UCRL-ID-132285 [DIRS 110868]; UCRL-ID-132286 [DIRS 110890]; UCRL-ID-132287 [DIRS 110867]). The SCW test medium is three orders-of-magnitude $(1,000 \times)$ more concentrated in some species than $\mathrm{J}-13$ well water and is slightly alkaline $(\mathrm{pH} \sim 8)$. The SAW test medium is three orders-of-magnitude $(1,000 \times)$ more concentrated in some species than J-13 well water and is acidic $(\mathrm{pH} 2.7)$. Two temperature levels $\left(60^{\circ} \mathrm{C}\right.$ and $\left.90^{\circ} \mathrm{C}\right)$ are included in this qualified testing program. All drip shields are considered to undergo general corrosion at a constant rate, characterized by the distributions shown in this section and Section 6.5.4.2.

The details on the repository environmental conditions are beyond the scope of this document and are discussed in Engineered Barrier System: Physical and Chemical Environment Model (BSC 2004 [DIRS 169860], Section 6). The relevance of the test media at the LTCTF to the repository environments is discussed in Section 2.2 of Engineering Materials Characterization Report (Estill 1998 [DIRS 117697]) and in Section 6.2 of this document. The test media used for this model development are plausible environments given the ionic species present in J-13 well water and the interaction of water with the near-field environment over extended periods.

During the high-temperature thermal period, during approximately the first 100 years after closure, in-drift gases will be displaced by water vapor, dropping the levels for all other gases in the drifts during that period (CRWMS M\&O 2000 [DIRS 153246], Section 3.3.4). Even this decrease in oxygen fugacity is not great enough to reverse redox reactions occurring in the repository (CRWMS M\&O 2000 [DIRS 153246], Section 3.3.4).

\subsubsection{Modeling Corrosion of Inner and Outer Surfaces of the Drip Shield}

The long-term corrosion tests performed at the LTCTF employed two types of specimen geometries (i.e., weight-loss specimens and creviced specimens). Correspondingly, there are two types of data treatment in this section. Treatment only using the corrosion rate data from weightloss specimens is referred to as "weight-loss only." As indicated in Section 6.3.2, the "weightloss only" treatment is used to model the corrosion rates on the inner surface of the drip shield. Another treatment uses a combination of the corrosion rate data from both weight-loss specimens and creviced specimens. This treatment is referred to as "weight-loss plus crevice." As indicated in Section 6.3.3, the model using this combination of LTCTF "weight-loss only" and 
"weight-loss plus crevice" data is used to model the corrosion rates on the outer surface of the drip shield because of its more complicated geometry and chemistry.

The inner and outer surfaces of the drip shield will be exposed in different environments. The detailed chemistry of the environments to which the inner and outer surfaces are exposed to is beyond of the scope of this document, however, the environments that the inner surface sees will be simpler than that the outer surface sees due to the absence of dripping water contact. Water contacting the outer surface of the drip shield will be either in the vapor, moist air, or dripping water mode. Dripping water will potentially lead to the formation of scale or precipitated salt deposits that mimic the type of corrosion represented by the crevice data. Therefore, the cumulative distribution function that best represents the general corrosion behavior of the drip shield outer surface is one that combines the weight-loss and crevice corrosion distributions. The inner surface of the drip shield will not be exposed to dripping water and need not account for the potential for crevice formation by scale or precipitated salt deposits. Therefore, general corrosion of the drip shield inner surface is better represented by a cumulative distribution function based only on the weight-loss specimens.

\subsubsection{Calculation of Corrosion Rate Based Upon Weight-Loss Measurement}

As previously discussed, general corrosion measurements have been based upon ASTM G 1-90 [DIRS 103515]. The general corrosion (or penetration) rate of an alloy in $\mu \mathrm{m} / \mathrm{yr}$ can be calculated from weight-loss data according to the following general formula:

$$
\text { Corrosion Rate }=\frac{(K \times W)}{(A \times T \times D)}
$$

where $K$ is a constant, $T$ is the time of exposure in hours, $A$ is the exposed area of the sample in square centimeters, $W$ is the mass loss in grams, and $D$ is the density in grams per cubic centimeter. The value of $K$ used for the LTCTF data was $8.76 \times 10^{7} \mu \mathrm{m} / \mathrm{yr} \mathrm{h} \mathrm{cm}^{-1}$ (ASTM G 1-90 [DIRS 103515]). This formula for corrosion rate can be rewritten in the following form:

$$
\frac{d p}{d t}=\frac{w}{\rho \times t} \frac{1}{[2(a \times b)+2(b \times c)+2(a \times c)]}
$$

where $d p / d t$ is the corrosion rate, $w$ is the mass loss in grams, $\rho$ is the density in grams per cubic centimeter, $t$ is the time of exposure in years, and the quantity in square brackets represents the exposed area of the sample in square centimeters. Without application of any conversion factor, the corrosion rate calculated with this formula has the units of centimeters per year. Multiplication of $d p / d t$ by $10^{4} \mu \mathrm{m} \mathrm{cm}^{-1}$ yields a corrosion rate with the units of micrometers per year. The weight-loss and dimensional change were measured with electronic instruments calibrated to traceable standards. Because all data was digitally transferred to computer, the possibility of human error was minimized.

Comparative sample calculations are used to compare the two formulae, Equations 22 and 23. Comparison is necessary to show that the error analysis in Section 6.5.4.2 applies to the formula given by ASTM G 1-90 [DIRS 103515]. 
With specific choices for values, Equation 22 yields:

$$
\begin{aligned}
& K=8.76 \times 10^{7} \mu m y r^{-1} \mathrm{hcm}^{-1} \\
& W=0.0001 \mathrm{gm} \\
& A=1.0 \mathrm{~cm}^{2} \\
& T=4380 h \\
& D=4.54 \mathrm{gm} \mathrm{cm}^{-3} \\
& \text { CorrosionRate }=\frac{\left(8.76 \times 10^{7} \mu \mathrm{myr}^{-1} \mathrm{~h} \mathrm{~cm}^{-1}\right)(0.0001 \mathrm{gm})}{\left(1.0 \mathrm{~cm}^{2}\right)(4380 \mathrm{~h})\left(4.54 \mathrm{gm} \mathrm{cm}^{-3}\right)}=0.44 \mu \mathrm{m} \mathrm{yr}^{-1}
\end{aligned}
$$

A calculation with Equation 23 and the same choices for values yields:

$$
\begin{aligned}
& k=10^{4} \mu \mathrm{m} \mathrm{cm}^{-1} \\
& w=0.0001 \mathrm{gm} \\
& 2(a \times b)+2(b \times c)+2(a \times c)=1.0 \mathrm{~cm}^{2} \\
& t=0.5 \mathrm{yr} \\
& \rho=4.54 \mathrm{gm} \mathrm{cm}^{-3} \\
& \frac{d p}{d t}=\frac{\left(10^{4} \mu \mathrm{cm}^{-1}\right)\left(0.0001 \mathrm{gm}^{-3}\right.}{\left(1.0 \mathrm{~cm}^{2}\right)(0.5 \mathrm{yr})\left(4.54 \mathrm{gm} \mathrm{cm}^{-3}\right)}=0.44 \mu \mathrm{yr}^{-1}
\end{aligned}
$$

As expected, the equations give identical results. The second formula is used as the basis of a formal error analysis of general corrosion rates determined from LTCTF data.

This analysis includes Ti Grade 16 samples exposed for 1 year and 5 years and the Ti Grade 7 samples for 2.5 years in the LTCTF. However, only the 1-year data are used in the model development. The 2.5- and 5-year data are used for the model validation (Section 7.4). Since the 2.5-year data are recently obtained, they are used for corroborative model validation.

Posttest specimen treatments were different for the 1-year test and 2.5- and 5-year tests. The 1-year specimens were cleaned with deionized water and a nylon brush (Estill 1998 [DIRS 117697], Section 2.2.7.1). Because very little cleaning was performed for the 1-year samples, the incomplete removal of oxide or deposits, or both, may account for the large negative values in Figure 10 and Figure 11 shown in Section 6.5.3.1.

In contrast, the 2.5-year and 5-year test specimens were cleaned more thoroughly and carefully as described in TIP-CM-51 [DIRS 169585] and DTN: LL030205912251.016 [DIRS 161755]. After approximately two and half years and five years of exposure to each solution or environmental condition, these specimens were removed from their respective test vessels to determine their weight loss. In all of the tested conditions, the coupons were covered with deposits. Therefore, the coupons were cleaned prior to final weighing. Cleaning was carried out according to ASTM G 1-90 [DIRS 103515]. For specimens exposed to SCW and SDW, the posttest specimens were descaled for 2 minutes in a cleaning solution prepared by diluting $150 \mathrm{~mL}$ of concentrated $\mathrm{HCl}$ acid $(37 \% \mathrm{HCl}$ of specific gravity of 1.19$)$ with deionized water to 
make 1,000 mL of solution (TIP-CM-51 [DIRS 169585]). The cleaning temperature was ambient. For specimens exposed to SAW, the posttest specimens were first exposed for 2 minutes to the same $\mathrm{HCl}$ solution used for descaling samples exposed to SCW and SDW (TIP-CM-51 [DIRS 169585]). The samples were then immersed at $95^{\circ} \mathrm{C}$ for 2 minutes in a solution prepared by dissolving $200 \mathrm{~g}$ of $\mathrm{NaOH}$ and $30 \mathrm{~g}$ of $\mathrm{KMnO}_{4}$ in deionized water to make $1,000 \mathrm{~mL}$ of solution. Finally, the specimens were immersed for 3 minutes in a solution prepared by dissolving $100 \mathrm{~g}$ of diammonium citrate in deionized water to make $1,000 \mathrm{~mL}$ of solution. Weight-loss measurements and scanning electron microscopy analysis showed that these cleaning methods removed all scale from tested samples, yet did not significantly affect untested foil samples (TIP-CM-51 [DIRS 169585]). These observations indicate that the cleaning process used for the 5-year samples adequately removed the scale from the samples thereby effectively eliminating uncertainty due to the cleaning process from the 5-year data. The only modifications to ASTM G 1-90 [DIRS 103515] methods were an increased immersion time and the use of a drying oven and desiccator to minimize air exposure.

\subsubsection{Corrosion Rates Based Upon 1-Year Weight-Loss Measurements}

Because the corrosion rates are calculated based on the weight-loss scatter, they are arranged in such a way that the weight (percentile) of each data point in the whole set of data (the number of the specimens used in the tests) is known. Plotting the percentile (weight) versus the corresponding corrosion rate results in a cumulative distribution function. Cumulative distribution functions in this report are established this way.

General corrosion rates for Ti Grade 16 based on LTCTF 1-year weight-loss samples are shown in Figure 10. Data obtained at $60^{\circ} \mathrm{C}$ and $90^{\circ} \mathrm{C}$ in various test media are plotted in the same figure to show that these measurements are virtually independent of temperature between $60^{\circ} \mathrm{C}$ and $90^{\circ} \mathrm{C}$. Furthermore, the composition of the test medium (SDW, SCW, or SAW) had little impact on the measurements. With the exception of four outliers, most of the rates plotted in Figure 10 are between approximately -200 and $+200 \mathrm{~nm} / \mathrm{yr}$. The median is approximately zero. 


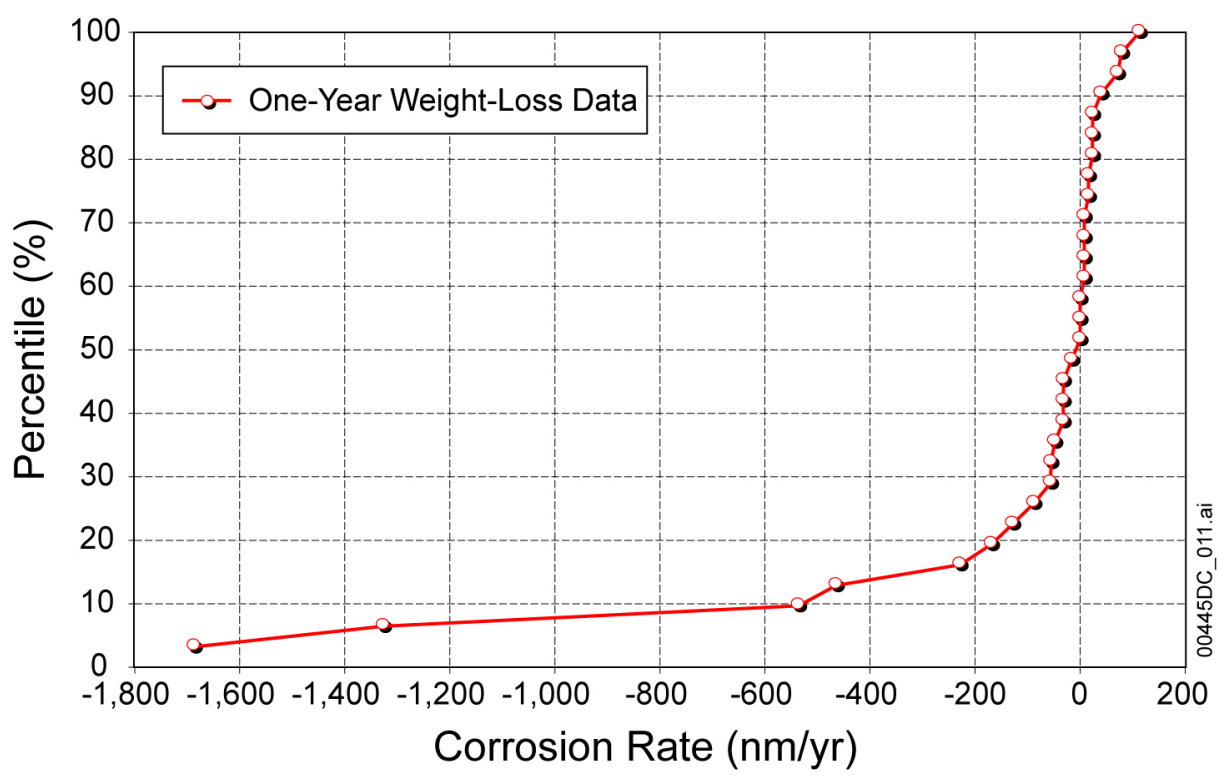

Source: DTN: LL990610605924.079 [DIRS 104994] - S99359_012.

Output DTN: MO0408MWDGLCDS.002.

Figure 10. Distribution of General Corrosion Rates of Ti Grade 16: LTCTF 1-Year Weight-Loss Samples

The outliers with large negative rates are believed to represent samples where there was significant amount of oxides or scale not completely removed during the posttest specimen cleaning, or both.

Similarly, all general corrosion rates for Ti Grade 16 based on LTCTF crevice samples (Estill 1998 [DIRS 117697], Section 2.2.6; DTN: LL990610605924.079 [DIRS 104994]) are shown in Figure 11. In this case, it also appears that the measurements are independent of temperature and test medium. Most of the rates plotted in Figure 11 are between -320 and $+320 \mathrm{~nm} / \mathrm{yr}$. The median is at approximately zero. The largest measured rate shown in Figure 11 (less than $+320 \mathrm{~nm} / \mathrm{yr}$ ) will not lead to failure of the drip shield during the 10,000-year service life. Based upon these data, the life of the drip shield is not limited by the general corrosion of Ti Grade 16 (an analog of Ti Grade 7) at temperatures less than those involved in the test $\left(90^{\circ} \mathrm{C}\right)$ during a period of 10,000 years. 


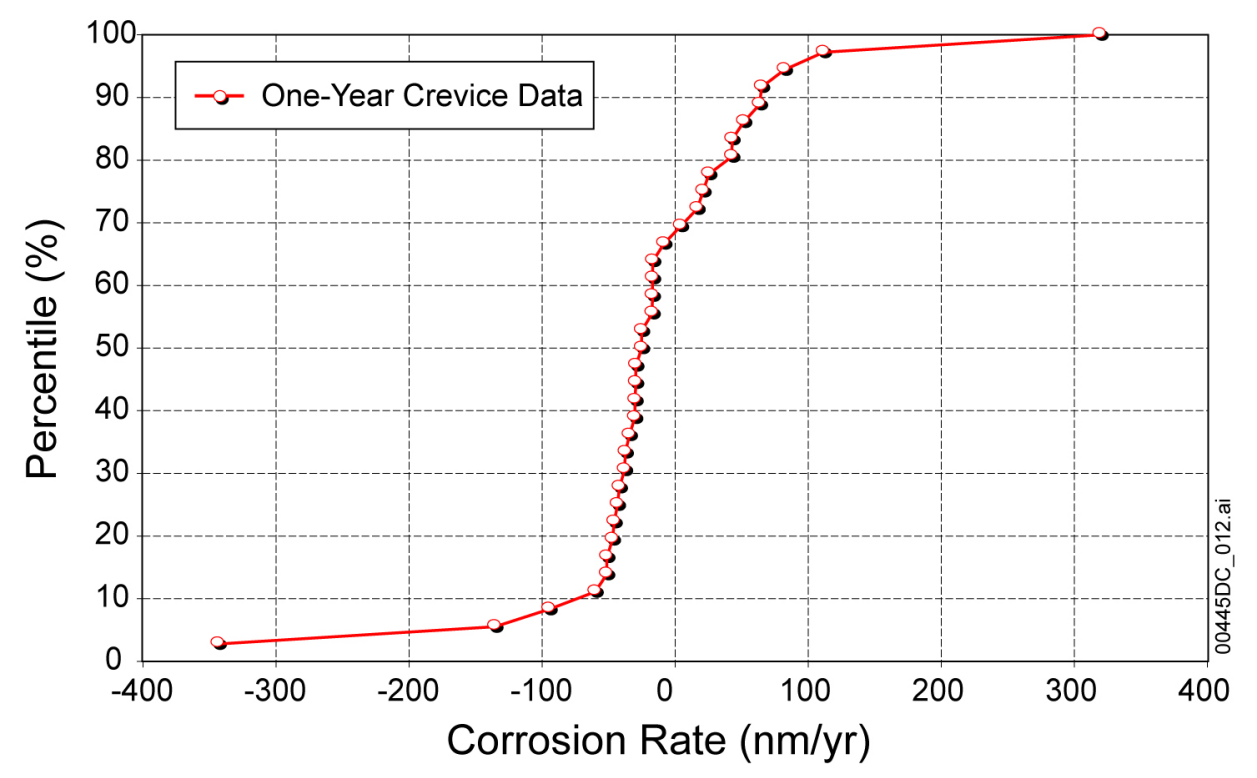

Source: DTN: LL990610605924.079 [DIRS 104994] S99359_009.

Output DTN: MO0408MWDGLCDS.002.

Figure 11. Distribution of General Corrosion Rates of Ti Grade 16: LTCTF 1-Year Crevice Sample

The distributions shown in this section are based upon all LTCTF data collected at $60^{\circ} \mathrm{C}$ and $90^{\circ} \mathrm{C}$. There was very little temperature dependence over this range. These distributions are used to predict the situations at slightly higher temperatures, up to the $120^{\circ} \mathrm{C}$ boiling point of SSW.

No obvious crevice attack was observed with the samples represented by Figure 11. The greater scatter in the crevice corrosion distribution indicates more variability in the corrosion process is related to the presence of the crevice. Corrosion inside the crevice could be more severe due to differential aeration, minor $\mathrm{pH}$ changes within the crevice, or both, but not severe enough to destroy the passive film as discussed in more detail in Section 6.6.4. It is also possible that a different surface finish treatment used for the crevice and weight-loss specimens may have led to different corrosion rates between the two types of specimens.

Water contacting the outer surface of the drip shield could be either in the vapor, moist air, or dripping water mode. Dripping water could lead to the formation of scale or precipitated salt deposits that could mimic the type of corrosion represented by the crevice data. Therefore, the cumulative distribution function that best represent the general corrosion behavior of the outer surface of the drip shield is one that combined the weight-loss (Figure 10) and crevice corrosion distributions (Figure 11). The inner surface of the drip shield is not exposed to dripping water nor excessive dust or scale deposition and, accordingly, need not account for the potential for crevice formation. Therefore, it would be better represented by a cumulative distribution function based on the corrosion rates obtained from the weight-loss only specimens (Figure 10). 


\subsubsection{Model Uncertainty}

\subsubsection{Uncertainty Analysis for Weight-Loss Measurements (Data Measurement Uncertainty)}

The general method used in the formal error analysis is now presented. Consider the dependent variable $y$ defined by the following generic function:

$$
y=f\left(x_{1}, x_{2}, x_{3}, x_{4}, \ldots x_{n}\right)
$$

where $x_{i}$ is the $i^{t h}$ independent variable. The total derivative of $y$ is then defined as:

$$
d y=\frac{\partial y}{\partial x_{1}} d x_{1}+\frac{\partial y}{\partial x_{2}} d x_{2}+\frac{\partial y}{\partial x_{3}} d x_{3}+\frac{\partial y}{\partial x_{4}} d x_{4}+\cdots+\frac{\partial y}{\partial x_{n}} d x_{n}
$$

Based upon this definition, the maximum error in $\mathrm{y}$ can then be defined as:

$$
\Delta y=\left|\frac{\partial y}{\partial x_{1}} \Delta x_{1}\right|+\left|\frac{\partial y}{\partial x_{2}} \Delta x_{2}\right|+\left|\frac{\partial y}{\partial x_{3}} \Delta x_{3}\right|+\left|\frac{\partial y}{\partial x_{4}} \Delta x_{4}\right|+\cdots+\left|\frac{\partial y}{\partial x_{n}} \Delta x_{n}\right|
$$

where $\Delta x_{i}$ is the error in the $i^{\text {th }}$ independent variable. Let the dependent variable $y$ be the general corrosion rate measured in the LTCTF,

$$
y=\frac{d p}{d t}=\frac{w}{\rho \times t} \frac{1}{[2(a \times b)+2(b \times c)+2(a \times c)]}
$$

where $d p / d t$ is the corrosion rate, $w$ is the mass loss in grams, $\rho$ is the density in grams per cubic centimeter, $t$ is the time of exposure in years, and the quantity in square brackets represents the exposed area of the sample in square centimeters. $a, b$, and $c$ are the dimensions of the test specimen.

The total derivative of the corrosion rate is:

$$
d y=\frac{\partial y}{\partial w} d w+\frac{\partial y}{\partial \rho} d \rho+\frac{\partial y}{\partial t} d t+\frac{\partial y}{\partial a} d a+\frac{\partial y}{\partial b} d b+\frac{\partial y}{\partial c} d c
$$

The maximum error in the corrosion rate is:

$$
\Delta y=\left|\frac{\partial y}{\partial w} \Delta w\right|+\left|\frac{\partial y}{\partial \rho} \Delta \rho\right|+\left|\frac{\partial y}{\partial t} \Delta t\right|+\left|\frac{\partial y}{\partial a} \Delta a\right|+\left|\frac{\partial y}{\partial b} \Delta b\right|+\left|\frac{\partial y}{\partial c} \Delta c\right|
$$

The partial derivates are:

$$
\frac{\partial y}{\partial w}=\frac{1}{\rho \times t} \frac{1}{[2(a \times b)+2(b \times c)+2(a \times c)]}
$$




$$
\begin{aligned}
& \frac{\partial y}{\partial \rho}=-\frac{w}{\rho^{2} \times t} \frac{1}{[2(a \times b)+2(b \times c)+2(a \times c)]} \\
& \frac{\partial y}{\partial t}=-\frac{w}{\rho \times t^{2}} \frac{1}{[2(a \times b)+2(b \times c)+2(a \times c)]} \\
& \frac{\partial y}{\partial a}=-\frac{w}{\rho \times t} \frac{[2 b+2 c]}{[2(a \times b)+2(b \times c)+2(a \times c)]^{2}} \\
& \frac{\partial y}{\partial b}=-\frac{w}{\rho \times t} \frac{[2 a+2 c]}{[2(a \times b)+2(b \times c)+2(a \times c)]^{2}} \\
& \frac{\partial y}{\partial c}=-\frac{w}{\rho \times t} \frac{[2 a+2 b]}{[2(a \times b)+2(b \times c)+2(a \times c)]^{2}}
\end{aligned}
$$

The maximum error in the corrosion rate is estimated by calculating numeric values of the partial derivatives from expected values of the independent variables, multiplication of each partial derivative by the corresponding error in independent variable ( $\Delta w, \Delta \rho, \Delta t, \Delta a, \Delta b$, and $\Delta c)$, and summation of the resulting products. There is some uncertainty in the density, which is explained. The error based upon this method is shown in Table 11 through Table 15.

Table 11. Summary of Error Analysis for Corrosion Rates Based Upon Weight-Loss Measurements

\begin{tabular}{|c|c|c|c|c|c|}
\hline \multirow{2}{*}{ Case } & \multirow{2}{*}{$\begin{array}{c}\text { Sample } \\
\text { Configuration }\end{array}$} & \multirow{2}{*}{ Exposure Time } & \multicolumn{3}{|c|}{ Analyzed Weight Loss } \\
\cline { 4 - 6 } & & $\mathbf{0 . 0 0 0 1} \mathbf{g}$ & $\mathbf{0 . 0 0 1 0 \mathbf { g }}$ & $\mathbf{0 . 0 1 0 0 \mathbf { g }}$ \\
\cline { 4 - 6 } & & $\begin{array}{c}\Delta \mathbf{y} \\
(\mathbf{n m} / \mathbf{y r})\end{array}$ & $\begin{array}{c}\Delta \mathbf{y} \\
(\mathbf{n m} / \mathbf{y r})\end{array}$ & $\begin{array}{c}\Delta \mathbf{y} \\
(\mathbf{n m} / \mathbf{y r})\end{array}$ \\
\hline 1 & Crevice & 12 month & 11.6 & 12.5 & 21.7 \\
\hline 2 & Weight-Loss & 12 month & 22.0 & 23.8 & 41.8 \\
\hline
\end{tabular}

Output DTN: MO0408MWDGLCDS.002. 
Table 12. Error Analysis for LTCTF Corrosion Rates-Definitions

\begin{tabular}{|c|c|c|}
\hline Parameter & Parameter Definition & Units \\
\hline$w$ & Weight loss & $g$ \\
\hline$\rho$ & Density & $\mathrm{g} \mathrm{cm}^{-3}$ \\
\hline$t$ & Exposure time & $\mathrm{hr}$ \\
\hline$a$ & Length & in \\
\hline$b$ & Width & in \\
\hline$c$ & Thickness & in \\
\hline$a$ & Length & $\mathrm{cm}$ \\
\hline$b$ & Width & $\mathrm{cm}$ \\
\hline$c$ & Thickness & $\mathrm{cm}$ \\
\hline$\partial y / \partial w$ & Partial derivative or rate with respect to weight loss & $\mathrm{cm} \mathrm{g}^{-1} \mathrm{hr}^{-1}$ \\
\hline$\partial y / \partial \rho$ & Partial derivative of rate with respect to density & $\mathrm{cm}^{4} \mathrm{~g}^{-1} \mathrm{hr}^{-1}$ \\
\hline$\partial y / \partial t$ & Partial derivative of rate with respect to exposure time & $\mathrm{cm} \mathrm{h}^{-2}$ \\
\hline$\partial y / \partial a$ & Partial derivative of rate with respect to length & $\mathrm{hr}^{-1}$ \\
\hline$\partial y / \partial b$ & Partial derivative of rate with respect to width & $\mathrm{hr}^{-1}$ \\
\hline$\partial y / \partial c$ & Partial derivative of rate with respect to thickness & $\mathrm{hr}^{-1}$ \\
\hline$\Delta w$ & Error in weight loss & g \\
\hline$\Delta \rho$ & Error in density & $\mathrm{g} \mathrm{cm}^{-3}$ \\
\hline$\Delta t$ & Error in exposure time & $\mathrm{hr}$ \\
\hline$\Delta a$ & Error in length & $\mathrm{cm}$ \\
\hline$\Delta b$ & Error in width & $\mathrm{cm}$ \\
\hline$\Delta c$ & Error in thickness & $\mathrm{cm}$ \\
\hline$(\partial y / \partial w) \times(\Delta w)$ & Weight-loss product & $\mathrm{cm} \mathrm{hr}^{-1}$ \\
\hline$(\partial y / \partial \rho) \times(\Delta \rho)$ & Density product & $\mathrm{cm} \mathrm{hr}^{-1}$ \\
\hline$(\partial y / \partial t) \times(\Delta t)$ & Exposure time product & $\mathrm{cm} \mathrm{hr}^{-1}$ \\
\hline$(\partial y / \partial a) \times(\Delta a)$ & Length product & $\mathrm{cm} \mathrm{hr}^{-1}$ \\
\hline$(\partial y / \partial b) \times(\Delta b)$ & Width product & $\mathrm{cm} \mathrm{hr}^{-1}$ \\
\hline$(\partial y / \partial c) \times(\Delta c)$ & Thickness product & $\mathrm{cm} \mathrm{hr}^{-1}$ \\
\hline$\Delta y$ & Sum of all products & $\mathrm{cm} \mathrm{hr}^{-1}$ \\
\hline$\Delta y$ & Sum of all products & $\mu \mathrm{m} / \mathrm{yr}$ \\
\hline$\Delta y$ & Sum of all products & $\mathrm{nm} / \mathrm{yr}$ \\
\hline
\end{tabular}


Table 13. Error Analysis for LTCTF Corrosion Rates-Chosen Weight Loss of 0.0001 Grams

\begin{tabular}{|c|c|c|}
\hline Parameter & $\begin{array}{l}\text { Crevice Samples } \\
\text { (12 months) }\end{array}$ & $\begin{array}{l}\text { Weight-Loss Samples } \\
\text { (12 months) }\end{array}$ \\
\hline$w$ & 0.0001 & 0.0001 \\
\hline$\rho$ & 4.52 & 4.52 \\
\hline$t$ & 8760 & 8760 \\
\hline$a$ (in) & 2.0000 & 2.0000 \\
\hline$b$ (in) & 2.0000 & 1.0000 \\
\hline$c$ (in) & 0.1200 & 0.1200 \\
\hline$a(\mathrm{~cm})$ & 5.0800 & 5.0800 \\
\hline$b(\mathrm{~cm})$ & 5.0800 & 2.5400 \\
\hline$c(\mathrm{~cm})$ & 0.3048 & 0.3048 \\
\hline$\partial y / \partial w$ & 4.3690E-07 & 8.2937E-07 \\
\hline$\partial y / \partial \rho$ & 9.6659E-12 & 1.8349E-11 \\
\hline$\partial y / \partial t$ & 4.9874E-15 & 9.4677E-15 \\
\hline$\partial y / \partial a$ & 8.1397E-12 & $1.5496 \mathrm{E}-11$ \\
\hline$\partial y / \partial b$ & 8.1397E-12 & $2.9332 \mathrm{E}-11$ \\
\hline$\partial y / \partial c$ & $1.5358 \mathrm{E}-11$ & 4.1507E-11 \\
\hline$\Delta w$ & 0.0003 & 0.0003 \\
\hline$\Delta \rho$ & 0.1 & 0.1 \\
\hline$\Delta t$ & 24 & 24 \\
\hline$\Delta a$ & 0.00254 & 0.00254 \\
\hline$\Delta b$ & 0.00254 & 0.00254 \\
\hline$\Delta c$ & 0.00254 & 0.00254 \\
\hline$(\partial y / \partial w) \times(\Delta w)$ & 1.3107E-10 & $2.4881 \mathrm{E}-10$ \\
\hline$(\partial y / \partial \rho) \times(\Delta \rho)$ & 9.6659E-13 & 1.8349E-12 \\
\hline$(\partial y / \partial t) \times(\Delta t)$ & 1.1970E-13 & 2.2722E-13 \\
\hline$(\partial y / \partial a) \times(\Delta a)$ & 2.0675E-14 & 3.9360E-14 \\
\hline$(\partial y / \partial b) \times(\Delta b)$ & $2.0675 \mathrm{E}-14$ & 7.4503E-14 \\
\hline$(\partial y / \partial c) \times(\Delta c)$ & $3.9009 \mathrm{E}-14$ & 1.0543E-13 \\
\hline$\Delta y$ & 1.3224E-10 & $2.5109 \mathrm{E}-10$ \\
\hline$\Delta y$ & 1.1584E-02 & 2.1996E-02 \\
\hline$\Delta y$ & $1.1584 \mathrm{E}+01$ & $2.1996 \mathrm{E}+01$ \\
\hline
\end{tabular}


Table 14. Error Analysis for LTCTF Corrosion Rates-Chosen Weight Loss of 0.001 Grams

\begin{tabular}{|c|c|c|}
\hline Parameter & $\begin{array}{l}\text { Crevice Samples } \\
\text { (12 months) }\end{array}$ & $\begin{array}{c}\text { Weight-Loss Samples } \\
\text { (12 months) }\end{array}$ \\
\hline$w$ & 0.0010 & 0.0010 \\
\hline$\rho$ & 4.52 & 4.52 \\
\hline$t$ & 8760 & 8760 \\
\hline$a$ (in) & 2.0000 & 2.0000 \\
\hline$b$ (in) & 2.0000 & 1.0000 \\
\hline$c$ (in) & 0.1200 & 0.1200 \\
\hline$a(\mathrm{~cm})$ & 5.0800 & 5.0800 \\
\hline$b(\mathrm{~cm})$ & 5.0800 & 2.5400 \\
\hline$c(\mathrm{~cm})$ & 0.3048 & 0.3048 \\
\hline$\partial y / \partial w$ & 4.3690E-07 & 8.2937E-07 \\
\hline$\partial y / \partial \rho$ & 9.6659E-11 & 1.8349E-10 \\
\hline$\partial y / \partial t$ & 4.9874E-14 & 9.4677E-14 \\
\hline$\partial y / \partial a$ & 8.1397E-11 & 1.5496E-10 \\
\hline$\partial y / \partial b$ & 8.1397E-11 & $2.9332 \mathrm{E}-10$ \\
\hline$\partial y / \partial c$ & $1.5358 \mathrm{E}-10$ & 4.1507E-10 \\
\hline$\Delta w$ & 0.0003 & 0.0003 \\
\hline$\Delta \rho$ & 0.1 & 0.1 \\
\hline$\Delta t$ & 24 & 24 \\
\hline$\Delta a$ & 0.00254 & 0.00254 \\
\hline$\Delta b$ & 0.00254 & 0.00254 \\
\hline$\Delta c$ & 0.00254 & 0.00254 \\
\hline$(\partial y / \partial w) \times(\Delta w)$ & 1.3107E-10 & $2.4881 \mathrm{E}-10$ \\
\hline$(\partial y / \partial \rho) \times(\Delta \rho)$ & 9.6659E-12 & 1.8349E-11 \\
\hline$(\partial y / \partial t) \times(\Delta t)$ & 1.1970E-12 & 2.2722E-12 \\
\hline$(\partial y / \partial a) \times(\Delta a)$ & 2.0675E-13 & $3.9360 \mathrm{E}-13$ \\
\hline$(\partial y / \partial b) \times(\Delta b)$ & 2.0675E-13 & 7.4503E-13 \\
\hline$(\partial y / \partial c) \times(\Delta c)$ & 3.9009E-13 & 1.0543E-12 \\
\hline$\Delta y$ & 1.4274E-10 & $2.7162 \mathrm{E}-10$ \\
\hline$\Delta y$ & 1.2504E-02 & 2.3794E-02 \\
\hline$\Delta y$ & $1.2504 \mathrm{E}+01$ & $2.3794 \mathrm{E}+01$ \\
\hline
\end{tabular}


Table 15. Error Analysis for LTCTF Corrosion Rates-Chosen Weight Loss of 0.01 Grams

\begin{tabular}{|c|c|c|}
\hline Parameter & $\begin{array}{c}\text { Crevice Samples } \\
\text { (12 months) }\end{array}$ & $\begin{array}{c}\text { Weight-Loss Samples } \\
\text { (12 months) }\end{array}$ \\
\hline$w$ & 0.0100 & 0.0100 \\
\hline$\rho$ & 4.52 & 4.52 \\
\hline$t$ & 8760 & 8760 \\
\hline a (in) & 2.0000 & 2.0000 \\
\hline$b$ (in) & 2.0000 & 1.0000 \\
\hline$c$ (in) & 0.1200 & 0.1200 \\
\hline$a(\mathrm{~cm})$ & 5.0800 & 5.0800 \\
\hline$b(\mathrm{~cm})$ & 5.0800 & 2.5400 \\
\hline$c(\mathrm{~cm})$ & 0.3048 & 0.3048 \\
\hline$\partial y / \partial w$ & 4.3690E-07 & 8.2937E-07 \\
\hline$\partial y / \partial \rho$ & 9.6659E-10 & 1.8349E-09 \\
\hline$\partial y / \partial t$ & 4.9874E-13 & $9.4677 \mathrm{E}-13$ \\
\hline$\partial y / \partial a$ & 8.1397E-10 & 1.5496E-09 \\
\hline$\partial y / \partial b$ & 8.1397E-10 & 2.9332E-09 \\
\hline$\partial y / \partial c$ & 1.5358E-09 & 4.1507E-09 \\
\hline$\Delta w$ & 0.0003 & 0.0003 \\
\hline$\Delta \rho$ & 0.1 & 0.1 \\
\hline$\Delta t$ & 24 & 24 \\
\hline$\Delta a$ & 0.00254 & 0.00254 \\
\hline$\Delta b$ & 0.00254 & 0.00254 \\
\hline$\Delta c$ & 0.00254 & 0.00254 \\
\hline$(\partial y / \partial w) \times(\Delta w)$ & 1.3107E-10 & $2.4881 \mathrm{E}-10$ \\
\hline$(\partial y / \partial \rho) \times(\Delta \rho)$ & $9.6659 \mathrm{E}-11$ & 1.8349E-10 \\
\hline$(\partial y / \partial t) \times(\Delta t)$ & 1.1970E-11 & $2.2722 \mathrm{E}-11$ \\
\hline$(\partial y / \partial a) \times(\Delta a)$ & 2.0675E-12 & 3.9360E-12 \\
\hline$(\partial y / \partial b) \times(\Delta b)$ & $2.0675 \mathrm{E}-12$ & 7.4503E-12 \\
\hline$(\partial y / \partial c) \times(\Delta c)$ & $3.9009 \mathrm{E}-12$ & 1.0543E-11 \\
\hline$\Delta y$ & 2.4773E-10 & 4.7695E-10 \\
\hline$\Delta y$ & 2.1702E-02 & 4.1781E-02 \\
\hline$\Delta y$ & $2.1702 \mathrm{E}+01$ & $4.1781 \mathrm{E}+01$ \\
\hline
\end{tabular}

From the estimated errors given in Table 11, it is concluded that the typical uncertainty observed in weight-loss and dimensional measurements prevent determination of corrosion rates less than $42 \mathrm{~nm} / \mathrm{yr}$ (with the weight-loss samples as the worst-case scenario). This estimate of error corresponds to about one standard deviation $(1 \sigma)$. Therefore, any measured corrosion rate less than about $170 \mathrm{~nm} / \mathrm{yr}(4 \sigma)$ will not be distinguishable from the measurement error.

General corrosion rates determined from measurements of weight loss in the LTCTF are shown in Figure 10 and Figure 11 for the inner and outer surfaces of the drip shield, respectively. The maximum rates shown in Figure 10 and Figure 11 are less than about $320 \mathrm{~nm} / \mathrm{yr}$. Any rate less than $320 \mathrm{~nm} / \mathrm{yr}$ demonstrates that the drip shield (wall thickness of $15 \mathrm{~mm}$ ) will not breach by 
general corrosion. The impact of the hole in the crevice samples on the error analysis was relatively small and, therefore, omitted.

\subsubsection{Uncertainty in Model Application (Parameter Uncertainty)}

Some parameter uncertainty arises from the fact that the oxide layer thickness is experimentally determined by comparing before-and-after specimen weights that are very close to each other, probably well within the accuracy of the weight-loss measurement methodology. A significant number of the measurements, in fact, indicated negative weight losses. The corrosion rate values given in Figure 10 and Figure 11 were derived from such measurements.

From the data given in Section 6.5.3, the uncertainty in general corrosion rates can be estimated. In the case of samples with generic weight-loss geometry, measured general corrosion rates are shown in Figure 10. The distribution of measured rates appears to be symmetric and centered close to zero. The maximum and minimum rates fall within the limit defined by $\pm 200 \mathrm{~nm} / \mathrm{yr}$ for the inner surfaces of the drip shield. In the case of samples with generic crevice geometry, measured general corrosion rates are shown in Figure 11. The distribution of measured rates appears to be slightly asymmetric, but still centered close to zero. The maximum and minimum rates fall within the limit defined by $\pm 320 \mathrm{~nm} / \mathrm{yr}$ for the outer surfaces of the drip shield. The negative rates could be due to either scale formation or incomplete removal of the oxide film.

Conservatively in the cumulative distribution functions negative rates are removed. As shown in Figure 12 and Figure 13, the rate at the $50^{\text {th }}$ percentile is approximately $25 \mathrm{~nm} / \mathrm{yr}$, the rate at the $90^{\text {th }}$ percentile is approximately $75 \mathrm{~nm} / \mathrm{yr}$, and the maximum rate is approximately $320 \mathrm{~nm} / \mathrm{yr}$. About $5 \%$ of the values fall between 100 and $320 \mathrm{~nm} / \mathrm{yr}$.

Another source of parameter uncertainty is implicit in applying the cumulative distribution functions of corrosion rates measured in experiments of 1-year duration to the thousands of years service life of the drip shield. A cumulative distribution function is a completely empirical model per ASTM C 1174-97 ([DIRS 105725]) and has no functional dependence on environmental or drip shield material parameters. However, there are credible analyses of the mechanisms of corrosion of $\mathrm{Ti}$ alloys that indicate the corrosion rate follows parabolic or logarithmic kinetics over long periods (Welsch et al. 1996 [DIRS 114895]).

Taking these factors into account, there is an approximately one order-of-magnitude parametric uncertainty biased toward lower rates in the cumulative distribution function models due to possible bias in the measurements, corresponding roughly to the range of the spread of 'negative' corrosion rates shown in Figure 10 and Figure 11. This uncertainty is offset by the uncertainty biased toward higher rates in applying the 1-year cumulative distribution functions to the long duration of repository service (i.e., no invocation of parabolically or logarithmically decreasing long-term corrosion kinetics). The estimated combined uncertainty resulting from these factors is approximately $100 \%$ within the combined cumulative distribution functions. The upper-end value for this uncertainty is, thus, approximately $320 \mathrm{~nm} / \mathrm{yr}$. If propagated throughout the model, this level of uncertainty would result in an estimated corrosion penetration at 10,000 years of approximately $3.2 \mathrm{~mm}$. This value is still small compared to the $15 \mathrm{~mm}$ drip shield thickness. There is some also uncertainty in the cumulative distribution function due to the unquantified effect of chemical environment parameters used in the testing that provided the 1-year exposure 
data upon which the cumulative distribution functions are based. This includes the effect of uncertainties involved with $\mathrm{CaCl}_{2}$ and fluoride. However, this uncertainty is small. This was discussed in the modeling analysis in Section 6.5.4.2. In particular it was demonstrated that even under extremely aggressive chemical exposure conditions (brines containing $35,000 \mathrm{mg} / \mathrm{L}$ of $\mathrm{Mg}^{2+}$ at $\left.250^{\circ} \mathrm{C}\right)$ relatively low rates $(\sim 400 \mathrm{~nm} / \mathrm{yr}$ ) were obtained for Ti Grade 7 (Molecke et al. 1982 [DIRS 161678]) and these rates were attributed to the high temperature and shorter exposure period (i.e., higher than the rates based on the long-term parabolic or logarithmic kinetics). Because these measured rates are near the upper bound levels of the cumulative distribution functions, the uncertainties in the corrosion rates due to unanticipated but possible aggressive chemical exposure conditions are included within the cumulative distribution function distributions.

\subsubsection{Composite Model for the General Corrosion Rates for Drip Shield}

A simple and defensible representation of the observed general corrosion rates is recommended. The primary difference between the exposure environments on the inner and the outer surfaces of the drip shield is that the drip shield outer surface may be exposed to a more complicated chemistry and geometry because dust or mineral films (from evaporation of dripping water), or both, may form crevices on the drip shield outer surfaces. In contrast, the inner surfaces of the drip shield will not be exposed to dripping water or significant dust film formation. Therefore, the general corrosion of the inner surface and the outer surface of the drip shield are modeled by using different sets of corrosion data. This approach is schematically illustrated in Figure 3. General corrosion of the inner surface of the drip shield is represented by a cumulative distribution function generated from the LTCTF weight-loss samples only (Figure 10). The negative weight-loss general corrosion rates were conservatively removed from the distribution. The numerical values for this distribution are shown in Table 16 and the cumulative distribution function is plotted in Figure 12. The general corrosion rates of the outer surface of the drip shield are represented by a cumulative distribution function generated from combining both the LTCTF weight-loss samples (Figure 10) and the crevice samples (Figure 11). The negative weight-loss general corrosion rates were conservatively removed from the distribution. The numerical values for this distribution are shown in Table 17 and the cumulative distribution function is plotted in Figure 13. 


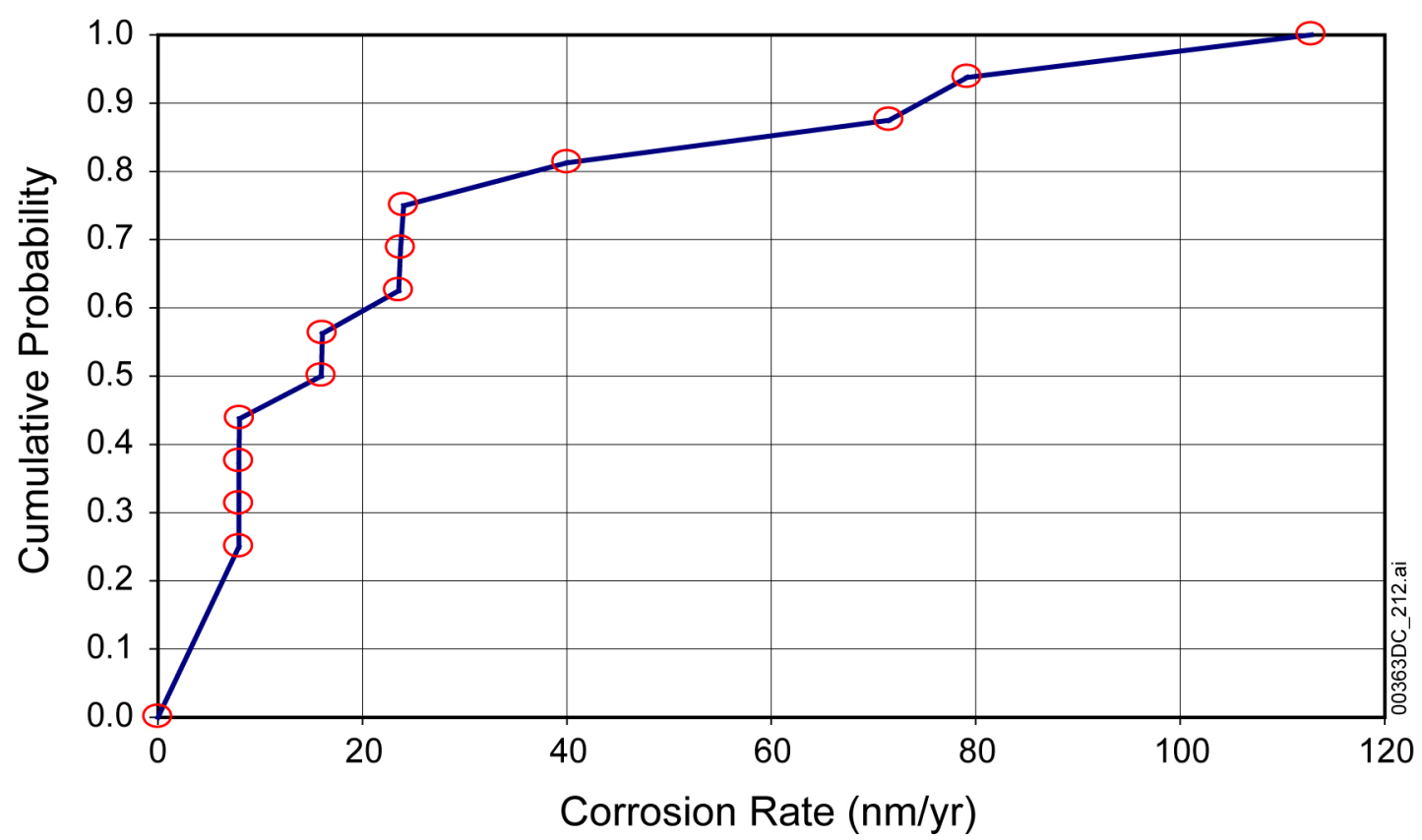

Source: DTN: LL990610605924.079 [DIRS 104994] S99359_036.

Output DTN: MO0408MWDGLCDS.002.

Figure 12. Distribution of General Corrosion Rates of Ti Grade 16: LTCTF 1-Year Weight-Loss Samples (Negative Rates Removed)

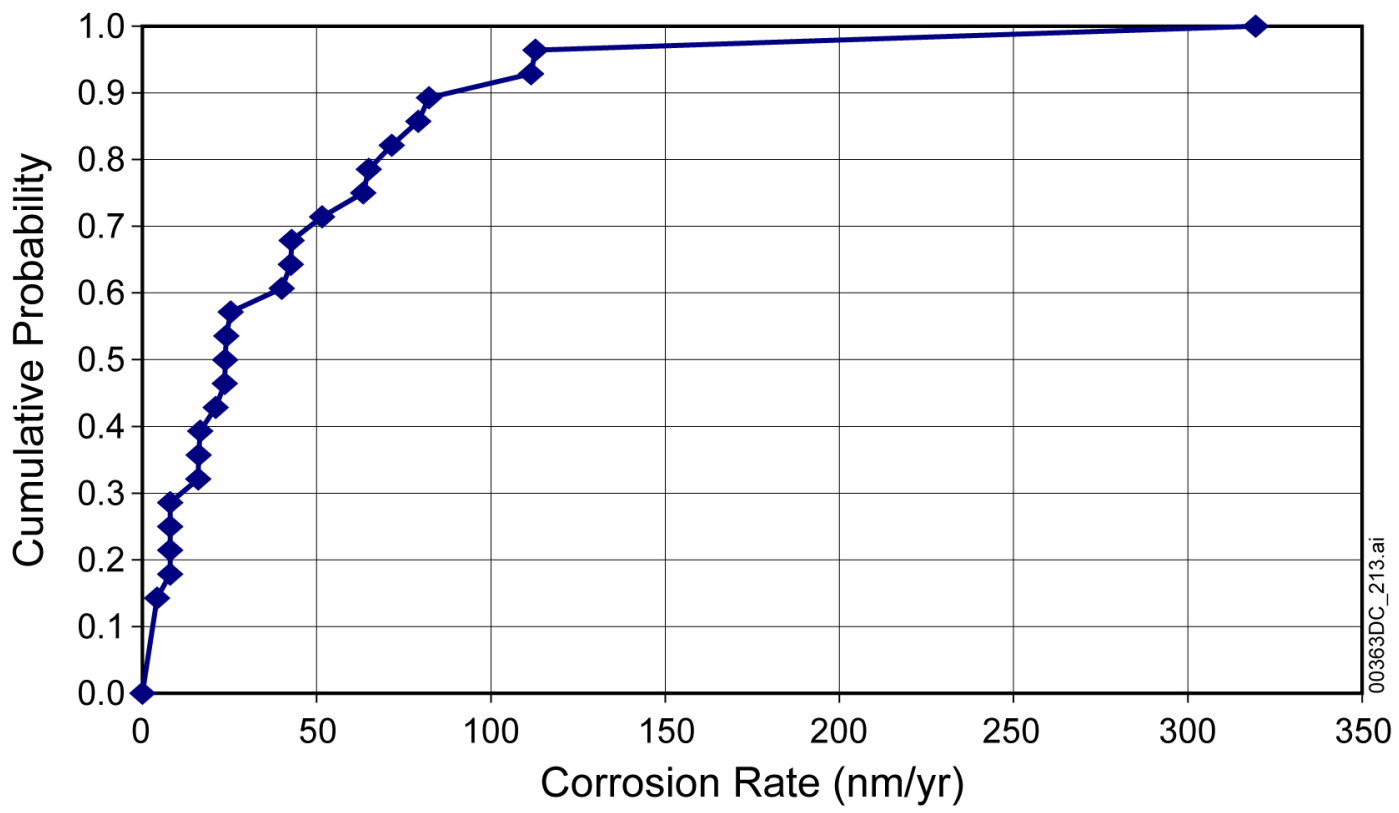

Source: DTN: LL990610605924.079 [DIRS 104994] S99359_035, S99359_036.

Output DTN: MO0408MWDGLCDS.002.

Figure 13. Distribution of General Corrosion Rates of Ti Grade 16: LTCTF 1-Year Weight-Loss and Crevice Samples (Negative Rates Removed) 
These general corrosion rates are considered to be entirely due to uncertainty (i.e., a single general corrosion rate is sampled from each distribution and applied to all drip shields in the repository). The general corrosion rate sampled for the outside surface of the drip shield is independent of the general corrosion rate sampled for the inner surface of the drip shield because the environments above and below the drip shield are not significantly correlated.

From Figure 12, it can be seen that for the nondripping water case the rate at the $50^{\text {th }}$ percentile is approximately $18 \mathrm{~nm} / \mathrm{yr}$, the rate at the $90^{\text {th }}$ percentile is approximately $75 \mathrm{~nm} / \mathrm{yr}$, and the maximum rate is less than $120 \mathrm{~nm} / \mathrm{yr}$. From Figure 13, it can be seen that for the dripping water case the rate at the $50^{\text {th }}$ percentile is approximately $25 \mathrm{~nm} / \mathrm{yr}$, the rate at the $90^{\text {th }}$ percentile is approximately $100 \mathrm{~nm} / \mathrm{yr}$, and the maximum rate is less than $320 \mathrm{~nm} / \mathrm{yr}$.

Table 16. Cumulative Distribution Function for General Corrosion Rates of Titanium Grade 16: LTCTF 1-Year Weight-Loss Samples (No Negative Rates)

\begin{tabular}{|c|c|c|}
\hline Sample & $\begin{array}{c}\text { Rate } \\
(\mathbf{m m} / \mathbf{y r})\end{array}$ & $\begin{array}{c}\text { Cumulative Distribution } \\
\text { Function }\end{array}$ \\
\hline 1 & $0.00000000 \mathrm{E}+00$ & 0.0000 \\
\hline 2 & $7.90540100 \mathrm{E}-06$ & 0.2500 \\
\hline 3 & $7.90899600 \mathrm{E}-06$ & 0.3125 \\
\hline 4 & $7.91733600 \mathrm{E}-06$ & 0.3750 \\
\hline 5 & $7.99205500 \mathrm{E}-06$ & 0.4375 \\
\hline 6 & $1.59679640 \mathrm{E}-05$ & 0.5000 \\
\hline 7 & $1.60740360 \mathrm{E}-05$ & 0.5625 \\
\hline 8 & $2.35658240 \mathrm{E}-05$ & 0.6250 \\
\hline 9 & $2.37302160 \mathrm{E}-05$ & 0.6875 \\
\hline 10 & $2.40329080 \mathrm{E}-05$ & 0.7500 \\
\hline 11 & $3.99976910 \mathrm{E}-05$ & 0.8125 \\
\hline 12 & $7.14961090 \mathrm{E}-05$ & 0.8750 \\
\hline 13 & $7.91641200 \mathrm{E}-05$ & 0.9375 \\
\hline 14 & $1.12788228 \mathrm{E}-04$ & 1.0000 \\
\hline
\end{tabular}

Source DTN: LL990610605924.079 [DIRS 104994] S99359_036.

Output DTN: MO0408MWDGLCDS.002. 
Table 17. Cumulative Distribution Function for General Corrosion Rates of Ti Grade 16: LTCTF 1-Year Weight-Loss and Crevice Samples (No Negative Rates)

\begin{tabular}{|c|c|c|}
\hline Sample & $\begin{array}{c}\text { Rate } \\
(\mathrm{mm} / \mathrm{yr})\end{array}$ & $\begin{array}{c}\text { Cumulative Distribution } \\
\text { Function }\end{array}$ \\
\hline 1 & $0.00000000 \mathrm{E}+00$ & $0.00000000 \mathrm{E}+00$ \\
\hline 2 & 4.18430800E-06 & 1.42857143E-01 \\
\hline 3 & 7.90540100E-06 & $1.78571429 \mathrm{E}-01$ \\
\hline 4 & 7.90899600E-06 & 2.14285714E-01 \\
\hline 5 & 7.91733600E-06 & $2.50000000 \mathrm{E}-01$ \\
\hline 6 & 7.99205500E-06 & $2.85714286 \mathrm{E}-01$ \\
\hline 7 & 1.59679640E-05 & $3.21428571 \mathrm{E}-01$ \\
\hline 8 & 1.60740360E-05 & 3.57142857E-01 \\
\hline 9 & 1.65389750E-05 & 3.92857143E-01 \\
\hline 10 & 2.10450870E-05 & 4.28571429E-01 \\
\hline 11 & 2.35658240E-05 & 4.64285714E-01 \\
\hline 12 & 2.37302160E-05 & $5.00000000 \mathrm{E}-01$ \\
\hline 13 & 2.40329080E-05 & $5.35714286 \mathrm{E}-01$ \\
\hline 14 & 2.52784890E-05 & $5.71428571 \mathrm{E}-01$ \\
\hline 15 & 3.99976910E-05 & $6.07142857 \mathrm{E}-01$ \\
\hline 16 & 4.26207080E-05 & $6.42857143 \mathrm{E}-01$ \\
\hline 17 & 4.28647310E-05 & 6.78571429E-01 \\
\hline 18 & 5.15303020E-05 & 7.14285714E-01 \\
\hline 19 & 6.33683700E-05 & 7.50000000E-01 \\
\hline 20 & 6.49668830E-05 & 7.85714286E-01 \\
\hline 21 & 7.14961090E-05 & 8.21428571E-01 \\
\hline 22 & 7.91641200E-05 & 8.57142857E-01 \\
\hline 23 & 8.22028960E-05 & 8.92857143E-01 \\
\hline 24 & 1.11563286E-04 & 9.28571429E-01 \\
\hline 25 & 1.12788228E-04 & $9.64285714 \mathrm{E}-01$ \\
\hline 26 & 3.19409704E-04 & $1.00000000 \mathrm{E}+00$ \\
\hline
\end{tabular}

Source: DTN: LL990610605924.079 [DIRS 104994] S99359_035 and S99359_036.

Output DTN: MO0408MWDGLCDS.002.

\subsubsection{Alternative Conceptual Models for the Representation of Drip Shield General Corrosion Rates}

The composite general corrosion model uses cumulative distribution functions to select values for the general corrosion rate. The cumulative distribution functions were obtained from the titanium corrosion testing at the LTCTF. The testing performed to support this model involved exposure of titanium alloy coupons for up to five years. The distribution of these rates is then considered in the model to be maintained over the regulatory period. In this way, the general corrosion model is based on the conservative assumption (Assumptions 5.3 and 5.4) that the corrosion rates will not decrease with time.

1. An alternative conceptual model is to apply a parabolic model (such as the one used for the dry oxidation model) to the cumulative distribution function. The implicit 
postulation behind such a model is that the basic mechanism for oxide layer growth under aqueous conditions would be essentially the same as for dry oxidation conditions, and that credit in the model could be taken for the inhibiting effect of the increasing oxide layer thickness on diffusion of oxidizing species to the underlying metal. This model is less conservative than the primary model discussed herein.

The primary difficulty with this model is that the parabolic form of the dry oxidation model (or the logarithmic form of the dry oxidation alternative conceptual model) used dry oxidation data obtained at high temperature (i.e., using exposure temperature as an accelerating factor for the oxidation rate per ASTM C 1174-97 ([DIRS 105725])), whereas the LTCTF data did not use temperature as an accelerating factor (the LTCTF data did use concentration as an accelerating factor in that the LTCTF testing solutions are highly concentrated (Table 7)). The formulation of explicit parabolic temperature dependence for the general corrosion rate is not be possible with currently available laboratory data. This model is not recommended for further consideration because it is less conservative than the primary general corrosion model and is not fully justifiable using the currently available LTCTF and literature data.

2. Another alternative conceptual model for the general corrosion of the drip shield is to regard the primary model cumulative distribution function as resulting from a consistent experimental bias in the measurement of the weight loss on the LTCTF titanium alloy samples. These measurements regularly resulted in "negative" corrosion rates, a physically impossible situation. If the weight-loss measurements were assumed to be consistently biased in a way that the cumulative distribution functions shown in Figure 10 and Figure 11 could be "shifted," it will add approximately $100 \mathrm{~nm} / \mathrm{yr}$ to each cumulative distribution function value. The few measured values remaining negative could be treated as experimental outliers. This model is more conservative than the primary model, and allows for an easier explanation of the way in which the experimental data were used. As with the primary model cumulative distribution function, however, it would not reflect the physically reasonable expectation that corrosion rates would in reality decrease in time as the (protective) oxide layer builds up. Furthermore, as discussed below, literature data do not support the use of such high rates to characterize the general corrosion of titanium alloys.

3. A third alternative conceptual model for the corrosion of the drip shield is to take the general corrosion penetration to be zero over the repository regulatory period of 10,000 years. This alternative conceptual model could be justified by invoking the following factors:

- Handbook compilations of the corrosion behavior such as those in ASM Handbook (Schutz and Thomas 1987 [DIRS 112147], pp. 705 and 706) show corrosion values of titanium as "nil" or micrometers or less per year for most exposure conditions. The only exposure conditions having general corrosion rates of tens to hundreds of micrometers per year were extremely concentrated, reducing, acidic media at high temperatures. These circumstances will not exist under repository conditions. 
- The titanium alloy corrosion layer on the drip shield forms slowly at moderately high temperatures. The corrosion layer formed on titanium in this manner is extremely protective, tenacious, and adherent to the base metal (Fukuzuka et al. 1980 [DIRS 160395]; Ogden 1960 [DIRS 160556], pp. 661 and 692), and may thereby provide some structural strength. This tenacity was demonstrated in the method of weight-loss measurement used to develop the corrosion rate data. Extremely acidic conditions were used to strip the corrosion product from the titanium base metal to enable measurement of the coupon weight losses.

- If the titanium alloy corrosion kinetics has logarithmic or parabolic reaction kinetics similar to other corrosion-resistant materials such as nickel alloys, the corrosion rate would be expected to level off after a short time relative to the regulatory period and result in a stable corrosion layer that stops growing (Section 6.3) (Fukuzuka 1980 [DIRS 160395]).

Because these factors indicate the corrosion rate under repository conditions will produce a few millimeters corrosion penetration depth at the outermost surface of the drip shield in 10,000 years and the drip shield thickness is $15 \mathrm{~mm}$, the corrosion layer will not affect the performance of the drip shield and need not be quantified in further detail.

\subsubsection{Influence of Fluoride on the Corrosion of Titanium}

Review of the titanium corrosion literature indicates that the presence of dissolved fluoride in a range of brine solutions can, under certain conditions, significantly increase the general corrosion rate of titanium alloys including $\mathrm{Ti}$ Grade 7 . The enhanced susceptibility of titanium to corrosion in environments containing fluoride and particularly in acidic fluoride-containing solutions is generally attributed to the formation of complexes such as $\mathrm{TiF}_{6}{ }^{2-}$ and $\mathrm{TiF}_{6}{ }^{3-}$, which are soluble in electrolyte solutions. The aggressiveness of fluoride in acidic solutions is well characterized (Mandry and Rosenblatt 1972 [DIRS 159747]). Using Auger spectroscopy measurements, Wilhelmsen and Grande (1987 [DIRS 151190]) confirmed the direct incorporation of $\mathrm{F}^{-}$into the passive film leading to enhanced dissolution only occurred under acidic conditions. Also, measurements of corrosion potential (Nakagawa et al. 1999 [DIRS 159828]) indicate that a combination of a significant $\mathrm{F}^{-}$concentration $(>500 \mu \mathrm{g} / \mathrm{g})$ and a low $\mathrm{pH}$ is critical for the loss of passivity. In artificial saliva (at $37^{\circ} \mathrm{C}$ ) passivity was maintained in solutions containing 500 to $1,000 \mathrm{ppm} \mathrm{F}^{-}$providing the $\mathrm{pH}$ was above 4.3. For lower $\mathrm{pH}$ values the corrosion potential fell from the range 0 to $-500 \mathrm{mV}(v s \mathrm{SCE})$ to $-850 \mathrm{mV}$. The latter potential is a clear indication that aggressive active corrosion conditions had been established. Polarization curves confirmed the introduction of an active region at these low $\mathrm{pH}$ values. It was generally concluded that the formation of $\mathrm{HF}$ at low $\mathrm{pH}$ was the key step causing film dissolution and the establishment of active conditions.

The importance of the passive film conditions in resisting corrosion in neutral fluoridecontaining solutions was also demonstrated in the studies by Brossia et al. (2001 [DIRS 159836]) and Lorenzo de Mele and Cortizo (2000 [DIRS 159833]). The latter authors conducted measurements in synthetic saliva $\left(\mathrm{pH}=6.5\right.$, containing $0.2 \mathrm{~mol} / \mathrm{L}$ of $\left.\mathrm{F}^{-}\right)$, which showed that if $\mathrm{F}^{-}$ 
was added shortly after electrode immersion (while the oxide film was still growing, and hence defective), the corrosion potential fell rapidly (indicating attack of the oxide). However, if the oxide were allowed to grow for four days (a sufficient period for the growth of a coherent oxide with a low defect concentration), then addition of the same amount of $\mathrm{F}^{-}$had no observable effect over the subsequent two days of exposure. They concluded that the susceptibility of titanium to corrosion in $\mathrm{F}^{-}$was associated with defects and flaws in the oxide.

In the case of the drip shield application in the repository, there is an early period of dry air exposure. During this time, the drip shield is subjected to a long period of thermal oxidation prior to aqueous exposure. Choi et al. (1992 [DIRS 159753]) have shown that thermal treatments not only thicken the oxide film but also significantly decrease the defect density in the film compared to films grown in aqueous environments. According to Hurlen and Hornkøl (1991 [DIRS 159814]), the kinetics of passive corrosion of titanium in neutral solutions is controlled by the migration of the predominant defect in the oxide (an oxygen vacancy, $\mathrm{O}_{\mathrm{V}}{ }^{\mathrm{II}}$ ) across the film. The increase in thickness and improvement in film properties would lead to a significant decrease in susceptibility to fluoride-induced film breakdown and an independence of the passive corrosion rate on $\mathrm{F}^{-}$concentration.

Thus, in reviewing the relevant literature on the effects of fluoride on enhanced general corrosion, it is important to separate the studies into those using relatively freshly polished specimens and those where the specimens were prefilmed either through longer-term ambient air exposure or through higher temperature exposures prior to corrosion testing.

\subsubsection{Summary of Studies Using Freshly Polished Specimens}

The polarization behavior of Ti Grade 7 in $1 \mathrm{M} \mathrm{NaCl}, 1 \mathrm{M} \mathrm{NaF}$, and $1 \mathrm{M} \mathrm{NaF}+1 \mathrm{M} \mathrm{NaCl}$ at $95^{\circ} \mathrm{C}$ has been studied by Brossia and Cragnolino (2000 [DIRS 162445], 2001 [DIRS 162420]; 2001 [DIRS 159840]) and Brossia et al. (2001 [DIRS 159836]). The effects of fluoride were found to decrease the $E_{\text {corr }}$ and result in a pseudo active/passive transition with a subsequent potential independent current region with current density considerably higher than those typically encountered during passive dissolution (as high as $10^{-3}$ to $10^{-1}$, as compared to $\sim 10^{-6} \mathrm{~A} / \mathrm{cm}^{2}$ ). Posttest examination of the specimens revealed that the corrosion was general in nature. The authors further performed potentiostatic tests (Brossia and Cragnolino 2001 [DIRS 162420]) and found the effect of fluoride became noted when the fluoride concentration reached about $5 \times 10^{-4} \mathrm{M}$. The effect of fluoride saturated at about $10^{-2} \mathrm{M}$ leading to a plateau current density of $4 \times 10^{-5} \mathrm{~A} / \mathrm{cm}^{2}$. The effect of other anions, nitrate and sulfate, were also examined. The authors concluded that at least at short times, the deleterious effects of fluoride overwhelm any beneficial effects from the presence of either nitrate or sulfate (Brossia and Cragnolino 2001 [DIRS 162420]). By comparing the corrosion behavior of a commercially pure titanium (non-palladium-bearing) in the presence of fluoride, the same authors concluded that the addition of palladium to titanium did not substantially improve the performance of titanium in the presence of fluoride (Brossia and Cragnolino 2001 [DIRS 159840]).

Pulvirenti et al. (2002 [DIRS 159841]) tested Ti Grade 7 in unchanged and modified J-13 well

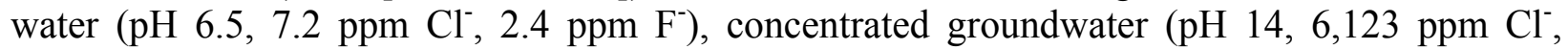
$1,550 \mathrm{ppm} \mathrm{F}^{-}$) and near-dryout groundwater $\left(\mathrm{pH} \mathrm{14,} \mathrm{48,077} \mathrm{ppm} \mathrm{Cl}^{-}, 14,423 \mathrm{ppm} \mathrm{F}^{-}\right)$. Starting with these three base compositions, they varied the chloride and fluoride contents and $\mathrm{pH}$ and 
tested disc and U-bend type specimens over a range of temperatures from $95^{\circ} \mathrm{C}$ to $250^{\circ} \mathrm{C}$. Also, for the specimens tested at $250^{\circ} \mathrm{C}$, in addition to the so-called simulated concentrated groundwater, other test solution anions were replaced with either chloride or fluoride ions. In a number of environment/temperature/ $\mathrm{pH}$ conditions, the authors found a deleterious effect of fluoride ion on general corrosion rates and under some conditions on pitting resistance.

More recently, Pulvirenti et al. (2003 [DIRS 162574]) further studied the effects of chloride:fluoride ratio, nitrate and sulfate on the deleterious effect of fluoride. It was reported that the most severe local attack on Ti Grade 7 occurred at approximately $120^{\circ} \mathrm{C}$ and at neutral $\mathrm{pH}$ in presence of fluoride with an excess of chloride. While the 30-day immersion test in near-neutral environments at $110^{\circ} \mathrm{C}$ showed no significant corrosion at chloride:fluoride ratios up to $1.13: 1$, the electrochemical studies detected a narrowing of the passive region at much lower chloride:fluoride ratio (1:1 by mole). The most severe corrosion occurred at the $\mathrm{pH}$ around neutral. Sulfate slowed, but did not inhibit localized corrosion of Ti Grade 7, while addition of nitrate acted effectively in inhibiting localized corrosion of Ti Grade 7. The increase in chloride:fluoride ratio slightly increased the $\mathrm{E}_{\text {corr }}$ but significantly decreased the $\mathrm{E}_{\text {repass. }}$ The passive region disappeared when the chloride:fluoride ratio reached about 1.1:1 where the short-term immersion tests failed to detect the effect of chloride:fluoride ratio.

To summarize the deleterious effects of fluoride on corrosion resistance of unprefilmed Ti Grade 7 reported by Pulvirenti et al. (2002 [DIRS 159841]; 2003 [DIRS 162574]) and Brossia et al. (2001 [DIRS 159836]), obviously enhanced corrosion of Ti Grade 7 was only observed in:

- Simple solutions containing only $\mathrm{NaCl}$ and $\mathrm{NaF}$ (Brossia and Cragnolino 2000 [DIRS 162445]; Brossia et al. 2001 [DIRS 159836])

- Near-dryout groundwater with the $\mathrm{pH}$ adjusted to below 4 (Pulvirenti et al. 2002 [DIRS 159841])

- Groundwater doped with chloride or fluoride without increasing the concentration of other species contained in the groundwater (Pulvirenti et al. 2002 [DIRS 159841])

- Concentrated groundwater with fluoride-only (i.e., replacing all other anions with $\mathrm{F}^{-}$) (Pulvirenti et al. 2002 [DIRS 159841])

- When electrochemical polarization method was used (Pulvirenti et al. 2003 [DIRS 162574]), and the test specimens were freshly polished prior to the test.

Furthermore:

- Doping halides in groundwater without increasing the concentration of other species also resulted in extensive pitting (Pulvirenti et al. 2002 [DIRS 159841]). 
On the other hand:

- In $105^{\circ} \mathrm{C}$ unmodified near-dryout groundwater $(48,000 \mathrm{ppm}$ chloride and $14,400 \mathrm{ppm}$ fluoride) with pHs adjusted to near neutral, corrosion of Ti Grade 7 was negligible (Pulvirenti et al. 2002 [DIRS 159841])

- In unmodified concentrated groundwater (6,123 ppm chloride and 3,097 ppm fluoride), the weight changes of Ti Grade 7 were negligible (although the authors reported the observation of micro-pits on the posttest specimens).

\subsubsection{Summary of Studies Using Air Prefilmed Specimens}

As described earlier, the importance of the condition of the passive film in resisting corrosion in neutral fluoride-containing solutions is demonstrated by Brossia et al. (2001 [DIRS 159836]) and Lorenzo de Mele and Cortizo (2000 [DIRS 159833]). They found that if the $\mathrm{F}^{-}$was added shortly after electrode immersion while the oxide film was still growing and, hence, defective, then the corrosion potential fell rapidly (indicating attack of the oxide). However, if the oxide was allowed to grow for four days, a sufficient period for the growth of a coherent oxide with a low defect concentration, then the subsequent addition of this concentration of $\mathrm{F}^{-}$had no observable effect over the subsequent two days of exposure.

Consistent with the observations on the corrosion resistance benefits from the formation of a stable passive prefilm, excellent corrosion behavior has been observed on both uncreviced and creviced Ti Grades 16 and 7 specimens tested in the LTCTF as described previously. These LTCTF specimens were preexposed for several months to ambient air after polishing at the specimen fabricator shop and before placement in the corrosion tanks. No deleterious effects of fluoride on corrosion resistance of these titanium alloys were observed in any of these tests, including tests in the so-called SCW environment $(\sim 1,000 \times$ ionic concentration of $\mathrm{J}-13$ well water with $\sim 1,619 \mathrm{mg} / \mathrm{L} \mathrm{F}^{-}, 5,047 \mathrm{mg} / \mathrm{L} \mathrm{Cl}^{-}, 5,482 \mathrm{mg} / \mathrm{L} \mathrm{NO}_{3}{ }^{-}, 13,209 \mathrm{mg} / \mathrm{L} \mathrm{SO}_{4}{ }^{2-}$, and 27 to $49 \mathrm{mg} / \mathrm{L} \mathrm{Si}$ at a $\mathrm{pH}$ of $\sim 8$ to 10 ).

Further insight into the role of a stable, low defect density passive film on titanium alloys can be obtained from studies of titanium and its alloys associated with dental implant applications in solutions containing fluoride (Nakagawa et al. 2001 [DIRS 159832]; Lorenzo de Mele and Cortizo 2000 [DIRS 159833]) because dental gels and rinses can contain between 1,000 and $10,000 \mu \mathrm{g} / \mathrm{g}(\mathrm{ppm})$ of fluoride with the $\mathrm{pH}$ between 3.5 and neutral. While a more acidic condition is required to induce the passive-to-active transition on Ti Grade 7 ( $\mathrm{pH}<3.7$ compared to 4.2 for Ti Grade 2), destruction of passivity can still be achieved for $\left[\mathrm{F}^{-}\right] \geq 500 \mathrm{ppm}$. However, the corrosion potential recovers, after its initial drop to the active region, over a period of $\sim 10$ minutes to a value of $\sim-400 \mathrm{mV}$, suggesting a partial reestablishment of passive conditions. Based on these studies, Nakagawa et al. (1999 [DIRS 159828]) developed the following linear relationship for the boundary between passive and active conditions:

$$
p H=1.49 \log \left[F^{-}\right](\text {in } p p m)+0.422
$$

According to this relationship, an active corrosion condition will not be achieved in groundwater with a neutral $\mathrm{pH}$, unless the $\mathrm{F}^{-}$concentration reaches approximately $20,000 \mathrm{ppm}$. The predicted 
fluoride concentration in waters from dust deliquescence and in seepage waters is dependent on the brine type predicted to form (BSC 2004 [DIRS 169860], Figures 6.13-15 and 6.13-27). In a calcium chloride-type brine, fluoride concentrations are predicted to be nominally $3 \times 10^{-4}$ to $10^{-5} \mathrm{~mol} / \mathrm{kg}$ with $\mathrm{pH}$ range of 3.5 to 6.5 . The fluoride concentration is low due to its solubility control by insoluble $\mathrm{CaF}_{2}$. In a sulfate-type brine, fluoride concentrations are predicted to be below $6 \times 10^{-3} \mathrm{~mol} / \mathrm{kg}$ with $\mathrm{pH}$ range 6.5 to 8 . In a carbonate-type brine, fluoride concentrations are predicted to be between $10^{-2}$ and $1 \mathrm{~mol} / \mathrm{kg}$ with $\mathrm{pH}$ range of 8.5 to 10 . The fluoride concentrations are predicted to be highest in the carbonate type brine, which requires the highest fluoride concentrations in order to induce active corrosion. For the predicted repository $\mathrm{pH}$ and fluoride levels, the $\mathrm{pH}$ levels are well above those that would induce active corrosion according to Equation 36.

\subsubsection{Effect of Ions other than Chloride and Fluoride}

In addition to the described benefit of forming a stable, low-defect density passive film on titanium before immersion in fluoride-containing brines, there can be a beneficial effect from other ions in the brine solution. One attempt to evaluate this effect was the measurements of Brossia et al. (2001 [DIRS 159836]) in $1 \mathrm{~mol} / \mathrm{L} \mathrm{NaCl}$ at $95^{\circ} \mathrm{C}$ under electrochemical conditions. These measurements showed a major increase in "passive" current densities for $\mathrm{F}^{\text {" concentrations }}$ $\geq \sim 10 \mathrm{mg} / \mathrm{L}$. Because these measurements were performed on freshly polished specimens the currents measured almost certainly reflect partially active conditions, because coherent, defectfree oxides would not have grown before polarization. These authors found that the presence of other anions, $\left(\mathrm{NO}_{3}{ }^{-}, \mathrm{SO}_{4}{ }^{2-}, \mathrm{Cl}^{-}\right)$exerted no influence on the current densities. This would not be surprising under active conditions since $\mathrm{F}^{-}$is far superior in its ability to complex dissolved titanium $\left(\mathrm{TiF}_{6}{ }^{2-}, \mathrm{TiF}_{6}{ }^{3-}\right)$ than the other anions. However, under passive conditions passivity is maintained even in the presence of $\mathrm{F}^{-}$when much larger concentrations of other anions are present. This is true because the mechanism for film breakdown in $\mathrm{F}^{-}$solutions is the same as that for chloride and the anions compete for absorption on defect sites on the passive surface of titanium (see above). Thus, it is not surprising to find the absence of a measurable influence of $\mathrm{F}^{-}$on the corrosion rates of titanium alloys in the LTCTF SCW tests containing $\sim 1,619 \mathrm{mg} / \mathrm{L} \mathrm{F}^{-}$, $5,047 \mathrm{mg} / \mathrm{L} \mathrm{Cl}^{-}, 5,482 \mathrm{mg} / \mathrm{L} \mathrm{NO}_{3}{ }^{-}, 13,209 \mathrm{mg} / \mathrm{L} \mathrm{SO}_{4}{ }^{2-}$, and 27 to $49 \mathrm{mg} / \mathrm{L} \mathrm{Si}$.

The influence of environmental factors, such as the concentration of $\mathrm{Cl}^{-}$and the availability of silicate, in suppressing titanium corrosion in the presence of $\mathrm{F}^{-}$, has been demonstrated for flue gas scrubber applications (Schutz and Grauman 1986 [DIRS 151165]). The environments tested were much hotter and more concentrated than those used in testing for dental applications, and hence more representative of repository conditions. $\mathrm{Ca}$ and $\mathrm{MgCl}_{2}$ concentrations were between 0.1 and $12.7 \%$ (i.e., $\mathrm{Cl}^{-}$concentrations up to $15,700 \mu \mathrm{g} / \mathrm{g}$ and with $\mathrm{SO}_{4}{ }^{2-}$ concentrations in the range 9,000 to $26,000 \mu \mathrm{g} / \mathrm{g}$ ), while the temperature was up to $177^{\circ} \mathrm{C}$, and the $\mathrm{pH}$ down to $\sim 1$, with $\mathrm{F}^{-}$in the range 0 to $12,000 \mu \mathrm{g} / \mathrm{g}$.

The influence of $\mathrm{F}^{-}$was much more muted than in dental applications. As generally observed, the passivity of Ti Grade 2 was lost for $\mathrm{pH} \leq 3$ when $\mathrm{F}^{-}$was present. For Ti Grade 12, this threshold for the loss of passivity was $<1.5$. An interesting synergism was observed between $\mathrm{Cl}^{-}$ and $\mathrm{F}^{-}$. The influence of fluoride decreases as the concentration of chloride increased. This was attributed to the common ion effect with $\mathrm{Ca}^{2+}$ leading to the precipitation of $\mathrm{CaF}_{2}$. The presence of fly ash eliminated any influence of the $\mathrm{F}^{-}$ion, an effect attributed to the introduction of $\mathrm{Fe}^{3+}$, a 
known inhibitor of titanium corrosion, and to the presence of $\mathrm{SiO}_{2}$, which would complex $\mathrm{F}^{-}$, thereby reducing its free concentration. At low $\mathrm{F}^{-}$concentration $(100 \mu \mathrm{g} / \mathrm{g})$, Schutz and Grauman (1986 [DIRS 151165]) found no influence of $\mathrm{F}^{-}$on electrochemically-determined repassivation potentials for Ti Grades 2,12 , and 7 at $82^{\circ} \mathrm{C}$ for the $\mathrm{pH}$ values as low as 1.5. Values remained greater than $7 \mathrm{~V}$. Crevice corrosion tests showed no susceptibility except at $177^{\circ} \mathrm{C}$, and for Ti Grade 7 passivity was maintained even at this temperature.

These results clearly suggest that environmental factors are very important in controlling titanium corrosion even at high temperatures and in very saline environments. The high salinity and the presence of silica in the Yucca Mountain environment will suppress the influence of $\mathrm{F}^{-}$ on titanium corrosion in a similar manner to that observed in flue gas scrubber liquors. When high $\mathrm{Ca}^{2+}$ concentrations are present soluble $\mathrm{F}^{-}$concentrations should be reduced to the 0.2 to $0.3 \mathrm{mg} / \mathrm{L}$ level.

One further repository feature that increases the corrosion resistance of the drip shield to fluoride is the initial period of ventilation. During this period the drip shield is subjected to a long period of thermal oxidation prior to aqueous exposure that will result in an increase in thickness and improvement in passive film properties. This will lead to a significant decrease in susceptibility to fluoride induced film breakdown and an independence of the passive corrosion rate on $\mathrm{F}^{-}$ concentration.

Based on the above discussion, it is not surprising that no influence of $\mathrm{F}^{-}$is observed on the passive corrosion rate of titanium specimens in the LTCTF tests. The concentration of $\mathrm{F}^{-}$in these tests is either relegated to a low value by precipitation in a high-calcium environment, or, even when present in substantial amounts $(1,619 \mathrm{mg} / \mathrm{L}$ in $\mathrm{SCW})$, displaced as an absorbed species from the passive surface by the much higher concentration of the other anions present. Additionally, the presence on the specimens of an air-formed film with a low defect concentration formed prior to immersion in the test would both eliminate the possibility of fluoride-induced passivity loss and maintain very low passive corrosion rates.

\subsubsection{Influence of Calcium Chloride on General Corrosion of Ti Grade 7}

There is potential for the development of environments containing high concentrations of calcium chloride ions (BSC 2001 [DIRS 155950], Section 7.3.1). As a result, effects of highly concentrated calcium chloride solutions on the Ti Grade 7 passive film behavior are evaluated in this report. The effect of high concentration of $\mathrm{CaCl}_{2}$ on localized corrosion as well as general corrosion will be evaluated in greater detail in Section 6.6.5. This section evaluates the influence of $\mathrm{CaCl}_{2}$ on general corrosion of Ti Grade 7 based on literature data accepted as established fact.

Table 18 shows the general corrosion rates of Ti Grade 7 in environments containing $\mathrm{Ca}^{2+}, \mathrm{Fe}^{3+}$, and $\mathrm{Mg}^{2+}$ at elevated temperatures. This data, which was obtained by other investigators, shows that the general corrosion rate of Ti Grade 7 in the presence of $\mathrm{CaCl}_{2}$ or $\mathrm{MgCl}_{2}$ is virtually negligible.

It can be reasonably concluded that, under repository exposure conditions, $\mathrm{Ca}^{2+} / \mathrm{Mg}^{2+}$ would not accelerate the general corrosion of titanium alloys (especially Ti Grade 7), even at high concentrations. 
Table 18. General Corrosion Rates of $\mathrm{Ti}$ Grade 7 in Selected Test Media Containing High Concentrations of Chlorides of $\mathrm{Ca}^{2+}, \mathrm{Mg}^{2+}$ and $\mathrm{Fe}^{3+}$ Ions at Elevated Temperature

\begin{tabular}{|l|l|l|}
\hline \multicolumn{1}{|c|}{ Test Medium } & \multicolumn{1}{c|}{ Temperature } & \multicolumn{1}{c|}{ Corrosion Rate, $\mathbf{m m} / \mathbf{y r}$} \\
\hline $62 \% \mathrm{CaCl}_{2}$ & \multicolumn{1}{c|}{$150^{\circ} \mathrm{C}$} & nil \\
\hline $10 \%$ and $30 \% \mathrm{FeCl}_{3}$ & Boiling & nil \\
\hline Saturated $\mathrm{MgCl}_{2}$ & Boiling & nil \\
\hline
\end{tabular}

Source: Schutz and Thomas 1987 [DIRS 112147], pp. 705 and 706.

\subsection{MODELING LOCALIZED CORROSION}

\subsubsection{Threshold Potential for Ti Grade 7}

In the localized corrosion model for the Ti Grade 7 drip shield, localized attack occurs if the open circuit corrosion potential $\left(E_{c o r r}\right)$ exceeds or is equal to the threshold potential for breakdown of the passive film $\left(E_{\text {critical }}\right)$ (Assumption 5.6):

$$
E_{\text {corr }} \geq E_{\text {critical }}
$$

The "threshold potential" is below the potential at which localized corrosion will not initiate and beyond which the passive film breakdown occurs. This potential is called by many different names, such as $E_{p}$ (pitting potential in case of pitting), $E_{\text {crevice }}$ (crevice potential in case of crevice corrosion) or $E_{b}$ (passive film breakdown potential in general). When actually measuring this critical potential from an experimentally obtained polarization curve, it is the investigator's preference to use the potential at which the current density reaches $10 \mu \mathrm{A} / \mathrm{cm}^{2}$ or $20 \mu \mathrm{A} / \mathrm{cm}^{2}$ (denoted as $E_{10}$ or $E_{20}$, respectively) or simply the potential at which the current density suddenly increases.

When the cyclic polarization technique is used, the potential at which the reverse scan crosses the passive region defined by the forward scan in a cyclic polarization test is another important parameter in localized corrosion study. In the literature, this potential is also called the repassivation potential $\left(E_{\text {repass }}\right)$ or protection potential $\left(E_{\text {prot }}\right)$ (Jones 1996 [DIRS 105076], Chapter 7). Corresponding to $E_{p}$ or $E_{\text {crevice, }}$, there is $E_{r p}$ or $E_{r c r e v}$, representing the repassivation potential for pitting and for crevice corrosion, respectively. Similar to measuring $E_{p}$ and $E_{c r e v i c e}$, $E_{r p}$ or $E_{r c r e v}$ can be measured as $E_{r 10}$ or $E_{r 20}$ (i.e., the potentials where the reverse scan current density reaches 10 or $20 \mu \mathrm{A} / \mathrm{cm}^{2}$ ). The repassivation potential (or protection potential) does not indicate the initiation of localized corrosion, but does indicate the repassivation capability of the passive film after the passive film is damaged. Above the repassivation potential and below $E_{b}$ (or $E_{p}, E_{\text {crevice, }} E_{20}$, or $E_{10}$ ), no new localized corrosion will initiate but already initiated pitting (or crevice corrosion) will continue to propagate. Below this potential, no new pits will initiate and already initiated localized corrosion will not propagate (Jones 1996 [DIRS 105076]).

Differences of opinion exist as to the criteria for choosing these threshold potentials and the understanding of the relationships between the threshold potentials and localized initiation. Gruss et al. (1998 [DIRS 100893) used the repassivation potential as the conservative estimate of windows of susceptibility to localized corrosion. Kehler et al. (2001 [DIRS 162231]) suggested that the repassivation potential might represent a lower bound of critical potentials and the 
passive film breakdown potential might represent an upper bound. Methods for experimentally determining these threshold potentials also differ. For instance, Scully et al. (1999 [DIRS 110246]) define the threshold potential for crevice corrosion of Alloy 22 as the point during the scan of electrochemical potential in the forward direction where the current density increases to a level of $10^{-6}$ to $10^{-5} \mathrm{~A} \mathrm{~cm}^{-2}$. Gruss et al. (1998 [DIRS 100893], Table 2) define the repassivation potential as the point where the current density drops to $10^{-6}$ to $10^{-7} \mathrm{~A} \mathrm{~cm}^{-2}$. Depending on the corrosion resistance of the materials, choosing the potentials at which the forward or reverse scan current density reaches 1,10 , or $20 \mu \mathrm{A} / \mathrm{cm}^{2}$ is possible. For instance, repassivation potentials 1, 2, and 3 in Table 19 and Table 20 were, thus, obtained per various criteria.

In this report, the threshold potential is defined as the potential where the current density in a cyclic polarization forward scan significantly increases, rather than the potential at which any specific value of the current density is reached. This potential is denoted as " $E_{\text {critical }}$ " in discussions of Section 6.6.2 and "Potential 1" in Figure 14 through Figure 18, respectively. The term "Potential 1" is used in order to be consistent with the terminology used in the source data (DTN: LL010105512251.011 [DIRS 155623]). Based on the discussions earlier in this section, although Table 19 and Table 20 list the values of these parameters, the concept of repassivation potential is not used in this report. The reasons that the passive film breakdown potential, rather than the repassivation potential, is chosen as the threshold potential for localized corrosion are twofold. First, the repassivation potentials were not always obtained in the cyclic polarization tests performed on titanium alloys. Secondly, when localized corrosion does not occur (i.e., no passive film breakdown) at the potentials as high as several volts, discussion of the repassivation potential does not make physical sense. Without passive film breakdown, discussion of passive film breakdown potential also does not make physical sense. However, because the localized corrosion of the drip shield material is modeled based on the $\Delta E$ criterion, choosing the potential difference between the open-circuit potential and the potential at which the current density starts to increase rapidly is an appropriate approach.

\subsubsection{Cyclic Polarization in Synthetic Concentrated J-13 Well Waters}

The YMP has used the cyclic polarization method to determine the threshold potentials for titanium alloys in various test media relevant to the environments expected in the repository. Relevant test environments include SDW, SCW, and SAW at $30^{\circ} \mathrm{C}, 60^{\circ} \mathrm{C}$, and $90^{\circ} \mathrm{C}$, as well as SSW at $100^{\circ} \mathrm{C}$ and $120^{\circ} \mathrm{C}$. The chemical compositions of these test media (SDW, SCW, SAW, SSW and BSW-12) are detailed in Table 7.

The cyclic polarization measurements have been based on ASTM G 5-94 [DIRS 117479]. The specimen holding time was short $(<24 \mathrm{~h})$ and always the same for all the tests. Representative cyclic polarization curves (DTN: LL010105512251.011 [DIRS 155623], S01009_001) are shown in Figure 14 through Figure 18. The cyclic polarization data for Ti Grade 7 in repositoryrelevant conditions are summarized in Table 19 and Table 20 (DTN: LL010105512251.011 [DIRS 155623], S01009_004).

In general, complete passivity (no passive film breakdown) is shown by these curves between the corrosion potential and the point defined as the "threshold potential" (Threshold Potential 1 in Figure 14 through Figure 18), which is in the potential range where oxygen evolution occurs as 
indicated by a large excursion in anodic current. Threshold Potential 1 (i.e., the potential at which the forward scan current density suddenly increases) is defined as the threshold potential for localized corrosion, $E_{\text {critical }}$, as used in this report. The repassivation potentials 1, 2, and 3 listed in Table 19 and Table 20 are not indicated in Figure 14 through Figure 18 because they are not used in this analysis. The potential difference between $E_{\text {corr }}$ and $E_{\text {critical }}$ is the criterion widely used for localized corrosion initiation.

Other standards such as ASTM G 3-89 [DIRS 138911] and ASTM G 61-86 [DIRS 127897] are also relevant. Deviations from the standard procedures were noted. For example, the procedure calls for sulfuric acid, whereas simulated Yucca Mountain waters are used in YMP tests. Also, unlike it is stated in the standard procedure, the electrolytes used here were fully aerated.

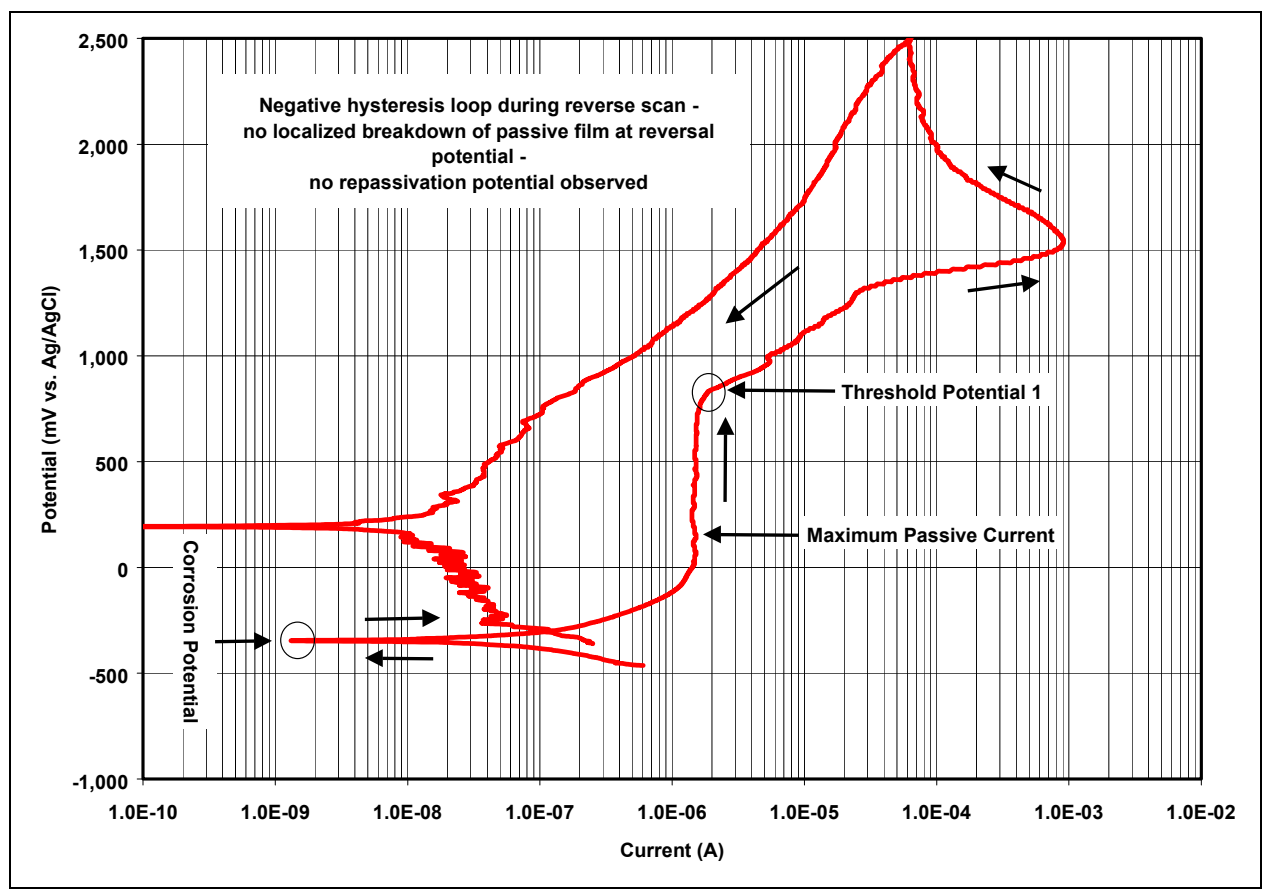

Source: DTN: LL010105512251.011 [DIRS 155623] S01009_001.

Figure 14. Ti Grade 7 in SSW at $120^{\circ} \mathrm{C}$ (NEA031s) 


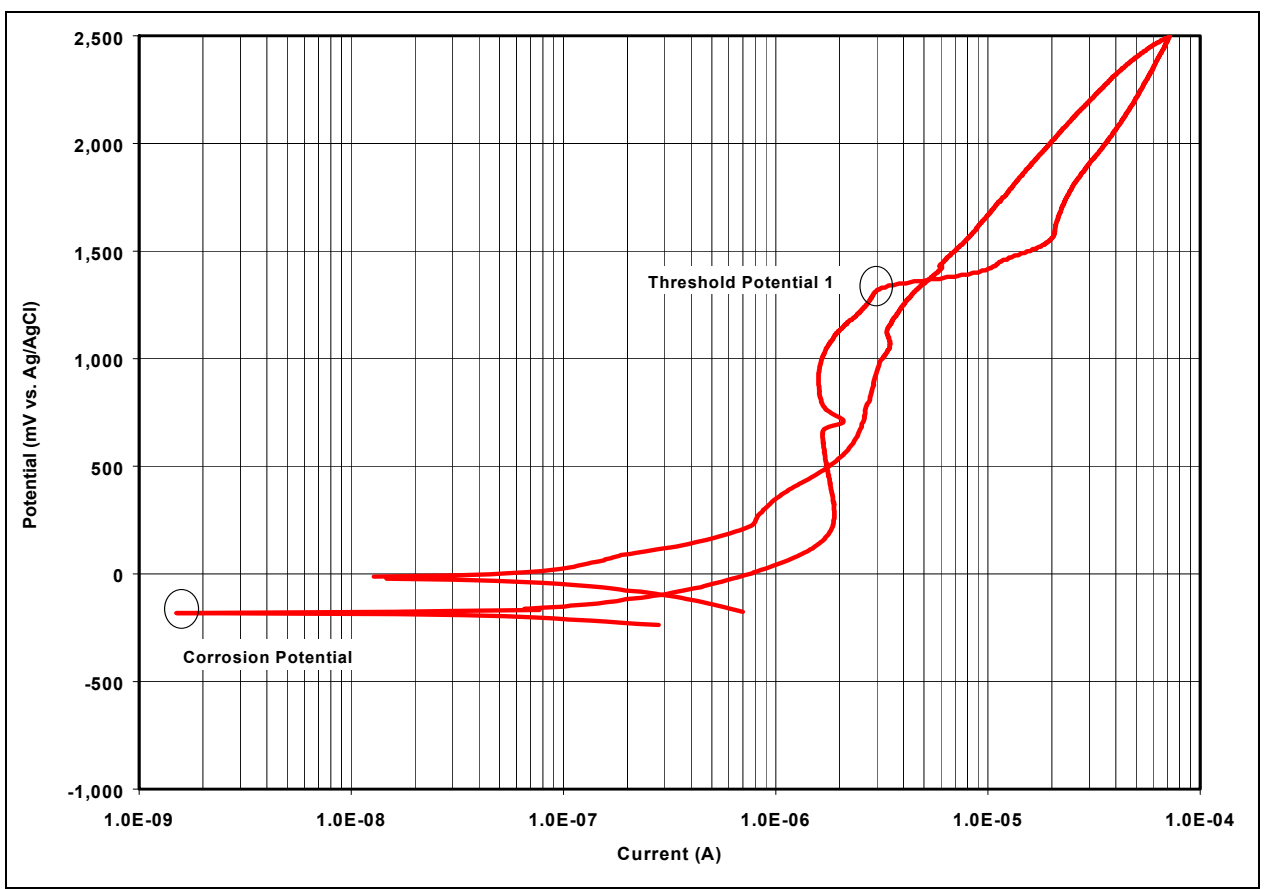

Source: DTN: LL010105512251.011 [DIRS 155623] S01009_001.

Figure 15. Ti Grade 7 in SAW at $90^{\circ} \mathrm{C}$ (NEA025)

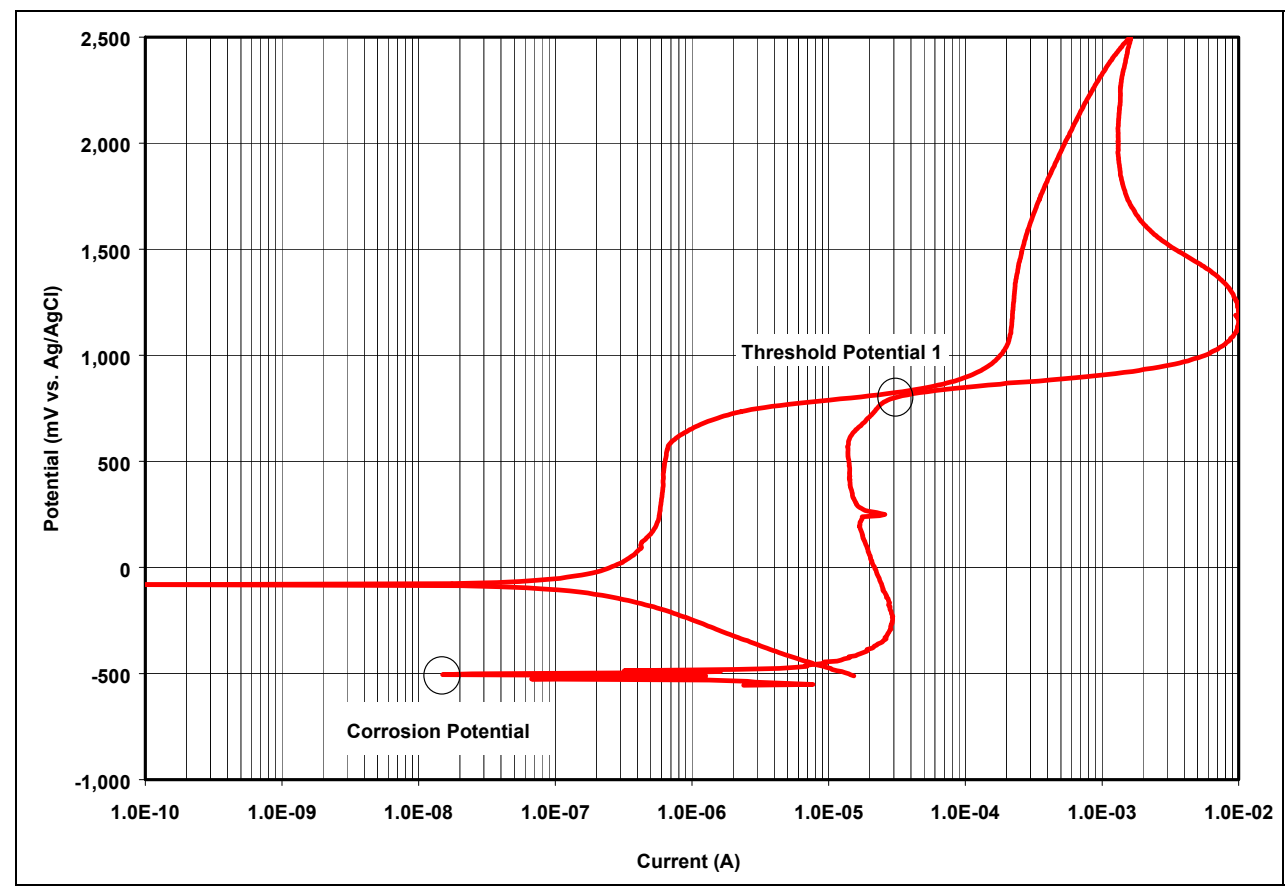

Source: DTN: LL010105512251.011 [DIRS 155623] S01009_001.

Figure 16. Ti Grade 7 in SCW at $90^{\circ} \mathrm{C}$ (NEA029) 


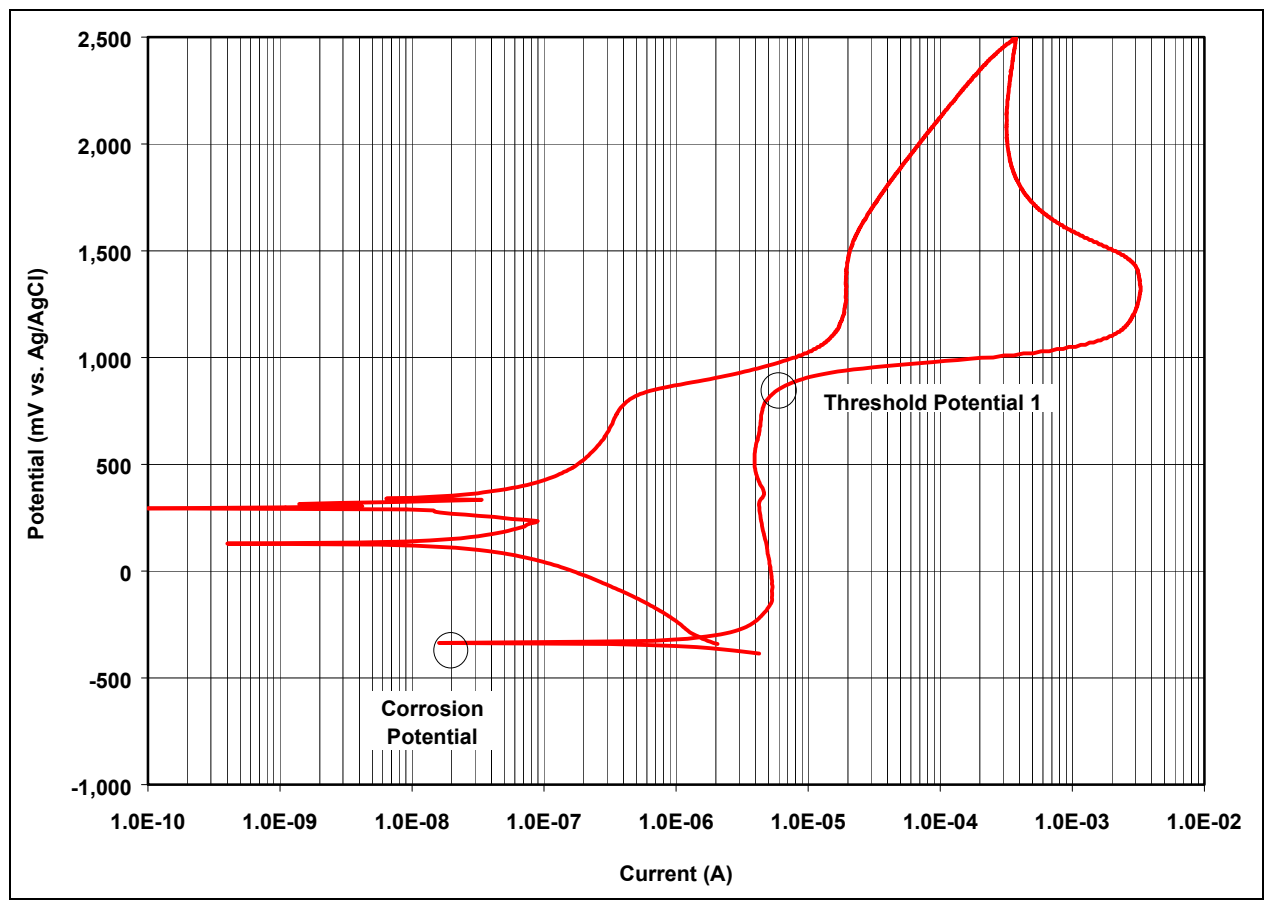

Source: DTN: LL010105512251.011 [DIRS 155623] S01009_001.

Figure 17. Ti Grade 7 in SCW at $60^{\circ} \mathrm{C}$ (NEA019)

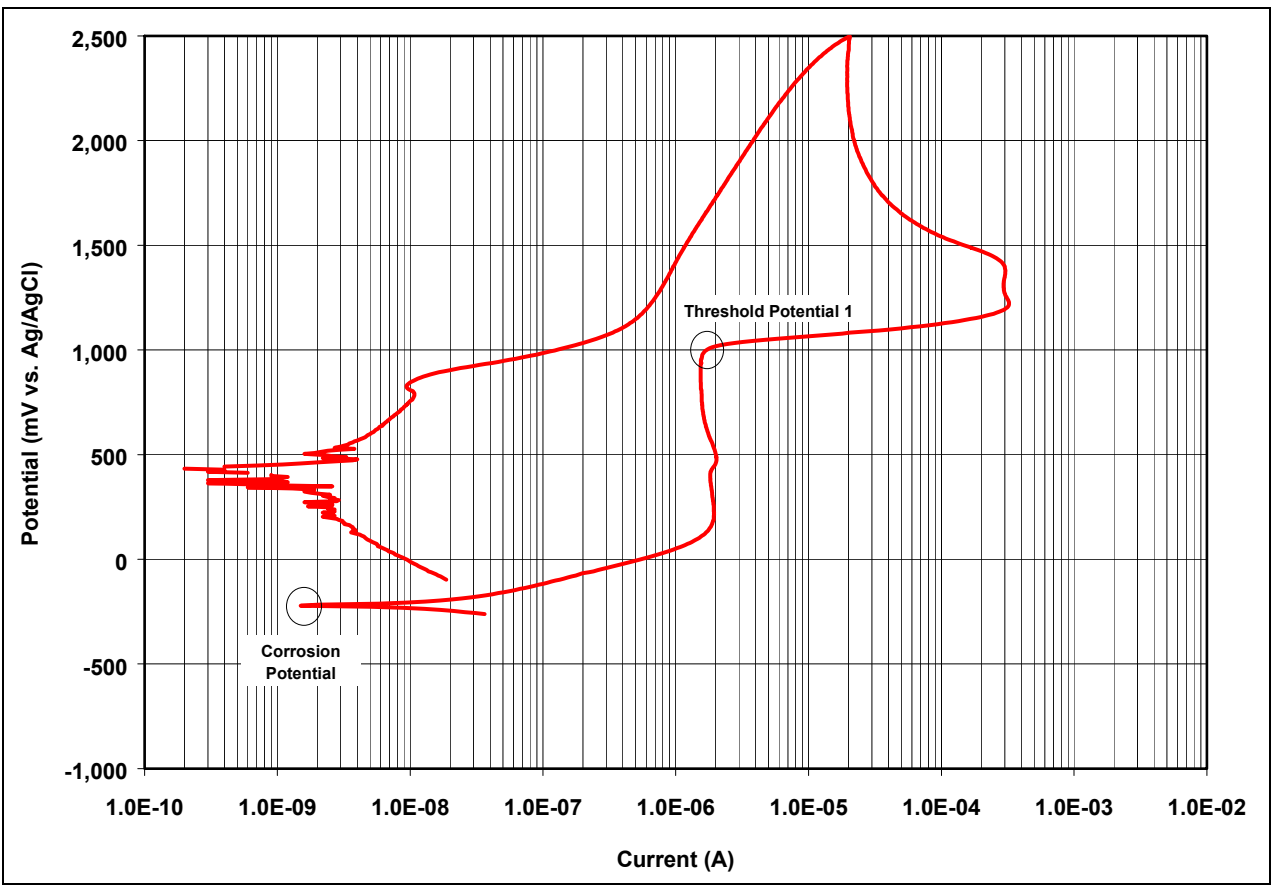

Source: DTN: LL010105512251.011 [DIRS 155623] S01009_001.

Figure 18. Ti Grade 7 in SCW at $30^{\circ} \mathrm{C}$ (NEA003) 
Table 19. Summary of Cyclic Polarization Data for Ti Grade 7 in Repository-Relevant Conditions (SDW and SCW)

\begin{tabular}{|c|c|c|c|c|c|c|c|c|}
\hline Sample ID & Electrolyte & $\begin{array}{c}\text { Temp. } \\
\left({ }^{\circ} \mathrm{C}\right)\end{array}$ & $\begin{array}{c}\text { Corrosion } \\
\text { Potential } \\
(\mathrm{mV})\end{array}$ & $\begin{array}{c}\text { Threshold } \\
\text { Potential } 1 \\
(\mathrm{mV})\end{array}$ & $\begin{array}{c}\text { Passive } \\
\text { Current } \\
\text { (amps) }\end{array}$ & $\begin{array}{c}\text { Repassivation } \\
\text { Potential } 1 \\
\text { (mV) }\end{array}$ & $\begin{array}{c}\text { Repassivation } \\
\text { Potential } 2 \\
\text { (mV) }\end{array}$ & $\begin{array}{c}\text { Repassivation } \\
\text { Potential } 3 \\
\text { (mV) }\end{array}$ \\
\hline NEA002 & SDW & 30 & -145 & 1,070 & 8.71E-07 & no breakdown & no breakdown & no breakdown \\
\hline NEA020 & SDW & 60 & -212 & 947 & 1.07E-06 & no breakdown & no breakdown & no breakdown \\
\hline NEA033 & SDW & 90 & -305 & 808 & $1.05 \mathrm{E}-08$ & no breakdown & no breakdown & no breakdown \\
\hline NEA001 & SDW & 30 & -99 & 1,000 & 1.15E-06 & no breakdown & no breakdown & no breakdown \\
\hline NEA034 & SDW & 90 & -305 & 752 & $1.32 \mathrm{E}-07$ & no breakdown & no breakdown & no breakdown \\
\hline NEA011 & SDW & 30 & -125 & 1,030 & 9.33E-07 & no breakdown & no breakdown & no breakdown \\
\hline NEA022 & SDW & 60 & -114 & 912 & $1.95 \mathrm{E}-06$ & no breakdown & no breakdown & no breakdown \\
\hline NEA023 & SDW & 60 & -214 & 874 & 1.07E-06 & no breakdown & no breakdown & no breakdown \\
\hline NEA005 & SCW & 30 & -37 & 958 & 3.89E-06 & no breakdown & no breakdown & no breakdown \\
\hline NEA017 & SCW & 60 & -331 & 880 & $5.25 \mathrm{E}-06$ & no breakdown & no breakdown & no breakdown \\
\hline NEA028 & SCW & 90 & -480 & 849 & 1.29E-05 & 762 & 798 & breakdown \\
\hline NEA004 & SCW & 30 & -187 & 968 & 2.63E-06 & no breakdown & no breakdown & no breakdown \\
\hline NEA018 & SCW & 60 & -364 & 796 & 6.17E-06 & no breakdown & no breakdown & no breakdown \\
\hline NEA029 & SCW & 90 & -506 & 654 & 2.95E-05 & 752 & 782 & breakdown \\
\hline NEA003 & SCW & 30 & -233 & 1,020 & $1.91 \mathrm{E}-06$ & no breakdown & no breakdown & no breakdown \\
\hline NEA019 & SCW & 60 & -351 & 849 & $5.50 \mathrm{E}-06$ & no breakdown & no breakdown & no breakdown \\
\hline NEA030 & SCW & 90 & -516 & 772 & 1.32E-06 & 798 & 808 & breakdown \\
\hline
\end{tabular}

Source: DTN: LL010105512251.011 [DIRS 155623] S01009_004. 
Table 20. Summary of Cyclic Polarization Data for Ti Grade 7 in Repository-Relevant Conditions (SAW and SSW)

\begin{tabular}{|l|c|c|c|c|c|c|c|c|}
\hline Sample ID & Electrolyte & $\begin{array}{c}\text { Temp. } \\
\left({ }^{\circ} \mathbf{C}\right)\end{array}$ & $\begin{array}{c}\text { Corrosion } \\
\text { Potential } \\
(\mathbf{m V})\end{array}$ & $\begin{array}{c}\text { Threshold } \\
\text { Potential 1 } \\
(\mathbf{m V})\end{array}$ & $\begin{array}{c}\text { Passive } \\
\text { Current } \\
(\mathbf{a m p s})\end{array}$ & $\begin{array}{c}\text { Repassivation } \\
\text { Potential 1 (mV) }\end{array}$ & $\begin{array}{c}\text { Repassivation } \\
\text { Potential 2 (mV) }\end{array}$ & $\begin{array}{c}\text { Repassivation } \\
\text { Potential 3 (mV) }\end{array}$ \\
\hline NEA010 & SAW & 30 & -153 & 1450 & $2.40 E-06$ & no breakdown & no breakdown & no breakdown \\
\hline NEA012 & SAW & 30 & -187 & 1430 & $1.48 E-06$ & no breakdown & no breakdown & no breakdown \\
\hline NEA013 & SAW & 60 & -99 & 1390 & $1.86 E-06$ & no breakdown & no breakdown & no breakdown \\
\hline NEA024 & SAW & 90 & -187 & 1300 & $1.55 E-06$ & no breakdown & no breakdown & no breakdown \\
\hline NEA009 & SAW & 30 & -284 & 1420 & $2.69 E-06$ & no breakdown & no breakdown & no breakdown \\
\hline NEA014 & SAW & 60 & -125 & 1420 & $1.86 E-06$ & no breakdown & no breakdown & no breakdown \\
\hline NEA025 & SAW & 90 & -187 & 1340 & $1.91 E-06$ & no breakdown & no breakdown & no breakdown \\
\hline NEA007 & SAW & 30 & -176 & 1440 & $1.35 E-06$ & no breakdown & no breakdown & no breakdown \\
\hline NEA008 & SAW & 30 & -145 & 1230 & $1.62 E-06$ & no breakdown & no breakdown & no breakdown \\
\hline NEA026 & SAW & 90 & -176 & 1330 & $1.95 E-06$ & no breakdown & no breakdown & no breakdown \\
\hline NEA032 & SSW & 100 & -211 & 921 & $3.24 E-06$ & no breakdown & no breakdown & no breakdown \\
\hline NEA031 & SSW & 120 & -336 & 813 & $1.55 E-06$ & no breakdown & no breakdown & no breakdown \\
\hline
\end{tabular}

Source: DTN: LL010105512251.011 [DIRS 155623] S01009_004.

NOTE: UI means that the data was uninterpretable; AP means that the cyclic polarization curve had an active-passive transition. All potentials were measured with a $\mathrm{Ag} / \mathrm{AgCl}$ reference electrode. Subtract $197 \mathrm{mV}$ from measured values to convert to the normal hydrogen electrode potential scale. 


\subsubsection{Correlation of Potential Versus Temperature and Composition for Various Test Media}

\subsubsection{Critical Potential Versus Temperature and Composition Model}

Whether passive film breakdown is observed in the cyclic polarization tests does not necessarily indicate whether localized corrosion will occur under repository conditions. The susceptibility of the material to localized corrosion is represented by Equation 37, rather than based on whether passive film breakdown actually occurs.

The values for corrosion and threshold potentials given in Table 19 and Table 20 are used to fit the difference $(\Delta E)$ between critical potential for localized corrosion initiation, $E_{\text {critical }}$, and corrosion potential, $E_{c o r r}$, as a function of absolute temperature, $T$, solution, $p H$, and the chloride ion concentration:

$$
\Delta E=d_{0}+d_{1} \cdot T+d_{2} \cdot \log \left(C l^{-}\right)+d_{3} \cdot p H+\varepsilon
$$

where $d_{o}, d_{1}, d_{2}$, and $d_{3}$ are constants determined from fitting Equation 38 by using the collected potential difference data in Table 19 and Table 20. Localized corrosion can initiate when $E_{\text {corr }}$ exceeds or is equal to $E_{\text {critical }}$. This is equivalent to the condition that $\Delta E$ is less than zero. The calculation is documented in detail in Appendix A. The model error term $(\varepsilon)$ represents data variance not explained by the fitting procedure and has a normal distribution with a mean of zero and variance of 10,500. Based on the data in Table 19 and Table 20, the median values of these parameters are: $d_{o}=2050, d_{1}=-1.17, d_{2}=14.1$, and $d_{3}=-48.9$, respectively. The covariance matrix resulting from the fitting procedure was determined to be:

$$
s=\left[\begin{array}{cccc}
56100 & -165 & 1150 & 66.1 \\
-165 & 0.506 & -4.36 & -1.07 \\
1150 & -4.36 & 535 & 116 \\
66.1 & -1.07 & 116 & 56.1
\end{array}\right]
$$

Figure 19 and Figure 20 are plots of $\Delta E v s \mathrm{pH}$ using Equations 38 and 39. Figure 19 shows the effect of $\mathrm{pH}$ and temperature under a constant chloride concentration $\left(3 \mathrm{~mol} / \mathrm{L} \mathrm{Cl}^{-}\right)$and Figure 20 shows the effect of $\mathrm{pH}$ and chloride concentration under a constant temperature of $380 \mathrm{~K}$. Together, the figures show that $\Delta E$ is significantly greater than zero over all ranges of $\mathrm{pH}$, chloride concentration, and temperature. They also show that the median $\Delta E$ increases slightly with increasing chloride concentration and temperature but significantly decreases with increasing $\mathrm{pH}$. Nevertheless, a gap between the corrosion potential and the threshold potential of several hundred millivolts is maintained even at very high $\mathrm{pH}$. Also, a gap on the order of several hundred millivolts is maintained even at the $-4 \sigma$-confidence level of the Table 19 and Table 20 data. Truncation at the $\pm 4 \sigma$-confidence level yields appropriate bounding values for use with this model because $99.994 \%$ of the model variance is accounted for by the choice of these bounds (i.e., the probability of sampling values outside these bounds is less than 1 in 10,000). Localized corrosion of $\mathrm{Ti}$ Grade 7 would not initiate in a repository-relevant environment even at $\mathrm{pH}$ values as high as 14 using these bounds. 


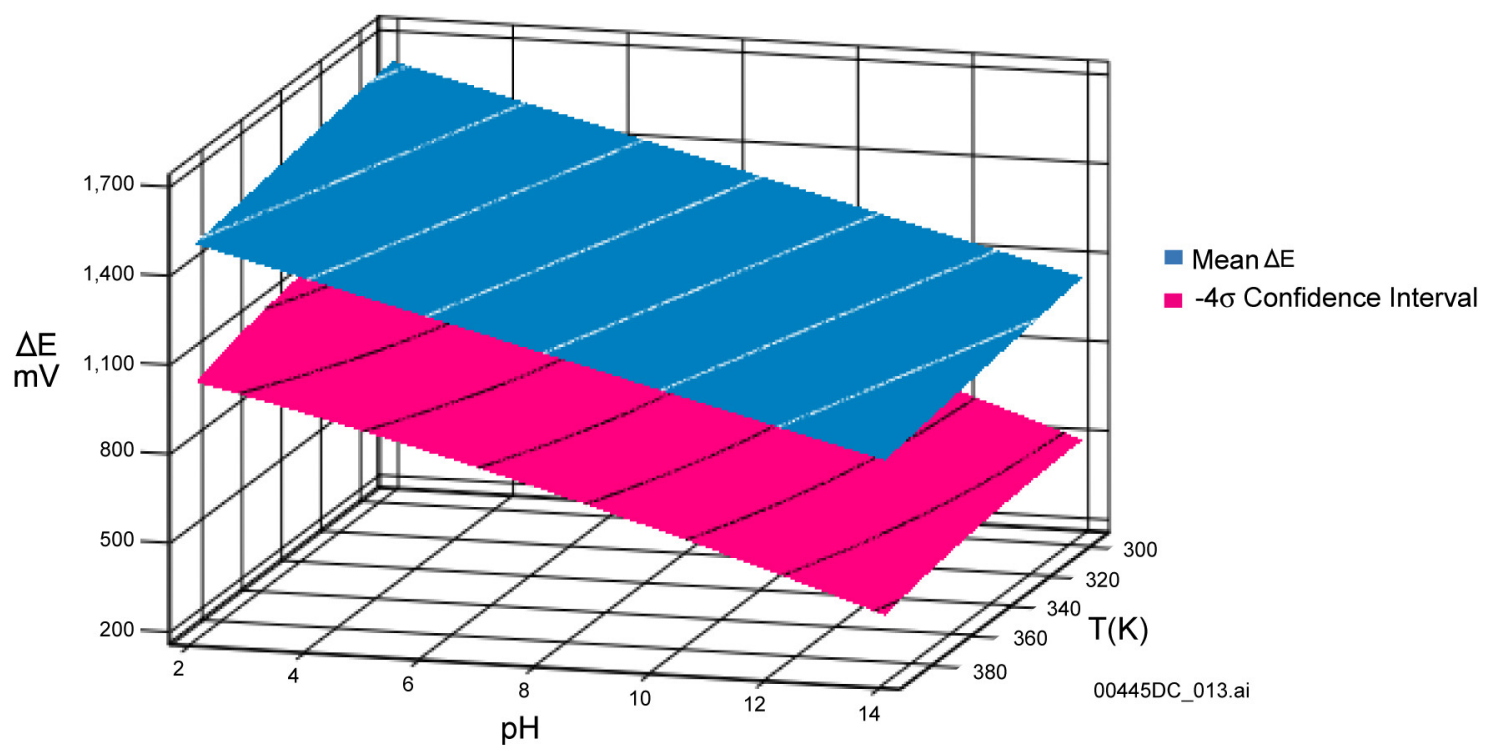

Output DTN: MO0408MWDGLCDS.002.

Figure 19. The Median $\Delta E$ and $-4 \sigma$ Confidence Interval Surface Versus $p H$ and Absolute Temperature for Ti Grade 7 Using a Chloride Ion Concentration of $3 \mathrm{~mol} / \mathrm{L}$

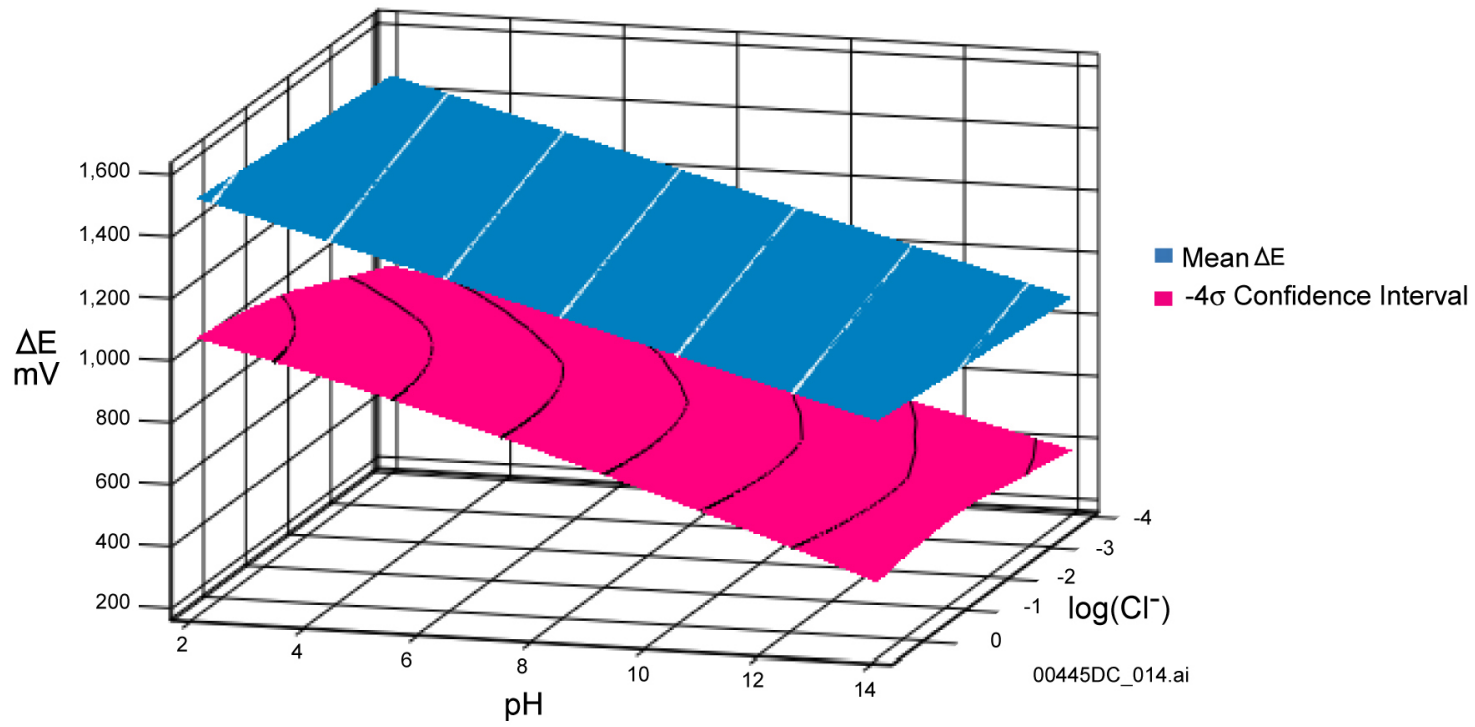

Output DTN: MO0408MWDGLCDS.002.

Figure 20. The Median $\Delta E$ and $-4 \sigma$ Confidence Interval Surface versus $p H$ and base 10 Logarithm of Chloride lon Concentration for Ti Grade 7 Using an Absolute Temperature of $400 \mathrm{~K}$

There is, however, some uncertainty associated with the extrapolation of the model beyond the compositional bounds of the SDW, SCW, SAW, and SSW (Table 7) used in the electropotential measurements in the development of the model (i.e., $\mathrm{pH}$ values from 2.7 to 8.1 and chloride concentration from 67 to $1.284 \times 10^{5} \mathrm{mg} / \mathrm{L}$ ). However, other investigators have noted that the increase in corrosion of titanium alloys in very aggressive brine solutions ( $\mathrm{pH}$ as low as 1 and as high as 14; chloride concentration on the order of $30 \%$ in solution) is marginal (Smailos and Köster 1987 [DIRS 159774]; Smailos et al. 1990 [DIRS 154820], Mattsson and Olefjord 1990 [DIRS 111885]; Kim and Oriani 1987 [DIRS 110236]). Nevertheless, the appropriateness of the 
localized corrosion models developed from data using relatively less aggressive environments has been questioned. To address this, short-term cyclic polarization measurements using highly concentrated $\mathrm{CaCl}_{2}$ solution have been conducted as discussed in Section 6.6.5.1.

\subsubsection{Crevice Corrosion}

Because pitting has not been observed in the Project's laboratory experiments and crevice corrosion initiates at lower temperature and potential than pitting, only crevice corrosion is considered in this model. In other words, when $E_{c o r r} \geq E_{\text {critical }}$, crevice corrosion initiates. Crevice corrosion is characterized by the breakdown of passive film inside the creviced area where the corrosion is locally accelerated. Before the passive film is broken down inside the creviced area, the corrosion rate inside could also be slightly higher than the exterior areas due to deoxygenation and acidification.

Due to the outstanding corrosion resistance of Ti Grade 7 (and Ti Grade 16), relatively little data exists for crevice corrosion under plausible exposure conditions. Hua et al. (2002 [DIRS 160670]) performed tests for crevice corrosion of Ti Grade 7 in Basic Saturated Water (BSW-12, 50,000 times more concentrated than J-13 well water by evaporation) (Table 7, DTN: LL040803112251.117 [DIRS 171362]) for up to eight weeks at temperatures from $60^{\circ} \mathrm{C}$ to $105^{\circ} \mathrm{C}$. Although the Ti Grade 7 specimens became discolored underneath the crevice formers after the test, no crevice corrosion was observed. Also, the preexisting surface imperfections, possibly due to material processing, remained after four and eight weeks of exposure (Hua and Gordon 2003 [DIRS 163111]). The authors concluded that the observed weight losses were due to general corrosion only (Hua et al. 2002 [DIRS 160670]). In LTCTF tests, Ti Grade 16 crevice specimens were immersed in SSW, SAW, SCW, and SDW at $60^{\circ} \mathrm{C}$ and $90^{\circ} \mathrm{C}$ (in $\mathrm{SSW}$ also at $120^{\circ} \mathrm{C}$ ) for one year and in SAW, SCW, and SDW at $60^{\circ} \mathrm{C}$ and $90^{\circ} \mathrm{C}$ for five years. No crevice corrosion attack was reported.

The crevice corrosion penetration rate of Ti Grades 7 or 16 specimens in YMP-related environments was not measured because crevice corrosion was not observed. Both the "weightloss specimens" and "crevice specimens" were tested in the same environments (SDW, SCW, and SAW at $60^{\circ} \mathrm{C}$ and $90^{\circ} \mathrm{C}$, and SSW at $120^{\circ} \mathrm{C}$ ). As shown in Figure 10 and Figure 11, the corrosion rates of $\mathrm{Ti}$ Grade 16 in SDW, SCW, and SAW at $60^{\circ} \mathrm{C}$ and $90^{\circ} \mathrm{C}$ are between approximately -200 and $+200 \mathrm{~nm} / \mathrm{yr}$ for weight-loss specimens and between approximately -320 and $+320 \mathrm{~nm} / \mathrm{yr}$ for crevice specimens, the negative values being a consequence of incomplete posttest specimen cleaning (Section 6.5.3). As indicated in Section 6.5.3, the greater scatter in the corrosion rate of crevice specimen distribution indicates more variability of corrosion related to the crevice. Corrosion inside the crevice could be more severe due to differential aeration or minor $\mathrm{pH}$ changes within the crevice, or both. However, crevice corrosion was not observed on the posttest specimens in LTCTF. Therefore, the different corrosion rates obtained from the weight-loss and crevice specimens are not indicative of crevice corrosion, but could be due to enhanced general corrosion inside the crevice at very early stage of immersion (e.g., one year), which decreases to an insignificant level in five years or less (Figure 22 and Figure 23), a negligible span of time compared to the 10,000-year regulatory period. It is also possible that a different surface finish treatment used for the crevice and weight-loss specimens may have led to different corrosion rates between the two types of specimens. 
The hydrolysis of dissolved metal in crevices can lead to the accumulation of $\mathrm{H}^{+}$and the corresponding suppression of $\mathrm{pH}$. For example, a $\mathrm{pH}<2$ has been observed in crevices made of stainless steel, as discussed by Sedriks (1996 [DIRS 105113]). In the case of titanium-based alloys, such low pH values can lead to hydrogen-induced cracking (Ikeda et al. 1994 [DIRS 145955]; Shoesmith et al. 1995 [DIRS 117892]; BSC 2004 [DIRS 169847]). Titanium and its alloys are usually passive over a broad range of $\mathrm{pH}$ and electrochemical potential, as illustrated by Pourbaix (1974 [DIRS 100817], pp. 213 to 222). Indeed, passivity can be lost under extreme general or local conditions. For example, the potential-pH diagram that accounts for the formation of both hydrated $\mathrm{TiO}_{2}$ and $\mathrm{Ti}(\mathrm{OH})_{3}$ shows a region of active dissolution over a broad range of electrochemical potentials at low $\mathrm{pH}$. The theoretical domains of corrosion, immunity, and passivation at $25^{\circ} \mathrm{C}$ show regions of active dissolution below $\mathrm{pH} 2$. Within the thermodynamic limits of water, titanium is expected to dissolve as either $\mathrm{Ti}^{3+}$ or $\mathrm{TiO}^{2+}$. Oxyanions such as $\mathrm{HTiO}_{3}{ }^{-}, \mathrm{TiO}_{4}{ }^{2-}$, and $\mathrm{HTiO}_{4}{ }^{-}$may form, but require very alkaline conditions.

These thermodynamically predicted possibilities, however, have not always been observed in laboratories. The crevice-corrosion resistance of titanium alloys has been extensively tested (Schutz and Thomas 1987 [DIRS 112147], p. 682). Crevice corrosion of titanium alloys will generally not occur below $70^{\circ} \mathrm{C}\left(160^{\circ} \mathrm{F}\right)$ regardless of $\mathrm{pH}$ or chloride concentration and will not occur at pHs higher than 10 regardless of temperature (Schutz and Thomas 1987 [DIRS 112147], p. 682). Ti Grade 12 (a titanium alloy less corrosion-resistant than Ti Grades 7 and 16) provides crevice corrosion resistance when brine $\mathrm{pH}$ falls between 3 and 11 at temperatures as high as $300^{\circ} \mathrm{C}\left(570^{\circ} \mathrm{F}\right)$ (Schutz and Thomas 1987 [DIRS 112147], Table 21 and pp. 682 and 687). Ti Grade 7 extends this crevice corrosion resistance to brine $\mathrm{pH}$ as low as 0.6 to 0.7 (Schutz and Thomas 1987 [DIRS 112147], p. 682). No crevice attack was observed for a Ti-0.2\% Pd alloy with both the metal-Teflon and metal-metal crevices with both the polished or as-received surfaces in $90^{\circ} \mathrm{C}$ deaerated brine for 582 days and in $170^{\circ} \mathrm{C}$ brine for 286 days (Gdowski 1997 [DIRS 102789], Table 15.1). Satoh et al. (1987 [DIRS 151157]) found no sign of crevice corrosion on Ti Grade 7 in boiling $42 \% \mathrm{MgCl}_{2}$ after 10 days.

The critical crevice-corrosion temperature (defined as the temperature above which crevice corrosion can occur) is determined experimentally as the temperature at which the corrosion potential and threshold potential become equal. This critical temperature was not observed in the LLNL cyclic polarization tests at temperatures up to $120^{\circ} \mathrm{C}$ as discussed in Section 6.6.2. This further confirms that the slightly higher corrosion rates obtained from the crevice specimens than those from weight-loss specimens in the 1-year tests are not due to the occurrence of crevice corrosion but the slightly enhanced corrosion due to the slightly more aggressive environment inside the crevices. Due to the excellent corrosion resistance of titanium alloys, the enhanced corrosion did not lead to the breakdown of passive film because no evidence of crevice corrosion was observed on the posttest specimens even after a 5-year exposure in repository environments (Section 7.5).

\subsubsection{Influence of Calcium Chloride on Localized Corrosion of Ti Grade 7}

The potential for the development of environments containing high concentrations of calcium chloride ions has been proposed (BSC 2001 [DIRS 155950], Section 7.3.1). As a result, effects of highly concentrated calcium chloride solutions on the Ti Grade 7 passive film behavior are evaluated in this report. 


\subsubsection{Effects of Calcium Cations on Passive Film Properties}

Angle-resolved x-ray photoelectron spectroscopy (XPS) has clearly shown that the oxide film is composed of an inner barrier layer, which acts as the primary passive oxide, and an outer more porous hydrated layer (Pan et al. 1994 [DIRS 159795]). As discussed by Macdonald (1999 [DIRS 154721]), the growth of such films is achieved by the transport of anion vacancies, produced at the metal barrier layer interface and consumed at the barrier layer-porous layer interface, and cation vacancies formed at the barrier layer-porous layer interface and consumed at the metal-barrier layer interface. For a given potential (applied either electrochemically or, as the corrosion potential, by a solution soluble oxidant), the barrier layer eventually achieves a constant thickness. Further growth of the overall oxide film then involves the thickening of the outer porous layer. In effect, the barrier layer maintains its steady-state thickness and passive properties by growth at the metal-barrier layer interface balanced by conversion to the outer porous layer at the barrier layer-porous layer interface.

According to Macdonald (1999 [DIRS 154721]), anionic entities were shown to be the most mobile leading to growth predominantly at the metal-barrier layer interface. Growth at this interface would be expected to generate a purer oxide and it is, therefore, not surprising that anodically grown films on titanium incorporate few impurities into the barrier layer (Pan et al. 1994 [DIRS 159795]). A second pertinent conclusion based on this understanding is that breakdown of the barrier layer leading to localized corrosion of titanium will involve anion transport processes. This interpretation is consistent with the general observation that anions such as $\mathrm{Cl}^{-}, \mathrm{F}^{-}$, and $\mathrm{Br}^{-}$(to a lesser degree) lead to the initiation of localized corrosion on passive metals and alloys (MacDonald 1999 [DIRS 154721]).

Based on the above investigations, the incorporation of $\mathrm{Ca}^{2+}$ in the inner barrier layer leading to film breakdown and the initiation of localized corrosion is not expected. Thus, any incorporation of $\mathrm{Ca}^{2+}$ (or the similarly behaving cation, $\mathrm{Mg}^{2+}$ ) under general passive corrosion conditions is confined to the outer porous hydrated layer. Such a process of cation incorporation will not lead to an increase in corrosion rate, and, if precipitated with insoluble anions (such as silicate), could lead to a decrease in corrosion rate by the sealing of the pores in the outer hydrated layer. If cations such as $\mathrm{Ca}^{2+}$ or $\mathrm{Mg}^{2+}$ are to accelerate passive corrosion, then it is likely via its ability to hydrolyze that the $\mathrm{pH}$ is reduced. If the $\mathrm{pH}$ decrease is large enough, then either the barrierporous layer conversion could be accelerated or local defects in the oxide could be activated leading to local film breakdown and the initiation of localized corrosion.

Considerable evidence exists to show $\mathrm{Ca}^{2+}$ and $\mathrm{Mg}^{2+}$ cations are incorporated into the outer porous layer of the oxide films present on titanium and its alloys. These studies range from those primarily interested in the performance of titanium as a body-implant material (Pan et al. 1994 [DIRS 159795]) to those in which titanium was tested for its durability under nuclear waste disposal conditions (Molecke et al. 1982 [DIRS 161678]; Smailos and Köster 1987 [DIRS 159774]).

For such an incorporation process to proceed, film growth must be maintained. The thicker oxide films observed in the presence of gamma radiation compared to those in its absence in the same environment can also be attributed to the maintenance of film growth by $\mathrm{H}_{2} \mathrm{O}_{2}$, produced radiolytically (Smailos and Köster 1987 [DIRS 159774]; Shoesmith and King 1998 
[DIRS 112178]). These measurements were made on Ti Grade 7 in the extremely concentrated German Q-brine in which $\mathrm{Mg}^{2+}$ is by far the dominant cation $(91,900 \mathrm{mg} / \mathrm{L}$ ) (Smailos et al. 1990 [DIRS 154820]). In the absence of radiation, after one year of exposure at $150^{\circ} \mathrm{C}$, the oxide thickness was $\sim 35 \mathrm{~nm}$ compared to $\sim 60 \mathrm{~nm}$ at a dose rate of $10^{3} \mathrm{Rad} /$ hour. After $\sim 1.5$ years of exposure at $10^{5} \mathrm{Rad} /$ hour $\left(90^{\circ} \mathrm{C}\right)$ (Smailos and Köster 1987 [DIRS 159774]) the film thickness was $\sim 600 \mathrm{~nm}$. The passive layer directly adjacent to the metal surface remained $\mathrm{TiO}_{2}$, while considerable amounts of $\mathrm{Mg}^{2+}$ accumulated in an overlayer (i.e., cation incorporation was confined to the outer layers and did not threaten the integrity of the more important inner barrier layer). A similar incorporation of $\mathrm{Ca}^{2+}$ would have been expected if this cation had been present in such large quantities.

It is concluded that the incorporation of $\mathrm{Ca}^{2+}$ and $\mathrm{Mg}^{2+}$ into the outer layers of the passive film is a consequence of the corrosion process, not a stimulant for it. If it were a stimulant, in the absence of the radiation field the corrosion rate would be low. This is clearly borne out by the measured corrosion rates in the absence of radiation, which for Ti Grade 7 are in the range $\leq 100 \mathrm{~nm} / \mathrm{yr}$ (after $~ 3.5$ years of exposure) in Q-brine, and independent of temperature between $90^{\circ} \mathrm{C}$ to $200^{\circ} \mathrm{C}$ (Smailos and Köster 1987 [DIRS 159774]). Similarly, low corrosion rates for Ti Grade $7\left(\sim 400 \mathrm{~nm} / \mathrm{yr}\right.$ in a brine containing $35,000 \mathrm{mg} / \mathrm{L}$ of $\mathrm{Mg}^{2+}$ at $\left.250^{\circ} \mathrm{C}\right)$ were obtained by Molecke et al. (1982 [DIRS 161678]). The higher rate observed by Molecke et al. (1982 [DIRS 161678]) can be attributed to the temperature and shorter exposure period.

Studies on the aggressive corrosion conditions encountered in the pulp and paper industry (Schutz and Xiao 1994 [DIRS 159798]) and in the highly saline environments encountered in flue gas scrubbers (Thomas and Bomberger 1983 [DIRS 151181]) show that the presence of $\mathrm{Ca}^{2+}$ even in relatively small amounts can inhibit the corrosion of titanium significantly. Schutz and Xiao (1994 [DIRS 159798]) show that $\mathrm{Ca}^{2+}$ present in the 1 to $200 \mathrm{mg} / \mathrm{L}$ range suppresses the corrosion rate in alkaline solutions containing 0.2 to $0.3 \mathrm{wt} \% \mathrm{H}_{2} \mathrm{O}_{2}$ from $65^{\circ} \mathrm{C}$ to $85^{\circ} \mathrm{C}$. A similar suppression of corrosion in these environments was observed by Wyllie et al. (1994 [DIRS 159799]) who concluded that this could be attributed to the incorporation of $\mathrm{Ca}^{2+}$ into a surface deposit. Unfortunately, these layers were not further characterized. In the case of the gas scrubber environments, the beneficial influence of $\mathrm{Ca}^{2+}$ was claimed to be its ability to precipitate the potentially aggressive anion, $\mathrm{F}^{-}$(Thomas and Bomberger 1983 [DIRS 151181]), a very advantageous feature under repository conditions. It is clear from this discussion that $\mathrm{Ca}^{2+}$ and $\mathrm{Mg}^{2+}$ should not accelerate the corrosion of titanium alloys, especially Ti Grade 7, when present in the exposure environment even at large concentrations.

\subsubsection{Results on Corrosion of Ti Grade 7 in High Concentration of $\mathrm{CaCl}_{2}$ and $\mathrm{MgCl}_{2}$}

The fact that environments containing $\mathrm{Ca}^{2+}$ and $\mathrm{Mg}^{2+}$ do not result in localized corrosion is clearly demonstrated in the LLNL cyclic polarization tests. Figure 21 shows an example of the cyclic polarization curves obtained for Ti Grade 7 in environments containing high concentration of calcium chloride $\left(8 \mathrm{M} \mathrm{CaCl}_{2}\right)$ at $100^{\circ} \mathrm{C}$. The $\Delta E$, defined as $E_{\text {critical }}-E_{\text {corr }}$ in Figure 21 , is as high as $>3.0 \mathrm{~V}$, if $E_{20}$ is chosen as the threshold potential, as normally observed for titanium alloys. Under this severe condition $\left(8 \mathrm{M} \mathrm{CaCl}_{2}\right.$ and $\left.100^{\circ} \mathrm{C}\right)$, Ti Grade 7 exhibited a perfect passive region (passive current density below about 2 to $3 \mu \mathrm{A} / \mathrm{cm}^{2}$ ) below about $1.5 \mathrm{~V}_{(\mathrm{SSC})}$. 


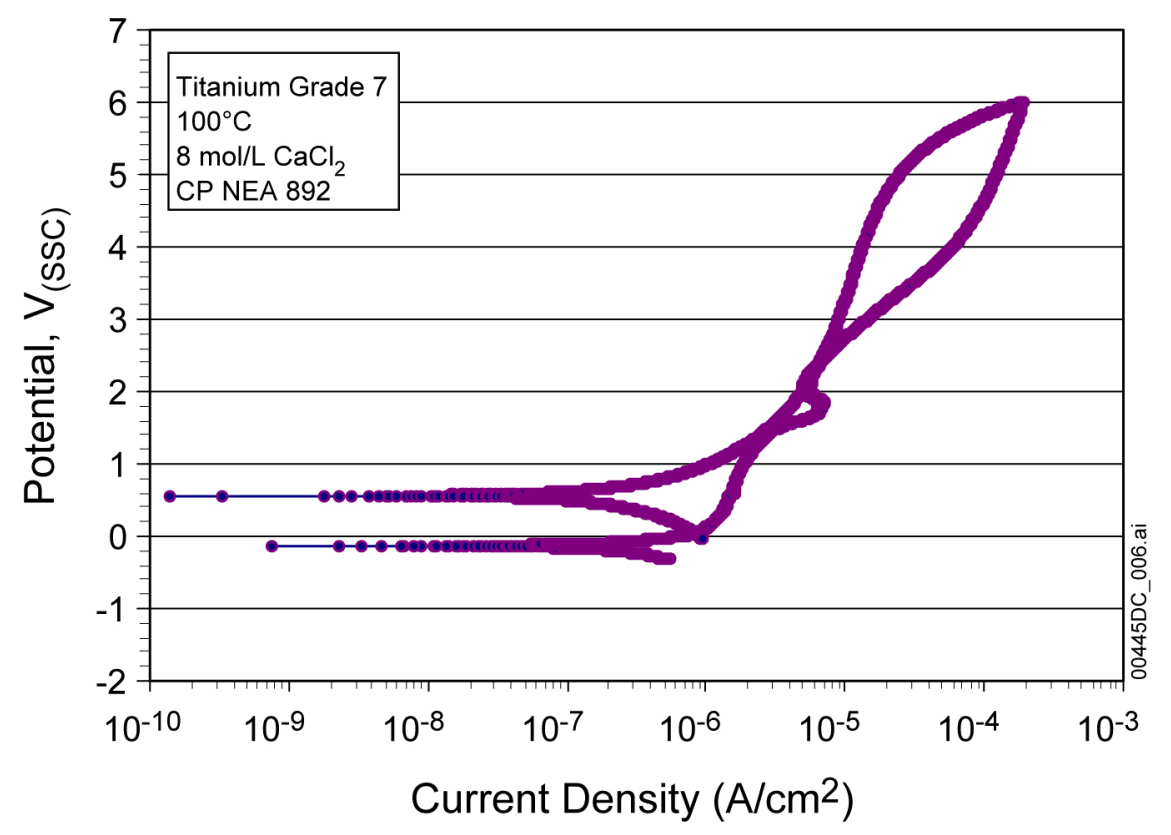

Output DTN: MO0408MWDGLCDS.002.

Figure 21. An Example Cyclic Polarization Curve of Ti Grade 7 in $8 \mathrm{M} \mathrm{CaCl}_{2}$ Water at $100^{\circ} \mathrm{C}$, Showing Very Large $\Delta E\left(E_{20}-E_{c o r r}\right)$ and a Perfect Passive Region Below About $1.5 \mathrm{~V}_{(\mathrm{SsC})}$

Table 21 summarizes the results obtained at LLNL for Ti Grade 7 in environments containing high concentration of $\mathrm{CaCl}_{2}$ and $\mathrm{MgCl}_{2}$. In Table 21, $E_{\text {corr }}$ is the free corroding potential after 1-hour exposure in the given electrolyte, $E_{20}$ is the potential in the forward scan of a cyclic polarization curve where the current density first reaches $20 \mu \mathrm{A} / \mathrm{cm}^{2}$, and $E_{200}$ is the potential in the forward scan of a cyclic polarization curve where the current density first reaches $200 \mu \mathrm{A} / \mathrm{cm}^{2} . E_{R 10}$ is the potential in the reverse polarization where the current density first reaches $10 \mu \mathrm{A} / \mathrm{cm}^{2}$ and $E_{R I}$ is the potential in the reverse polarization where the current density first reaches $1 \mu \mathrm{A} / \mathrm{cm}^{2}$. The data was obtained in concentrated $\mathrm{CaCl}_{2}$ solutions at $100^{\circ} \mathrm{C}$ and $150^{\circ} \mathrm{C}$ (DTN: LL030409412251.050 [DIRS 163647]) in environments as indicated. In general ( 5 out of 6 tests), the $\Delta E$ values are greater than $2 \mathrm{~V}$, suggesting a significant margin of safety. The specimen NEA894 shows a $\Delta E$ value of $1.4 \mathrm{~V}$, which is high enough to exclude the possibility of localized corrosion. 
Table 21. Electrochemical Tests of Ti Grade 7 in Environments Containing $\mathrm{Ca}$ and $\mathrm{Mg}$

\begin{tabular}{|c|c|c|c|c|c|c|c|c|c|}
\hline $\begin{array}{c}\text { Specimen } \\
\text { ID }\end{array}$ & $\begin{array}{c}\text { Specimen, } \\
\text { Surface } \\
\text { Finish }\end{array}$ & Environment & $\begin{array}{c}\mathrm{T} \\
\left({ }^{\circ} \mathrm{C}\right)\end{array}$ & $\begin{array}{l}E_{\text {corr }} \\
\text { (mV, } \\
\text { SSC) }\end{array}$ & $\begin{array}{l}\mathrm{E}_{20} \\
\text { (mV, } \\
\text { SSC) }\end{array}$ & $\begin{array}{c}\mathrm{E}_{200}(\mathrm{mV}, \\
\text { SSC) }\end{array}$ & $\begin{array}{l}E_{\mathrm{R} 10} \\
\text { (mV, } \\
\text { SSC) }\end{array}$ & $\begin{array}{l}\mathrm{E}_{\mathrm{R} 1} \\
(\mathrm{mV}, \\
\mathrm{SSC})\end{array}$ & $\begin{array}{l}\Delta \mathrm{E}= \\
E_{20}- \\
E_{\text {corr }}\end{array}$ \\
\hline NEA891 & Disc, 600 & $8 \mathrm{M} \mathrm{CaCl}_{2}$ & 100 & -45 & 2,680 & N/A & $\mathrm{N} / \mathrm{A}$ & $\mathrm{N} / \mathrm{A}$ & 2,725 \\
\hline NEA892 & Disc, 600 & $8 \mathrm{M} \mathrm{CaCl}_{2}$ & 100 & -219 & 3,220 & $\mathrm{~N} / \mathrm{A}(\sim 6,000)$ & 3,260 & 986 & 3,439 \\
\hline NEA893 & Disc, 600 & $8 \mathrm{M} \mathrm{CaCl}_{2}$ & 100 & -296 & 3,180 & $\sim 4,880$ & $\mathrm{~N} / \mathrm{A}$ & $\mathrm{N} / \mathrm{A}$ & 3,476 \\
\hline NEA894 & Disc, 600 & $9 \mathrm{M} \mathrm{CaCl}_{2}$ & 150 & -176 & 1240 & 3,450 & 889 & 246 & 1,416 \\
\hline NEA895 & Disc, 600 & $9 \mathrm{M} \mathrm{CaCl}_{2}$ & 150 & -205 & 2,180 & 3,630 & 1140 & 501 & 2,385 \\
\hline NEA896 & Disc, 600 & $\begin{array}{l}9 \mathrm{M} \mathrm{CaCl}_{2}+ \\
0.9 \mathrm{M} \mathrm{Ca}(\mathrm{NO} 3)_{2}\end{array}$ & 150 & -108 & 2,410 & 3,400 & $N / A$ & $N / A$ & 2,518 \\
\hline
\end{tabular}

Source Data: DTN: LL030409412251.050 [DIRS 163647].

Output DTN: MO0408MWDGLCDS.002.

NOTE: $\quad E_{\text {corr }}$ is the free corroding potential after $1 \mathrm{~h}$ exposure in the given electrolyte; $E_{20}$ is the potential in the forward scan of a cyclic polarization curve where the current density first reaches $20 \mu \mathrm{A} / \mathrm{cm}^{2}$; $E_{200}$ is the potential in the forward scan of a cyclic polarization curve where the current density first reaches $200 \mu \mathrm{A} / \mathrm{cm}^{2}$; $E_{R 10}$ is the potential in the reverse polarization where the current density first reaches $10 \mu \mathrm{A} / \mathrm{cm}^{2}$ and $E_{R 1}$ is the potential in the reverse polarization where the current density first reaches $1 \mu \mathrm{A} / \mathrm{cm}^{2}$.

The effect of calcium chloride on general passive dissolution of Ti Grade 7 can also be evaluated by comparing Figure 21 with Figure 14 through Figure 18 (Section 6.6.2). In Figure 21, the passive current density of Ti Grade 7 in $8 \mathrm{M} \mathrm{CaCl}_{2}$ is about 1 to $2 \mu \mathrm{A} / \mathrm{cm}^{2}$, similar to those observed on Ti Grade 7 in SSW at $120^{\circ} \mathrm{C}$ (Figure 14, Section 6.6.2), SAW at $90^{\circ} \mathrm{C}$ (Figure 15, Section 6.6.2), SCW at $30^{\circ} \mathrm{C}$ (Figure 18, Section 6.6.2) and less greater than those observed on Ti Grade 7 in SCW at $60^{\circ} \mathrm{C}$ and $90^{\circ} \mathrm{C}$ (Figure 16 and Figure 17, Section 6.6.2). Note that SDW, $\mathrm{SCW}$, and SAW contain $0.5,<1.0$, and $1,000 \mathrm{ppm} \mathrm{Ca}^{2+}$, respectively. The similar passive dissolution rates of Ti Grade 7 in Figure 21 and in Figure 14 through Figure 18 clearly indicate that the influence of calcium chloride on the general passive corrosion rate of Ti Grade 7 is insignificant.

For Ti Grade 7, a $2 \mu \mathrm{A} / \mathrm{cm}^{2}$ corrosion current density is equivalent, based on the Faraday's law, to a corrosion rate of $24 \mu \mathrm{m} /$ year or $2.4 \times 10^{4} \mathrm{~nm} / \mathrm{yr}$. This seemingly very high corrosion rate (240 $\mathrm{mm}$ in 10,000 years), however, is not realistic. The cyclic polarization tests reflected in Figure 21 and Table 21 were performed one hour after the specimens were immersed in the environments. The passive current density values can only be used as a reference, rather than the absolute value of corrosion rate.

\subsection{OTHER FACTORS CONSIDERED IN MODELING DRIP SHIELD CORROSION}

\subsubsection{Gamma Radiolysis}

Ambient-temperature cyclic polarization studies have been performed with Stainless Steel Type $316 \mathrm{~L}$ samples in $0.018 \mathrm{M} \mathrm{NaCl}$ solution during exposure to $3.3 \mathrm{Mrad} \mathrm{h}^{-1}$ gamma radiation (Glass et al. 1986 [DIRS 105021]). This investigator found that with gamma radiation the corrosion current shifted in the anodic direction by approximately $200 \mathrm{mV}$, with very little increase in the corresponding corrosion current density. However, the separation between the corrosion potential and the threshold for localized attack decreased slightly. This shift in 
corrosion potential was shown to be due to the formation of hydrogen peroxide and was subsequently confirmed by others (Kim 1999 [DIRS 110698]). In the work by Glass et al. (1986 [DIRS 105021]), ambient-temperature cyclic polarization of Stainless Steel Type 316L in acidic $(\mathrm{pH} \sim 2) 1.5 \mathrm{M} \mathrm{NaCl}$ during exposure to $0.15 \mathrm{Mrad} \mathrm{h}^{-1}$ gamma radiation showed a $100 \mathrm{mV}$ anodic shift in the corrosion potential with very little effect on the corrosion current. While the $E_{\text {corr }}$ shift for Ti Grade 7 will probably be somewhat different than that of Stainless Steel Type $316 \mathrm{~L}$, it is doubtful that the shift will ever be sufficient for $E_{c o r r}$ to exceed $E_{\text {critical }}$, and therefore will not lead to initiation of localized corrosion processes.

Smailos and Köster (1987 [DIRS 159774], Figure 8) observed that even when exposed to a radiation field of $10^{5} \mathrm{rad} / \mathrm{hr}\left(10^{3} \mathrm{~Gy} / \mathrm{hr}\right)$ in salt brines containing aggressive oxidants, the corrosion rate of titanium-palladium alloy after 610 days exposure stabilized at a rate of less than $1 \mathrm{~nm} / \mathrm{yr}$. The maximum radiation field for the drip shield is expected to be about $10^{2} \mathrm{~Gy} / \mathrm{hr}$. In the absence of the radiation field the corrosion rate stabilized at about $0.1 \mathrm{~nm} / \mathrm{yr}$.

Gamma irradiation exposure experiments in aggressive $\mathrm{MgCl}_{2}$ brines showed, even at dose rates above $1,000 \mathrm{rad} / \mathrm{hr}$, only a minor enhancement of film growth rates on Ti Grade 7, and passivity was not threatened (Shoesmith and King 1998 [DIRS 112178], p. 30). Based on this data it is concluded that, even in aggressive $\mathrm{MgCl}_{2}$ brines, the radiation levels in the repository will not be high enough to result in an enhancement of corrosion processes on Ti Grade 7.

\subsubsection{Microbially Influenced Corrosion}

Corrosion handbooks and literature reviews generally state that titanium alloys are immune to microbially influenced corrosion (Revie 2000 [DIRS 159370], Chapter 47; Little and Wagner 1996 [DIRS 131533]; Brossia et al. 2001 [DIRS 159836], Section 4.1.3). It is the remarkable stability of the $\mathrm{TiO}_{2}$ passive film formed on titanium alloys that confers this immunity. While titanium is susceptible to biofouling in seawater solutions, the biofilm does not compromise the integrity of the passive film and, therefore, biofouled titanium maintains its resistance to localized corrosion processes (Revie 2000 [DIRS 159370], Chapter 47). It has been reported that production of nitrates, polythionates, thiosulfates, and oxygen associated with aerobic biologic activity does not significantly increase the corrosion rate of titanium alloys (Brossia et al. 2001 [DIRS 159836], Section 4.1.3).

Steep gradients in $\mathrm{O}_{2}$ and $\mathrm{pH}$ can exist within biofilms; typically aerobic and near neutral in the outer layers becoming acidic and low in $\mathrm{O}_{2}$ close to the metal surface (Shoesmith and Ikeda 1997 [DIRS 151179], Section 6). Hydrogen peroxide has been detected in biofilms at millimolar levels, the amount of which is thought to be controlled by bacteria enzymes during the aerobic respiration process (Shoesmith and Ikeda 1997 [DIRS 151179]). Hydrogen peroxide maintains a low $\mathrm{pH}(<3)$ near the metal by oxidizing metal cations that then undergo hydrolysis. These chemical changes can lead to ennoblement (a shift of the corrosion potential to more positive values) of titanium by up to $500 \mathrm{mV}$ (Shoesmith and Ikeda 1997 [DIRS 151179], Section 6). It is clear from Figure 19 and Figure 20 that $\Delta E$ far exceeds $500 \mathrm{mV}$ at low $\mathrm{pH}$ values (i.e., localized corrosion will not initiate even if the corrosion potential is increased by $500 \mathrm{mV}$ ). Ennoblement can also lead to several beneficial effects including thickening of the passive film and a decrease in the number density of defects (Shoesmith and Ikeda 1997 [DIRS 151179], 
Section 3 and 6). According to Shoesmith et al. (1995 [DIRS 117892]), the initiation of crevice corrosion under biofilms has never been observed for titanium.

Therefore, microbially influenced corrosion will have no significant effect on either general or localized corrosion processes of titanium alloys under the repository exposure conditions.

\subsubsection{Aging and Phase Stability}

Ti Grade 7 is a stabilized alpha $(\alpha)$ phase alloy and possesses outstanding phase stability. While Ti Grade 7 contains small amounts of alloying elements (DTN: MO0003RIB00073.000 [DIRS 152926]), it is essentially a pure titanium alloy that has little capability to form intermetallic compounds under the thermal exposure conditions in the repository.

Pure titanium is an allotropic element (i.e., existing in more than one crystallographic form) (Gdowski 1997 [DIRS 102789]). Above $883^{\circ} \mathrm{C}$, it has the body-centered cubic (bcc) crystal structure called the beta $(\beta)$ phase. Below $883^{\circ} \mathrm{C}$, it transforms to a hexagonal close-packed (hcp) structure called the alpha ( $\alpha$ ) phase. Ti Grades 7 and 16 are $\alpha$-phase alloys and have very small additions of palladium. The solubility of palladium in these materials is about $1 \mathrm{wt} \%$ at $400^{\circ} \mathrm{C}$. The nominal concentrations of palladium in Ti Grades 7 and 16 are well below the solubility limit at this temperature (Gdowski 1997 [DIRS 102789], pp. 1 to 8). Titaniumpalladium intermetallic compounds capable of forming in this system have not been reported to occur in Ti Grades 7 and 16 with normal heat treatments.

The drip shield temperature is governed by the temperature of the underlying waste package. The recommended thermal goals of cladding and drift wall design require that $T_{\text {clad }}{ }^{\max } \leq 350^{\circ} \mathrm{C}$ and $T_{D W}{ }^{\max }{ }_{\text {postclosure }} \leq 200^{\circ} \mathrm{C}$ (Williams 2003 [DIRS 162731], Table 1). The transition from $\alpha$ - to $\beta$-phase titanium should not occur at these temperatures. The cladding on the spent nuclear fuel (SNF) limits the waste package temperature to levels below $350^{\circ} \mathrm{C}$. At these low temperatures, no $\alpha-\beta$ transition will occur and palladium is well below its solubility limit. Such a low temperature on the long-term phase stability and phase-dependent corrosion rate has no detrimental effect. Hua et al. (2002 [DIRS 160670]) tested both the base metal and welded metal of Ti Grade 7 in BSW-12 environment at $60^{\circ} \mathrm{C}, 70^{\circ} \mathrm{C}, 80^{\circ} \mathrm{C}, 90^{\circ} \mathrm{C}, 100^{\circ} \mathrm{C}$, and $105^{\circ} \mathrm{C}$ for up to eight weeks (Hua et al. 2002 [DIRS 160670]; Hua and Gordon 2003 [DIRS 163111]). No difference in weight loss and, therefore, in corrosion rates was observed between the base metal and welds. The boundaries between the welds and heat-affected zone and between the heataffected zone and base metal were invisible and unattacked after the severe test. Therefore, the effects of phase instability possibly caused by thermal processes (e.g., welding) on degradation of Ti Grades 7 and 16 is insignificant. The effects of nonthermal processes of titanium alloys on their corrosion resistance and integrity are negligible.

\subsubsection{Effects of Irregular Environmental Conditions}

A twenty-year atmospheric corrosion study has been performed (Covington and Schutz 1981 [DIRS 151102]) on titanium in marine environments. The maximum corrosion rate was found to be $2.5 \times 10^{-5} \mathrm{~mm} / \mathrm{yr}(25 \mathrm{~nm} / \mathrm{yr})$. In the LLNL tests at LTCTF, approximately half of the samples are submersed and the other half are in the saturated vapor above the aqueous phase. There were 
a limited number of the samples at the water line. No difference in corrosion rates of these samples was observed because of the different environments.

\subsection{SUMMARY ASSESSMENT OF ALTERNATIVE CONCEPTUAL MODELS}

The development and analysis of the alternative conceptual models for dry oxidation and general corrosion are described in Sections 6.4.2 and 6.5.6, respectively. Numerical values for the fitting parameters for the dry oxidation model were developed and typical results for the primary and alternative dry oxidation model are given in Section 6.4. Numerical values for the fitting parameters for the alternative model for general corrosion were not derived because in the absence of values for the long-term Arrhenius (temperature) dependence of the general corrosion, the model is not considered a valid alternative to the primary model. Table 22 summarizes the alternative conceptual models considered.

Table 22. Alternative Conceptual Models Considered

\begin{tabular}{|c|c|c|c|}
\hline $\begin{array}{c}\text { Alternative } \\
\text { Conceptual Model }\end{array}$ & Key Characteristics & $\begin{array}{c}\text { Summary of Subsystem } \\
\text { Evaluation }\end{array}$ & $\begin{array}{c}\text { TSPA } \\
\text { Evaluation } \\
\text { Recommended }\end{array}$ \\
\hline $\begin{array}{l}\text { Logarithmic dry } \\
\text { oxidation model }\end{array}$ & $\begin{array}{l}\text { 1) Oxide layer fully stabilizes after a } \\
\text { short exposure time } \\
\text { 2) Oxide layer completely stops } \\
\text { oxygen diffusion to metal/oxide } \\
\text { interface }\end{array}$ & $\begin{array}{l}\text { Insufficient long-term data to } \\
\text { justify nonconservative model }\end{array}$ & No \\
\hline $\begin{array}{l}\text { General corrosion } \\
\text { cumulative distribution } \\
\text { function adjusted for } \\
\text { parabolic kinetics }\end{array}$ & $\begin{array}{l}\text { 1) Corrosion rate decreases } \\
\text { parabolically with time. } \\
\text { 2) Dry oxidation temperature } \\
\text { dependence (Arrhenius term) } \\
\text { applies to general corrosion }\end{array}$ & $\begin{array}{l}\text { Insufficient long-term data to } \\
\text { justify nonconservative model }\end{array}$ & No \\
\hline $\begin{array}{l}\text { General corrosion } \\
\text { cumulative distribution } \\
\text { function adjusted for } \\
\text { experimental artifact } \\
\text { of negative corrosion } \\
\text { rates for some } \\
\text { samples }\end{array}$ & $\begin{array}{l}\text { 1) A consistent and reproducible } \\
\text { bias occurred in the LTCTF tests }\end{array}$ & $\begin{array}{l}\text { The nature of the short-term } \\
\text { corrosion testing is such that the } \\
\text { closeness of the before-and-after } \\
\text { weight-loss measurements will } \\
\text { be consistently unpredictable }\end{array}$ & No \\
\hline $\begin{array}{l}\text { General corrosion } \\
\text { rate levels off after a } \\
\text { short exposure period } \\
\text { and becomes } \\
\text { essentially zero }\end{array}$ & $\begin{array}{l}\text { 1) Parabolic corrosion kinetics } \\
\text { operative over a short time } \\
\text { 2) Corrosion product layer on the } \\
\text { titanium is tenacious, adherent, and } \\
\text { protective of the underlying metallic } \\
\text { substrate }\end{array}$ & $\begin{array}{l}\text { Common practice in the literature } \\
\text { of titanium usage to take } \\
\text { corrosion rate under certain } \\
\text { exposure conditions as "nil" }\end{array}$ & No \\
\hline
\end{tabular}

\subsection{SUMMARY OF PRIMARY MODEL}

\subsubsection{Model Implementation}

Figure 1 and Figure 3 summarize the models for the dry oxidation, general corrosion, and localized corrosion of Ti Grade 7. The threshold $R H$ is first used to determine whether dry oxidation, humid-air corrosion, or aqueous-phase corrosion will predominate. If $R H<R H_{\text {critical }}$, the parabolic oxide growth law represented by Equation 9 is used to calculate the dry oxidation corrosion rate as a function of temperature. 
If the threshold $R H$ is exceeded, humid-air corrosion or aqueous-phase corrosion will occur. The inner surfaces the drip shield will only experience no-drip condition (humid-air corrosion). The outer drip shield surface can be exposed under either drip (aqueous-phase corrosion) or no-drip (humid-air corrosion) conditions. The corrosion and critical potentials are used to determine whether the mode of attack is general corrosion only or general corrosion and localized corrosion. The correlation of data represented by Equations 38 and 39 are used as the basis for estimating these potentials.

In the implementation of the general corrosion models, the corrosion rates will be based on the cumulative distribution function values tabulated in Table 16 and Table 17, and shown in Figure 12 and Figure 13, to simulate the inner and outer surfaces of the drip shield, respectively (Section 6.5). Also, because there is no functional relationship between the corrosion rates at any particular position on a single drip shield, between different drip shields, or on the chemical environment for each realization, there will be no variability in the rate selected from the cumulative distribution functions within a given realization of the model.

The possible influences of $\mathrm{CaCl}_{2}$ and fluoride ions on the corrosion behavior of titanium alloys have been evaluated. It is concluded that the influences of $\mathrm{CaCl}_{2}$ and fluoride ions are insignificant. The effect of gamma radiolysis, aging, and microbially influenced corrosion on the corrosion behavior of the drip shield is judged to be insignificant given the level of other uncertainties in the corrosion models.

\subsubsection{Summary of Primary Model Uncertainties}

Uncertainties associated with the formulation of the dry oxidation model are discussed in Section 6.4.3. Data uncertainties associated with the cumulative distribution functions for the inner and outer surfaces of the drip shield are the result of uncertainties in the LTCTF experimental weight-loss measurements for the 1-year corrosion samples. The number of significant figures used in reporting the corrosion rate data in and Table 16 and Table 17 (Section 6.5.6) are not intended to imply that the experimental coupon weight-loss values could be measured to that degree of accuracy. The data uncertainties result from possible bias in the 1-year weight-loss measurements that form the basis of the cumulative distribution functions. The uncertainties in rate data based on error analysis of weight-loss measurements are analyzed in Section 6.5.4.1 and showed that uncertainties in corrosion penetration rates less than approximately $170 \mathrm{~nm} / \mathrm{yr}$ (the $4 \sigma$ value discussed in Section 6.5.4) were indistinguishable from measurement error. This creates a potential bias toward higher corrosion rates due to the measurement uncertainties and rejection of samples showing "negative" weight gains. If incorporated into the cumulative distribution functions, these negative values would offset some of the positive-only cumulative distribution function rates over many realizations.

Parametric uncertainties in the general corrosion models are due to the formulation of the cumulative distribution functions and the manner in which they are applied over the service lifetime of the drip shield. These parametric uncertainties result from the application of the cumulative distribution functions based on 1-year corrosion rate data over time spans of 10,000 years or more. Highly corrosion-resistant materials such as titanium generally exhibit parabolic or logarithmic reaction kinetics (i.e., the rate of the corrosion reaction decreases in time as a protective film forms on the surface). This effect is not factored into the 1-year cumulative 
distribution function data. The uncertainty introduced by not factoring parabolic or logarithmic kinetics into the cumulative distribution function models is solely in the direction of conservatism (i.e., the rates taken from the cumulative distribution functions will always be greater than if parabolic or logarithmic kinetics were accounted for). These uncertainties are analyzed in Section 6.5.4.1.

The "negative" weight losses measured for some samples (Figure 10 and Figure 11) represented a physically unlikely situation and a source of uncertainty in the cumulative distribution function models. The range of negative corrosion rates shown in these figures may be taken as an indication of a negative bias in the measurements. These uncertainties due to measurement bias in the 1-year cumulative distribution functions are expected to be offset by the lower rates that would result from accounting for the parabolic or logarithmic kinetics that could control longterm corrosion. In this way, the uncertainties in the general corrosion rates may be regarded as being already incorporated in the cumulative distribution functions (i.e., each data point in the drip cumulative distribution function has $100 \%$ uncertainty within the approximately 0 to 320 $\mathrm{nm} / \mathrm{yr}$ range shown in Figure 13 and each data point in the no-drip cumulative distribution function has $100 \%$ uncertainty within the approximately 0 to $113 \mathrm{~nm} / \mathrm{yr}$ range shown in Figure 12). The TSPA realizations should directly use the cumulative distribution function sampled values, and the zero rate and maximum rate values for each cumulative distribution function are bounding.

Uncertainties associated with the implementation of the localized corrosion model are primarily associated with whether the chemical conditions under which $E_{\text {corr }}$ would exceed $E_{\text {critical }}$ could ever occur in the repository. The analyses in Section 6.6 indicate that localized corrosion is very unlikely to occur within the likely range of potential water chemistries.

\subsection{DESCRIPTION OF BARRIER CAPABILITY}

10 CFR 63 [DIRS 156605] defines a barrier as "any material, structure, or feature that, for a period to be determined by NRC, prevents or substantially reduces the rate of movement of water or radionuclides from the Yucca Mountain repository to the accessible environment, or prevents the release or substantially reduces the release rate of radionuclides from the waste." 10 CFR 63.102 (h) and 10 CFR 63.113 (a) [DIRS 156605] require that the repository system must include multiple barriers, both natural and engineered.

The capability of a barrier is defined by its ability to achieve one or more of the functions described above (i.e., the extent to which it can prevent or delay the movement of water or radionuclides, or prevent or reduce the release rate from the waste). In this report, the drip shield is considered as the barrier to prevent or reduce water flow that could contact the waste package, and, in the event of a waste package breach, prevents or reduces water flow from contacting the waste form. The drip shields divert any moisture that might seep from the drift walls, including condensed water vapor, around the waste packages to the drift floor for thousands of years. Because of the low corrosion rates of titanium (Section 6.5.4.2), the initial breaches of the drip shields due to corrosion degradation processes will not occur until approximately 35,000 years (obtained by dividing the $15 \mathrm{~mm}$ DS thickness by the sum of the maximum values in Table 16 and Table 17). Therefore, even in the event of a breach of a waste package before its corresponding drip shield, advective transport of radionuclides cannot occur until after 
approximately 35,000 years. The ability of the drip shield to prevent or reduce water flow is the property that makes the drip shield a part of the engineered barrier system.

The analyses in this report show that the rate of general corrosion of the drip shield is small enough that the primary model and the alternative conceptual models all indicate that the maximum extent of general corrosion (dry oxidation, general corrosion on inner surfaces, and general corrosion on outer surfaces) penetration would be on the order of a few millimeters after 10,000 years, compared to a drip shield thickness of $15 \mathrm{~mm}$. The localized corrosion analysis in this report shows that there would be no localized corrosion (pitting, crevice corrosion, microbially influenced corrosion, etc.) under the environmental conditions to which the drip shield is exposed. 
INTENTIONALLY LEFT BLANK 


\section{MODEL VALIDATION}

Models described in this report are expected to adequately predict drip shield degradation processes of the under the exposure conditions expected in the repository for a period of at least 10,000 years. This long time of application makes it difficult to validate these models in the usual way, i.e., by comparison of model predicted values with those observed experimentally for the whole range of time (ASTM C 1174-97 1998 [DIRS 105725], Sections 19.3 and 20.4). Consequently, by validating the input parameter values used and comparing these parameters and model predictions to available peer reviewed data, these models are validated. As required by AP-2.27Q and stated in the technical work plan for this activity (BSC 2004 [DIRS 171583], Table 2-1), the level of confidence (i.e., Level of Validation) required for the models developed in this report is Level I meaning the Level of Model Importance is low. An adequate level of confidence in the drip shield degradation models will be obtained by building confidence in the methods used to develop the models and corroborating or validating the model output values and alternate conceptual models with those available in the peer reviewed scientific literature.

\subsection{CONFIDENCE BUILDING DURING MODEL DEVELOPMENT TO ESTABLISH SCIENTIFIC BASIS AND ACCURACY FOR INTENDED USE}

For Level I validation, the development of the model should be documented in accordance with the requirements of Section 5.3.2(b) of AP-SIII.10Q. The development of the drip shield degradation models was conducted according to these criteria, as discussed below:

(1) Selection of input parameters and/or input data, and a discussion of how the selection process builds confidence in the model. (AP-SIII.10Q, 5.3.2(b) (1) and AP-2.27Q, Attachment 3, Level I (a))

The inputs to the drip shield degradation models have all been obtained from controlled sources (Table 2), including discussion about selection of input and design parameters. Assumptions are described in Section 5. Detailed discussion about model concepts can be found throughout Section 6 and particularly in Section 6.3. Thus, this requirement can be considered satisfied.

(2) Description of calibration activities, and/or initial boundary condition runs, and/or run convergences, simulation conditions set up to span the range of intended use and avoid inconsistent outputs, and a discussion of how the activity or activities build confidence in the model. Inclusion of a discussion of impacts of any non-convergence runs. (AP-SIII.10Q, 5.3.2(b)(2); AP-2.27Q, Attachment 3, Level I (e)).

Discussion of initial and boundary conditions are described in Sections 1.2, 6, and 8, where the drip shield degradation models and ranges of application are discussed. Sections 6.4, 6.5, and 6.6 provide discussion of various model results. Discussion about nonconvergence runs is not applicable to this report because no nonconvergences were encountered. Thus, this requirement can also be considered satisfied.

(3) Discussion of the impacts of uncertainties to the model results including how the model results represent the range of possible outcomes consistent with 
important uncertainties. (AP-SIII.10Q 5.3.2(b)(3); AP-2.27Q, Attachment 3, Level 1 (d) and (f)).

Uncertainties associated with the drip shield degradation models are summarized in Sections 6.9.2 and 8. More detailed discussions of the impact of uncertainties on the model results developed in this report are discussed in Sections 6.4.3 and 6.5.4, and throughout Section 6.6.

Section 6.4.3 discusses the effects of data uncertainties on the dry oxidation model developed in this report. Uncertainties in the conceptual model and parameters used for dry oxidation modeling were characterized and quantified. Section 6.5.4 discusses uncertainty in the drip shield general corrosion model. Both uncertainty in the measurement and analysis process were considered. Throughout Section 6.6 uncertainty in the drip shield localized corrosion model is discussed. Localized corrosion in carbonate-based solutions and chloride-based brines was considered.

(4) Formulation of defensible assumptions and simplifications. (AP-2.27Q, Attachment 3, Level I (b)).

Discussion of assumptions and simplifications are provided in Section 5 with appropriate technical bases for their use.

(5) Consistency with physical principles, such as conservation of mass, energy, and momentum. (AP-2.27Q, Attachment 3, Level I (c)).

Consistency with physical principles is demonstrated by the conceptual and mathematical formulations found throughout Section 6 and particularly in Section 6.3.

\subsection{CONFIDENCE BUILDING AFTER MODEL DEVELOPMENT TO SUPPORT THE SCIENTIFIC BASIS OF THE MODEL}

Model validation activities associated with drip shield degradation modeling are identified in Table 2-1 of Technical Work Plan For: Regulatory Integration Modeling and Analysis of the Waste Form and Waste Package (BSC 2004 [DIRS 171583]).

Activity One: Are the corrosion rates of the general corrosion model of the drip shield reasonable and consistent with the experimental rates measured for the conditions expected in the repository?

Activity Two: Is the response of the correlation for $E_{\text {corr }}$ and $E_{\text {critical }}$ of the drip shield reasonable and consistent with the literature data of relevant corrosion resistant titanium alloys and available analogues for the conditions expected in the repository?

The Technical Work Plan specifies that the corroborating data must match qualitatively. These validation activities are consistent with those in AP-SIII.10Q, Section 5.3.2c)3). Several alternative conceptual models were also considered consistent with AP-SIII.10Q, Section 5.3.2c)2). 
The model validation documented in this section addresses the dry oxidation, the general corrosion, and the localized corrosion models for drip shield. The dry oxidation model covers the situation when the relative humidity is below the threshold relative humidity $\left(R H_{\text {critical }}\right)$ (Assumption 5.2). The general corrosion models cover the corrosion of the inner surface and outer surface of the drip shield. The localized corrosion is modeled based on the $\Delta E$ approach. The purpose of the localized corrosion model is to characterize the localized degradation of the drip shield. Although no localized corrosion will occur, the presence of crevices on the outer surface of the drip shield is considered by modeling general corrosion of the outer surface of the drip shield using the "weight-loss plus crevice" corrosion rate data. The level of confidence required of the models is Level I, as explained in Table 2-1 of Technical Work Plan For: Regulatory Integration Modeling and Analysis of the Waste Form and Waste Package (BSC 2004 [DIRS 171583]).

Model validation is accomplished in part by comparing experimental measurements of key model parameters to corroborative data that has been published in the open scientific literature. Calculated corrosion rates can be compared to experimental measurements to ensure that those rates are reasonable.

\subsection{DRY OXIDATION MODEL}

The validation activity used to determine that the required level of confidence (Level I) in the dry oxidation model has been obtained is whether the corrosion rates (or a range of the rates) of the general corrosion model (the dry oxidation portion) of the drip shield are reasonable and consistent with rates measured for the conditions expected in the repository. In this section, the data used to develop the dry oxidation model (Schutz and Thomas 1987 [DIRS 112147], p. 685, Figure 25) is compared to data from Ogden (1960 [DIRS 160556], Chapter 30, Figure 30.18). The parabolic functional form used in the primary dry oxidation model is also compared to the logarithmic functional form considered as an alternative conceptual model (Section 6.4.2).

The development of the dry oxidation model used well established facts (the parabolic law and logarithmic law for oxide growth) and handbook data (Schutz and Thomas 1987 [DIRS 112147]) for the dry air oxidation of titanium to formulate the models (Section 6.4) and other independent literature data to confirm the predictions of the model are reasonable and the required level of confidence obtained, as discussed below.

The dry oxidation form of general corrosion is the direct oxidation of the titanium surface by oxygen in dry air. Validation of the dry oxidation model for Ti Grade 7 is difficult because (1) the paucity of quantitative data concerning very long-term low-temperature air oxidation and (2) the high degree of oxidation resistance of titanium and titanium alloys (the primary reason for the selection of Ti Grade 7 as the drip shield material). This makes quantitative comparison of the model results and literature data difficult. Experimental data for the oxidation rates are obtained by small weight-loss or weight-gain measurements (i.e., comparing before/after specimen weights that are nearly identical to each other). The dry oxidation model was primarily developed using weight-loss data (i.e., the weight difference between the samples before the corrosion test and the samples after posttest chemical or mechanical removal of the oxide layer), such as from the ASM Handbook (Schutz and Thomas 1987 [DIRS 112147], p. 685, Figure 25), a widely accepted source for this type of data. Ogden (1960 [DIRS 160556], Chapter 30, Figure 
30.18) presented short-term weight-gain data (i.e., obtained by weighing samples before and after exposure without removal of the oxide layer) for the oxidation of unalloyed titanium in dry air at several temperatures between 480 and $2,370^{\circ} \mathrm{F}$ (approximately $250^{\circ} \mathrm{C}$ to $1,300^{\circ} \mathrm{C}$ ). $\mathrm{Oggden}$ (1960 [DIRS 160556], Chapter 30, Figure 30.18) gives values for the weight-gain rates due to oxidation of approximately $0.0025,0.025$, and $0.045 \mathrm{mg} / \mathrm{cm}^{2}-\mathrm{hr}$, respectively at $750^{\circ} \mathrm{F}, 950^{\circ} \mathrm{F}$, and $1,110^{\circ} \mathrm{F}$ measured at an early stage of exposure. Using a density of about $4.5 \mathrm{~g} / \mathrm{cm}^{3}$ for unalloyed titanium, these values translate to oxide layer depth growth rates of approximately 6.2, 61.7, and $110 \mathrm{~nm} / \mathrm{hr}$ at these respective temperatures. For comparison purposes, the Schutz and Thomas (1987 [DIRS 112147]) values given in Table 8 at these approximate temperatures are 5.6 (11.1 nm in two hours), 15.6 (31.1 nm in two hours), and 48.3 (96.7 nm in two hours) $\mathrm{nm} / \mathrm{hr}$, respectively. Thus, the Ogden (1960 [DIRS 160556], pp. 678 to 696) data validates the rates used to develop the dry oxidation model. From $250^{\circ} \mathrm{C}$ to $600^{\circ} \mathrm{C}$, short-term testing shows a transition in oxide layer growth kinetics from logarithmic to parabolic for titanium, with logarithmic kinetics being observed below $\sim 400^{\circ} \mathrm{C}$, and parabolic kinetics subsequently persisting to $\geq 600^{\circ} \mathrm{C}$. A key feature of logarithmic growth kinetics is that oxide growth is much slower than that predicted by the parabolic growth law (Section 6.3.1). Oxide growth by a logarithmic law will eventually lead to a virtually constant thickness of the oxide (Section 6.4.2). However, the times over which these observations were made (hours) were small compared to the repository regulatory period (thousands of years). Oxide layer growth could continue if the mechanism of oxide growth at the oxide-air interface oxide was replaced by oxygen dissolution into the metal at the metal-oxide interface. On a laboratory timeframe, such a process would not be observed at temperatures in the $200^{\circ} \mathrm{C}$ range because the diffusion coefficient for oxygen in $\alpha$ titanium is very low at low temperature. Thus, the absence of long-term oxidation data makes it difficult to conclude that a continuing very slow oxidation with a logarithmic growth rate would be maintained over repository-relevant time periods. For this reason the more conservative parabolic growth rate was considered as the primary dry oxidation model.

Fukusuka et al. (1980 [DIRS 160395]) noted that surface oxide films formed by thermal oxidation (an air exposure condition similar to the drip shield exposure condition after emplacement) were much more tenacious and resistant to subsequent aqueous immersion corrosion than oxide films formed on titanium by aqueous anodization. Surface oxide films approximately $37 \mathrm{~nm}$ thick formed by thermal oxidation remained unchanged after immersion for 250 hours in $\mathrm{HCl}$ solutions, whereas anodically formed oxide films approximately $100 \mathrm{~nm}$ thick decreased to only a few nanometers after only 20 hours immersion. Moreover, Smailos and Köster (1987 [DIRS 159774], Figure 8) observed that even when exposed to a radiation field of $10^{5} \mathrm{rad} / \mathrm{hr}\left(10^{3} \mathrm{~Gy} / \mathrm{hr}\right)$ in salt brines containing aggressive oxidants, the corrosion rate of titanium -palladium alloy after 610 days exposure stabilized at a rate of less than $1 \mathrm{~nm} / \mathrm{yr}$. The maximum radiation field for the drip shield is expected to be about $10^{2} \mathrm{~Gy} / \mathrm{hr}$. In the absence of the radiation field, the corrosion rate stabilized at about $0.1 \mathrm{~nm} / \mathrm{yr}$. This indicates that the oxide film that forms on the drip shield in under much less aggressive dry air conditions would be stable or increase in thickness only very slowly, on the order of tens of nanometers over the regulatory period. Thus, the parabolic model for dry oxidation may be taken as being validated as a conservative predictor of the dry oxidation of the drip shield (also see Section 6.3.1).

From the foregoing analysis of literature data and information, it has been determined that the required level of confidence (Level I) in the dry oxidation model has been obtained. 


\subsection{GENERAL CORROSION MODEL}

The validation activity used to determine that the required level of confidence (Level I) in the models for the inner and outer surfaces of the drip shield has been obtained is whether the corrosion rates (or a range of the rates) of the general corrosion models of the drip shield are reasonable and consistent with the rates measured for the conditions in the repository. In this section, the 1-year general corrosion rates for Ti Grade 16 (used for the base case drip shield general corrosion model) are compared to literature data for the corrosion rates of relevant titanium alloys (Mattsson and Olefjord 1990 [DIRS 111885]; Molecke et al. 1982 [DIRS 161678]). Also, laboratory data (5-year Ti Grade 16 data and 2.5-year Ti Grade 7 data) not used to develop the base case drip shield general corrosion model are compared to the 1-year Ti Grade 16 data used for model development.

General corrosion (or passive dissolution) by water or water vapor is the uniform thinning of the drip shield at its corrosion potential $\left(E_{\text {corr }}\right)$. The general corrosion model is based on weight-loss measurements of Ti Grade 16, which is an analog of Ti Grade 7, specimens exposed in a range of exposure conditions at the LTCTF. The 1-year data are used for the model development, while the 5-year data are used for the model validation.

The outer surface of the drip shield is a worst-case scenario considering the more complicated chemistry and geometry the outer surface will see. The corrosion rates of the outer surfaces are treated by using the combination of weight-loss specimen data and weight-loss plus crevice specimen data. The model shows that at $0 \%, 50 \%$, and $100 \%$, the corrosion rates are 0,24 , and $320 \mathrm{~nm} / \mathrm{yr}$, respectively (Section 6.5.5, Table 17, and Figure 13). These rates are independent of solution composition, $\mathrm{pH}$ over the range 2.7 to 8.0 , and temperature in the range of $60^{\circ} \mathrm{C}$ to $90^{\circ} \mathrm{C}$. There is good evidence to justify that the values obtained are consistent with values obtained by others using different measurement techniques.

Mattsson and Olefjord (1990 [DIRS 111885]), using a combination of depth profiling by ion sputtering and x-ray photoelectron spectroscopy (XPS), measured (over a six-year period) rates in the range $0.5 \mathrm{~nm} / \mathrm{yr}$ to $4 \mathrm{~nm} / \mathrm{yr}$ on Ti Grades 2 and 7 specimens in compacted clays saturated with saline solutions at $95^{\circ} \mathrm{C}$. The absence of a temperature dependence $\left(90^{\circ} \mathrm{C}\right.$ to $\left.200^{\circ} \mathrm{C}\right)$ was observed by Smailos et al. (1986 [DIRS 119592], 1990 [DIRS 154820]) and Smailos and Köster (1987 [DIRS 159774]) in aggressive German Q-brines ( $\mathrm{NaCl} \mathrm{1.4 \% ;} \mathrm{KCl} 4.7 \% ; \mathrm{MgCl}_{2} 26.8 \%$; $\mathrm{MgSO}_{4} 1.4 \% ; \mathrm{H}_{2} \mathrm{O} 65.7 \% ; \mathrm{pH}=4.9$ at $25^{\circ} \mathrm{C}$ ) over an exposure period of $\sim 3.5$ years. Even at $250^{\circ} \mathrm{C}$, Molecke et al. (1982 [DIRS 161678]) found a corrosion rate for Ti Grade 12 of only $400 \mathrm{~nm} / \mathrm{yr}$ in aerated brine similar in composition to the one used by Kim and Oriani (1987 [DIRS 110236]). For Ti Grade 2, Molecke et al. (1982 [DIRS 161678]) obtained an activation energy of $\sim 29 \mathrm{~kJ} / \mathrm{mol}$. Smailos et al. (1986 [DIRS 119592], 1990 [DIRS 154820]), Smailos and Köster (1987 [DIRS 159774]) and Molecke et al. (1982 [DIRS 161678]) used weight change measurements to determine corrosion rates.

The fact that the range of experimental techniques used to measure corrosion rates produced corrosion rates very similar to those obtained by weight change methods on LTCTF specimens clearly indicates that, despite the uncertainties involved in their measurement, the present corrosion rates from the LTCTF specimens are conservatively consistent with expectations. A second significant feature of the corrosion rates reported in these studies is their similarity 
despite the wide range of exposure environments and temperatures used. This is consistent with the observation that the rates measured in the LTCTF tests are effectively independent of environment and temperature. Thus, the absence of a temperature dependence in most other cases suggests an additional important mechanistic feature besides film growth kinetics. The accumulation of surface deposits (LTCTF tests) and the incorporation of brine constituents into the outer layers of the passive film are possible mechanisms.

\subsubsection{Corrosion Rates Based Upon 5-Year Weight-Loss Measurements}

General corrosion rates of Ti Grade 16 in SCW, SDW, and SAW at LTCTF for five years at the LTCTF (DTN: LL030205912251.016 [DIRS 161755]) were obtained under the same test conditions as the 1-year data except the posttest specimen cleaning procedures differed as described in Section 6.5.3. The corrosion rates of Ti Grade 16 in SAW were in general lower than the corrosion rates in SCW and, therefore, not included in this report. The 5-year Ti Grade 16 general corrosion rate data is used for corroborative model validation and is not used for the base case drip shield corrosion model.

The general corrosion rates for Ti Grade 16 based on LTCTF 5-year weight-loss only specimens and weight-loss plus crevice samples in SDW and SCW are shown in Figure 22 and Figure 23, respectively.

Again, these measurements are independent of temperature between $60^{\circ} \mathrm{C}$ and $90^{\circ} \mathrm{C}$. Furthermore, the composition of the test medium (SDW or SCW) had little impact on the measurements. The corrosion rates obtained from the 5-year tests are significantly lower than those obtained based on the 1-year data. The 5-year weight-loss specimen data had a maximum value of about $58 \mathrm{~nm} / \mathrm{yr}$ with most of the other values under $20 \mathrm{~nm} / \mathrm{yr}$. The 5 -year crevice specimen data shows a maximum single value of about $77 \mathrm{~nm} / \mathrm{yr}$ with most of the values below about $30 \mathrm{~nm} / \mathrm{yr}$. The median is at approximately $5 \mathrm{~nm} / \mathrm{yr}$ and $10 \mathrm{~nm} / \mathrm{yr}$ for weight-loss specimens and crevice specimens, respectively. 


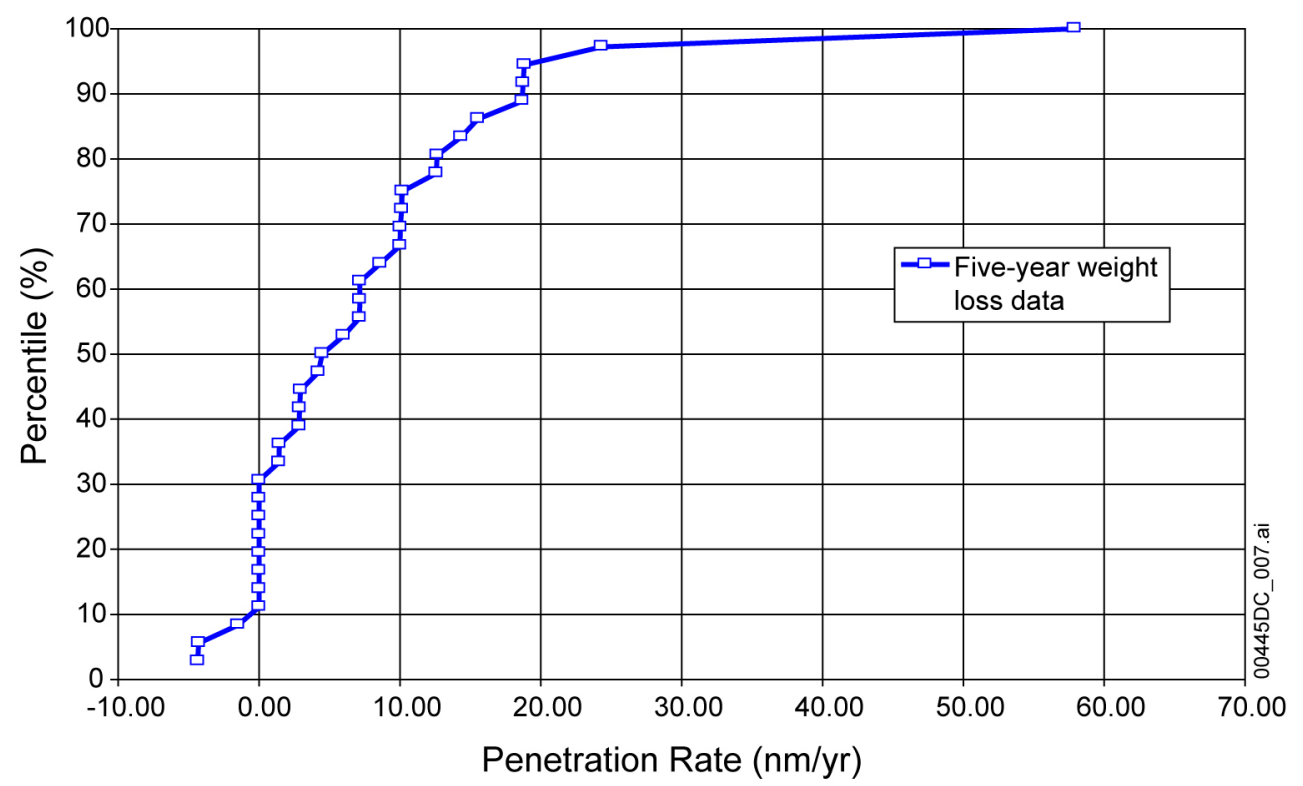

Source Data: DTN: LL030205912251.016 [DIRS 161755].

Output DTN: MO0408MWDGLCDS.002.

Figure 22. Distribution of General Corrosion Rates of Ti Grade 16: LTCTF 5-Year Weight-Loss Specimens

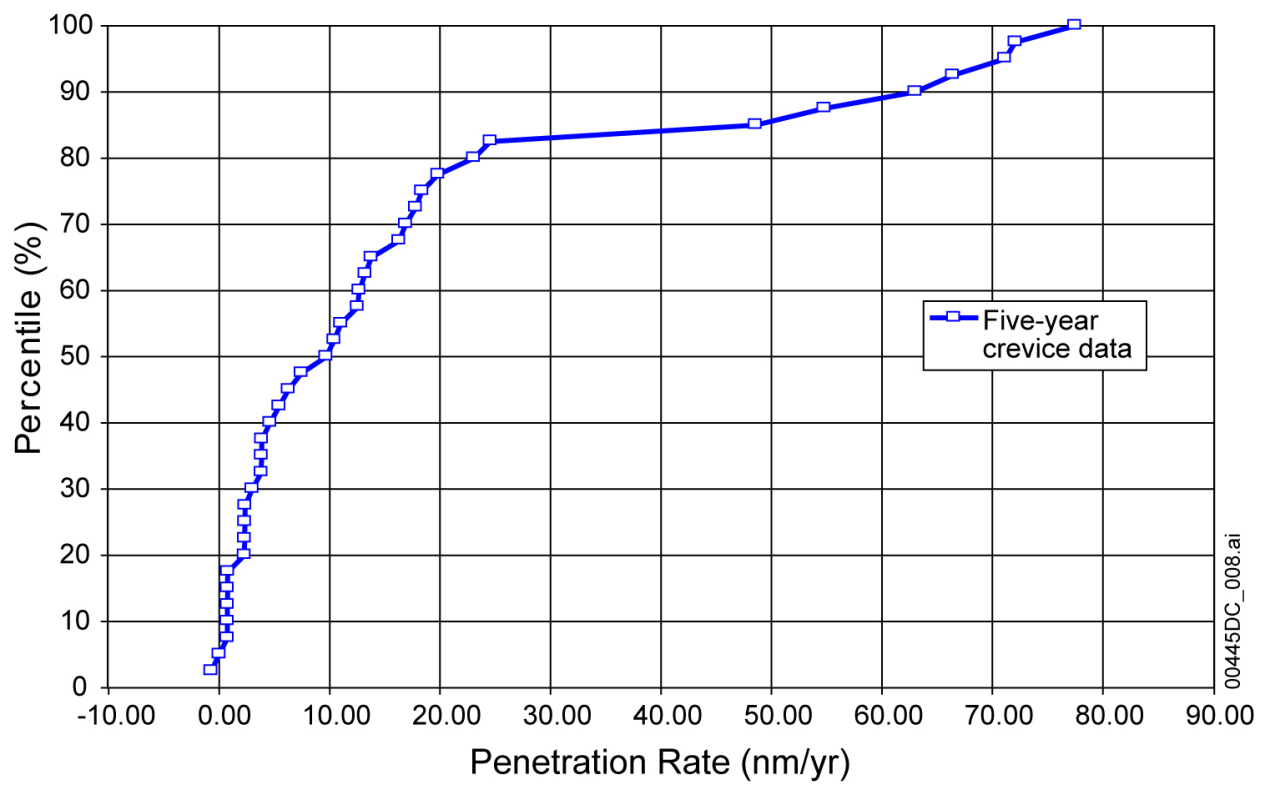

Source Data: DTN: LL030205912251.016 [DIRS 161755].

Output DTN: MO0408MWDGLCDS.002.

Figure 23. Distribution of General Corrosion Rates of Ti Grade 16: LTCTF 5-Year Crevice Specimens

In contrast to the 1-year exposure results, the corrosion rates obtained from the 5-year exposure tests contain fewer negative values. The median corrosion rate for the 5-year data is higher than that of the 1-year data. This is not surprising considering the difference in posttest sample treatment in the 1- and 5-year tests. As indicated earlier in this report, the posttest specimen 
treatments were different for the 1- and 5-year tests. The 1-year specimens were cleaned with deionized water and a nylon brush (Estill 1998 [DIRS 117697], Section 2.2.7.1). In contrast, the 5-year specimens were cleaned more thoroughly and carefully as discussed in DTN: LL030205912251.016 [DIRS 161755] and TIP-CM-51 [DIRS 169585]. Complete descaling was observed and no corrections for scale deposits are needed.

For specimens exposed to SCW and SDW, the 5-year posttest specimens were descaled in a cleaning solution prepared by diluting $150 \mathrm{~mL}$ of concentrated $\mathrm{HCl}$ acid $(37 \% \mathrm{HCl}$ with a specific gravity of 1.19) with deionized water to make $1,000 \mathrm{~mL}$ of solution. The cleaning temperature was ambient. The only modifications to the ASTM methods were an increased immersion time and the use of a drying oven and desiccator to minimize air exposure.

Similar to the treatment of the 1-year data, the cumulative distribution function based on the corrosion rates obtained from the weight-loss only specimens (Figure 22), is used to model the corrosion of the inner surfaces of the drip shield. The cumulative distribution function based on the corrosion rates obtained from the weight-loss only specimens and creviced specimens (Figure 23) is used to model the corrosion of the outer surfaces of the drip shield.

The 5-year corrosion data from the LTCTF show much lower corrosion rates than those based on the 1-year data (Section 6.5.3.1), suggesting that parabolic or logarithmic kinetics may be operative and, thus, help validate that the use of the cumulative distribution functions based on 1-year data (Figure 12 and Figure 13) is a sufficiently conservative representation of longer term corrosion rates. A source of parameter uncertainty discussed in Section 6.5.4.2 is further supported by the initial 5-year corrosion test results, which show corrosion rates lower than the 1-year data. The 5-year weight-loss (the inner surface case) data had a maximum value of $58 \mathrm{~nm} / \mathrm{yr}$ with most of the other values under $20 \mathrm{~nm} / \mathrm{yr}$. The 5 -year crevice (added to the weightloss data for the outer surface case) shows a maximum single value of $77 \mathrm{~nm} / \mathrm{yr}$ with most of the values below about $30 \mathrm{~nm} / \mathrm{yr}$. A comparison of the 5-year data (the cumulative distribution functions shown in Figure 22 and Figure 23) with the 1-year data (the cumulative distribution functions shown in Figure 10 and Figure 11) indicates that physical mechanisms that could have maintained the early corrosion rates, such as maintaining the defect structure in the corrosion layer, apparently do not keep the rates from decreasing over the longer exposure periods. This indicates that the cumulative distribution functions based on the 1-year tests predict long-term rates that are conservative. The 1- and 5-year corrosion data from the LTCTF are compared in Figure 24 (for inner surface) and in Figure 25 (for outer surface). These figures indicate that the 1 -year cumulative distribution functions can be taken as an upper bound limit for the short-term uncertainties for the recommended cumulative distribution functions. 


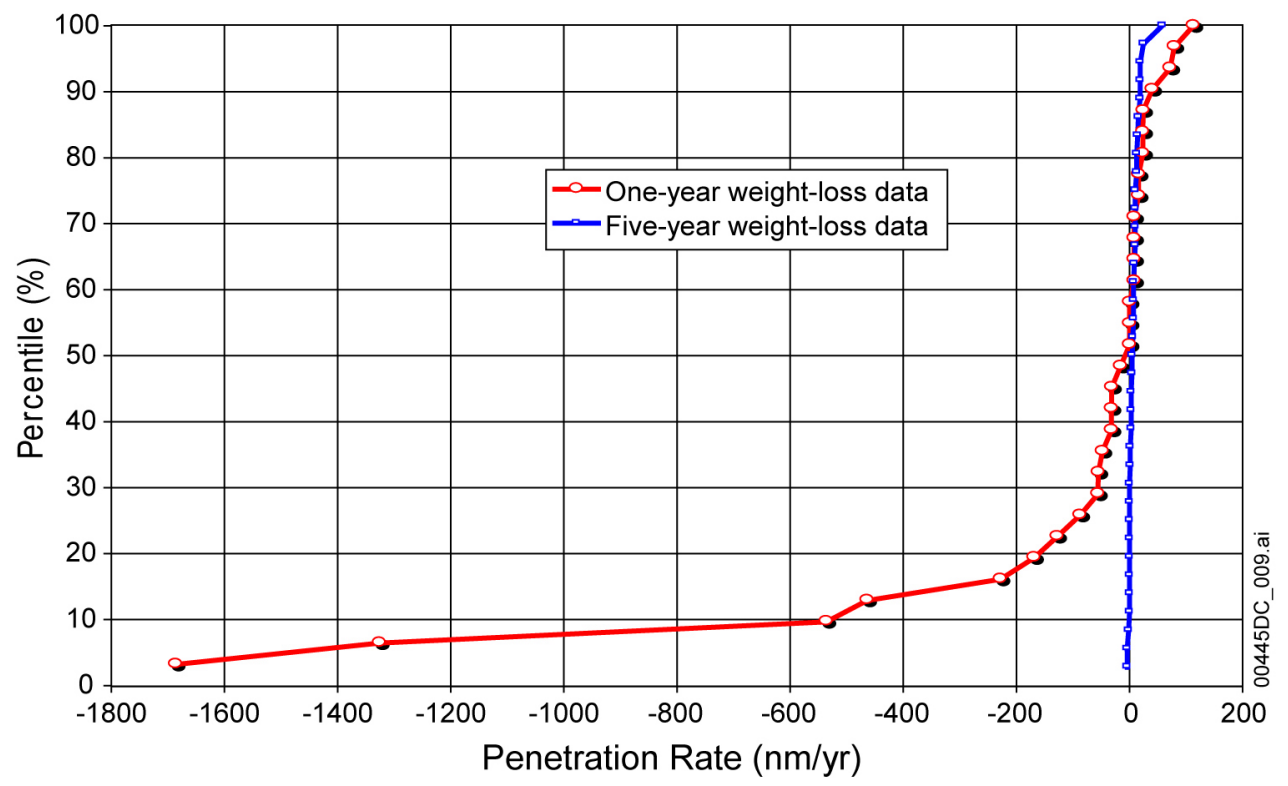

Output DTN: MO0408MWDGLCDS.002.

Figure 24. Comparison of 1-Year and 5-Year Corrosion Rates Obtained from Weight-Loss Specimens

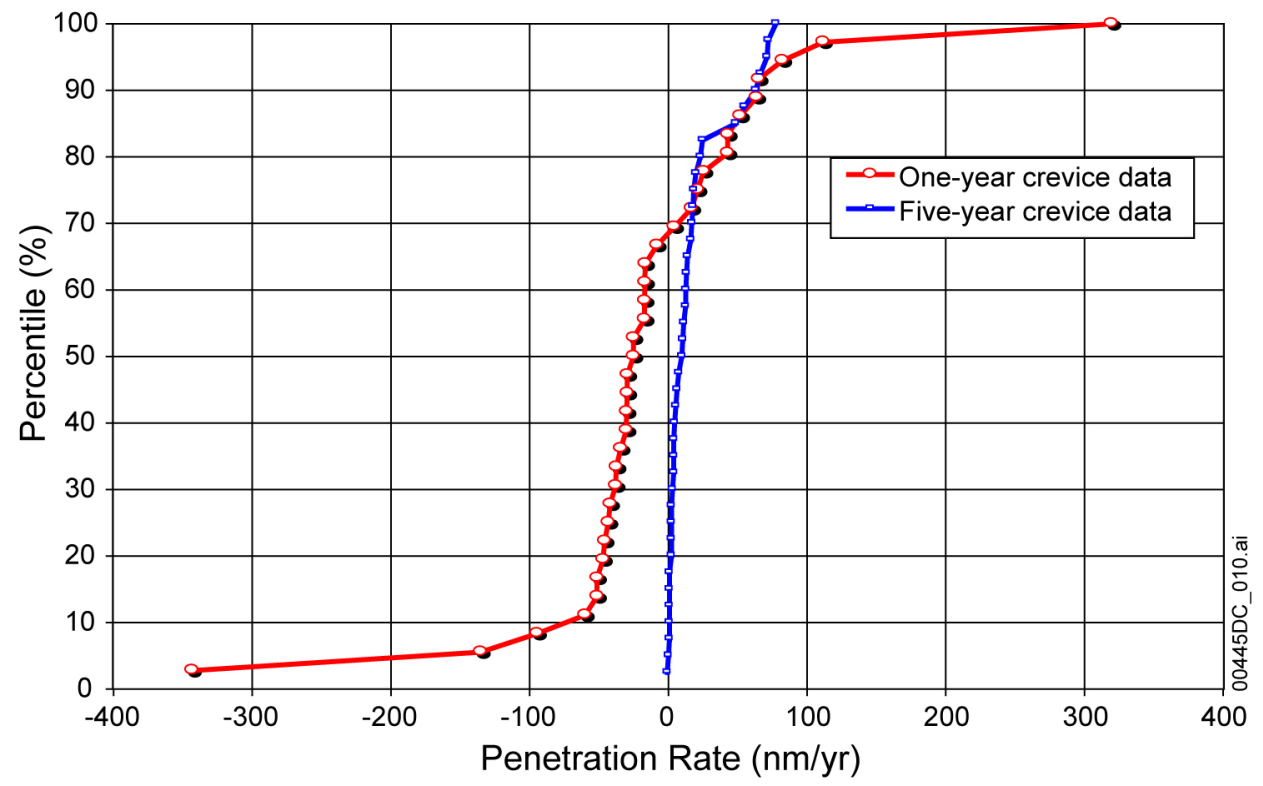

Output DTN: MO0408MWDGLCDS.002.

Figure 25. Comparison of 1-Year and 5-Year Corrosion Rates Obtained from Crevice Specimens

\subsubsection{Comparison of 1-, 2.5-, and 5-Year General Corrosion Rates}

The LTCTF has also obtained corrosion rate data for Ti Grade 7 exposed in both vapor and liquid phases of SAW, SCW, and SDW at $60^{\circ} \mathrm{C}$ and $90^{\circ} \mathrm{C}$ for two and a half (2.5) years with weight-loss specimens and creviced specimens, respectively (DTN: LL030410012251.056 [DIRS 169583]). The data are obtained under the same test conditions as the 1-year and 5-year Ti Grade 16 data. The posttest specimen cleaning procedures for the 2.5 -year test were the same as those for the 5-year Ti Grade 16 data. The 2.5-year Ti Grade 7 corrosion rate data are used for 
corroborative model validation in this document. Plots of the 2.5-year weight-loss and crevice data are shown in Figure 26.
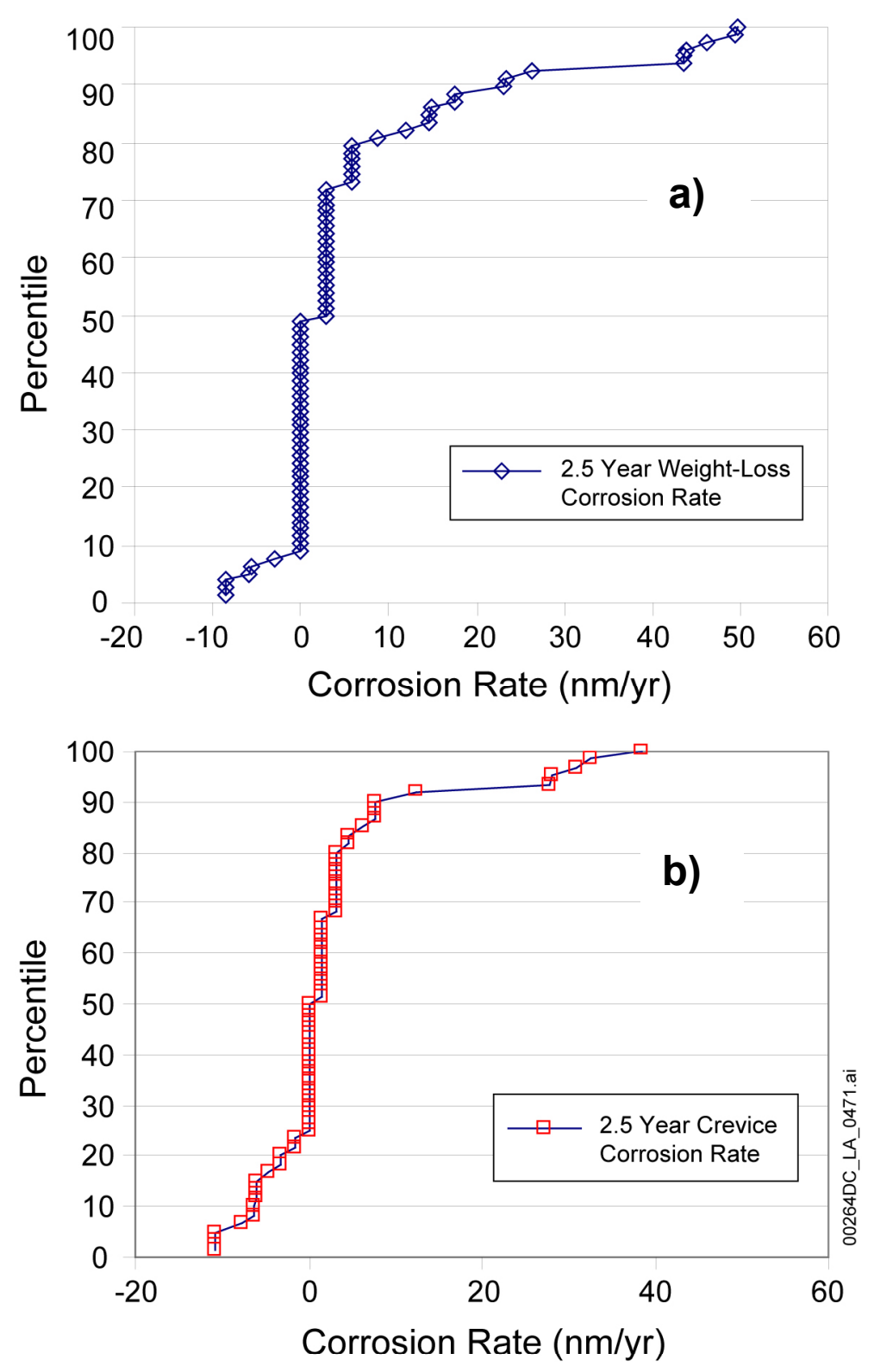

Output DTN: MO0408MWDGLCDS.002.

Figure 26. Ti Grade 7 2.5-Year a) Weight-Loss and b) Crevice Specimen Corrosion Rates

The maximum and median values of 1-year, 2.5-year and 5-year corrosion rate data are summarized in Table 23. 
Table 23. Summary of 1-, 2.5-, and 5-Year Corrosion Data Comparison

\begin{tabular}{|l|c|c|c|c|c|c|}
\hline & \multicolumn{2}{|c|}{ Ti Grade 16 } & \multicolumn{2}{c|}{ Ti Grade 7 } & \multicolumn{2}{c|}{ Ti Grade 16 } \\
\hline & \multicolumn{2}{|c|}{ 1-Year, $\mathbf{n m} / \mathbf{y r}$} & \multicolumn{2}{c|}{ 2.5-Year, $\mathbf{n m} / \mathbf{y r}$} & \multicolumn{2}{c|}{ 5-Year, nm/yr } \\
\hline Specimen Type & Weight-Loss & Crevice & Weight-Loss & Crevice & Weight-Loss & Crevice \\
\hline Median & 0 & 0 & 6 & 3 & 5 & 10 \\
\hline Maximum & 113 & 320 & 50 & 38 & 58 & 77 \\
\hline
\end{tabular}

Output DTN: MO0408MWDGLCDS.002.

A more direct comparison of the 1-, 2.5-, and 5-year maximum corrosion rate data is presented in Figure 27. Three important conclusions can be drawn from Figure 27. First, the corrosion rate of titanium alloys decreases with time parabolically or obeys a power-law (e.g., Rate $=\mathrm{A}^{*} \mathrm{t}^{\mathrm{n}}$ ). Secondly, the 2.5-year maximum corrosion rate, obtained from Ti Grade 7, is apparently lower than the 5-year corrosion rate, obtained from Ti Grade 16. This observation supports the conclusion that the general corrosion resistance of Ti Grade 7 is superior to that of Ti Grade 16. Lastly, the difference between the corrosion rates obtained from the weight-loss specimens and crevice specimens diminishes at the prolonged exposure times.

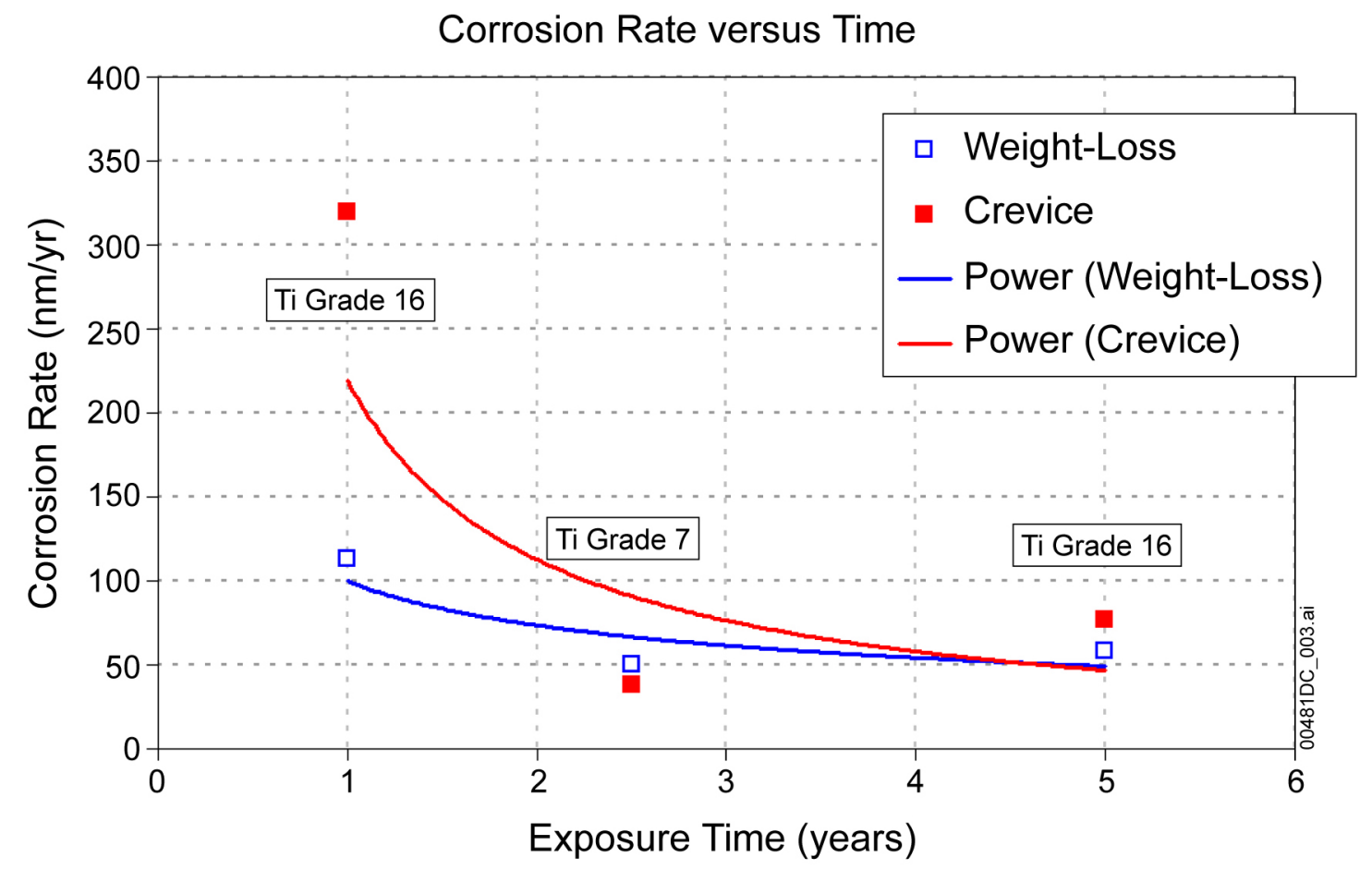

Output DTN: MO0408MWDGLCDS.002.

Figure 27. Comparison of 1-Year (Ti Grade 16), 2.5-Year (Ti Grade 7), and 5-Year (Ti Grade 16) Corrosion Rates Obtained from Weight-Loss Specimens and Crevice Specimens, Showing the Decreasing Trend in Corrosion Rate

During test exposure, the specimens may accumulate silica deposits, thereby complicating the direct conversion of the recorded weight losses to corrosion rates. When measuring corrosion rates it is common to attempt to remove these deposits by using various chemical and physical means that could themselves also introduce uncertainties in the corrosion rates. 
Because the solubility of titanium in the test environments employed is very low, it is possible the specimens experience a weight gain due to a combination of passive oxide growth and the accumulation of the aforementioned surface silica deposits. The surface silica deposits may also impede the corrosion process. Therefore, the corrosion rates will decrease with time because the passive film tends to a steady-state thickness with the increase in exposure period. For rate measurements based on weight changes (i.e., an integrated rate over the total exposure period), this is seen as a decrease in corrosion rate, as clearly demonstrated by comparing the 1-year and 5-year corrosion data.

From the foregoing analysis of literature data and information and comparison of the cumulative distribution function models with the 5-year LTCTF data, it has been determined that the required level of confidence (Level I) in the model has been obtained. The current general corrosion model was validated by comparing the model-predicted rates against values obtained from the literature (e.g., cited results from aggressive industrial applications or from laboratory testing).

\subsection{LOCALIZED CORROSION}

The validation activity used to determine that the required level of confidence (Level I) in $E_{\text {corr }}$ and $E_{\text {critical }}$ determinations for localized corrosion that have been obtained are 1) whether the response of the correlation for $E_{\text {corr }}$ and $E_{\text {critical }}$ of the drip shield is reasonable and consistent with the literature data of relevant corrosion-resistant titanium alloys and available analogues for the conditions expected in the repository. In this section, the corrosion potential analysis developed in Section 6.6 is discussed in relation to analyses presented in the literature (Schutz and Thomas 1987 [DIRS 112147], Table 23; Hua et al. 2004 [DIRS 167022]).

The corrosion potential formulation developed in Section 6.6 was developed using electrochemical and cyclic polarization data. The formulation is validated as discussed below by verification of the test methodology by comparison with appropriate ASTM electrochemical testing standards and by comparison with handbook data. As a result, the appropriate level of confidence (Level I) has been obtained.

The threshold and corrosion potentials for a given material depend on the chemistry and constituents of the water. The general range of threshold potential values (approximately 1,000 to $1,400 \mathrm{mV}$ vs $\mathrm{Ag} / \mathrm{AgCl}$ reference electrode) may be partially validated as conservative for their intended purpose of providing materials criteria by comparison with published Ti Grade 7 breakdown pitting potentials in concentrated $\mathrm{NaCl}$ solutions of approximately 5,200 to $9,600 \mathrm{mV}$ (Schutz and Thomas 1987 [DIRS 112147], Table 23). Factors such as temperature, addition of alloying elements and chloride ion concentration may shift the pitting potential slightly towards either more noble or less noble directions around about 7 V (SCE) (Hua et al. 2004 [DIRS 167022], Figure 12). The worst-case scenario is that the addition of $6 \%$ aluminum and $4 \%$ vanadium (to yield Ti Grade 5) will lower the pitting potential to about $2 \mathrm{~V}_{(\mathrm{SCE})}$. However, the open-circuit potentials of titanium alloys under the repository conditions are around $0 \mathrm{~V}$ (Hua et al. 2004 [DIRS 167022], CRWMS M\&O 2000 [DIRS 154666]). Therefore, pitting is not considered a localized corrosion scenario of titanium alloys under repository conditions. 
Crevice corrosion is considered as the scenario of localized corrosion of titanium alloys in this document. The drip shield localized corrosion analysis in this report is based on the comparison of threshold and corrosion potentials for titanium alloys at various temperature, $\mathrm{pH}$, and chloride levels. The corrosion and threshold potentials used to plot the potential vs composition and temperature curves (Figure 19 and Figure 20) were obtained from cyclic polarization curves (Figure 14 through Figure 18). The test methodology used was that in ASTM G 5-94 [DIRS 117479], but using more repository-relevant water chemistries. This standard is widely used and accepted for this type of polarization testing.

Because no crevice corrosion attack was observed in LTCTF tests for up to five years of exposure in repository related environments and the cyclic polarization results indicated that the $\Delta E$ values are large enough to rule out the possibility of localized corrosion, crevice corrosion does not need to be modeled.

From the foregoing analysis of literature data and information, it has been determined that the required level of confidence (Level I) in the localized corrosion and critical potentials has been obtained.

\subsection{MODEL VALIDATION SUMMARY}

The dry oxidation model developed in Section 6.4 was validated for its intended use in Section 7.3 by comparing the data used to develop the dry oxidation model (Schutz and Thomas 1987 [DIRS 112147], p. 685, Figure 25) to literature data from Ogden (1960 [DIRS 160556], Chapter 30, Figure 30.18). The parabolic functional form used in the primary dry oxidation model is also compared to the logarithmic functional form considered as an alternative conceptual model (Section 6.4.2).

The general corrosion model developed in Section 6.5 was validated for its intended use in Section 7.4 by comparing the 1-year general corrosion rates for Ti Grade 16 (used for the base case drip shield general corrosion model) to literature data for the corrosion rates of relevant titanium alloys (Mattsson and Olefjord 1990 [DIRS 111885]; Molecke et al. 1982 [DIRS 161678]). Also, laboratory data (5-year Ti Grade 16 data and 2.5-year Ti Grade 7 data) not used to develop the base case drip shield general corrosion model are compared to the 1-year Ti Grade 16 data used for model development.

The localized corrosion model developed in Section 6.6 was validated for its intended use in Section 7.5 by comparison to analyses presented in the literature (Schutz and Thomas 1987 [DIRS 112147], Table 23; Hua et al. 2004 [DIRS 167022]).

All models were determined to have met the required level of confidence (Level I). Acceptance criterion of the TWP for model validation (corroborating data match qualitatively) has been met. 
INTENTIONALLY LEFT BLANK 


\section{CONCLUSIONS}

The corrosion behavior of the Ti Grade 7 drip shield material (throughout much of this report, Ti Grade 16 is used as an analogue for Ti Grade 7 in general corrosion analysis) has been modeled. The corrosion modes addressed in this report include dry oxidation, general corrosion (including humid-air corrosion and aqueous-phase corrosion) of the inner and outer surfaces of the drip shield and localized corrosion of the outer surface of the drip shield. In addition, other factors potentially deleterious to the corrosion resistance of titanium alloys, such as microbially influenced corrosion and presence of radiolysis, aging and phase instability, calcium chloride, and fluoride were analyzed.

\subsection{OVERVIEW OF CORROSION MODES}

As illustrated in Figure 1, the threshold $\mathrm{RH}, R H_{\text {critical }}$, is first used to determine whether dry oxidation will occur. If dry oxidation is determined to occur $\left(R H<R H_{\text {critical }}\right.$, see Assumption 5.2), the parabolic growth law is used to calculate the oxidation rate as a function of temperature (Section 6.3.1 and Section 6.4). If the $R H$ is equal to or greater than $R H_{\text {critical }}(R H \geq$ $R H_{\text {critical }}$ ), humid-air corrosion will occur in the absence of dripping water, and aqueous-phase corrosion will occur in the presence of dripping water (Section 6.3.2 and Section 6.3.3, respectively). The corrosion and critical potentials are used to determine whether the mode of attack is general corrosion $\left(E_{\text {corr }}<E_{\text {critical }}\right)$ or the combination of general corrosion and localized corrosion $\left(E_{\text {corr }} \geq E_{\text {critical }}\right)$.

When modeling corrosion of the inner and outer surfaces of the drip shield, no differentiation is made between the humid-air corrosion and aqueous-phase corrosion. General corrosion on the inner surface of the drip shield is modeled by using a cumulative distribution function based on analysis of weight-loss specimens exposed for one year in the LTCTF (Table 16). General corrosion of the outer surface of the drip shield is modeled by using a cumulative distribution function based on analysis of weight-loss and creviced specimens exposed for one year in the LTCTF (Table 17). This is discussed in Sections 6.5.3 and 6.5.5. Limited amounts of 5-year corrosion test data (Figure 22 and Figure 23) and 2.5-year data (Figure 27) were obtained at LTCTF. Comparison of 1 - and 5-year corrosion test data (Figure 24 and Figure 25) and comparison of the 1-, 2.5-, and 5-year maximum corrosion rate data (Figure 27) suggest that modeling based on the 1-year data is sufficiently conservative (Section 6.5.3) considering the fact that the corrosion rate decreases with time. The effects of radiolysis (Section 6.7.1), microbially influenced corrosion (Section 6.7.2), and fluoride (Section 6.5.7) on the general corrosion behavior of titanium alloys and calcium chloride on localized corrosion (Section 6.6.5) and general corrosion (Section 6.5.8) are also discussed. Conclusions drawn are that these factors will not limit the lifetime of the titanium alloys in repository environments. Section 6.9 contains a more detailed discussion of the implementation of the model in TSPA.

\subsection{DRY OXIDATION}

Dry oxidation occurs at any relative humidity below the threshold value for humid-air corrosion. The rate of dry oxidation is limited by mass transport through this growing metal oxide film. The measured oxide thickness and the thickness calculated according to the primary model are summarized in Table 9. The primary model (Section 6.4.1) predicts oxide layer thicknesses of 
about $132 \mathrm{~nm}$ after a hundred years, about $417 \mathrm{~nm}$ after 1,000 years, and about 1,320 $\mathrm{nm}$ after 10,000 years of exposure at $200^{\circ} \mathrm{C}$. These values indicate that dry oxidation is a negligible contribution to degradation of the drip shield. The literature information shows that the oxidation of Ti Grade 7 obeys the logarithmic growth (Section 6.4.2) that predicts even lower oxide growth rate. On this basis, dry oxidation does not need to be explicitly modeled in TSPA. The output of primary dry oxidation model is summarized in Table 24.

Table 24. Output of Primary Model for Dry Oxidation of Titanium

\begin{tabular}{|c|c|c|c|c|c|}
\hline \multirow[b]{2}{*}{$\begin{array}{l}\text { Output } \\
\text { Name }\end{array}$} & \multirow[b]{2}{*}{$\begin{array}{c}\text { Output } \\
\text { Description }\end{array}$} & \multirow[b]{2}{*}{ DTN } & \multicolumn{3}{|c|}{ Output Uncertainty } \\
\hline & & & $\begin{array}{l}\text { Sources of } \\
\text { Uncertainty }\end{array}$ & $\begin{array}{l}\text { Uncertainty } \\
\text { Distribution } \\
\text { (if applicable) }\end{array}$ & $\begin{array}{c}\text { Characteristic Values } \\
\text { (if applicable) }\end{array}$ \\
\hline $\begin{array}{l}\text { DOX Oxide } \\
\text { Thickness } \\
\text { (Table 9) }\end{array}$ & $\begin{array}{l}\text { Titanium Oxide } \\
\text { Thickness under } \\
\text { dry oxidation } \\
\text { condition per } \\
\text { Primary Model } \\
\text { (Measured vs } \\
\text { Calculated) }\end{array}$ & MO0408MWDGLCDS.002 & $\begin{array}{l}\text { Section } \\
6.4 .3\end{array}$ & $\mathrm{~N} / \mathrm{A}$ & $\begin{array}{l}132 \mathrm{~nm} \text { after } 100 \\
\text { years, about } 417 \mathrm{~nm} \\
\text { after } 1,000 \text { years, and } \\
\text { about } 1320 \mathrm{~nm} \text { after } \\
10,000 \text { years of } \\
\text { exposure at } 200^{\circ} \mathrm{C}\end{array}$ \\
\hline
\end{tabular}

\subsection{GENERAL CORROSION}

Both humid-air corrosion and aqueous-phase corrosion are treated as general corrosion in case when $E_{\text {corr }}<E_{\text {critical }}$. Localized corrosion occurs if $E_{\text {corr }} \geq E_{\text {critical }}$. However, as indicated in Section 6.3 and Section 8.1, when modeling corrosion of the inner and outer surfaces of the drip shield, no differentiation is made between the humid-air corrosion and aqueous-phase corrosion. General corrosion on the inner surface of the drip shield is modeled by using a cumulative distribution function based on analysis of weight-loss specimens exposed for one year in the LTCTF (Table 16). General corrosion of the outer surface of the drip shield is modeled by using a cumulative distribution function based on analysis of weight-loss and creviced specimens exposed for one year in the LTCTF (Table 17). This is discussed in Sections 6.5.3 and 6.5.5. General corrosion of the inner surface and outer surface should be modeled in TSPA.

The general corrosion rates for Ti Grade 16 based on LTCTF 1-year weight-loss samples (i.e., modeling corrosion of the inner surface of the drip shield) are shown in Figure 13. The general corrosion rates for Ti Grade 16 based on LTCTF 1-year weight and crevice samples (i.e., modeling corrosion of the outer surface of the drip shield) are shown in Figure 12. Based upon these data, it does not appear that the life of the drip shield will be limited by the general corrosion of Ti Grade 16 (an analog of Ti Grade 7) at temperatures less than those involved in the test $\left(90^{\circ} \mathrm{C}\right)$ during a period of 10,000 years.

The general corrosion rates for Ti Grade 16 based on LTCTF 5-year weight-loss samples and crevice samples in SDW and SCW are shown in Figure 22 and Figure 23, respectively. The corrosion rates obtained from the 5-year tests are used to validate the model developed based on the 1-year data. The 5-year corrosion rate data are significantly lower than those obtained from the 1-year data. The 5-year weight-loss (no-drip case or the inner surface case) data had a maximum value of about $58 \mathrm{~nm} / \mathrm{yr}$ with most of the other values under $20 \mathrm{~nm} / \mathrm{yr}$. The 5 -year weight-loss plus crevice data shows a maximum single value of about $77 \mathrm{~nm} / \mathrm{yr}$ with most of the 
values below about $30 \mathrm{~nm} / \mathrm{yr}$. The median is at approximately $5 \mathrm{~nm} / \mathrm{yr}$ and $10 \mathrm{~nm} / \mathrm{yr}$ for weightloss samples and crevice samples, respectively. The 5-year specimens were cleaned more thoroughly and carefully. The comparison of 1 - and 5-year corrosion rates also indicates that the 1-year cumulative distribution functions themselves can be taken as upper bound limit for the short-term uncertainties for the recommended cumulative distribution functions. The maximum and median values of 1-, 2.5-, and 5-year corrosion rate data are summarized in Table 23.

The maximum observed corrosion rate, which is much less than 1 micrometer per year, clearly indicates that the life of the drip shield is not be limited by general corrosion during a 10,000-year service life. The corrosion rates in this model are constant and do not decrease with time. This treatment is conservative, as it is well known that corrosion rates decreases with time.

The variation in these cumulative distribution functions is considered to be entirely due to uncertainty (Section 6.5.5) (i.e., a single general corrosion rate is sampled from each distribution and applied to all drip shields in the repository). The general corrosion rate sampled for the outside surface of the drip shield is independent of the general corrosion rate sampled for the inner surface of the drip shield because the environments above and below the drip shield are not significantly correlated.

Section 6.5.4.1 evaluated the uncertainty due to data measurement. The estimated errors are summarized in Table 11. It is concluded that the typical uncertainty observed in weight loss and dimensional measurements prevent determination of corrosion rates less than $42 \mathrm{~nm} / \mathrm{yr}$. This estimate of error corresponds to about one standard deviation $(1 \sigma)$. Therefore, any measured corrosion rate less than approximately $170 \mathrm{~nm} / \mathrm{yr}(4 \sigma)$ will not be distinguishable from the measurement error. General corrosion rates determined from measurements of weight loss in the LTCTF are shown in Figure 10 and Figure 11. The maximum rates shown in Figure 10 and Figure 11 are less than about $320 \mathrm{~nm} / \mathrm{yr}$, greater than the estimated $4 \sigma$ value. General corrosion rates less than $320 \mathrm{~nm} / \mathrm{yr}$ guarantees that the drip shield (wall thickness of $15 \mathrm{~mm}$ ) will not breach by general corrosion during the 10,000-year regulatory period.

In the general corrosion rate cumulative distribution functions (Figure 12 and Figure 13) all negative rates are eliminated and the entire distribution is due to uncertainty. It is estimated that there is an approximately one order-of-magnitude parametric uncertainty biased toward lower rates in the cumulative distribution function models due to possible bias in the measurements, corresponding roughly to the range of the spread of "negative" corrosion rates shown in Figure 10 and Figure 11. This uncertainty is offset by the uncertainty biased toward higher rates in applying the 1-year cumulative distribution functions to the long duration of repository service (i.e., no invocation of parabolically or logarithmically decreasing long-term corrosion kinetics).

It is also concluded that the presence of high concentration of $\mathrm{CaCl}_{2}$ and fluoride ions will not significantly enhance the general corrosion of the drip shield material under repository conditions (Section 6.6.5 and Section 6.5.7).

It can be concluded that the Ti Grade 7 drip shield material is immune to microbially influenced corrosion (Section 6.7.2). Based on the literature data, it is concluded that, even in aggressive $\mathrm{MgCl}_{2}$ brines, the radiation levels in the repository are not high enough to result in the enhancement of corrosion processes on Ti Grade 7 (Section 6.7.1). 
The outputs of the general corrosion model are summarized Table 25.

Table 25. Output of Model for General Corrosion of Ti Grade 16 (Ti Grade 7)

\begin{tabular}{|c|c|c|c|c|c|}
\hline \multirow[b]{2}{*}{ Output Name } & \multirow[b]{2}{*}{$\begin{array}{c}\text { Output } \\
\text { Description }\end{array}$} & \multirow[b]{2}{*}{ DTN } & \multicolumn{3}{|c|}{ Output Uncertainty } \\
\hline & & & $\begin{array}{l}\text { Sources of } \\
\text { Uncertainty }\end{array}$ & $\begin{array}{l}\text { Uncertainty } \\
\text { Distribution } \\
\text { (if applicable) }\end{array}$ & $\begin{array}{c}\text { Characteristic } \\
\text { Values } \\
\text { (if applicable) }\end{array}$ \\
\hline $\begin{array}{l}\text { 1-year drip } \\
\text { shield inner } \\
\text { surface } \\
\text { cumulative } \\
\text { distribution } \\
\text { function } \\
\text { (Table 16, } \\
\text { Figure 12) }\end{array}$ & $\begin{array}{l}\text { The cumulative } \\
\text { distribution } \\
\text { function for } \\
\text { General } \\
\text { Corrosion Rates } \\
\text { of Ti Grade 16: } \\
\text { LTCTF 1-year } \\
\text { Weight-Loss } \\
\text { Samples - No } \\
\text { Negative Rates }\end{array}$ & MO0408MWDGLCDS.002 & Measurement & $\begin{array}{l}\text { Entire } \\
\text { distribution }\end{array}$ & N/A \\
\hline $\begin{array}{l}\text { 1-year drip } \\
\text { shield outer } \\
\text { surface } \\
\text { cumulative } \\
\text { distribution } \\
\text { function } \\
\text { (Table 17, } \\
\text { Figure 13) }\end{array}$ & $\begin{array}{l}\text { cumulative } \\
\text { distribution } \\
\text { function for } \\
\text { General } \\
\text { Corrosion Rates } \\
\text { of Ti Grade 16: } \\
\text { LTCTF 1-year } \\
\text { Weight-Loss and } \\
\text { Crevice Samples } \\
\text { - No Negative } \\
\text { Rates }\end{array}$ & MO0408MWDGLCDS.002 & Measurement & $\begin{array}{l}\text { Entire } \\
\text { distribution }\end{array}$ & $\mathrm{N} / \mathrm{A}$ \\
\hline $\begin{array}{l}\text { Error analysis } \\
\text { (Table 11) }\end{array}$ & $\begin{array}{l}\text { Summary of } \\
\text { Error Analysis for } \\
\text { Corrosion Rates } \\
\text { Based on } \\
\text { Weight-Loss } \\
\text { Measurements }\end{array}$ & MO0408MWDGLCDS.002 & Measurement & $\mathrm{N} / \mathrm{A}$ & N/A \\
\hline
\end{tabular}

NOTE: The 5-year corrosion rate distribution data (Figure 22 and Figure 23) are not considered as the model output but are used to validate the model. The 5-year corrosion rate data are valuable information and may be useful for future analysis and modeling. Therefore, although the 5-year corrosion rate data are not included in Table 25, they are included in the Output DTN: MO0408MWDGLCDS.002.

\subsection{LOCALIZED CORROSION}

The localized corrosion model for the titanium drip shield is based on the criterion that localized attack occurs if the open circuit corrosion potential $\left(E_{\text {corr }}\right)$ exceeds or is equal to the threshold potential for breakdown of the passive film $\left(E_{\text {critical }}\right)$ (Section 6.6). The cyclic polarization data for Ti Grade 7 in repository-relevant conditions (SDW) are summarized in Table 19 and Table 20.

The correlation of potential versus temperature and composition for various test media is shown in Figure 19 and Figure 20 (Section 6.6.3). The numerical form of the localized corrosion initiation model is shown in Equations 38 and 39. The critical potential versus temperature and composition model indicates that localized corrosion of Ti Grade 7 would not initiate in repository-relevant environments even at $\mathrm{pH}$ values as high as 14 . On this basis localized corrosion initiation (and hence propagation) does not need to be implemented in TSPA. 
Figure 19 and Figure 20 also show the uncertainty in the model (bounded at the $-4 \sigma$ confidence level). The covariance and model error term, $\varepsilon$, are sources of uncertainty.

Based on the cyclic polarization measurements of Ti Grade 7 in high concentration of $\mathrm{CaCl}_{2}$ (Figure 21 and Table 21 in Section 6.6.5), it is not likely that calcium chloride will have significantly detrimental effect on the localized corrosion resistance of Ti Grade 7.

Based on the test results and literature review, crevice corrosion of Ti Grades 7 and 16 is not likely to occur under the repository conditions (Section 6.6.4).

The outputs related to localized corrosion are summarized in Table 26.

Table 26. Output of Model for Localized Corrosion of Ti Grade 7

\begin{tabular}{|c|c|c|c|c|c|}
\hline \multirow[b]{2}{*}{ Output Name } & \multirow[b]{2}{*}{$\begin{array}{c}\text { Output } \\
\text { Description }\end{array}$} & \multirow[b]{2}{*}{ DTN } & \multicolumn{3}{|c|}{ Output Uncertainty } \\
\hline & & & $\begin{array}{l}\text { Sources of } \\
\text { Uncertainty }\end{array}$ & $\begin{array}{c}\text { Uncertainty } \\
\text { Distribution } \\
\text { (if applicable) }\end{array}$ & $\begin{array}{c}\text { Characteristic } \\
\text { Values } \\
\text { (if applicable) }\end{array}$ \\
\hline $\begin{array}{l}\Delta \mathrm{E}=\mathrm{E}_{\text {critical }}-\mathrm{E}_{\text {corr }} \\
\text { (Equations } 38 \\
\text { and } 39 \text { ) }\end{array}$ & $\begin{array}{l}\text { Localized } \\
\text { corrosion } \\
\text { initiation model } \\
\text { for Ti Grade } 7\end{array}$ & MO0408MWDGLCDS.002 & $\begin{array}{l}\text { Covariance } \\
\text { and Model } \\
\text { error term }\end{array}$ & Section 6.6.3 & $\begin{array}{l}\text { Model error is } \\
\text { given by } \\
\text { normal } \\
\text { distribution } \\
\text { with mean of } \\
\text { zero and } \\
\text { variance of } \\
10,500 \mathrm{mV}\end{array}$ \\
\hline $\begin{array}{l}\text { Summary of } \\
\text { Effect of } \mathrm{CaCl}_{2}\end{array}$ & $\begin{array}{l}\text { Summary of } \\
\text { test results for } \\
\text { effects of } \mathrm{CaCl}_{2} \\
\text { and } \mathrm{MgCl}_{2} \text { on } \\
\text { corrosion } \\
\text { behavior of } \\
\text { Ti Grade } 7\end{array}$ & MO0408MWDGLCDS.002 & Measurement & $\mathrm{N} / \mathrm{A}$ & $\begin{array}{l}\Delta \text { Es are } \\
\text { greater than } \\
2.0 \mathrm{~V}\end{array}$ \\
\hline
\end{tabular}

\subsection{UNCERTAINTIES}

Uncertainties associated with the model based on the electrochemical measurements and the weight-loss measurements are addressed in Sections 6.4.3, Section 6.5.4, and Section 6.9.2, respectively. A summary of error analysis for corrosion rates based upon weight-loss measurements is in output DTN: MO0408MWDGLCDS.002.

\subsection{YUCCA MOUNTAIN REVIEW PLAN ACCEPTANCE CRITERIA}

The Yucca Mountain Review Plan, Final Report (NRC 2003 [DIRS 163274]) contains Acceptance Criteria that are intended to establish the basis for the review of the material contained in the License Application. As this report serves, in part, as the basis for the License Application, it is important to show how the information contained herein addresses each of the applicable Acceptance Criteria.

The drip shield is intended to protect the waste package, thereby prolonging waste package life. Therefore, the drip shield must help meet criteria specific to Technical Work Plan For: 
Regulatory Integration Modeling and Analysis of the Waste Form and Waste Package (BSC 2004 [DIRS 171583]), which has identified Acceptance Criteria based on the requirements mentioned in Project Requirements Document (Canori and Leitner 2003 [DIRS 166275]) and the NRC's Yucca Mountain Review Plan, Final Report (NRC 2003 [DIRS 163274]).

\subsubsection{System Description and Demonstration of Multiple Barriers}

For the Yucca Mountain Review Plan criterion entitled System Description and Demonstration of Multiple Barriers (NRC 2003 [DIRS 163274], Section 2.2.1.1.3; Canori and Leitner 2003 [DIRS 166275], PRD-002/T-014, PRD-002/T-016), the following Acceptance Criteria were addressed:

\section{Acceptance Criteria 1-Identification of Barriers is Adequate}

Barriers relied upon to achieve compliance with 10 CFR 63.113(b), as demonstrated in the total system performance assessment, are adequately identified and clearly linked to their capability.

The system this model report addresses is the engineering barrier system. The barrier that this report addresses is the drip shield. The identification of the barriers is described in Sections 1.3 and 6.10 .

\section{Acceptance Criteria 2-Description of Barrier Capability Is Acceptable}

The capability of the identified barriers to prevent or substantially reduce the movement of water or radionuclides from the Yucca Mountain repository to the accessible environment or prevent the release or substantially reduce the release rate of radionuclides from the waste is adequately identified and described:

(1) The information on the time period over which each barrier performs its intended function, including any changes during the compliance period, is provided;

(2) The uncertainty associated with barrier capabilities is adequately described;

(3) The described capabilities are consistent with the results from the total system performance assessment;

(4) The described capabilities are consistent with the definition of a barrier at 10 CFR 63.2

The purpose of the drip shield is to divert any moisture that might seep from the drift walls, including condensed water vapor, around the waste packages to the drift floor for 10,000 years. The drip shield also reduces any damage to waste packages in the event of rockfalls, as the emplacement drifts degrade over time. This is described in Sections 1.3 and 6.10, as well as Section 6.5 as part of the conceptual model discussion for general and localized corrosion of the drip shield. 


\section{Acceptance Criteria 3-Technical Basis for Barrier Capability is Adequately Presented.}

The technical bases are consistent with the technical basis for the performance assessment. The technical basis for assertions of barrier capability is commensurate with the importance of each barrier's capability and the associated uncertainties.

The technical basis for the barrier capability is documented in Sections 6.4, 6.5, 6.6, and 6.7. Section 6.4 documents the technical basis for the dry oxidation model. Section 6.5 documents the technical basis for the general corrosion model, and Section 6.6 documents the technical basis for the localized corrosion model. Section 6.7 discusses the influence of other factors on the corrosion of the drip shield including gamma radiolysis, microbially influenced corrosion, and aging and phase stability.

\subsubsection{Degradation of Engineered Barriers}

For the Yucca Mountain Review Plan criterion entitled Degradation of Engineered Barriers (NRC 2003 [DIRS 163274], Section 2.2.1.3.1.3; Canori and Leitner 2003 [DIRS 166275], PRD-002/T-015), the following Acceptance Criteria were addressed:

\section{Acceptance Criteria 1-System Description and Model Integration are Adequate}

(1) TSPA adequately incorporates important design features, physical phenomena and couplings and uses consistent assumptions throughout the degradation of engineered barriers abstraction process;

(2) Abstraction uses assumptions, technical bases, data and models that are appropriate and consistent with [those used] in other abstractions.

(3) The descriptions of the engineered barriers, design features, degradation processes, physical phenomena, and couplings that may affect the degradation of the engineered barriers are adequate.

(4) Initial and boundary conditions are propagated consistently throughout the abstraction process.

(5) Sufficient technical basis for the inclusion and exclusion of FEPs are provided;

(6) Adequate technical bases are provided, for selecting the design criteria, that mitigate any potential impact of in-package criticality on repository performance, including considering all features, events, and processes that may increase the reactivity of the system inside the waste package.

(7) Guidance in NUREG 1297 and NUREG 1298 [re: Expert Elicitation] are followed. 
The drip shield system this report addresses is described in Sections 1 and 6.10 as part of the conceptual model discussion for general and localized corrosion of the drip shield. The system description and model integration are adequate.

The model abstraction outputs are supported by objective comparisons described in Section 6 . Sufficient data have been obtained, as documented in Section 4.1, to develop and validate the model.

Uncertainties in the data used for the general corrosion model analysis were characterized and quantified, and propagated through the general corrosion model (Section 6.5.4). Uncertainties in the data used for the localized corrosion model analysis were characterized and quantified, and propagated through the localized corrosion model (Section 6.6.3).

The physical phenomena, factors (including design features, environmental factors, and their coupling) are described in Section 6.3 of this report as part of the conceptual model discussion for general and localized corrosion of the drip shield. The models developed in this report are adequately incorporated into TSPA. Integration of the submodels for drip shield corrosion degradation analysis is also described in Section 6.3. Throughout this report, the analyses use assumptions, technical bases, input data and models that appropriately reflect the design of the drip shield and the humid air and groundwater media that may come in contact with the waste package. Assumptions used in this report are addressed in Section 5. The data, technical bases and models are addressed in Sections 4.1 and 6. This information is used in a manner that is consistent with other abstractions of processes associated with the degradation of the drip shield. Initial and boundary conditions are propagated consistently throughout the abstraction process as described in Sections 1.2, 6, and 8 of this report where the drip shield degradation models and ranges of application are discussed.

The features, events, and processes (FEPs) treated in this report are identified in Section 6. Sufficient technical basis for the inclusion of FEPs are provided in Section 6.3 as part of the conceptual model discussion for drip shield degradation and The technical basis for the barrier capability is documented in Sections 6.4, 6.5, 6.6, and 6.7. Section 6.4 documents the technical basis for exclusion of dry oxidation. Section 6.5 documents the technical basis for inclusion of humid-air and aqueous general corrosion, and Section 6.6 documents the technical basis for the exclusion of localized corrosion. Section 6.7 discusses the basis for exclusion of the effects other factors on the corrosion of the drip shield including gamma radiolysis, microbially influenced corrosion, and aging and phase stability.

See also DTN: MO0407SEPFEPLA.000 [DIRS 170760] for a description of these FEPs and the FEPS Screening of Processes and Issues in Drip Shield and Waste Package Degradation (BSC 2004 [DIRS 169997]) for a complete list of all FEPs related to waste package and drip shield degradation.

Those sections of the acceptance criterion that relate to the selection of design criteria are not applicable to this report because design criteria are not selected in this report. Those sections of the acceptance criterion that relate to the use of expert elicitation are not applicable to this report because expert elicitation was not used in this report. 


\section{Acceptance Criteria 2-Data Are Sufficient for Model Justification}

(1) Parameters used to evaluate the degradation of EBS are adequately justified;

(2) Sufficient data have been collected to establish initial and boundary conditions;

(3) Data on the degradation of the engineered barriers (e.g. - general and localized corrosion, microbially induced corrosion, galvanic interactions, hydrogen embrittlement and phase stability) are based on laboratory measurements, site-specific field measurements, industrial and/or natural analogs and tests designed to replicate anticipated conditions. As appropriate, sensitivity or uncertainty analyses are provided and are shown to be adequate.

(4) Degradation models for the applicable processes are adequate. For example, general and localized corrosion, microbially induced corrosion, galvanic interactions, hydrogen embrittlement and phase stability are given appropriate consideration and treatment.

Section 4.1 documents the input data and their use in the model analysis. The input data and parameters used to evaluate the performance of the drip shield were obtained from controlled sources and were adequately justified for their intended use (Section 4.1). Section 4.1 shows that sufficient data have been collected to establish initial and boundary conditions for the models developed in this report. The data used was based on laboratory measurements under testing conditions designed to replicate anticipated repository exposure conditions. Degradation models for the processes relevant to degradation of the drip shield were given appropriate consideration (Section 6) and were found to be adequate for their intended use (Section 7).

\section{Acceptance Criteria 3-Data Uncertainty is Characterized and Propagated Through The Model Abstraction}

(1) Models use parameter values, assumed ranges, probability distributions and/or bounding assumptions that are technically defensible, reasonably account for uncertainties and variabilities, and do not result in under-representation of the risk estimate.

(2) Appropriate parameters, based on techniques that may include laboratory experiments, field measurements, and industrial analogs are used.

(3) Assumed range of values and probability distributions for parameters used in conceptual and process-level models are not likely to underestimate the actual degradation and failure of engineered barriers.

(4) Appropriate methods of NDE of fabricated-engineered barriers are used to assess the type, size and location of fabrication defects that may lead to premature failure of engineered barriers. 
(5) Where sufficient data do not exist, the definition of parameter values and conceptual models is based on appropriate use of other sources, such as expert elicitation.

Each of the models developed in this report use parameter values, assumed ranges, probability distributions or bounding assumptions, or both, that are technically defensible, reasonably account for uncertainties and variabilities, and do not result in under-representation of the risk estimate. The various models developed in this report use data and parameters that were developed based on laboratory experiments (Section 4.1) or bounding assumptions, or both, that are technically defensible and reasonably account for uncertainties and variabilities. The effects of uncertainties on the parameter ranges and uncertainty distributions in the models developed in this report are discussed in Sections 6.4.3, 6.5.4, and 6.6. The uncertainties are summarized in Section 6.9.2.

Those sections of the acceptance criterion that relate to nondestructive examination of fabricated engineered barriers are not applicable to this report because no such analyses were analyzed in this report. Those sections of the acceptance criterion that relate to the use of other sources, such as expert elicitation, are not applicable to this report because no other sources were used in the creation of this report.

\section{Acceptance Criteria 4-Model Uncertainty is Characterized and Propagated Through the Model Abstraction}

(1) Alternative modeling approaches are considered and are consistent with available data and current scientific understanding.

(2) Consideration of conceptual model uncertainty is consistent with available site characterization data, laboratory experiments, . . . and the treatment of uncertainty does not result in under-estimation of the risk estimate.

(3) Alternative modeling approaches, consistent with available data and current scientific understanding, are used and the modeling results are evaluated using tests that are sensitive to the processes modeled.

Alternative modeling approaches that are consistent with available data and current scientific understanding are considered and discussed throughout this report and summarized in Table 22 in Section 6.8. Specifically, an alternative conceptual model for dry oxidation using a logarithmic rate law is discussed in Section 6.4.2. Alternative conceptual models for general corrosion of the drip shield are discussed in Section 6.5.6. Although these alternative models are not used in TSPA, they are used, where applicable, for model validation in Section 7.

Consideration of uncertainties of the models developed in this report is an integral part of the model development and validation. Conceptual model uncertainty is consistent with the information that has been developed through laboratory experiments (Section 4.1). The treatment of uncertainty is unlikely to result in under-representation of the risk estimates. The primary model for dry oxidation (using a parabolic growth law, Section 6.4.1) is conservative relative to the alternative model for dry oxidation (using a logarithmic growth law, Section 6.4.2). The distribution used to model general corrosion of the drip shield is based on data for 
Ti Grade 16 exposed for one year (Section 6.5.5). This choice is conservative in two respects: 1) the general corrosion rate of Ti Grade 7 (the drip shield material) is lower than the general corrosion rate of Ti Grade 16 (Section 7.4.2) and 2) the general corrosion rate of titanium alloys decreases with exposure time (Section 7.4.2). The effects of uncertainties on the parameter ranges and uncertainty distributions in the models developed in this report are discussed in Sections 6.4.3, 6.5.4, and 6.6. The uncertainties are summarized in Section 6.9.2.

\section{Acceptance Criteria 5-Model Abstraction Output Is Supported By Objective Comparisons}

(1) Models implemented in this total system performance assessment abstraction provide results consistent with output from detailed process-level models and or empirical observations (laboratory and field testing, and/or natural analogs).

(2) Numerical corrosion models used to calculate the lifetime of the engineered barriers are adequate representations, considering the associated uncertainties in long term behavior, range of conditions (including residual stresses)and the variability in fabrication processes.

(3) Evidence is sufficient to show that models will not underestimate the actual degradation and failure of engineered barriers.

(4) Mathematical degradation models are based on the same environmental parameters, material factors, assumptions and approximations shown to be appropriate for closely analogous applications.

(5) Accepted and well documented procedures are used to construct and test the numerical models that simulate the EBS chemical environment and degradation of EBS;

(6) Sensitivity analyses or bounding analyses are provided to support the abstraction of the degradation of engineered barriers.

The results of drip shield degradation models developed in this report are implemented in the TSPA as specified in this report, therefore the TSPA model results are consistent with output from this report. The models developed in this report were compared with laboratory data used to develop the models in the applicable subsections in Section 6. The models developed in this report were compared with laboratory or literature data not used in model development in the applicable subsections in Section 7. As discussed in response to previous Acceptance Criteria, there is sufficient evidence that the models developed in this report will not underestimate the actual degradation and failure of the drip shield. The mathematical models developed in this report were based on data collected using materials and exposure environments relevant to those expected in the repository. The models developed in this report were constructed following the accepted and well-documented AP-SIII.10Q, Models. 
INTENTIONALLY LEFT BLANK 


\section{INPUTS AND REFERENCES}

\subsection{DOCUMENTS CITED}

133378 ASM International 1987. Corrosion. Volume 13 of ASM Handbook. Formerly 9th Edition, Metals Handbook. Materials Park, Ohio: ASM International. TIC: 240704.

162445 Brossia, C.S. and Cragnolino, G.A. 2000. "Effects of Environmental, Electrochemical, and Metallurgical Variables on the Passive and Localized Dissolution of Ti Grade 7." Corrosion/2000, 55th Annual Conference \& Exposition, March 26-31, 2000, Orlando, Florida. Paper No. 00211. Houston, Texas: NACE International. TIC: 254067.

159840 Brossia, C.S. and Cragnolino, G.A. 2001. "Effect of Palladium on the Localized and Passive Dissolution of Titanium." Corrosion/2001 56th Annual Conference \& Exposition, March 11-16, 2001, Houston, Texas, USA. Paper No. 01127. Houston, Texas: NACE International. TIC: 253171.

162420 Brossia, C.S. and Cragnolino, G.A. 2001. "Effects of Environmental and Metallurgical Conditions on the Passive and Localized Dissolution of Ti-0.15\%Pd." Corrosion, 57, (9), 768-776. Houston, Texas: National Association of Corrosion Engineers. TIC: 254028.

159836 Brossia, C.S.; Browning, L.; Dunn, D.S.; Moghissi, O.C.; Pensado, O.; and Yang, L. 2001. Effect of Environment on the Corrosion of Waste Package and Drip Shield Materials. CNWRA 2001-003. San Antonio, Texas: Center for Nuclear Waste Regulatory Analyses. TIC: 252324.

155950 BSC (Bechtel SAIC Company) 2001. FY 01 Supplemental Science and Performance Analyses, Volume 1: Scientific Bases and Analyses. TDR-MGR-MD-000007 REV 00 ICN 01. Las Vegas, Nevada: Bechtel SAIC Company. ACC: MOL.20010801.0404; MOL.20010712.0062; MOL.20010815.0001.

158966 BSC 2002. The Enhanced Plan for Features, Events, and Processes (FEPs) at Yucca Mountain. TDR-WIS-PA-000005 REV 00. Las Vegas, Nevada: Bechtel SAIC Company. ACC: MOL.20020417.0385.

168489 BSC 2004. D\&E / PA/C IED Emplacement Drift Configuration and Environment. 800-IED-MGR0-00201-000-00B. Las Vegas, Nevada: Bechtel SAIC Company. ACC: ENG.20040326.0001.

169860 BSC 2004. Engineered Barrier System: Physical and Chemical Environment Model. ANL-EBS-MD-000033, Rev. 03. Las Vegas, Nevada: Bechtel SAIC Company.

161237 BSC 2004. Environment on the Surfaces of the Drip Shield and Waste Package Outer Barrier. ANL-EBS-MD-000001, Rev. 01. Las Vegas, Nevada: Bechtel SAIC Company. 
169997 BSC 2004. FEPs Screening of Processes and Issues in Drip Shield and Waste Package Degradation. ANL-EBS-PA-000002, Rev. 03. Las Vegas, Nevada: Bechtel SAIC Company.

169984 BSC 2004. General Corrosion and Localized Corrosion of Waste Package Outer Barrier. ANL-EBS-MD-000003, Rev. 02. Las Vegas, Nevada: Bechtel SAIC Company.

169847 BSC 2004. Hydrogen-Induced Cracking of the Drip Shield. ANL-EBS-MD-000006 REV 02. Las Vegas, Nevada: Bechtel SAIC Company. ACC: DOC.20040909.0004.

169565 BSC 2004. Multiscale Thermohydrologic Model. ANL-EBS-MD-000049, Rev. 02. Las Vegas, Nevada: Bechtel SAIC Company.

169218 BSC 2004. Natural Analogue Synthesis Report. TDR-NBS-GS-000027 REV 01. Las Vegas, Nevada: Bechtel SAIC Company. ACC: DOC.20040524.0008.

168361 BSC 2004. Q-List. 000-30R-MGR0-00500-000-000 REV 00. Las Vegas, Nevada: Bechtel SAIC Company. ACC: ENG.20040721.0007.

170992 BSC 2004. Safety Classification of SSCs and Barriers. 000-00C-MGR0-01000-00000A. Las Vegas, Nevada: Bechtel SAIC Company. ACC: ENG.20040721.0005.

169985 BSC 2004. Stress Corrosion Cracking of the Drip Shield, the Waste Package Outer Barrier, and the Stainless Steel Structural Material. ANL-EBS-MD-000005, Rev. 02. Las Vegas, Nevada: Bechtel SAIC Company.

171583 BSC 2004. Technical Work Plan For: Regulatory Integration Modeling and Analysis of the Waste Form and Waste Package. TWP-WIS-MD-000009 REV 00 ICN 01. Las Vegas, Nevada: Bechtel SAIC Company. ACC: DOC.20040910.0001.

166275 Canori, G.F. and Leitner, M.M. 2003. Project Requirements Document. TER-MGRMD-000001 REV 02. Las Vegas, Nevada: Bechtel SAIC Company. ACC: DOC.20031222.0006.

159753 Choi, Y-K.; Seo, S-S.; Chjo, K-H.; Choi, Q-W.; and Park, S-M. 1992. "Thin Titanium Dioxide Film Electrodes Prepared by Thermal Oxidation." Journal of the Electrochemical Society, 139, (7), 1803-1807. New York, New York: Electrochemical Society. TIC: 253120.

151102 Covington, L.C. and Schutz, R.W. 1981. "Resistance of Titanium to Atmospheric Corrosion." Corrosion/81, International Corrosion Forum, April 6-10, 1981, Toronto, Ontario, Canada. Pages 113/1-113/7. Houston, Texas: National Association of Corrosion Engineers. TIC: 248534. 
102933 CRWMS M\&O 1999. Waste Package Materials Properties. BBA000000-017170210-00017 REV 00. Las Vegas, Nevada: CRWMS M\&O.

ACC: MOL.19990407.0172.

154666 CRWMS M\&O 2000. Review of the Expected Behavior of Alpha Titanium Alloys Under Yucca Mountain Conditions. TDR-EBS-MD-000015 REV 00. Las Vegas, Nevada: CRWMS M\&O. ACC: MOL.20010108.0011.

153246 CRWMS M\&O 2000. Total System Performance Assessment for the Site Recommendation. TDR-WIS-PA-000001 REV 00 ICN 01. Las Vegas, Nevada: CRWMS M\&O. ACC: MOL.20001220.0045.

171539 DOE (U.S. Department of Energy) 2004. Quality Assurance Requirements and Description. DOE/RW-0333P, Rev. 16. Washington, D.C.: U.S. Department of Energy, Office of Civilian Radioactive Waste Management.

ACC: DOC.20040907.0002.

147480 Drever, J.I. 1997. "Evaporation and Saline Waters." Chapter 15 of The Geochemistry of Natural Waters: Surface and Groundwater Environments. 3rd Edition. Upper Saddle River, New Jersey: Prentice Hall. TIC: 246732.

117697 Estill, J.C. 1998. "Long-Term Corrosion Studies.” 2.2 of Engineered Materials Characterization Report. McCright, R.D., ed. UCRL-ID-119564 Volume 3 Rev.1.1. Livermore, California: Lawrence Livermore National Laboratory. ACC: MOL.19981222.0137.

160395 Fukuzuka, T.; Shimogori, K.; Satoh, H.; and Kamikubo, F. 1980. “On the Beneficial Effect of the Titanium Oxide Film Formed by Thermal Oxidation." Titanium '80, Science and Technology, Proceedings of the Fourth International Conference on Titanium, Kyoto, Japan, May 19-22, 1980. Kimura, H. and Izumi, O., eds. 27832792. Warrendale, Pennsylvania: Metallurgical Society of AIME. TIC: 253426.

105020 Gartland, P.O. 1997. “A Simple Model of Crevice Corrosion Propagation for Stainless Steels in Seawater." Corrosion 97, The NACE International Annual Conference and Exposition, March 9-14, 1997, New Orleans, Louisiana. Paper No. 417. Houston, Texas: NACE International. TIC: 245216.

102789 Gdowski, G.E. 1997. Degradation Mode Survey Candidate Titanium - Base Alloys for Yucca Mountain Project Waste Package Materials. UCRL-ID-121191, Rev. 1. Livermore, California: Lawrence Livermore National Laboratory. ACC: MOL.19980120.0053.

105021 Glass, R.S.; Overturf, G.E.; Van Konynenburg, R.A.; and McCright, R.D. 1986. "Gamma Radiation Effects on Corrosion-I. Electrochemical Mechanisms for the Aqueous Corrosion Processes of Austenitic Stainless Steels Relevant to Nuclear Waste Disposal in Tuff." Corrosion Science, 26, (8), 577-590. Oxford, Great Britain: Pergamon. TIC: 226179. 
100893 Gruss, K.A.; Cragnolino, G.A.; Dunn, D.S.; and Sridhar, N. 1998. "Repassivation Potential for Localized Corrosion of Alloys 625 and C22 in Simulated Repository Environments." Proceedings of Corrosion 98, March 22-27, 1998, San Diego, California. Pages 149/1 to 149/15. Houston, Texas: NACE International. TIC: 237149.

100814 Harrar, J.E.; Carley, J.F.; Isherwood, W.F.; and Raber, E. 1990. Report of the Committee to Review the Use of J-13 Well Water in Nevada Nuclear Waste Storage Investigations. UCID-21867. Livermore, California: Lawrence Livermore National Laboratory. ACC: NNA.19910131.0274.

163111 Hua, F. and Gordon, G. 2003. "On Apparent Bi-Linear Corrosion Rate Behavior of Ti Grade 7 in Basic Saturated Water (BSW-12) Below and Above $80^{\circ} \mathrm{C}$."

Corrosion/2003, 58th Annual Conference \& Exposition, March 16-20, 2003,

San Diego, California. Paper No. 03687. Houston, Texas: NACE International. TIC: 254248.

167022 Hua, F.; Mon, K.; Pasupathi, V.; Gordon, G.; and Shoesmith, D. 2004. "Corrosion of Ti Grade 7 and Other Ti Alloys in Nuclear Waste Repository Environments - A Review." Corrosion/2004, 59th Annual Conference \& Exposition, March 28-April 1, 2004, New Orleans. Paper No. 04689. Houston, Texas: NACE International. TIC: 255943.

160670 Hua, F.; Sarver, J.; Jevec, J.; and Gordon, G. 2002. “General Corrosion Studies of Candidate Container Materials in Environments Relevant to Nuclear Waste Repository." Corrosion/2002, 57th Annual Conference \& Exposition, April 7-11, 2002, Denver, Colorado. Paper No. 02530. Houston, Texas: NACE International. TIC: 252067.

159814 Hurlen, T. and Hornkøl, S. 1991. "Anodic Growth of Passive Films on Titanium." Electrochimica Acta, 36, (1), 189-195. New York, New York: Pergamon. TIC: 253118.

145955 Ikeda, B.M.; Bailey, M.G.; Quinn, M.J.; and Shoesmith, D.W. 1994. "The Development of an Experimental Data Base for the Lifetime Predictions of Titanium Nuclear Waste Containers." Application of Accelerated Corrosion Tests to Service Life Prediction of Materials. Cragnolino, G. and Sridhar, N., eds. ASTM STP 1194. Pages 126-142. Philadelphia, Pennsylvania: American Society for Testing and Materials. TIC: 247730.

105076 Jones, D.A. 1996. Principles and Prevention of Corrosion. 2nd Edition. Upper Saddle River, New Jersey: Prentice Hall. TIC: 241233.

162231 Kehler, B.A.; Ilevbare, G.O.; and Scully, J.R. 2001. "Crevice Corrosion Stabilization and Repassivation Behavior of Alloy 625 and Alloy 22." Corrosion, 57, (12), 10421065. Houston, Texas: NACE International. TIC: 254305. 
110698 Kim, Y-J. 1999. "In-Situ Electrochemical Impedance Measurement of Oxide Film on 304 SS in $288^{\circ} \mathrm{C}$ Water." Corrosion 99. Paper No. 437, 1-11. Houston, Texas: NACE International. TIC: 246024.

110236 Kim, Y.J. and Oriani, R.A. 1987. "Brine Radiolysis and its Effect on the Corrosion of Grade 12 Titanium (1)." Corrosion, 43, (2), 92-97. Houston, Texas: NACE. TIC: 246022.

131202 Lide, D.R., ed. 1991. CRC Handbook of Chemistry and Physics. 72nd Edition. Boca Raton, Florida: CRC Press. TIC: 3595.

131533 Little B. and Wagner P. 1996. “An Overview of Microbiologically Influenced Corrosion of Metals and Alloys Used in the Storage of Nuclear Wastes." Canadian Journal of Microbiology, 42, (4), 367-374. Ottawa, Canada: National Research Council of Canada. TIC: 246614.

159833 Lorenzo de Mele, M.F. and Cortizo, M.C. 2000. "Electrochemical Behaviour of Titanium in Fluoride-Containing Saliva." Journal of Applied Electrochemistry, 30, (1), 95-100. Dordrecht, The Netherlands: Kluwer Academic Publishers.

TIC: 253126.

154721 Macdonald, D.D. 1999. "Passivity-The Key to Our Metals-Based Civilization." Pure and Applied Chemistry, 71, (6), 951-978. Oxford, England: Blackwell Science. TIC: 249795.

159747 Mandry, M.J. and Rosenblatt, G. 1972. "The Effect of Fluoride Ion on the Anodic Behavior of Titanium in Sulfuric Acid." Journal of the Electrochemical Society, 119, (1), 29-33. New York, New York: Electrochemical Society. TIC: 253119.

111885 Mattsson, H. and Olefjord, I. 1990. "Analysis of Oxide Formed on Ti During Exposure in Bentonite Clay-I. The Oxide Growth." Werkstoffe und Corrosion, 41, (7), 383-390. Weinheim, Germany: VCH Verlagsgesellschaft mbH. TIC: 246290.

161678 Molecke, M.A.; Ruppen, J.A.; and Diegle, R.B. 1982. Materials for High-Level Waste Caister/Overpacks in Salt Formations. SAND82-0429. Albuquerque, New Mexico: Sandia National Laboratories. TIC: 231459.

151146 Moroishi, T. and Shida, Y. 1980. "Oxidation Behaviour of Titanium in High Temperature Steam." Titanium '80 Science and Technology Proceedings of the Fourth International Conference on Titanium, Kyoto, Japan, May 19-22, 1980. Kimura, H. and Izumi, O., eds. 2773-2782. Warrendale, Pennsylvania: Metallurgical Society of AIME. TIC: 248768.

159832 Nakagawa, M.; Matsuya, S.; and Udoh, K. 2001. "Corrosion Behavior of Pure Titanium and Titanium Alloys in Fluoride-Containing Solutions." Dental Materials Journal, 20, (4), 305-314. Tokyo, Japan: Japanese Society for Dental Materials and Devices. TIC: 253166. 
159828 Nakagawa, M.; Matsuya, S.; Shiraishi, T.; and Ohta, M. 1999. "Effect of Fluoride Concentration and $\mathrm{pH}$ on Corrosion Behavior of Titanium for Dental Use." Journal of Dental Research, 78, (9), 1568-1572. Baltimore, Maryland: American Association for Dental Research. TIC: 253167.

163274 NRC (U.S. Nuclear Regulatory Commission) 2003. Yucca Mountain Review Plan, Final Report. NUREG-1804, Rev. 2. Washington, D.C.: U.S. Nuclear Regulatory Commission, Office of Nuclear Material Safety and Safeguards. TIC: 254568.

160556 Ogden, H.R. 1960. “Titanium and Its Alloys.” In Materials, Volume I, Chapter 30 of Reactor Handbook. 2nd Edition. New York, New York: Interscience Publishers. TIC: 245052.

159795 Pan, J.; Thierry, D.; and Leygraf, C. 1994. "Electrochemical and XPS Studies of Titanium for Biomaterial Applications with Respect to the Effect of Hydrogen Peroxide." Journal of Biomedical Materials Research, 28, 113-122. New York, New York: John Wiley \& Sons. TIC: 253221.

100817 Pourbaix, M. 1974. Atlas of Electrochemical Equilibria in Aqueous Solutions. Houston, Texas: National Association of Corrosion Engineers. TIC: 208955.

159841 Pulvirenti, A.L.; Needham, K.M.; Adel-Hadadi, M.A.; Barkatt, A.; Marks, C.R.; and Gorman, J.A. 2002. "Corrosion of Titanium Grade 7 in Solutions Containing Fluoride and Chloride Salts." Corrosion/2002, 57th Annual Conference \& Exposition, April 711, 2002, Denver, Colorado. Paper No. 02552. Houston, Texas: NACE International. TIC: 253169.

162574 Pulvirenti, A.L.; Needham, K.M.; Wong, D.S.; Adel-Hadadi, M.A.; Barkatt, A.; Marks, C.R.; and Gorman, J.A. 2003. "Fluoride Corrosion of Ti-Grade 7: Effects of Other Ions." Corrosion/2003, 58th Annual Conference \& Exposition, March 16-20, 2003, San Diego, California. Paper No. 03686. Houston, Texas: NACE International. TIC: 254029.

159370 Revie, R.W., ed. 2000. Uhlig's Corrosion Handbook. 2nd Edition. New York, New York: John Wiley \& Sons. TIC: 248360.

110056 Sargent-Welch Scientific Company 1979. Periodic Table of the Elements. Catalog Number S-18806. Skokie, Illinois: Sargent-Welch Scientific Company. TIC: 245069.

151157 Satoh, K.; Shimogori, K.; and Kamikubo, F. 1987. "The Crevice Corrosion Resistance of Some Titanium Materials: A Review of the Beneficial Effects of Palladium." Platinum Metals Review, 31, (3), 115-121. London, England: Johnson Matthey. TIC: 248582.

168772 Schutz, R.W. 2003. “2003 F.N. Speller Award Lecture: Platinum Group Metal Additions to Titanium: A Highly Effective Strategy for Enhancing Corrosion 
Resistance.” Corrosion, 59, (12), 1043-1057. Houston, Texas: NACE International. TIC: 255969.

151165 Schutz, R.W. and Grauman, J.S. 1986. "Corrosion Behavior of Titanium and Other Alloys in Laboratory FGD Scrubber Environments.” Materials Performance, 25, (4), 35-42. Houston, Texas: National Association of Corrosion Engineers.

TIC: 248559.

112147 Schutz, R.W. and Thomas, D.E. 1987. "Corrosion of Titanium and Titanium Alloys." In Corrosion, Volume 13, Pages 669-706 of ASM Handbook. Formerly 9th Edition, Metals Handbook. Materials Park, Ohio: ASM International. TIC: 240704.

159798 Schutz, R.W. and Xiao, M. 1994. "Development of Practical Guidelines for Titanium in Alkaline Peroxide Bleach Solutions." 1994 International Pulp Bleaching Conference, June 13-16, 1994, Hyatt Regency Hotel, Vancouver, British Columbia. 2, 153-158. Montreal, Canada: Canadian Pulp and Paper Association. TIC: 253218.

110246 Scully, J.R.; Hudson, J.L.; Lunt, T.; Ilevbare, G.; and Kehler, B. 1999. Localized Corrosion Initiation and Transition to Stabilization in Alloys 625 and C-22.

Charlottesville, Virginia: University of Virginia. TIC: 246630.

105113 Sedriks, A.J. 1996. Corrosion of Stainless Steels. 2nd Edition. Pages 179 and 377. New York, New York: John Wiley \& Sons. TIC: 245121.

151179 Shoesmith, D.W. and Ikeda, B.M. 1997. The Resistance of Titanium to Pitting, Microbially Induced Corrosion and Corrosion in Unsaturated Conditions. AECL11709. Pinawa, Manitoba, Canada: Whiteshell Laboratories. TIC: 236226.

112178 Shoesmith, D.W. and King, F. 1998. The Effects of Gamma Radiation on the Corrosion of Candidate Materials for the Fabrication of Nuclear Waste Packages. AECL-11999. Pinawa, Manitoba, Canada: Atomic Energy of Canada Limited. ACC: MOL.19990311.0212.

117892 Shoesmith, D.W.; Ikeda, B.M.; Bailey, M.G.; Quinn, M.J.; and LeNeveu, D.M. 1995. A Model for Predicting the Lifetimes of Grade-2 Titanium Nuclear Waste Containers. AECL-10973. Pinawa, Manitoba, Canada: Atomic Energy of Canada Limited. TIC: 226419.

159774 Smailos, E. and Köster, R. 1987. "Corrosion Studies on Selected Packaging Materials for Disposal of High Level Wastes." Materials Reliability in the Back End of the Nuclear Fuel Cycle, Proceedings of a Technical Committee Meeting, Vienna, 2-5 September 1986. IAEA TECHDOC-421, 7-24. Vienna, Austria: International Atomic Energy Agency. TIC: 252877.

119592 Smailos, E.; Schwarzkopf, W.; and Koster, R. 1986. "Corrosion Behaviour of Container Materials for the Disposal of High-Level Wastes in Rock Salt Formations." Nuclear Science and Technology. EUR 10400. Luxembourg, Luxembourg:

Commission of the European Communities. TIC: 248245. 
154820 Smailos, E.; Schwarzkopf, W.; Köster, R.; Fiehn, B.; and Halm, G. 1990. Corrosion Testing of Selected Packaging Materials for Disposal of High-Level Waste Glass in Rock Salt Formations. KfK 4723. Karlsruhe, Germany: Kernforschungszentrum Karlsruhe GmbH. TIC: 215124.

151181 Thomas, D.E. and Bomberger, H.B. 1983. "The Effects of Chlorides and Fluorides on Titanium Alloys in Simulated Scrubber Environments." Materials Performance, Pages 29-36. Houston, Texas: National Association of Corrosion Engineers. TIC: 248580 .

105114 Walton, J.C.; Cragnolino, G.; and Kalandros, S.K. 1996. "A Numerical Model of Crevice Corrosion for Passive and Active Metals.” Corrosion Science, 38, (1), 1-18. Amsterdam, The Netherlands: Pergamon. TIC: 233439.

114895 Welsch, G.; Smialek, J.L.; Doychak, J.; Waldman, J.; and Jacobson, N.S. 1996. "High Temperature Oxidation and Properties." Chapter 2 of Oxidation and Corrosion of Intermetallic Alloys. Welsch, G. and Desai, P.D.; eds. West Lafayette, Indiana: Purdue University. TIC: 245280.

151190 Wilhelmsen, W. and Grande, A.P. 1987. "The Influence of Hydrofluoric Acid and Fluoride Ion on the Corrosion and Passive Behaviour of Titanium." Electrochimica Acta, 32, (10), 1469-1474. New York, New York: Pergamon Press. TIC: 248574.

162731 Williams, N.H. 2003. "Thermal Inputs for Evaluations Supporting TSPA-LA, Supplement." Interoffice memorandum from N.H. Williams (BSC) to Distribution, April 4, 2003, 0205035938, with enclosures. ACC: MOL.20030501.0081.

159799 Wyllie, W.E., II.; Brown, B.E.; and Duquette, D.J. 1994. "The Corrosion of Titanium in Alkaline Peroxide Bleach Liquors." Corrosion 94, The Annual Conference and Corrosion Show. Paper No. 421. Houston, Texas: NACE International.

TIC: 253214.

\subsection{CODES, STANDARDS, REGULATIONS, AND PROCEDURES}

15660510 CFR 63. Energy: Disposal of High-Level Radioactive Wastes in a Geologic Repository at Yucca Mountain, Nevada. Readily available.

AP-2.22Q, Rev. 1, ICN 1. Classification Analyses and Maintenance of the Q-List. Washington, D.C.: U.S. Department of Energy, Office of Civilian Radioactive Waste Management. ACC: DOC.20040714.0002.

AP-2.14Q, Rev. 3, ICN 0. Document Review. Washington, D.C.: U.S. Department of Energy, Office of Civilian Radioactive Waste Management.

ACC: DOC.20030827.0018.

AP-2.27Q, Rev. 1, ICN 4. Planning for Science Activities. Washington, D.C.: U.S. Department of Energy, Office of Civilian Radioactive Waste Management.

ACC: DOC.20040610.0006. 
AP-SIII.2Q, Rev. 1, ICN 2. Qualification of Unqualified Data. Washington, D.C.: U.S. Department of Energy, Office of Civilian Radioactive Waste Management. ACC: DOC.20040127.0008.

AP-SIII.10Q, Rev. 2, ICN 6. Models. Washington, D.C.: U.S. Department of Energy, Office of Civilian Radioactive Waste Management.

ACC: DOC.20040805.0005.

AP-SV.1Q, Rev. 1, ICN 1. Control of the Electronic Management of Information. Washington, D.C.: U.S. Department of Energy, Office of Civilian Radioactive Waste Management. ACC: DOC.20040308.0001.

162726 ASTM B 265-02. 2002. Standard Specification for Titanium and Titanium Alloy Strip, Sheet, and Plate. West Conshohocken, Pennsylvania: American Society for Testing and Materials. TIC: 254000.

105725 ASTM C 1174-97. 1998. Standard Practice for Prediction of the Long-Term Behavior of Materials, Including Waste Forms, Used in Engineered Barrier Systems (EBS) for Geological Disposal of High-Level Radioactive Waste. West Conshohocken, Pennsylvania: American Society for Testing and Materials. TIC: 246015.

103515 ASTM G 1-90 (Reapproved 1999). 1999. Standard Practice for Preparing, Cleaning, and Evaluating Corrosion Test Specimens. West Conshohocken, Pennsylvania: American Society for Testing and Materials. TIC: 238771.

138911 ASTM G 3-89 (Reapproved 1999). 1989. Standard Practice for Conventions Applicable to Electrochemical Measurements in Corrosion Testing. West Conshohocken, Pennsylvania: American Society for Testing and Materials. TIC: 247076.

138917 ASTM G 48-99a. 1999. Standard Test Methods for Pitting and Crevice Corrosion Resistance of Stainless Steels and Related Alloys by Use of Ferric Chloride Solution. West Conshohocken, Pennsylvania: American Society for Testing and Materials. TIC: 247546.

117479 ASTM G 5-94. 1994. Standard Reference Test Method for Making Potentiostatic and Potentiodynamic Anodic Polarization Measurements. Philadelphia, Pennsylvania: American Society for Testing and Materials. TIC: 231902.

127897 ASTM G 61-86 (Reapproved 1998). 1987. Standard Test Method for Conducting Cyclic Potentiodynamic Polarization Measurements for Localized Corrosion Susceptibility of Iron-, Nickel-, or Cobalt-Based Alloys. West Conshohocken, Pennsylvania: American Society for Testing and Materials. TIC: 246716.

LP-SI.11Q-BSC, Rev. 0, ICN 0. Software Management. Washington, D.C.: U.S. Department of Energy, Office of Civilian Radioactive Waste Management. ACC: DOC.20040225.0007. 
169585 TIP-CM-51 Rev. 0, Change Notice CM-51-0-4. Long Term Corrosion Test Facility Specimen De-Scaling Procedure for Alloy 22, Alloy C4, Titanium Alloys, TiGr 7, TiGr 12, and TiGr 16 Specimens. Livermore, California: Lawrence Livermore National Laboratory. ACC: MOL.20030927.0180.

110868 UCRL-ID-132285. Formulation and Make-Up of Simulated Dilute Water, Low Ionic Content Aqueous Solution. Livermore, California: Lawrence Livermore National Laboratory. TIC: 245767.

110890 UCRL-ID-132286. Formulation and Make-Up of Simulated Concentrated Water(SCW), High Ionic Content Aqueous Solution. Livermore, California: Lawrence Livermore National Laboratory. TIC: 245768.

110867 UCRL-ID-132287. Formulation and Make-Up of Simulated Acidic Concentrated Water (SAW), High Ionic Content Aqueous Solution. Livermore, California:

Lawrence Livermore National Laboratory. TIC: 245766.

\subsection{SOURCE DATA}

155623 LL010105512251.011. General Corrosion and Localized Corrosion of the Drip Shield. Submittal date: 01/17/2001.

161755 LL030205912251.016. Titanium (Ti) Grade 16 Corrosion Rate Data in Simulated Diluted and Concentrated Well Water (SDW and SCW).

Submittal date: 02/13/2003.

163647 LL030409412251.050. Electrochemical Data of Titanium Gr. 7 in CaCl2 Solutions. Submittal date: 05/29/2003.

169583 LL030410012251.056. LTCTF Corrosion Rate Calculations for 2 1/2 - Year Exposed Titanium Alloy GR7 Specimens Cleaned Under TIP-CM-51. Submittal date: $07 / 16 / 2003$.

171362 LL040803112251.117. Target Compositions of Aqueous Solutions Used for Corrosion Testing. Submittal date: 08/14/2004.

104994 LL990610605924.079. LTCTF Data for C-22, TIGR7, TIGR12 and TIGR16. Submittal date: 06/13/1999.

152926 MO0003RIB00073.000. Physical and Chemical Characteristics of Ti Grades 7 and 16. Submittal date: $03 / 13 / 2000$.

170760 MO0407SEPFEPLA.000. LA FEP List. Submittal date: 07/20/2004.

\subsection{OUTPUT DATA}

MO0408MWDGLCDS.002. General Corrosion and Localized Corrosion of the Drip Shield for LA. Submittal date: 08/27/2004. 
APPENDIX A

DETAILED CALCULATION OF EQUATIONS 38 AND 39 AND FIGURE 19 AND

FIGURE 20 (TI GRADE $7 \Delta$ E ANALYSIS) 
INTENTIONALLY LEFT BLANK 


\section{APPENDIX A - DETAILED CALCULATION OF EQUATIONS 38 AND 39 AND FIGURE 19 AND FIGURE 20 (TI GRADE 7 AE ANALYSIS)}

\begin{tabular}{|c|c|c|c|c|c|c|}
\hline \multicolumn{7}{|l|}{ Dat $:=$} \\
\hline Sample & Solution & $\mathrm{T}$ & Ecorr & Ecrit1 & \multirow{2}{*}{$\begin{array}{c}\mathrm{Cl}- \\
\mathrm{mg} / \mathrm{L}\end{array}$} & \multirow[t]{2}{*}{$\mathrm{PH}^{*}$} \\
\hline ID & & ${ }^{\circ} \mathrm{C}$ & \multicolumn{2}{|c|}{$\mathrm{mV}$ vs. $\mathrm{Ag} / \mathrm{AgCl}$} & & \\
\hline NEA002 & SDW & 30 & -145 & 1070 & 67 & 10.00 \\
\hline NEA020 & SDW & 60 & -212 & 947 & 67 & 10.00 \\
\hline NEA033 & SDW & 90 & -305 & 808 & 67 & 10.00 \\
\hline NEA001 & SDW & 30 & -99 & 1000 & 67 & 10.00 \\
\hline NEA034 & SDW & 90 & -305 & 752 & 67 & 10.00 \\
\hline NEA011 & SDW & 30 & -125 & 1030 & 67 & 10.00 \\
\hline NEA022 & SDW & 60 & -114 & 912 & 67 & 10.00 \\
\hline NEA023 & SDW & 60 & -214 & 874 & 67 & 10.00 \\
\hline NEA005 & SCW & 30 & -37 & 958 & 6700 & 10.00 \\
\hline NEA017 & SCW & 60 & -331 & 880 & 6700 & 10.00 \\
\hline NEA028 & SCW & 90 & -480 & 849 & 6700 & 10.00 \\
\hline NEA004 & SCW & 30 & -187 & 968 & 6700 & 10.00 \\
\hline NEA018 & SCW & 60 & -364 & 796 & 6700 & 10.00 \\
\hline NEA029 & SCW & 90 & -506 & 654 & 6700 & 10.00 \\
\hline NEA003 & SCW & 30 & -233 & 1020 & 6700 & 10.00 \\
\hline NEA019 & SCW & 60 & -351 & 849 & 6700 & 10.00 \\
\hline NEA030 & SCW & 90 & -516 & 772 & 6700 & 10.00 \\
\hline NEA010 & SAW & 30 & -153 & 1450 & 24250 & 2.70 \\
\hline NEA012 & SAW & 30 & -187 & 1430 & 24250 & 2.70 \\
\hline NEA013 & SAW & 60 & -99 & 1390 & 24250 & 2.70 \\
\hline NEA024 & SAW & 90 & -187 & 1300 & 24250 & 2.70 \\
\hline NEA009 & SAW & 30 & -284 & 1420 & 24250 & 2.70 \\
\hline NEA014 & SAW & 60 & -125 & 1420 & 24250 & 2.70 \\
\hline NEA025 & SAW & 90 & -187 & 1340 & 24250 & 2.70 \\
\hline NEA007 & SAW & 30 & -176 & 1440 & 24250 & 2.70 \\
\hline NEA008 & SAW & 30 & -145 & 1230 & 24250 & 2.70 \\
\hline NEA026 & SAW & 90 & -176 & 1330 & 24250 & 2.70 \\
\hline NEA032 & SSW & 100 & -211 & 921 & 128000 & 6.25 \\
\hline NEA031 & SSW & 120 & -336 & 813 & 128000 & 6.25 \\
\hline
\end{tabular}

Columns 1 through 5 are from the input DTN: LL010105512251.011 [DIRS 155623] S01009_004.

Columns 6 ([Cl-) and $7(\mathrm{pH})$ are from DTN: LL040803112251.117 [DIRS 171362].

* If a range of $\mathrm{pH}$ values are given the average value was used (i.e., for SSW, $(7+5.5) / 2=6.25)$ 
Here, for Ti Grade 7, $\Delta \mathrm{E}=($ Ecrit1 - Ecorr $)$ is fit to a linear function of Temperature $(\mathrm{K}), \log (\mathrm{Cl})$, and $\mathrm{pH}$, i.e.:

$$
\begin{aligned}
& \Delta \mathrm{E}=(\text { Ecrit } 1-\text { Ecorr })=\mathrm{d}_{0}+\mathrm{d}_{1} \cdot \mathrm{T}+\mathrm{d}_{2} \cdot \log (\mathrm{Cl})+\mathrm{d}_{3} \cdot \mathrm{pH} \\
& \mathrm{rY}:=\text { Dat }^{\langle 2\rangle}-\text { Dat }^{\left\langle{ }^{2}\right\rangle} \\
& \mathrm{rX}^{\langle 0\rangle}:=\frac{\overrightarrow{\text { Dat }^{\langle 0\rangle}}}{\text { Dat }^{\langle 0\rangle}} \\
& \mathrm{rX}^{\langle 1\rangle}:=\mathrm{Dat}^{\langle 0\rangle}+273.1 \text { ؛ } \\
& \mathrm{rX}^{\langle 2\rangle}:=\log \left(\frac{\mathrm{Dat}^{\langle 3\rangle}}{35453}\right) \\
& \mathrm{rX}^{\langle 3\rangle}:=\mathrm{Dat}^{\langle 4\rangle}
\end{aligned}
$$

This is a vector of ones. Used to calculate the constant $\mathrm{d}_{0}$ of the model

\section{Temperature converted to Kelvin}

Logarithm (base 10) of chloride concentration. $\mathrm{Cl}^{-}$in $\mathrm{mg} / \mathrm{L}$ converted to $\mathrm{Cl}^{-}$in $\mathrm{mol} / \mathrm{L}$ by division by $35.453 \mathrm{~g} / \mathrm{mol}(35,453 \mathrm{mg} / \mathrm{mol})$ (Sargent-Welch Scientific Company 1979 [DIRS 110056]).

Regression Coefficients

$$
\mathrm{rb}:=\left(\mathrm{rX}^{\mathrm{T}} \cdot \mathrm{rX}\right)^{-1} \cdot \mathrm{rX}^{\mathrm{T}} \cdot \mathrm{rY} \quad \mathrm{rb}^{\mathrm{T}}=\left(\begin{array}{cccc}
2.05 \times 10^{3} & -1.17 \times 10^{0} & 1.41 \times 10^{1} & -4.89 \times 10^{1}
\end{array}\right)
$$

Covariance

$$
\begin{aligned}
& r \Sigma:=\left|\frac{\left(r^{T} \cdot r Y-r b^{T} \cdot r X^{T} \cdot r Y\right)}{(\text { length }(r Y)-\operatorname{cols}(r X))}\right| \cdot\left(r X^{T} \cdot r X\right)^{-1} \\
& \mathrm{r} \Sigma=\left(\begin{array}{cccc}
5.61 \times 10^{4} & -1.65 \times 10^{2} & 1.15 \times 10^{3} & 6.61 \times 10^{1} \\
-1.65 \times 10^{2} & 5.06 \times 10^{-1} & -4.36 \times 10^{0} & -1.07 \times 10^{0} \\
1.15 \times 10^{3} & -4.36 \times 10^{0} & 5.35 \times 10^{2} & 1.16 \times 10^{2} \\
6.61 \times 10^{1} & -1.07 \times 10^{0} & 1.16 \times 10^{2} & 5.61 \times 10^{1}
\end{array}\right) \\
& \text { SStot }:=\sum(\mathrm{rY}-\operatorname{mean}(\mathrm{rY}))^{2} \quad \text { SStot }=1.211 \times 10^{6} \quad \text { Sum of Squares total } \\
& \text { SSres }:=\sum(\mathrm{rY}-\mathrm{rX} \cdot \mathrm{rb})^{2} \quad \text { SSres }=2.619 \times 10^{5} \quad \text { Sum of Squares residual } \\
& \text { SSreg }:=\sum(\mathrm{rX} \cdot \mathrm{rb}-\operatorname{mean}(\mathrm{rY}))^{2} \quad \text { SSreg }=9.489 \times 10^{5} \quad \text { Sum of Squares regression } \\
& \text { Rsq }:=\frac{\text { SSreg }}{\text { SStot }} \quad \text { Rsq }=0.784 \quad \text { Coefficient of determination }
\end{aligned}
$$


Correlation coefficient matrix

$$
\begin{aligned}
& \mathrm{i}:=0 . \operatorname{rows}(\mathrm{r} \Sigma)-1 \quad \mathrm{j}:=0 . . \operatorname{cols}(\mathrm{r} \Sigma)-1 \quad \operatorname{Corr}_{\mathrm{i}, \mathrm{j}}:=\frac{\mathrm{r} \Sigma_{\mathrm{j}, \mathrm{i}}}{\sqrt{\mathrm{r} \Sigma_{\mathrm{j}, j} \cdot \sqrt{\mathrm{r} \Sigma_{\mathrm{i}, \mathrm{i}}}}} \\
& \operatorname{Corr}=\left(\begin{array}{cccc}
1 & -0.981 & 0.21 & 0.037 \\
-0.981 & 1 & -0.265 & -0.201 \\
0.21 & -0.265 & 1 & 0.668 \\
0.037 & -0.201 & 0.668 & 1
\end{array}\right)
\end{aligned}
$$

Residual standard deviation measures the spread around the regression line

$$
\mathrm{s}_{\mathrm{e}}:=\sqrt{\frac{\mathrm{SSres}}{\operatorname{rows}(\mathrm{rX})-\operatorname{cols}(\mathrm{rX})}} \quad \mathrm{s}_{\mathrm{e}}=102.344
$$

$\mathrm{EE}(\mathrm{T}, \mathrm{Cl}, \mathrm{pH}, \mathrm{z})$ is a function that evaluates $\Delta \mathrm{E}$ using the median surface, $\mathrm{Xo} \mathrm{rb}$, a given $\mathrm{z}$-value (number of standard deviations away from the median values), the residual variance $\left(\mathrm{s}_{\mathrm{e}}\right)^{2}$, and the covariance matrix, $\mathrm{r} \Sigma$.

$$
\mathrm{EE}(\mathrm{T}, \log \mathrm{Cl}, \mathrm{pH}, \mathrm{z}):=\mid \begin{aligned}
& \mathrm{Xo} \leftarrow\left(\begin{array}{ll}
1 & \mathrm{~T} \log \mathrm{Cl} \mathrm{pH}
\end{array}\right) \\
& \left(\mathrm{Xo} \cdot \mathrm{rb}+\mathrm{z} \cdot \sqrt{\mathrm{s}_{\mathrm{e}}^{2}+\mathrm{Xo} \cdot \mathrm{r} \Sigma \cdot(\mathrm{Xo})^{\mathrm{T}}}\right)
\end{aligned}
$$


The following steps evaluate $\mathrm{EE}$ at various values of $\mathrm{T}$ and $\mathrm{pH}$ for a constant chloride ion concentration of $3 \mathrm{~mol} / \mathrm{L}$.

$$
\begin{aligned}
& \mathrm{Np}:=50 \quad \mathrm{n} 1:=0 . . \mathrm{Np} \quad \mathrm{n} 2:=0 . . \mathrm{Np} \\
& \mathrm{TT}_{\mathrm{n} 1, \mathrm{n} 2}:=300+\frac{(400-300)}{\mathrm{Np}} \cdot \mathrm{n} 1 \quad \mathrm{ppH}_{\mathrm{n} 1, \mathrm{n} 2}:=2+\frac{(14-2)}{\mathrm{Np}} \cdot \mathrm{n} 2 \\
& \mathrm{Z} 3:=\overrightarrow{\mathrm{EE}(\mathrm{TT}, \log (3), \mathrm{ppH}, 0)} \quad \mathrm{Z} 3 \mathrm{~m} 4:=\overrightarrow{\mathrm{EE}(\mathrm{TT}, \log (3), \mathrm{ppH},-4)}
\end{aligned}
$$

$\Delta \mathrm{E}$

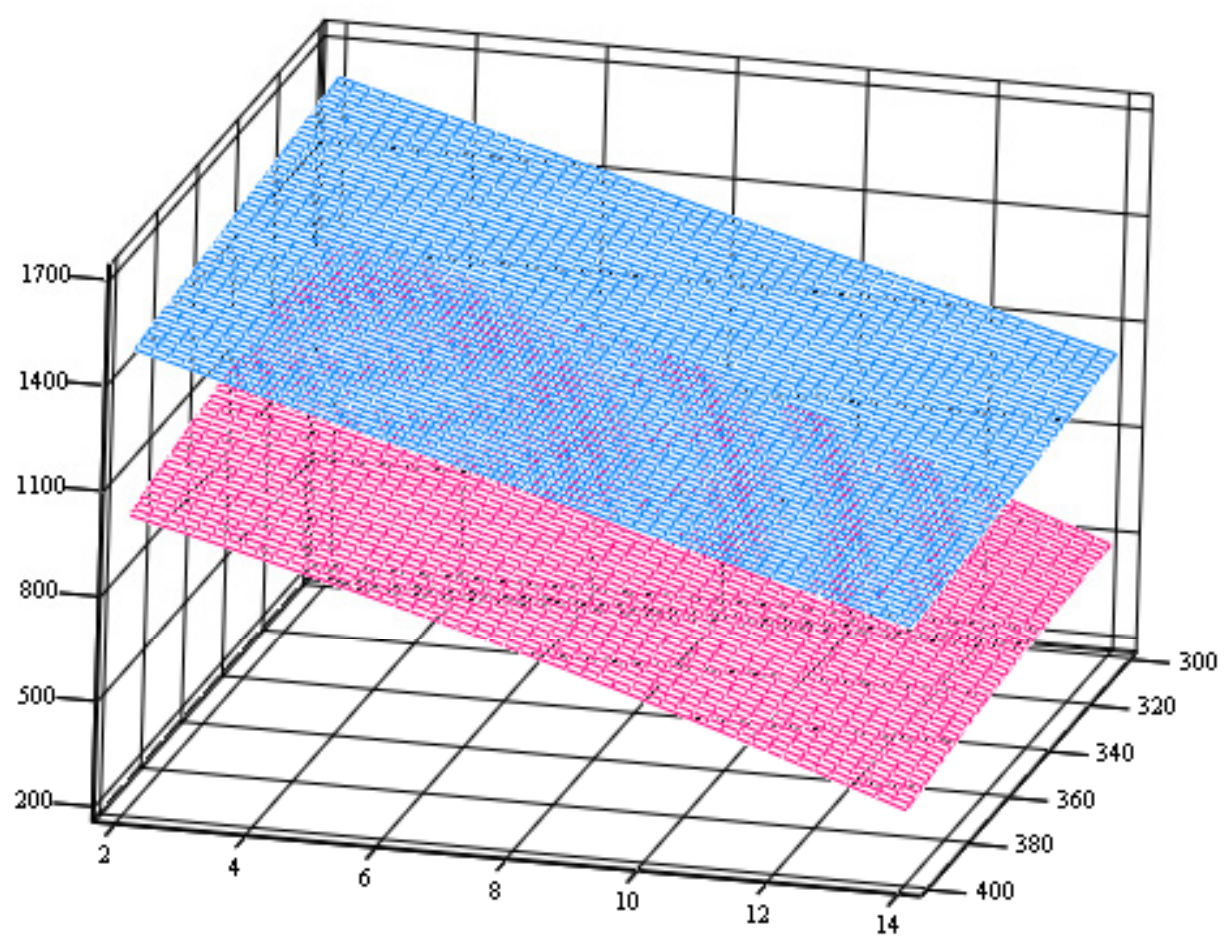

(TT, ppH, Z3), (TT, ppH, Z3m4) 
The following steps evaluate $\mathrm{EE}$ at various values of chloride concentration and $\mathrm{pH}$ for a constant temperature of $400 \mathrm{~K}$.

$$
\begin{aligned}
& \mathrm{Np}_{n}:=50 \quad \mathrm{n}_{1}:=0 . . \mathrm{Np} \quad \mathrm{n}_{\wedge \wedge i}:=0 . . \mathrm{Np} \\
& \mathrm{iCl}_{\mathrm{n} 1, \mathrm{n} 2}:=-4+\frac{(\log (4)--4)}{\mathrm{Np}} \cdot \mathrm{n} 1 \quad \quad \mathrm{ipH}_{\mathrm{n} 1, \mathrm{n} 2}:=2+\frac{(14-2)}{\mathrm{Np}} \cdot \mathrm{n} 2
\end{aligned}
$$

$$
\mathrm{Z} 4:=\overrightarrow{\mathrm{EE}(400, \mathrm{iCl}, \mathrm{ipH}, 0)}
$$

$\mathrm{Z} 4 \mathrm{~m} 4:=\overrightarrow{\mathrm{EE}(400, \mathrm{iCl}, \mathrm{ipH},-4)}$
$\mathrm{Z} 4$ is the median surface

$\mathrm{Z} 4 \mathrm{~m} 4$ is the $-4 \sigma$ confidence surface

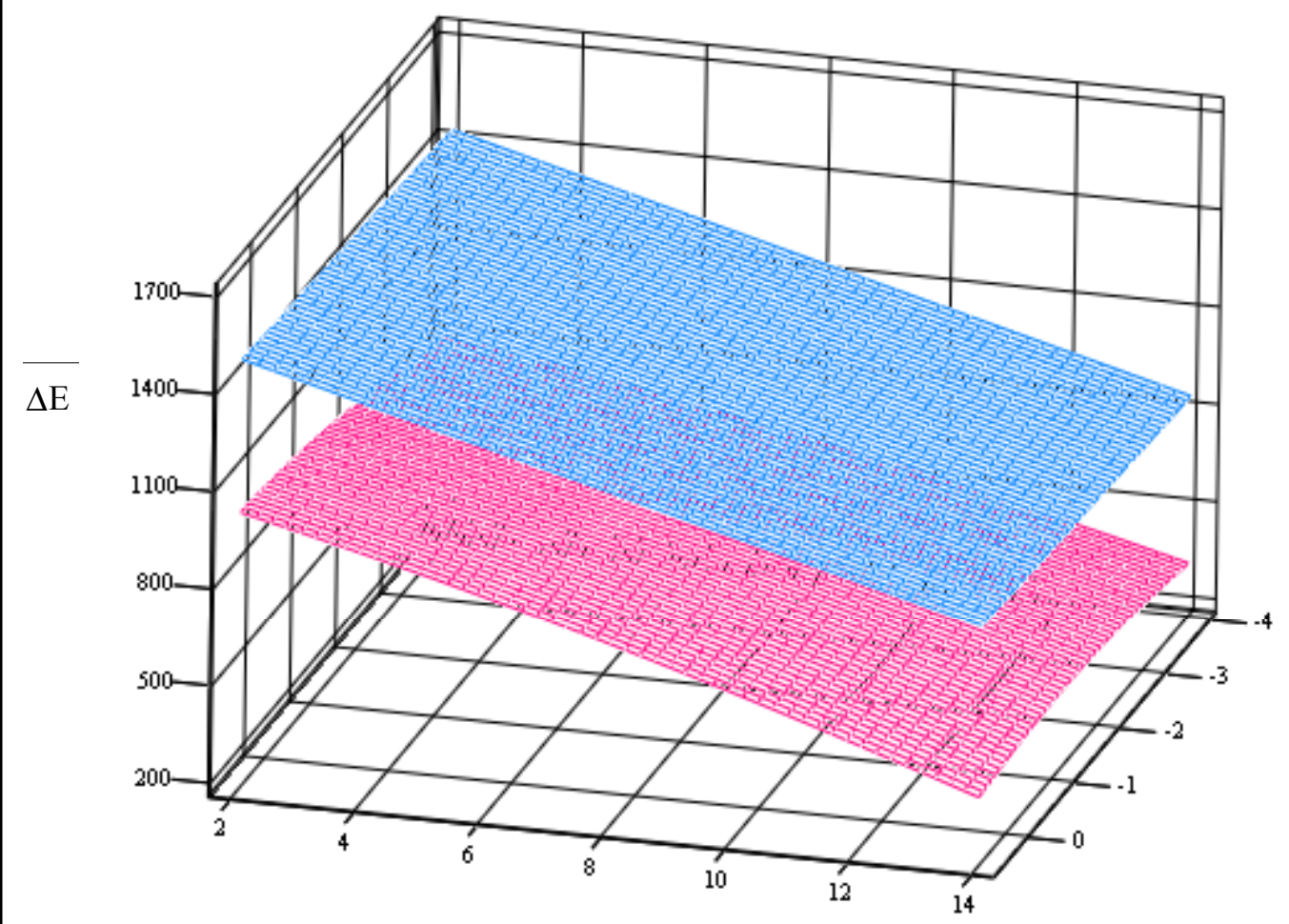

(iCl, ipH, Z4), (iCl, ipH, Z4m4) 
INTENTIONALLY LEFT BLANK 